INSTITUTO DE PESQUISAS ENERGÉTICAS E NUCLEARES

Autarquia Associada à Universidade de São Paulo

AVALIAÇÃO DA CONTAMINAÇÃO POR ELEMENTOS INORGÂNICOS E ÉSTERES FTÁLICOS EM POEIRA DOMÉSTICA DA

REGIÃO METROPOLITANA DE SÃO PAULO

VALDIRENE DE OLIVEIRA SCAPIN

Tese apresentada como parte dos requisitos para a obtenção do Grau de Doutor em Ciências na Área de Tecnologia Nuclear - Materiais.

Orientadora:

Profa. Dra. Ivone Mulako Sato

SÃO PAULO 
"Por mais longa que seja a caminhada o mais importante é dar o primeiro passo." Vinícius de Moraes

Dedico este trabalho aos meus anjos, Irene $\mathcal{A}$. A. de Oliveira e Ortis de Oliveira, por suas histórias de sucesso na educação dos filhos, diante de todas as adversidades. As minhas irmãs, Gilmara e Fabiana que com bastante carinho me apoiaram em tudo. 
Ao meu adorado esposo Marcos A. Scapin, que me ensinou as prioridades na vida. A minha filha, Mariane de Oliveira Scapin, motivo de entusiasmo e paixão pela vida. 


\section{AGRADECIMENTOS}

Primeiramente agradeço a Deus por tudo.

À Dra. Ivone Mulako Sato, que acreditou na minha capacidade de desenvolver este trabalho e ajudou a torná-lo realidade. Agradeço ainda pelas críticas e opiniões sempre muito valiosas para o meu crescimento profissional.

Ao Dr. Marcos Antonio Scapin, pelo incentivo e por todas as suas recomendações e críticas que ajudaram a enriquecer bastante o desenvolvimento deste trabalho.

À Dra. Vera Lucia Ribeiro Salvador, pela ajuda em todos os aspectos, amizade e carinho.

À Dra. Maria Aparecida Faustino Pires, Gerente do Centro de Química e Meio Ambiente (CQMA) pelo apoio e incentivo para a realização deste trabalho.

Ao Instituto de Pesquisas Energéticas e $\mathcal{N}$ ucleares pela oportunidade.

Ao Dr. José Oscar Willian V. Bustillos pela realização das análises orgânicas por CGMS.

Á SHIMADZU do Brasil que gentilmente cedeu o Cromatógrafo Gasoso-Espectrômetro de Massa e toda a infra-estrutura para a realização das análises.

À Enga Kumi Shiota Ozawa, responsável pela realização das análises orgânicas por GCMS e o carinho que sempre me recebeu.

Á minha amiga Dra. Andreza Portella Ribeiro por sua ajuda nos tratamentos estatísticos dos resultados e sugestões, o qual foi fundamental para a finalização do trabalho.

Ao Dr. Nelson B. Lima e Rene Olivier pela amizade e tempo desprendido nas análises realizadas no laboratório de XRD. 
Ao Dr. Jorge Eduardo de S. Sarķis pela gentileza em permitir a utilização do agitador eletromagnético para of fracionamento das amostras.

Ás funcionárias da Secretaria Acadêmica Ilze Cristina Puglia, Vera Lúcia Mariano Garcia e Maria do Rosário T. Ferreira pela amizade, presteza, apoio e atenção que contribuíram para a realização deste trabalho.

Aos meus familiares que sempre torceram por mim.

A Coordenação de Aperfeiçoamento de Pessoal de Nivel Superior (CAPES), pela concessão da bolsa do doutorado. 


\title{
AVALIAÇÃO DA CONTAMINAÇÃO POR ELEMENTOS INORGÂNICOS E ÉSTERES FTÁLICOS EM POEIRA DOMÉSTICA DA REGIÃO METROPOLITANA DE SÃO PAULO
}

\author{
Valdirene de Oliveira Scapin
}

\begin{abstract}
RESUMO
A poeira doméstica tem sido identificada como um importante vetor de exposição por substâncias inorgânicas e orgânicas, potencialmente tóxicas, em crianças e adultos. A composição da poeira tem uma forte influência de contaminantes provenientes de ambientes internos e externos. Durante o uso normal ou por intempéries, de uma variedade de artefatos e materiais, as substâncias químicas são desincorporadas para o meio ambiente. Uma vez liberadas, elas tendem a se acumular e enriquecer na poeira doméstica; e por meio de exposição contínua (mecanismos de inalação, ingestão e contato direto com a pele) afeta a saúde humana. Neste trabalho, foi realizada uma avaliação da contaminação por constituintes inorgânicos e ésteres ftálicos em poeira doméstica; e a correlação com as prováveis fontes antropogênicas. As amostras de poeira foram coletadas de 69 residências, nos bairros Pirituba, Freguesia do Ó, Jaraguá e Perus, da região metropolitana de São Paulo, entre 2006 e 2008. As amostras foram separadas nas frações: 850 , 850-300, 300-150, 150-75, 75$63 \mathrm{e}<63 \mu \mathrm{m}$. A análise por fluorescência de raios $X$ (WDXRF) mostrou a presença de $\mathrm{Na}, \mathrm{Mg}, \mathrm{Al}, \mathrm{Si}, \mathrm{P}, \mathrm{S}, \mathrm{Cl}, \mathrm{K}, \mathrm{Ca}, \mathrm{Ti}, \mathrm{Cr}, \mathrm{Mn}, \mathrm{Fe}, \mathrm{Ni}, \mathrm{Cu}, \mathrm{Zn}, \mathrm{Br}, \mathrm{Rb}, \mathrm{Sr}, \mathrm{Zr}$ e Pb. A análise por cromatografia de fase gasosa acoplada o espectrômetro de massa (GCMS) a presença de ésteres ftálicos (DEHP, DnBP, DEP, DEHA, BBP e DMP). A partir do fator de enriquecimento (FE), os elementos $\mathrm{P}, \mathrm{S}, \mathrm{Cr}, \mathrm{Ni}, \mathrm{Cu}, \mathrm{Zn}$ e $\mathrm{Pb}$ foram classificados como sendo significantemente e extremamente enriquecidos na poeira. As contribuições naturais e antropogênicas foram identificadas por meio de ferramentas estatísticas como análise de fatores (AF) e cluster (AC). Os elementos $\mathrm{Cr}, \mathrm{Ni}, \mathrm{Cu}, \mathrm{Zn}$ e $\mathrm{Pb}$ foram encontrados em concentrações significativamente elevadas com relação aos valores de exposição total (ingestão, inalação e contato dérmico) e de risco.
\end{abstract}




\title{
ASSESSMENT OF CONTAMINATION FOR INORGANIC ELEMENTS AND PHTHALATE ESTERS IN HOUSEHOLD DUST FROM THE METROPOLITAN REGION OF SÃO PAULO
}

\author{
Valdirene de Oliveira Scapin
}

\begin{abstract}
Household dust has been identified as an important vector of exposure by inorganic and organic substances potentially toxic in children and adults. The dust composition has a strong influence of contaminants provided from internal and external environments. During the natural process of wearing or weather incidents of artifacts and materials variety, the chemical substances are released into the environment in the steam form or by leaching from final products. Once released, they can be accumulated and enriched in the dust; and by continuous exposure (inhalation, ingestion and dermal contact mechanisms), these substances are harmful to human health. In this work, a study to determine the inorganic constituents and phthalate esters concentrations in residential indoor environment dust samples, correlating them with the probable anthropogenic sources was proposed. Dust samples were collected from 69 residences in neighborhoods Pirituba, Freguesia do Ó, Jaraguá and Perus of the São Paulo metropolitan region, using a domestic vacuum cleaner, between 2006 and 2008. The samples were sieved in the fractions of $850,850-300,300-150,150-75,75-63$ and $<63 \mu \mathrm{m}$. The analysis by X-ray fluorescence (WDXRF) showed the presence of $\mathrm{Na}, \mathrm{Mg}, \mathrm{Al}, \mathrm{Si}, \mathrm{P}, \mathrm{S}, \mathrm{Cl}, \mathrm{K}, \mathrm{Ca}, \mathrm{Ti}$, $\mathrm{Cr}, \mathrm{Mn}, \mathrm{Fe}, \mathrm{Ni}, \mathrm{Cu}, \mathrm{Zn}, \mathrm{Br}, \mathrm{Rb}, \mathrm{Sr}, \mathrm{Zr}$ and $\mathrm{Pb}$. The presence of phthalate esters (DEHP, DnBP, DEP, DEHA, DMP and BBP) was detected, by GCMS analyses. From the enrichment factor (EF), the elements $\mathrm{P}, \mathrm{S}, \mathrm{Cr}, \mathrm{Ni}, \mathrm{Cu}, \mathrm{Zn}$ and $\mathrm{Pb}$ were classified as being significant and extremely enriched in the dust. The natural and anthropogenic contributions by statistical tools as factor analysis (AF) and cluster were identified. The elements $\mathrm{Cr}, \mathrm{Ni}, \mathrm{Cu}, \mathrm{Zn}$ and $\mathrm{Pb}$ were present significantly elevated concentrations in relation to the total exposure values (ingestion, inhalation and skin contact) and to risk.
\end{abstract}




\section{SUMÁRIO}

1. INTRODUÇÃO

1.1 A poeira

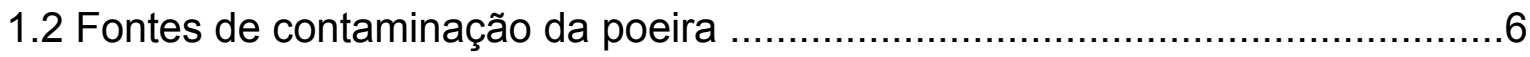

1.3 Contaminantes potencialmente tóxicos presentes na poeira ..............................

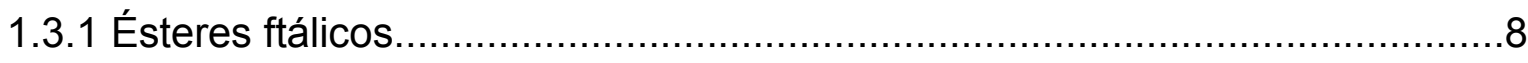

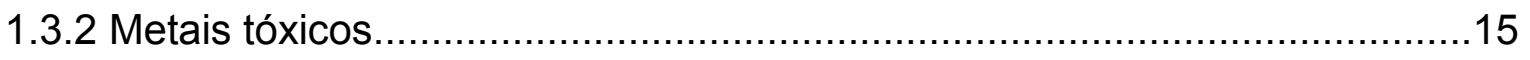

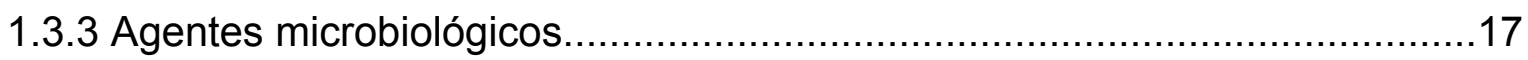

1.4 Os riscos de exposição à poeira doméstica................................................19

1.4.1 Efeitos adversos provocadas pela exposição à poeira................................21

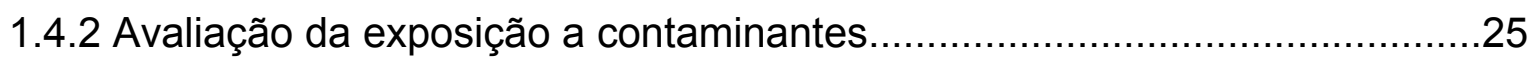

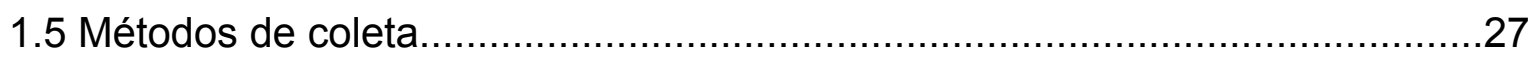

1.5.1 Processamento e ensaios de amostras de poeira.....................................29

2. OBJETIVO GERAL

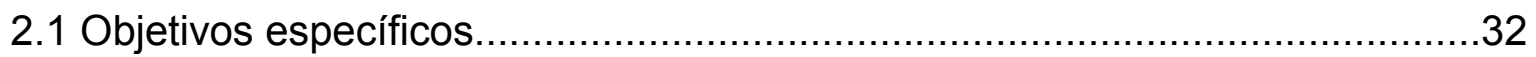

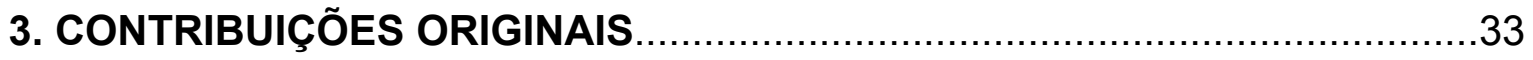

4. MATERIAIS E MÉTODOS

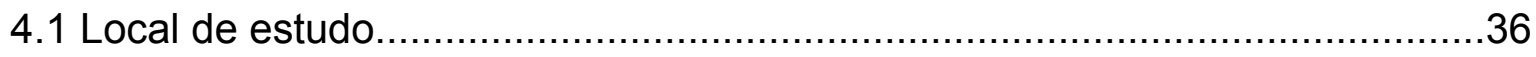

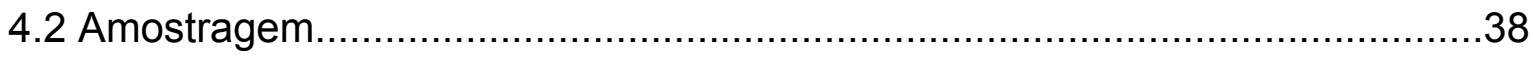

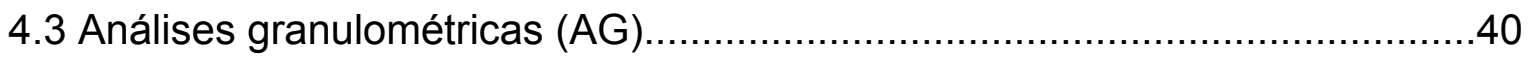

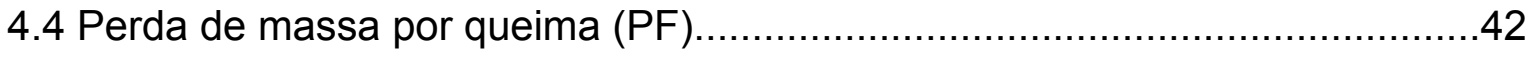


4.5 Determinação dos constituintes inorgânicos por espectrometria de fluorescência de raios $X$ por dispersão de comprimento de onda (WDXRF)

4.5.1 Preparação de amostras para análise por WDXRF ................................44

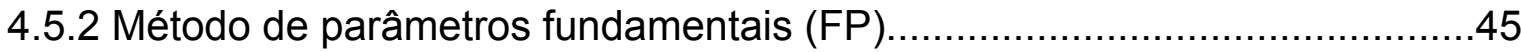

4.6 Determinação de ésteres ftálicos por cromatografia de fase gasosa acoplado ao espectrômetro de massa (GCMS)

4.6.1 Preparação de amostras para análises por GCMS

4.7 Determinação das fases cristalinas por difração de raios $X$

(XRD). .56

4.8 Determinação do fator de enriquecimento (FE) .57

4.9 Qualificação da poeira.

4.10 Determinação das fontes de contaminação por Análises de Fatores (AF) e Cluster (AC) 60

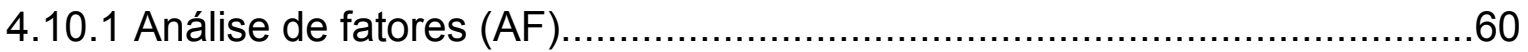

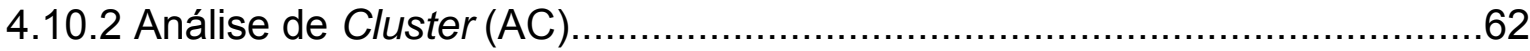

4.11 Avaliação do nível de exposição para os parâmetros de ingestão, inalação e contato dérmico.

4.12 Mapas de Distribuição 65

5. RESULTADOS E DISCUSSÃO

5.1 Ensaios físicos 68

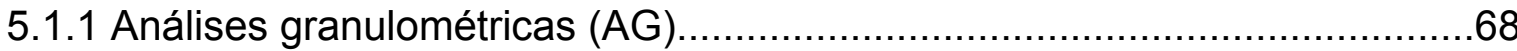

5.1.2 Perda de massa por queima (PF) ...................................................

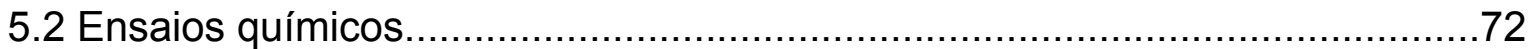

5.2.1 Avaliação da metodologia WDXRF........................................................ 
5.2.2 Resultados das análises dos constituintes inorgânicos na poeira doméstica.

5.2.3 Resultados das análises de ésteres ftálicos por cromatografia de fase gasosa acoplado ao espectrômetro de massa (GCMS)

5.2.4 Identificação das fases cristalinas por difração de raios $X$ (XRD).

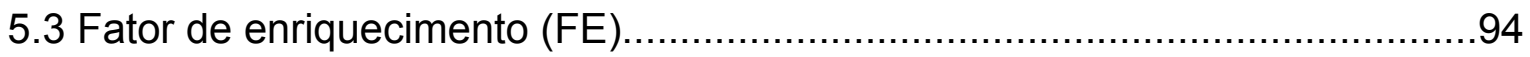

5.4 Qualificação da poeira doméstica........................................................96

5.5 Determinação das fontes de contaminação por análises de fatores (AF) e cluster (AC). 100

5.6 Determinação dos níveis de exposição para ingestão, inalação e contato dérmico.

5.7 Mapas de distribuição......................................................................... 115

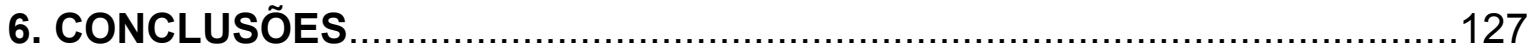

SUGESTÕES PARA TRABALHOS FUTUROS ....................................... 130

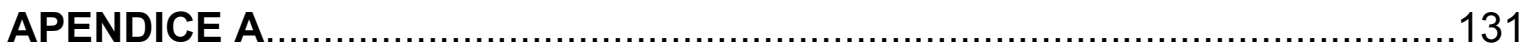

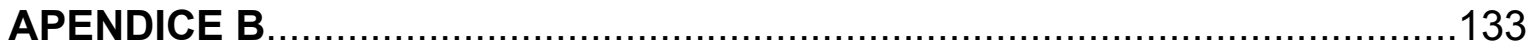

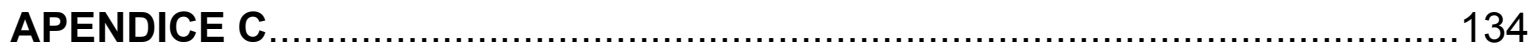

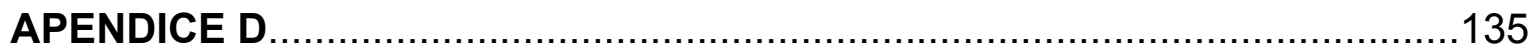

APENDICE E

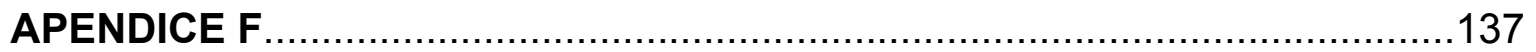

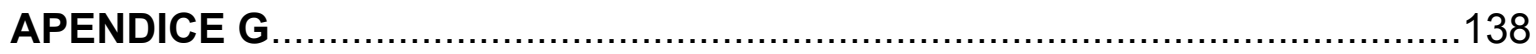

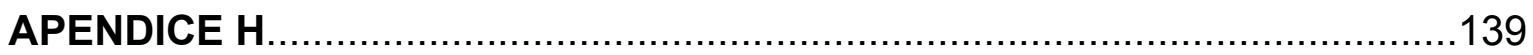

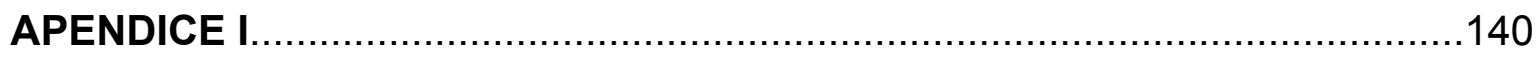

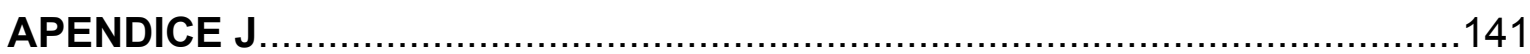


APENDICE K

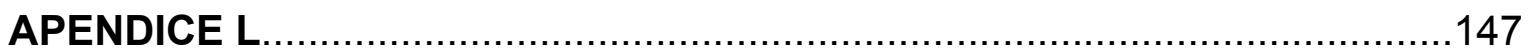

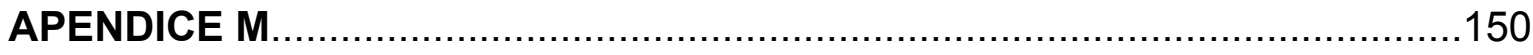

APENDICE N

APENDICE O

APENDICE P

ANEXO A

ANEXO B

ANEXO C

ANEXO D

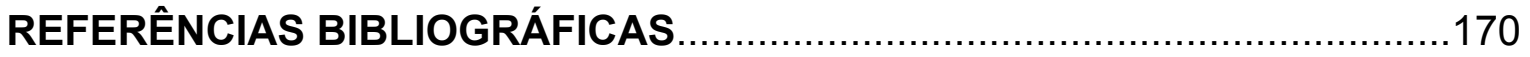

\section{LISTAS DE FIGURAS}

FIGURA 1 - Poeira solta (a) e assentada (b) a um dissipador de calor de uma CPU.

FIGURA 2 - Principais fontes de contaminação de ambiente residencial................7

FIGURA 3 - Mecanismos de obtenção dos ésteres ftálicos .................................11

FIGURA 4 - Concentração total de contaminantes testados em amostras de poeira doméstica

FIGURA 5 - Concentração de ésteres ftálicos encontrados em poeira doméstica

FIGURA 6 - Concentração média de ésteres ftálicos em poeira doméstica de diferentes países 
FIGURA 7 - Mapa da Região Metropolitana de São Paulo e os municípios Freguesia do Ó, Pirituba, Perus e Jaraguá amostrados

FIGURA 8 - Mapa da região em estudo com os pontos de coleta de amostras de poeira doméstica $(n=60)$

FIGURA 9 - Foto da coleta de amostras de poeira doméstica com aspiradores e sacos de papel de filtro descartável

FIGURA 10 - Foto da amostra de poeira (a) e do agitador eletromagnético (b) para separação granulométrica.

FIGURA 11 - Foto do espectrômetro RIGAKU Co., modelo RIX 3000

FIGURA 12 - Foto mostrando as etapas de preparação de pastilha prensada de poeira para análises por WDXRF.

FIGURA 13 - Foto do equipamento GCMS, SHIMADZU Co., modelo QP2010 Plus

FIGURA 14 - Esquema das etapas de preparação das amostras de poeira para análise por GCMS

FIGURA 15 - Foto do difratômetro de raios X Multiflex, Rigaku Co.......................56

FIGURA 16 - Porcentagem em massa das frações A, B, C, D, E e F de 69 amostras

FIGURA 17 - Distribuição granulométrica nas frações $\mathbf{D}, \mathbf{E}$ e $\mathbf{F}$ 69

FIGURA 18 - Valores de Z-score calculados para os MRCs 2781, 1547 e № $9 . .76$

FIGURA 19 - Difratograma da análise direta em amostras de poeira de ambiente residencial. Quartzo (Q), Albita (A), Gibbsita (G), Rutile (R), Calcita (C), Dolomita (D), Caulinita (Ca) e Coesita (Co) 91

FIGURA 20 - Difratograma da análise direta em amostras de poeira de ambiente residencial. Quartzo (Q), Albita (A), Gibbsita (G), Dolomita (D), Sulfeto de silício (SS) e Caulinita (Ca)

FIGURA 21 - Difratograma da análise direta em amostras de poeira de ambiente residencial. Quartzo (Q), Rutile (R), Dolomita (D), Calcita (C).......93

FIGURA 22 - Carta de controle das razões para as frações $\mathbf{D}, \mathbf{E}$ e F 99

FIGURA 23 - Dendograma do resultado do método Ward's de análise de cluster hierárquico para as três frações $\mathbf{D}$ 
FIGURA 24 - Dendograma do resultado do método Ward's de análise de cluster hierárquico para as três frações $\mathbf{E}$

FIGURA 25 - Dendograma do resultado do método Ward's de análise de cluster hierárquico para as três frações $\mathbf{F}$

FIGURA 26 - Mapa de distribuição do Ni para as frações $\mathbf{D}$ e $\mathbf{F}$ 117

FIGURA 27 - Mapa de distribuição do Zn para as frações $\mathbf{D}$ e $\mathbf{F}$ 118

FIGURA 28 - Mapa de distribuição do Cu para as frações $\mathbf{D}$ e $\mathbf{F}$ 119

FIGURA 29 - Mapa de distribuição do Pb para as frações $\mathbf{D}$ e $\mathbf{F}$ 120

FIGURA 30 - Mapa de distribuição do $\mathrm{Cr}$ para as frações $\mathbf{D}$ e $\mathbf{F}$ 121

FIGURA 31 - Mapa de distribuição do $\mathbf{S}$ para as frações $\mathbf{D}$ e $\mathbf{F}$ 122

FIGURA 32 - Mapa de distribuição do P para as frações $\mathbf{D}$ e $\mathbf{F}$ 123

FIGURA 33 - Mapa de distribuição do DEHP e DnBP para a fração $\mathbf{F}$ 124

FIGURA 34 - Mapa de distribuição do DEP e DEHA para a fração $\mathbf{F}$ 125

FIGURA 35 - Mapa de distribuição do BBP e DMP para a fração $\mathbf{F}$ 126

\section{LISTAS DE TABELAS}

TABELA 1 - Características físicas da poeira doméstica assentada 6

TABELA 2 - Principais propriedades físico-químicas de alguns ftalatos .9

TABELA 3 - Média Aritmética $(\bar{X})$ e intervalo de concentração (IC) para os elementos $\mathrm{Pb}, \mathrm{Cd}$, Cu e $\mathrm{Zn}$ em amostras de poeira doméstica em regiões distintas

TABELA 4 - Perda de massa por queima das 69 amostras de poeira (frações D, E e F) de cada ponto de amostragem $(P A=69)$ 
TABELA 5 - Valores certificados, média aritmética $(\bar{X})$ e desvio padrão (DP) determinados, desvio padrão relativo percentual (DPR\%) e erro relativo percentual (ER\%) para os MCRS Domestic Sludge, Peach Leaves e Sargasso

TABELA 6 - Valor certificado, determinado e o limite de determinação do método (LQ) para o MRC NIST 2781

TABELA 7 - Concentração elementar $(\bar{X})$ e intervalo de concentração de elementos (IC) (massa relativa) de 69 amostras de poeira nas frações D, E e F e os valores de background (CC) .

TABELA 8 - Concentração elementar $(\bar{X})$ e intervalo de concentração de elementos (IC) (massa real) de 69 amostras de poeira nas frações

D, E e F e os valores de background (CC).

TABELA 9 - Valores dos desvios padrão relativo percentual (DPR\%), intervalo de concentração (IC), limites de detecção (LD) e quantificação (LQ) para os ésteres ftálicos

TABELA 10 - Média Aritmética $(\bar{X})$ e intervalo de concentração (IC) (masa relativa) para os compostos DEHP, DnBP, DEP, DEHA, BBP e DMP determinados por GCMS, na fração $F$

TABELA 11 - Valores de percentis dos compostos DEHP, DnBP e, BBP reportados na literatura nos anos de 1991, 1998, 2001, 2003 e 2004, na Alemanha e neste estudo (NE)

TABELA 12 - Média Aritmética $(\bar{X})$ e intervalo de concentração (IC) (masa real) para os compostos DEHP, DnBP, DEP, DEHA, BBP e DMP determinados por GCMS, na fração $F$ e valores orientadores (VO)

TABELA 13 - Valores de fator de enriquecimento $(F E)$ e classe de contaminação. (Salomons e Forstner, 1984; Sinex e Wright, 1988; Klerks e Levinton, 1989; Sutherland et al., 2000; Zhang e Liu, 2002; Loska e Wiechuła, 2003; Han et al., 2006) .................................95

TABELA 14 - Média e intervalo do fator de enriquecimento (FE) nas frações D, E e F, para a massa real .96

TABELA 15 - Valores médios $(\bar{X})$ e intervalo (IC) determinados neste estudo (NE) e os orientadores de Referência de Qualidade (RQ) e Prevenção (PR) para solo no Estado de São Paulo (CETESB, 2005) 
TABELA 16 - Matriz de fatores loadings obtida a partir da análise de fatores (AF) da fração D

TABELA 17 - Matriz de fatores loadings obtida a partir da análise de fatores (AF) da fração $E$

TABELA 18 - Matriz de fatores loadings obtida a partir da análise de fatores (AF) da fração $\mathbf{F}$

TABELA 19 - Média Aritmética $(\bar{X})$ e intervalo de concentração (IC) de 69 amostras de poeira doméstica, nas frações $D, E$ e $F$, em $\mu \mathrm{g} \mathrm{g}^{-1}$ por dia

TABELA 20 - Valores das vias de exposição total, ingestão diária tolerável (TDI) e risco para adultos e crianças (CETESB, 2001) 


\section{INTRODUÇÃO}

O avanço tecnológico vem promovendo melhores condições de qualidade de vida, entretanto, associado a estes benefícios, nota-se a degradação da biosfera com a mesma velocidade. Este fato passou a ser intensificado a partir da revolução industrial nos séculos XVIII e XIX, visto que, uma economia industrializada centrada no espaço urbano e baseada no consumo elevado de matérias-primas e energia modificou significativamente o impacto do homem sobre a natureza. Naquele período, pensava-se que os recursos da natureza seriam infinitos e o meio ambiente teria capacidade de absorver indefinidamente os detritos gerados pela sociedade industrial (Resende, 2007).

A influência negativa do ser humano sobre o meio ambiente passou a ser percebida somente a partir do século $\mathrm{XX}$, especialmente, após a primeira $\mathrm{e}$ segunda guerra mundial. Entretanto, o crescimento da população e da atividade econômica global mostrou que a preocupação apenas com o controle da poluição e regulamentações ambientais de proteção a fauna e a flora eram insuficientes perante o problema que se estabelecia (John, 2000).

Dentro do pensamento sustentável, o ciclo de vida de um produto, ou seja, suas etapas de obtenção de matéria prima, fabricação, operação, desgaste e o seu descarte, devem estar inseridos no conceito de se produzir a menor quantidade de resíduos, de modo a minimizar os impactos ambientais, sociais e econômicos. Assim, a escolha por materiais que provenham de fontes de recursos renováveis e recicláveis e que consumam pouca energia nos processos de fabricação são os apropriados para a obtenção de um sistema sustentável.

Entretanto, mesmo inserido neste conceito, de acordo com alguns órgãos ambientais nacionais e internacionais, muitos produtos e materiais (ao qual se tem contato diário) apresentam em sua composição química, substâncias potencialmente tóxicas e agressivas ao meio ambiente e à saúde humana (WHO 1997, ECA, 2000, INDEX, 2005, California EPA, 2005). Estas substâncias são 
incorporadas a estes materiais para Ihes conferir propriedades específicas e também diminuição de custos.

Como exemplos, podem ser citados o uso de hormônios disruptores alcalinofenóis em cosméticos e produtos de higiene pessoal, causadores de disfunções hormonais; uso de ésteres ftálicos e parafinas cloradas em brinquedos, artefatos automobilísticos, cosméticos, tintas, adesivos e outros, que são prejudiciais ao sistema reprodutivo e potenciais causadores de câncer. Os retardadores de chama, a base de compostos bromados, utilizados especialmente em aparelhos eletro-eletrônicos, contém teores significativos de metais como $\mathrm{Ni}$, $\mathrm{Zn}, \mathrm{Cd}, \mathrm{Sn}, \mathrm{As}, \mathrm{Ba}, \mathrm{Hg}, \mathrm{Pb}$ e outros. Compostos orgânicos usados em plásticos, carpetes e pisos de PVC como agentes contra o mofo, poeira e ácaros, são prejudiciais ao sistema imunológico (Peters, 2003a; Peters, 2004).

A literatura apresenta que muitos artefatos tendem a desincorporar estas substâncias em decorrência do uso normal ou por intempéries, contaminando os ambientes externos e internos. Nos ambientes internos esta contaminação é mais acentuada, visto que, estas substâncias são adsorvidas pela poeira presente no ambiente, especialmente porque muitas pessoas ficam a maior parte de seu tempo em ambientes fechados.

Os primeiros estudos sobre a qualidade de ambientes internos se iniciaram em 1970, por grupos de profissionais de países desenvolvidos, das áreas de química, biologia, arquitetura, medicina e engenharia civil, demonstrando que os teores de $\mathrm{CO}, \mathrm{CO}_{2}, \mathrm{NO}_{2}$ e material particulado estavam significantemente mais altos que os em ambientes externos (WHO, 2000).

Posteriormente, os estudos realizados pela Agência de Proteção Ambiental dos Estados Unidos (U. S. EPA), mostraram que os teores de gases poluentes e materiais particulados estavam de duas a cinco vezes acima dos determinados em ambientes externos. Além disto, foi observada também que a concentração destes parâmetros independe das cidades de serem pouco ou muito industrializadas (U.S. EPA, 1987 e 1997). 
No Brasil, os estudos sobre a qualidade do ar de ambientes internos se iniciaram por volta de 1993. Os resultados obtidos para escritórios, hotéis e restaurantes mostraram uma variedade de substâncias tóxicas e teores acima ou próximo aos limites de tolerância estabelecidos pelas legislações internacionais. Entre 1995-96, outros estudos mostram que os teores de materiais particulados, $\mathrm{CO}, \mathrm{CO}_{2}, \mathrm{NO}_{2}, \mathrm{O}_{3}, \mathrm{SO}_{2}$ e outros estariam cerca de dez vezes acima aos determinados em ambientes externos (Brickus, 1999).

Atualmente, uma grande importância é dada para a qualidade do ar interno, visto que, é vasta a documentação que aborda as questões quanto aos tipos de poluentes, fontes e efeitos sobre a saúde, planos de prevenção, normativas e padrões de qualidade. Entretanto, é constatada a inexistência de trabalhos científicos no que diz respeito à qualidade da poeira dos ambientes internos, especialmente domésticos.

Neste trabalho foi proposta a determinação de constituintes inorgânicos e ésteres ftálicos, potencialmente tóxicos, em amostras de poeira doméstica, da Zona Norte, da Região Metropolitana de São Paulo (RMSP). Além disso, foi realizada uma avaliação do nível de contaminação e comparação com os valores de exposição para ingestão, inalação, contato dérmico e de risco a saúde humana e identificação das prováveis fontes de contaminação.

\subsection{A poeira}

A poeira ou simplesmente pó é um nome genérico atribuído a materiais sólidos com tamanho de partícula inferior a $500 \mu \mathrm{m}$. As suas características químicas e físico-químicas são diferenciadas por ambientes residenciais, escolares, trabalho (escritórios), localidade, qualidade do ar exterior, idade do ambiente, materiais utilizados na edificação, mobílias e seus estados de conservação, sistemas de ventilação e aquecimento, hábitos de limpeza, atividades dos ocupantes ou usuários e outros, além dos fatores sazonais. Este 
material é composto de poeira solta (solta no ambiente) e assentada, aderida sobre uma superfície (bunnies dust, Lioy et al., 2002). Na FIG. 1 é mostrado um exemplo de poeira solta (a) e assentada (aderida a um dissipador de calor da CPU do laptop após três anos de uso e sem limpeza) (b), como ilustração.

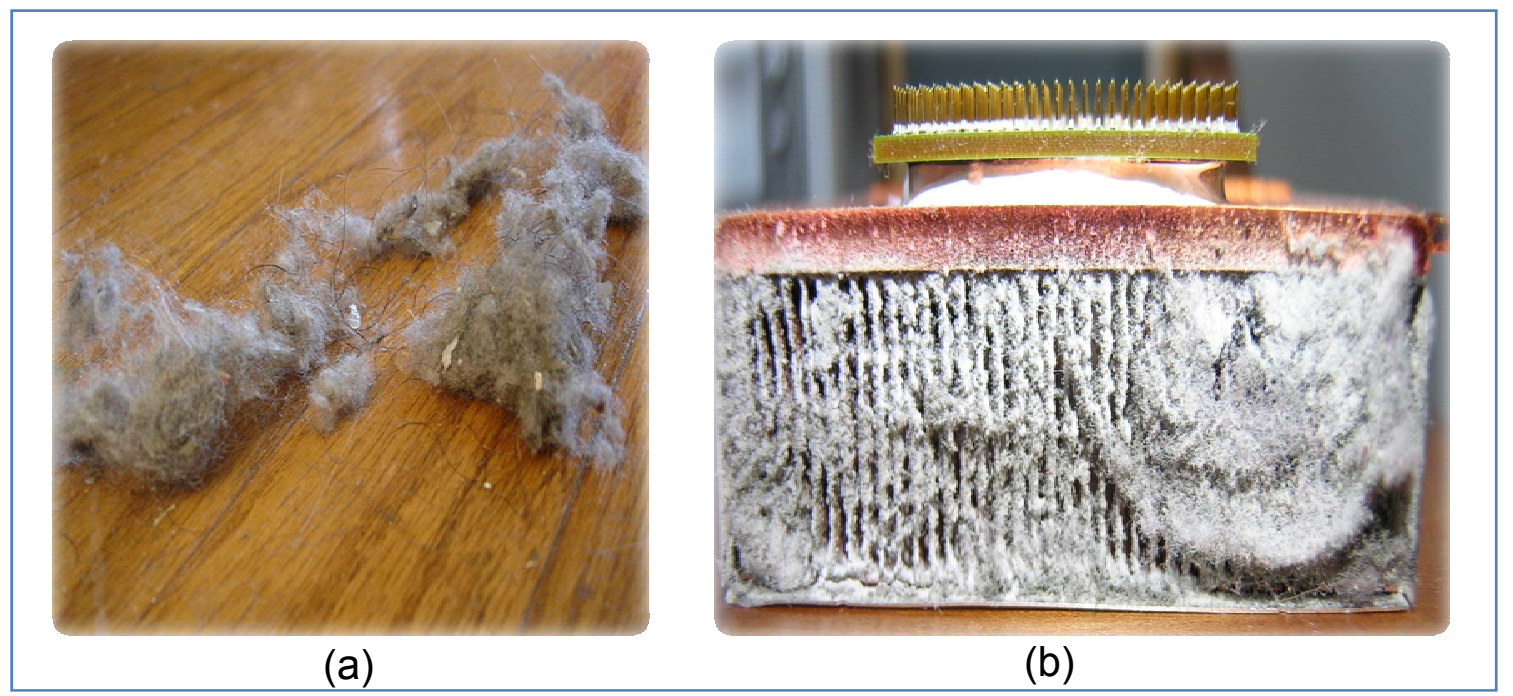

Fonte: Audrius Meskauskas (http://commons.wikimedia.org/wiki/File:Laptop_dust.jpg)

FIGURA 1 - Poeira solta (a) e assentada (b) a um dissipador de calor de uma CPU

A composição química deste material varia entre os espaços de um ambiente e fatores anteriormente mencionados. Em decorrência disso, a poeira é definida como um material de composição química complexa e heterogênea (U.S. EPA, 1997; Edwards et al., 1998; Butte e Heinzow, 2002; Morawska, 2003).

A literatura tem relatado que os diâmetros aerodinâmicos de partículas variam, entre <1 a $100 \mu \mathrm{m}$ e que as partículas com tamanho superior a $30 \mu \mathrm{m}$ tende a se depositar como poeira assentada e as inferiores, permanecerem em suspensão no ar (Morawska e Salthammer, 2003). Para exemplificar os diferentes diâmetros aerodinâmicos de partículas e suas respectivas massas relativas serão apresentados três estudo em amostras de poeira doméstica: 
Que Hee et al. (1985) realizaram um estudo em amostras de poeira doméstica para avaliar a relação entre os diâmetros aerodinâmicos de partículas e suas massas relativas. Obtiveram os seguintes resultados: partículas $<44 \mu \mathrm{m}$ : $<18 \%$; entre 44-149 $\mu \mathrm{m}:<58 \% ; 149-177 \mu \mathrm{m}:<4,5 \% ; 177-246 \mu \mathrm{m}:<2,7 \% ; 246-392$ $\mu \mathrm{m}:<6,1 \% ; 392-833 \mu \mathrm{m}:<11 \%$.

Mølhave et al. (2000) realizaram um estudo semelhante, porém para amostras de escritórios. Obtiveram os seguintes resultados: partículas entre 0-3 $\mu \mathrm{m}:<0,1 \%$; 3-6 $\mu \mathrm{m}:<0,1 \%$; 6-10 $\mu \mathrm{m}:<0,4 \%$; 10-25 $\mu \mathrm{m}:<6,3 \% ; 25-50 \mu \mathrm{m}:<12 \%$; 50-125 $\mu \mathrm{m}$ : <41\%; maiores que $125 \mu \mathrm{m}$ : <40\%.

Estudo posterior com amostras de ambientes residenciais mostrou massa relativa entre 10 a 36\% para a fração $<63 \mu \mathrm{m}$ e 13-76\%, fração entre $63 \mu \mathrm{m}-2 \mathrm{~mm}$ (Salthammer (2003) apud Morawska, 2003).

Os trabalhos acima mencionados comprovam a variabilidade nos diâmetros aerodinâmicos de partículas e massa relativa, demonstrando que as características da poeira variam consideravelmente em função dos fatores sazonais, localidade, sistemas de ventilação e aquecimento e outros, acima citados.

Os parâmetros físicos como taxa de deposição, umidade e conteúdo de matéria orgânica também contribuem para confirmar a influência dos fatores ambientais sobre as características da poeira. Na TAB 1, são apresentados os valores típicos de massa, taxa de deposição, distribuição do tamanho de partícula e perda de massa por queima, determinados em amostra de poeira assentada. 
TABELA 1 - Características físicas da poeira doméstica assentada

\begin{tabular}{|c|c|c|}
\hline Características & Valores típicos & Referências \\
\hline Massa & $0,6-1,3 \mathrm{~g} \mathrm{~m}^{2}$ & $\begin{array}{l}\text { Roberts et al., 1991; } \\
\text { Thatcher et al., } 1995 \text { e } \\
\text { Calabrese et al., } 1992\end{array}$ \\
\hline Taxa de deposição & $0,0022-0,08 \mathrm{~g} \mathrm{~m}^{2}$ por dia & $\begin{array}{l}\text { Hawley, 1985; Edwards et } \\
\text { al., 1998; Seifert et al., } \\
2000 .\end{array}$ \\
\hline $\begin{array}{l}\text { Distribuição do tamanho } \\
\text { de partícula }\end{array}$ & $\begin{array}{r}>125 \mu \mathrm{m}(40 \%) \\
50-125 \mu \mathrm{m}(41 \%) \\
25-50 \mu \mathrm{m}(18,3 \%) \\
<10 \mu \mathrm{m}(0,6 \%) \\
63 \mu \mathrm{m}-2 \mathrm{~mm}(37,2 \%) \\
>63 \mu \mathrm{m}(23,1 \%)\end{array}$ & Molhave et al., 2000 \\
\hline $\begin{array}{l}\text { Perda de massa por } \\
\text { queima* }\end{array}$ & $\begin{array}{r}63 \mu \mathrm{m}-2 \mathrm{~mm}(38,6 \%) \\
>63 \mu \mathrm{m}(58,6 \%)\end{array}$ & saltnammer, zuvs \\
\hline
\end{tabular}

\subsection{Fontes de contaminação da poeira doméstica}

As fontes de contaminação da poeira doméstica são classificadas como naturais e/ou antropogênicas de origem interna e externa.

As contaminações naturais, de origem interna, estão associadas aos resíduos da decomposição de animais, insetos, plantas, desgaste ou deterioração de materiais e detritos como cabelos, peles, pelos e outros; e a de origem externa, são os fragmentos de solo, rochas, erupções vulcânicas, sal marinho, partículas formadas das emissões gasosas $\left(\mathrm{H}_{2} \mathrm{~S}, \mathrm{NH}_{3}, \mathrm{NO}_{\mathrm{x}}\right.$ e $\left.\mathrm{HC}\right)$ e outros (Morawska e Salthammer, 2003).

As contaminações antropogênicas de origem interna estão associadas a atividades gerais, desenvolvidas no ambiente como, fumar, cozinhar, limpar, dedetizar, reformar, decorar e outros; e as externas são resíduos provenientes de atividades desenvolvidas na indústria, agricultura, mineração, transportes, construção e outros (Morawska e Salthammer, 2003). 
Na FIG. 2, é mostrado um esquema, de uma residência e os seus ambientes típicos como a cozinha (A), quarto (B), sala de estar (C), banheiro (D), lavanderia $(E)$ e quintal $(F)$ e as prováveis fontes (naturais e/ou antropogênicas) que contribuem para a contaminação da poeira formada nas residências.

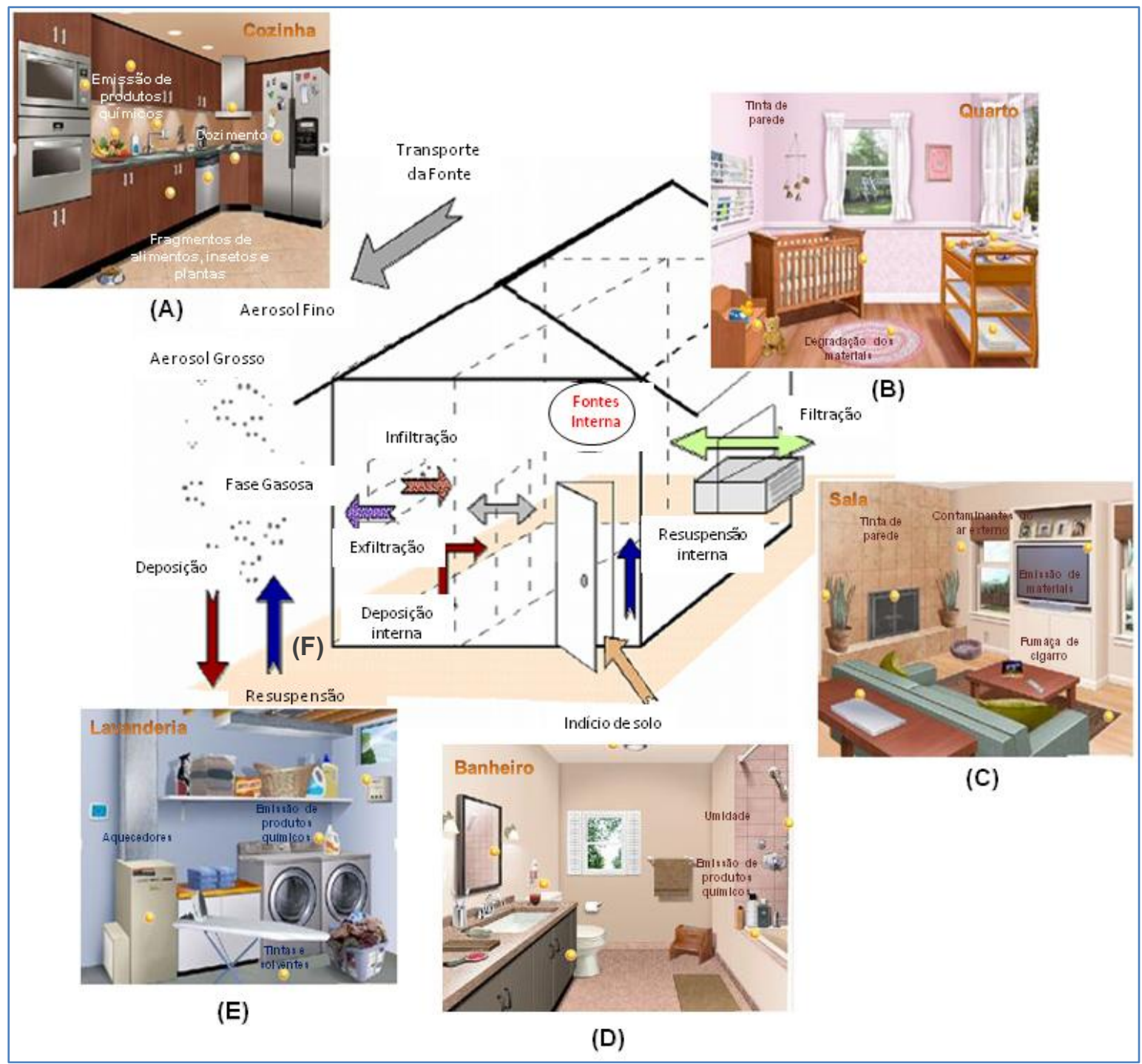

Fonte: Foto adaptada da WebMD (http://www.webmd.com/default.htm) e Jin-Hwa Lee

FIGURA 2 - Principais fontes de contaminação de ambiente residencial

De acordo com a literatura, a poeira doméstica tem apresentado níveis de concentração significativamente elevados para algumas substâncias potencialmente tóxicas. Dentre elas, ésteres ftálicos (aditivo de materiais plástico), hidrocarbonetos aromáticos policíclicos (aditivos de adesivos), bifenila policloradas (aditivos na formulação de plastificantes, tintas, adesivos e 
pesticidas), retardadores de chama (aditivos de equipamentos eletro-eletrônicos) e asbesto (revestimentos e coberturas de edifícios, gessos e estuques) e metais, especialmente o chumbo (aditivo de tintas). A presença destas substâncias, em poeira doméstica, é atribuída aos processos de degradação dos artefatos presentes nos ambientes ( $A, B, C, D$ e $E$ ), hábitos ocupacionais e processos de infiltração (ventilação e trânsito de pessoas) (Farfel et al., 1994c; HUD 2001; Lanphear et al., 1997, 1998; Bercker et al., 2002).

\subsection{Contaminantes potencialmente tóxicos presentes na poeira}

Os contaminantes potencialmente tóxicos presentes na poeira podem ser classificados como substâncias orgânicas, inorgânicas e agentes biológicos. Entre as orgânicas são destacados os ésteres ftálicos, alquilfenóis, pesticidas, eterdifenil-polibromado, organoestânicos e retardadores de chama bromados. As contaminações inorgânicas, apresentam em sua estrutura os elementos como cromo, manganês, níquel, cobre, zinco, arsênio, cádmio, chumbo e outros; e entre os agentes biológicos encontram-se os ácaros, fungos, bactérias e outros.

Estas substâncias quando adsorvidas pela poeira doméstica tornam-se uma fonte potencial de risco, provocando efeitos adversos à saúde humana.

\subsection{1 Ésteres ftálicos}

Os ésteres ftálicos (EFs), também conhecidos como ftalatos, são substâncias orgânicas derivadas do ácido 1,2-benzeno dicarboxílico. Estruturalmente, apresentam um anel benzênico ligado a dois grupos ésteres. As configurações meta e para são conhecidas como isoftalato e tereftalato respectivamente, enquanto que a orto é conhecida pelo nome genérico de ftalato (Kirk e Othmer (1967) apud Loureiro, 2002). 
Os EFs foram sintetizados pela primeira vez na década de 1850, mas só encontraram aplicação no mercado de materiais de alta polimerização em 1920. A produção aumentou significativamente nos anos 50, após a síntese do di (2etilhexil) ftalato (DEHP) em 1933, que demonstrou eficiência no aumento da flexibilidade do PVC (Inchalik e Rubin( 1996) apud Loureiro, 2002).

$\mathrm{Na}$ TAB. 2, são apresentadas algumas propriedades dos EFs como estado físico (EF), ponto de ebulição (PE) e solubilidade em água (SA), expressas nas unidades: - $\log \mathrm{Cw}$ sat, $\mu \mathrm{g} \cdot \mathrm{mL}^{-1}$ e log Koct/água, dos ésteres ftálicos (EFs) mais utilizados no PVC.

Tabela 2 -Principais propriedades físico-químicas de alguns ftalatos

\begin{tabular}{|c|c|c|c|c|c|}
\hline \multirow[b]{2}{*}{ EFs } & \multirow[b]{2}{*}{$\mathrm{EF}\left(25^{\circ} \mathrm{C}\right)$} & \multirow[b]{2}{*}{$\operatorname{PE}\left({ }^{\circ} \mathrm{C}\right)$} & \multicolumn{3}{|c|}{ SA } \\
\hline & & & $-\log C_{w}{ }^{\text {sat }}(\#)$ & $\mu \mathrm{g} \cdot \mathrm{mL}^{-1}$ & $\begin{array}{c}\text { Log } \\
\text { Koct/água }\end{array}$ \\
\hline $\begin{array}{l}\text { Dimetil ftalato } \\
\text { (DMP) }\end{array}$ & $\begin{array}{l}\text { líquido incolor } \\
\text { viscoso }\end{array}$ & $283,7^{\circ} \mathrm{C}$ & 1,646 & $4,5 \times 104$ * & $\begin{array}{c}1,53^{*} / 1,83 \\
\#\end{array}$ \\
\hline $\begin{array}{l}\text { Dietil ftalato } \\
\text { (DEP) }\end{array}$ & $\begin{array}{l}\text { líquido incolor } \\
\text { viscoso }\end{array}$ & $298^{\circ} \mathrm{C}$ & 2,364 & $1,2 \times 103$ * & $\begin{array}{c}2,35^{\star} / 2,76 \\
\#\end{array}$ \\
\hline $\begin{array}{l}\text { Butil benzil } \\
\text { ftalato (BBP) }\end{array}$ & $\begin{array}{l}\text { líquido incolor } \\
\text { viscoso }\end{array}$ & $370^{\circ} \mathrm{C}$ & 5,180 & $<100$ & $\begin{array}{c}4,91 * / 4,59 \\
\#\end{array}$ \\
\hline $\begin{array}{l}\text { Dinbutil ftalato } \\
\text { (DnBP) }\end{array}$ & óleo incolor & $340^{\circ} \mathrm{C}$ & 4,402 & 1,01 * & $\begin{array}{c}4,57^{*} / 4,37 \\
\#\end{array}$ \\
\hline $\begin{array}{l}\text { Di etilhexil } \\
\text { ftalato (DEHP) }\end{array}$ & óleo incolor & $384^{\circ} \mathrm{C}$ & 6,374 & $4,1 \times 10-2$ * & $\begin{array}{c}9,64 * / 7,06 \\
\#\end{array}$ \\
\hline $\begin{array}{l}\text { Di n-octil ftalato } \\
\text { (DNOP) }\end{array}$ & $\begin{array}{l}\text { óleo } \\
\text { levemente } \\
\text { colorido }\end{array}$ & $220^{\circ} \mathrm{C}$ & 6,137 & $<100$ & $6,99 \#$ \\
\hline $\begin{array}{l}\text { Di hexil ftalato } \\
\text { (DHP) }\end{array}$ & $\begin{array}{l}\text { líquido incolor } \\
\text { viscoso }\end{array}$ & $350^{\circ} \mathrm{C}$ & 6,144 & -- & $6,30 \#$ \\
\hline $\begin{array}{l}\text { Di isobutil ftalato } \\
\text { (DIBP) }\end{array}$ & $\begin{array}{l}\text { líquido incolor } \\
\text { viscoso }\end{array}$ & $296^{\circ} \mathrm{C}$ & -- & 6,2 & 4,11 \\
\hline $\begin{array}{l}\text { Di ciclohexil } \\
\text { ftalato (DCHP) }\end{array}$ & $\begin{array}{l}\text { sólido } \\
\text { granular } \\
\text { branco }\end{array}$ & $220^{\circ} \mathrm{C}$ & 2,630 & -- & $4,90 \#$ \\
\hline $\begin{array}{l}\text { Di metoxi etil } \\
\text { ftalato (DMEP) }\end{array}$ & $\begin{array}{l}\text { líquido incolor } \\
\text { viscoso }\end{array}$ & -- & 1,860 & -- & $2,90 \#$ \\
\hline $\begin{array}{l}\text { Di etoxi etil } \\
\text { ftalato (DEEP) }\end{array}$ & $\begin{array}{l}\text { líquido incolor } \\
\text { viscoso }\end{array}$ & -- & 3,090 & -- & $4,05 \#$ \\
\hline $\begin{array}{l}\text { Di pentil ftalato } \\
\text { (DPP) }\end{array}$ & líquido incolor & $342^{\circ} \mathrm{C}$ & 5,839 & -- & $4,85 \#$ \\
\hline $\begin{array}{l}\text { Di propil ftalato } \\
\text { (DPrP) }\end{array}$ & líquido incolor & $304^{\circ} \mathrm{C}$ & 3,401 & -- & $3,64 \#$ \\
\hline
\end{tabular}

Fonte: NTP(1991); " Leyder e Boulanger (1983); \# Thomsen,M. (1999) apud Loureiro, 2002 
A volatilidade nas condições normais de temperatura e pressão é geralmente baixa, especialmente para os compostos com grupos de cadeia longa como o DEHP. Isto, pode ser verificado pelos pontos de ebulição dos produtos. Os ftalatos com pequenos grupos alquil são razoavelmente solúveis em água, enquanto, que os de cadeia maiores, diminuem a solubilidade no meio aquoso por causa de predominância da estrutura lipofílica. A solubilidade em água pode ser medida em $-\log C_{\mathrm{w}}{ }^{\text {sat }}$ ou $\mu \mathrm{g} \mathrm{mL} \mathrm{m}^{-1}$. O primeiro parâmetro mede a saturação do produto na água sob a forma logarítmica, enquanto o segundo demonstra de forma mais direta esta solubilidade (Loureiro, 2002).

O coeficiente de partição octanol/água (Log $\mathrm{K}_{\text {oct/água }}$ ) mede a tendência do produto de permanecer na fase orgânica ou na aquosa, também refletindo o caráter lipofílico do produto.

Entre os ésteres ftálicos mencionados, na TAB. 2, o DEHP foi e continua sendo o mais utilizado. Em 1997, foram produzidas cerca de 595.000 t na Europa Ocidental (relatório da avaliação de risco do DEHP, 2008), das quais $250.000 \mathrm{t}$, na Alemanha. Em 2007, houve uma diminuição significativa, entretanto foram produzidas cerca de $340.000 \mathrm{t}$; das quais $60.000 \mathrm{t}$ foram exportadas (Lassen et al., 2009).

O segundo ftalato mais utilizado, refere-se ao DINP, cuja produção em 1994 foi próxima a 185.000 t (relatório da avaliação de risco do DEHP, 2003) - a sua produção também tem diminuído ao longo dos últimos 10 anos chegando a 10.000 t em 2007.

Os EFs, com cadeias alquil muito longas, não se ligam quimicamente aos polímeros, deste modo, se desincorporam dos materiais aos quais foram introduzidos. Assim, migram para o ambiente e, consequentemente, podem ser absorvidos por pessoas que nele interajam (Ittershagen et al. (2007) apud Loureiro, 2002). 
A literatura tem reportado que os EFs estão presentes em diferentes meios como esgotos e águas residuais (Gimeno et al., 2003; López-Jiménez et al., 2005; Cháfer-Pericás et al., 2008), ar de ambientes internos (Fromme et al., 2004; Toda et al., 2004), poeira doméstica (Rudel et al., 2003; Becker et al., 2004; Bornehag et al., 2005; Abb et al., 2009), leite materno (Main et al., 2006; Zhu et al., 2006), alimentos (especialmente oleifero) (Di Bella et al., 1999; Sørensen, 2006) e produtos de consumo (Chen et al., 2005; De Orsi et al., 2006). Os dados acima mencionados têm motivado as indústrias químicas a substituir os EFs (especialmente o DEHP) por outras substâncias como, adipatos, acelatos, trimelitatos ou sebacatos (Ahrens et al., 2003).

Em relação aos ambientes internos residenciais, pode ser destacado um estudo realizado nos estados da Califórnia, Maine, Massachusetts, Michigan, Nova lorque, Oregon e Washington (U.S.A.). Por meio de aspirador de pó comercial foram coletadas amostras de poeira doméstica em dez residências de cada estado. Para cada amostra foram analisados 7 ésteres ftálicos (EFs), 7 éteres difenil polibromados (PBDE), 14 pesticidas (incluindo pentaclorofenol), 7 alquilfenóis, 7 organoestânicos e 2 perfluorados (PFC), totalizando um conjunto de 44 substâncias (Costner et al., 2005).

Costner et al. (2005) mostraram que entre o total de substâncias analisadas, os EFs apresentaram teores próximos a 90\%, alquilfenóis, 5,60\%; pesticidas, 2,60\%; ésteres difenílicos polibromados, 1,90\%; organoestânico, $0,13 \%$ e químicos perfluorados, $0,10 \%$ (FIG. 4). Em relação aos sete EFs determinados, o DEHP apresentou a maior concentração $\left(329,45 \mu \mathrm{g} \mathrm{g}^{-1}\right)$, cerca de 5 vezes maior que o $\operatorname{BBP}\left(69,37 \mu \mathrm{g} \mathrm{g}^{-1}\right)$ e cerca de 20 vezes maior que o DBP $\left(20,15 \mu \mathrm{g} \mathrm{g}^{-1}\right)$, mostrado na FIG. 5 . 


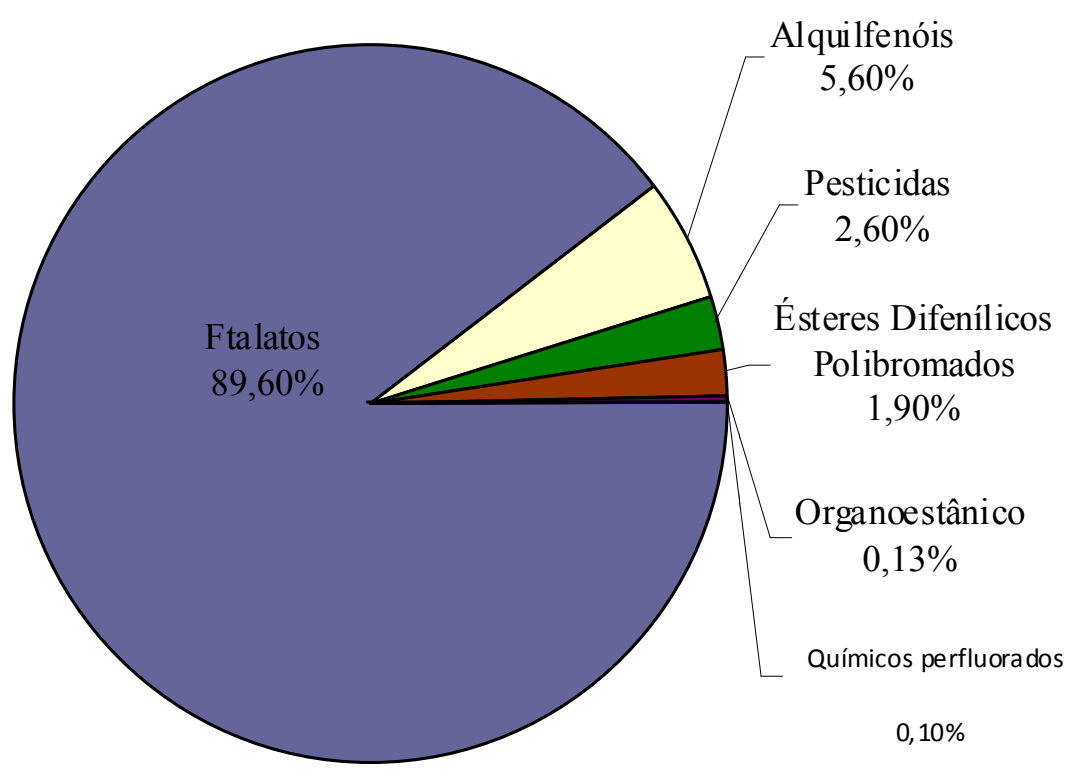

Fonte: Costner et al., 2005.

FIGURA 4 - Concentração total de contaminantes testados em amostras de poeira doméstica.

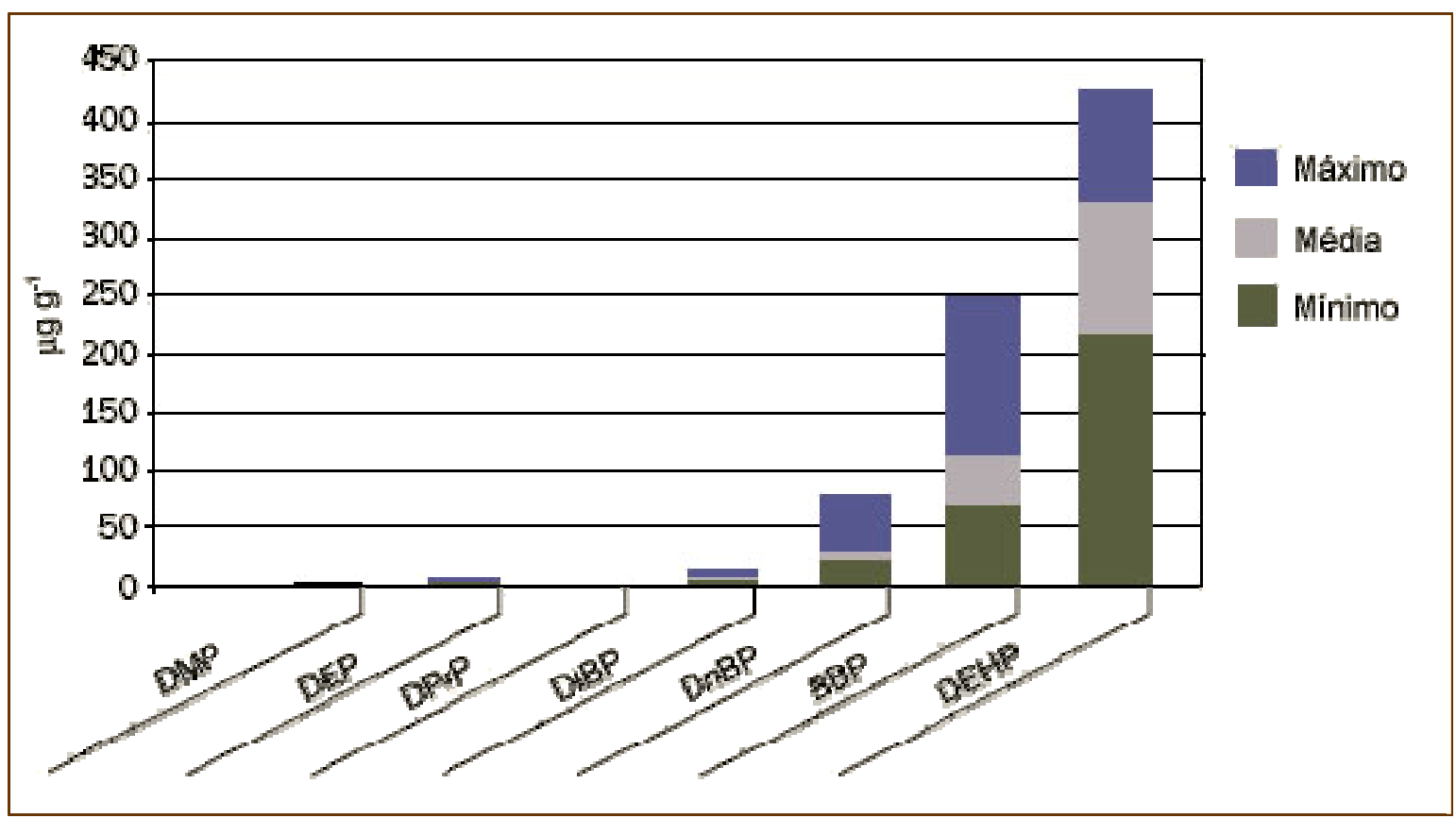

Fonte: Costner et al., 2005

FIGURE 5 - Concentração de ésteres ftálicos encontrados em poeira doméstica 
Neste mesmo estudo, os seus resultados foram comparados com os obtidos na Bélgica (Al Bitar, 2004), Brasil (Santillo et al., 2003), Reino Unido (Rudel et al., 2003) e Estados Unidos (Costner et al., 2004) e verificou a mesma relação de concentração para os EFs, DEHP>BBP>DnBP>DIBP (FIG. 6); e que a concentração dos EFs é significativamente superior nos Estados Unidos e Bélgica em comparação com o Reino Unido e Brasil.

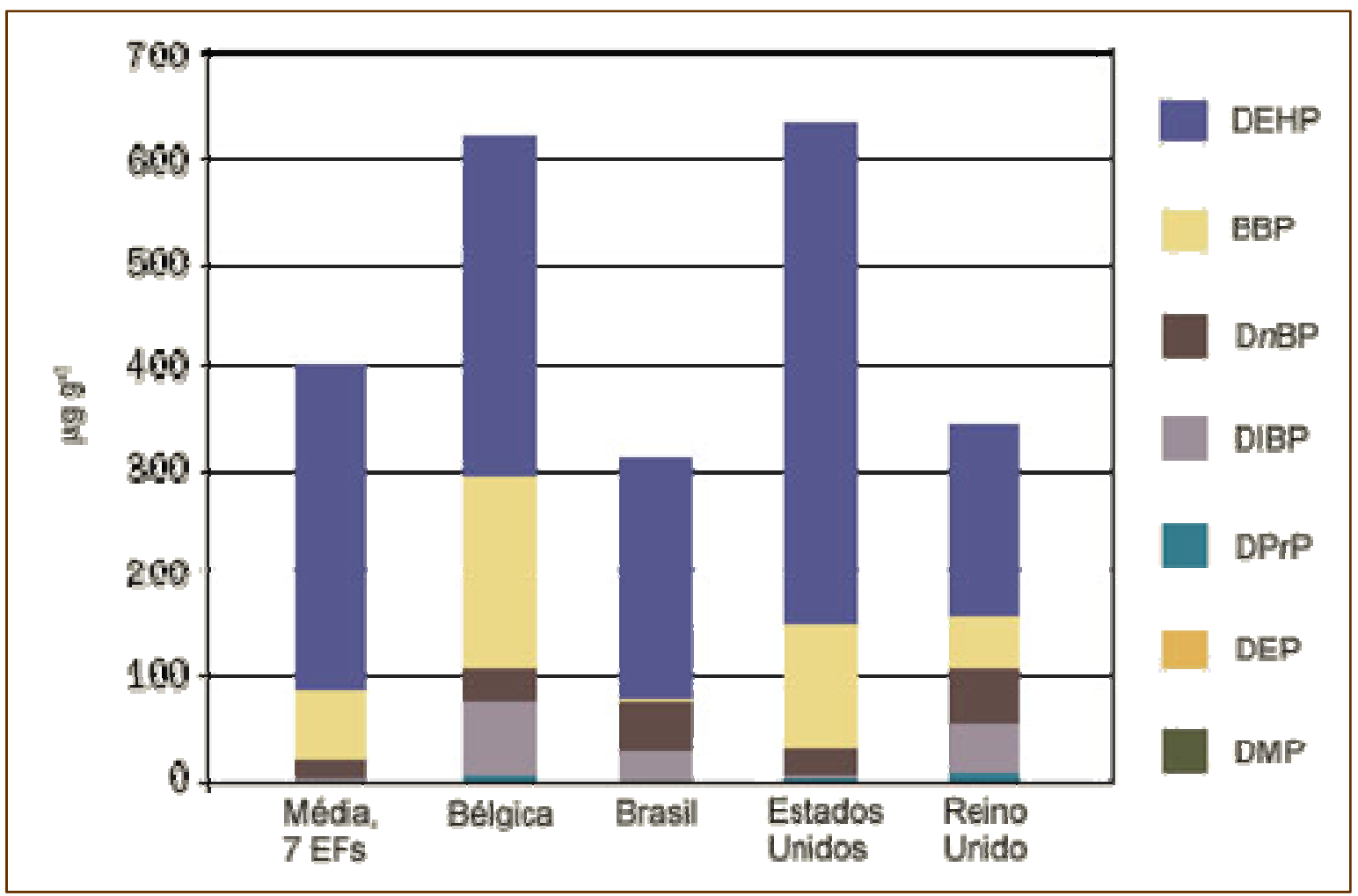

Fonte: Al Bitar (2004); Costner et al. (2004); Rudel et al. (2003); Santillo et al. (2003) apud Costner, 2005.

FIGURA 6 - Concentração média de ésteres ftálicos em poeira doméstica de diferentes países

Por causa das propriedades toxicológicas dos EFs e os riscos para a saúde humana frente a sua exposição, estas substâncias são classificadas como agentes desreguladores endócrinos e degeneradores do fígado e testículos (Jorgensen et al., 2000; Jonsson et al., 2005; Duty, 2005; Hauser et al., 2006; Heudorf et al., 2007). 
Em Janeiro de 2007 foi implementada a legislação (DIRECTIVA 2005/84/EC do Parlamento Europeu e do Conselho de 14 de Dezembro de 2005, que altera, pela vigésima segunda vez, a Directiva 76/769/CEE do Conselho relativa à aproximação das disposições legislativas, regulamentares $e$ administrativas dos Estados-Membros respeitantes à limitação da colocação no mercado e da utilização de determinadas substâncias e preparações perigosas (ftalatos nos brinquedos e artigos de puericultura (ANEXO A, p. 161), que restringe à utilização de EFs e determina que o compostos di (2-etilhexil) ftalato (DEHP), di-n-butil ftalato (DnBP) e benzil butil ftalato (BBP) não podem ser utilizados, como substâncias ou componentes de preparações em concentrações superiores a 0,1\% em massa de material plastificado, em brinquedos e artigos de puericultura. Os brinquedos e artigos de puericultura que contiverem estes ftalatos numa concentração superior ao limite referido não devem ser colocados no mercado. Além disso, estes ftalatos não devem ser utilizados em cosméticos em razão de sua toxicidade a reprodução. O DEHP pode ser utilizado em materiais que não tenham contato com alimentos gordurosos, desde que, não exceda o limite de migração da substância (SML) $1,5 \mathrm{mg} \mathrm{kg}^{-1}$ de alimento. DEHP não é permitido para utilização em aplicações de uso único, tais como selos boné ou juntas. Os EFs di-isononilo (DINP), di-isodecilo (DIDP) e di-n-octilo (DNOP) não podem ser utilizados, como substâncias ou componentes de preparações, em concentrações superiores a 0,1\% em massa de material plastificado, em brinquedos e artigos de puericultura que as crianças possam pôr na boca. Os brinquedos e artigos de puericultura que contenham estes ftalatos numa concentração superior ao limite acima determinado não podem ser comercializados.

O Ministério da Economia e da Inovação do Brasil, por meio do Decreto-Lei $N^{0}$ 10/2007 (ANEXO B, p. 165) também limitou o uso dos EFs acima mencionados, com as mesmas restrições da Comunidade Européia. 


\subsubsection{Metais tóxicos}

A presença de constituintes inorgânicos e partículas metálicas, especialmente metais tóxicos em amostras de poeira doméstica estão associados às fontes naturais e/ou antropogênicas, como mencionado anteriormente.

Os estudos realizados, em amostras de poeira doméstica têm mostrado a presença de metais como $\mathrm{Cr}, \mathrm{Ni}, \mathrm{Cu}, \mathrm{Zn}, \mathrm{Cd}, \mathrm{Pb}$ e outros em concentrações significativas, demonstrando que estas amostras encontram-se enriquecidas quando comparadas com os teores da crosta continental (Fergusson e Kim, 1991; Rasmussen, 2004).

A seguir é apresentada a comparação entre cinco estudos realizada por Morawska e Salthammer (2003), em que foram determinados os teores dos elementos $\mathrm{Pb}, \mathrm{Cd}$, $\mathrm{Cu}$ e $\mathrm{Zn}$ por espectrometria de massa com acoplamento de plasma induzido (ICPMS) em amostras de poeira doméstica de diferentes localidades e metodologias. Estes elementos foram selecionados por serem potenciais causadores de efeitos adversos à saúde humana, especialmente para as crianças entre 1 e 4 anos. De acordo com a literatura, crianças expostas às poeiras com concentrações elevadas de $\mathrm{Pb}\left(>10 \mu \mathrm{g} \mathrm{dL}^{-1}\right)$ podem desencadear vários efeitos à saúde como hiperatividade, letargia, perda de audição ou de memória, e/ou dificuldades de aprendizagem (Paoliello e Chasin, 2001; von Lindern et al., 2003; Riederer et al., 2005).

Davies et al. (1985) analisaram 59 amostras, com tamanho de grão $<1 \mathrm{~mm}$, coletadas na Pensilvânia (U. S. A.) pelos próprios moradores, utilizando aspirador de pó comercial. Foram realizados ensaios de perda de massa por queima (430 ${ }^{\circ} \mathrm{C}$ por $24 \mathrm{~h}$ ) e determinação de $\mathrm{Pb}, \mathrm{Cd}$, Cu e Zn após o processo de digestão em meio ácido nítrico.

Kim e Fergusson (1993) determinaram os mesmos elementos em 120 amostras, coletadas na Nova Zelândia por meio de bomba de vácuo e filtro de fibra de vidro e processo de digestão em meio ácido nítrico. 
O'Rourke et al. (1999) analisaram 176 amostras, com tamanho de grão $<65,5 \mu \mathrm{m}$, coletadas no Arizona (U. S. A.) e digestão em meio ácido nítrico.

Seifer et al. (2000b) utilizaram de 3900 amostras, coletadas pelos próprios moradores, utilizando aspirador de pó comercial, na Alemanha e os teores de Pb, $\mathrm{Cd}, \mathrm{Cu}$ e $\mathrm{Zn}$ foram determinados após o processo de digestão em meio ácido nítrico.

Tong e Lam (2000) determinaram os mesmos elementos em 151 amostras, coletadas na China, por meio de um mini aspirador de pó, com tamanho de grão $<0,25 \mathrm{~mm}$, após digestão em meio ácido nítrico.

Na TAB. 3, é apresentada a média aritmética e o intervalo de concentração para os elementos $\mathrm{Pb}, \mathrm{Cd}$, Cu e $\mathrm{Zn}$ referente aos trabalhos acima mencionados.

TABELA 3 - Média aritmética $(\bar{X})$ e intervalo de concentração (IC) para os elementos $\mathrm{Pb}, \mathrm{Cd}$, Cu e $\mathrm{Zn}$ em amostras de poeira doméstica para em regiões distintas

\begin{tabular}{|c|c|c|c|c|c|}
\hline \multirow{2}{*}{ Região } & & \multicolumn{4}{|c|}{$\bar{X}$ e IC $\left(\mu \mathbf{g ~ g}^{-1}\right)$} \\
\hline & & $\mathrm{Pb}$ & $\mathrm{Cd}$ & $\mathrm{Cu}$ & $\mathrm{Zn}$ \\
\hline Pensilvânia (1985) & $\begin{array}{c}\bar{X} \\
I C\end{array}$ & $\begin{array}{c}346 \\
56-2061\end{array}$ & $\begin{array}{c}0,7 \\
0,2-2,3\end{array}$ & $\begin{array}{c}159 \\
26-813\end{array}$ & $\begin{array}{c}937 \\
187-4315\end{array}$ \\
\hline $\begin{array}{l}\text { Nova Zelândia } \\
\text { (1993) }\end{array}$ & $\begin{array}{l}\bar{X} \\
I C\end{array}$ & $\begin{array}{c}573 \\
101-3510\end{array}$ & $\begin{array}{c}4,23 \\
0,557-21,0\end{array}$ & $\begin{array}{c}165 \\
54,2-1010\end{array}$ & $\begin{array}{c}8980 \\
871-205000\end{array}$ \\
\hline Arizona (1999) & $\begin{array}{c}\bar{X} \\
I C\end{array}$ & 58,8 & $* * *$ & $\begin{array}{l}* * * \\
* * *\end{array}$ & $\begin{array}{l}* * * \\
* * *\end{array}$ \\
\hline Alemanha (2000) & $\begin{array}{l}\bar{X} \\
I C\end{array}$ & $\begin{array}{c}4 \\
0,1-37000\end{array}$ & $\begin{array}{c}0,9 \\
0,05-220\end{array}$ & $\begin{array}{c}76 \\
12-540\end{array}$ & $\begin{array}{c}469 \\
30-600\end{array}$ \\
\hline China (2000) & $\begin{array}{l}\bar{X} \\
I C\end{array}$ & $\begin{array}{c}157,4 \\
0,1-1415,2\end{array}$ & $\begin{array}{c}4,3 \\
0,02-2340,6\end{array}$ & $\begin{array}{c}310,8 \\
46,6-32611\end{array}$ & $\begin{array}{c}1408,8 \\
71,8-12940,2\end{array}$ \\
\hline
\end{tabular}


Os resultados evidenciam que a fontes de contaminação variam de região para região. Entretanto, em relação aos teores médios de $\mathrm{Pb}$, foi verificada uma correlação entre os determinados na Pensilvânia $\left(346 \mu \mathrm{g} \mathrm{g}^{-1}\right)$ com os da Nova Zelândia $\left(573 \mu \mathrm{g} \mathrm{g}^{-1}\right)$. Segundo os autores, estes teores estariam associados ao desgaste de tinta a base de chumbo. Outra associação refere-se aos teores de zinco, $8980 \mu^{-1} \mathrm{~g}^{-1}$ (Nova Zelândia) e 1408,8 $\mu \mathrm{g} \mathrm{g}^{-1}$ (China), os autores atribuem a presença deste elemento ao desgaste, de tapetes de borracha e rufos galvanizados (chapa de flander). Eles encerram a discussão, concluindo que a presença de elementos está associada com os fatores de desgaste de artefatos, e questões socioeconômicas, especialmente as edificações muito antigas e baratas.

\subsubsection{Agentes microbiológicos}

Os agentes microbiológicos presentes na poeira são parâmetros tão importantes quanto às substâncias potencialmente tóxicas, visto que, um dos principais agentes causadores de alergia respiratória (alergênico) está correlacionado com a presença de ácaro, mofo (fungos), bactérias e outros. Neste caso, uma característica importante é a idade da poeira, ou seja, quanto mais antiga maior é seu malefício (alergenicidade), por causa da degeneração, decomposição e maior acúmulo de substâncias químicas.

\section{- Ácaros}

Os ácaros (Dermatophagoides) são artrópodes que pertencem à classe dos aracnídeos, sobrevivem a uma temperatura de $25{ }^{\circ} \mathrm{C}$ e umidade relativa do ar entre 70 e $80 \%$ (Arlain et al. apud Moraes, 2006). Eles se desenvolvem nos móveis, papéis de parede, carpetes, acolchoados, travesseiros e colchões e se alimentam basicamente de pele humana naturalmente descamada. A propriedade alérgica provém de suas fezes, que apresenta a proteína alergizante, geralmente 
em flocos de 10 a $14 \mu \mathrm{m}$ de diâmetro. Elas podem entrar em suspensão no ar ambiente por processos de varredura, aspiração ou ventilação e se depositarem na poeira (Platts-Mills et al. , 2005). Os sintomas alérgicos são a falta de ar, chiado do peito, coriza, lágrima nos olhos e outros.

- Fungos, bactérias e vírus

Os fungos, as bactérias e os vírus podem desencadear a asma, uma doença inflamatória crônica das vias áreas, causada especialmente pela inalação de uma toxina integrante da parede celular de algumas bactérias, a qual, é libertada após a destruição desta parede. A sua identificação e quantificação é feita por meio de ensaios de contagem da unidade de formação de colônias (UFCs) (Hunter et al. (1996) apud Moraes et al., 2006). Pesquisadores do National Institute of Environmental Health Sciences (NIEHS) e da Universidade de Lowa, descobriram uma forte associação entre os níveis de endotoxina e os sintomas da asma. De acordo com os cientistas as maiores concentrações foram determinadas no chão da cozinha, porém verificou-se que o ambiente mais agressivo para a saúde é o quarto.

- Insetos

Os insetos compõem o grupo de animais mais diversificado existente na Terra, apresentando mais de 800 mil espécies descritas. Dentre elas, as mais comuns nos ambientes domésticos estão às baratas. Elas, assim como os ácaros produzem alérgenos, que se acumulam na poeira dos ambientes internos, como por exemplo, colchões, roupas de cama, móveis estofados, carpetes e especialmente, cozinha (por causa dos alimentos), contribuindo para doenças relacionadas com a inflamação de vias aéreas (De Lucca et al., 1999; Eggleston et al., 1998; De Blay et al. (1999) apud Moraes et al., 2006). 
- Animais domésticos

Entre os animais domésticos, os mais comuns são os cães e gatos. Além dos alérgenos presentes em suas salivas e pele, outro parâmetro que contribui com as doenças alérgicas, são seus pelos, visto que, em razão de suas pequenas dimensões permanecem suspensos no ar, por várias horas (D'Amato et al. apud Moraes, 2006).

\subsection{Os riscos de exposição à poeira doméstica}

A literatura tem reportado que a exposição à poeira doméstica tem sido uma fonte potencial de risco à saúde (Roberts, 1992), visto que, este material adsorve substâncias potencialmente tóxicas e por meio de inalação, contato dérmico ou ingestão, estas substâncias podem ser absorvidas pelas pessoas (Hawley, 1985). Os pesquisadores de todo mundo tem procurado mostrar uma correlação entre alguns efeitos adversos a saúde como irritação dos olhos e mucosas, alergias, insuficiência respiratória e cardiovascular, alterações do sistema imunológico, deficiência no aparelho reprodutor e até o desenvolvimento de câncer, em razão a exposição frente à poeira doméstica.

Hawley (1985) reportou que a absorção dérmica pode ocorrer pelo contato direto com mobílias, pisos e outros objetos. Neste artigo, é estimado que cerca de $30 \mathrm{mg}$ por dia de poeira seja absorvida pelas mãos das crianças e $50 \mathrm{mg}$ dos adultos. A inalação pode ocorrer pela suspensão ou resuspensão após as atividades como limpeza, brincadeiras e outros. Segundo o autor, as crianças inalam entre 0,15 a $0,34 \mathrm{mg}$ de poeira por dia, enquanto que os adultos cerca de $0,80 \mathrm{mg}$. 
Segundo Lewis (1994), as crianças compõem o grupo de risco mais preocupante, já que, possui o hábito de rastejar-se no chão e de levar objetos ou as mãos a boca após entrarem em contato com o piso ou tapetes empoeirados.

A contaminação indireta geralmente ocorre por meio de ingestão acidental de partículas aderidas aos alimentos, objetos ou a pele. Estimam-se que as crianças mais jovens ingiram entre 50 e $100 \mathrm{mg}$ de poeira por dia e os adultos cerca de 0,56 mg. Além disso, uma pequena porcentagem de crianças com comportamento intencional de ingerir itens não alimentares (Pica) pode ingerir até $10 \mathrm{~g}$ de solo e poeira por dia. Um estudo realizado na Alemanha (Lewis et al., 2001), mostrou que a quantidade de poeira ingerida por crianças com idade entre 1 a 6 anos é de 20-100 mg dia ${ }^{-1} ; 7$ a 14 anos, 5-25 $\mathrm{mg} \mathrm{dia}^{-1}$; adolescentes e adultos (15-75 anos de idade) 2-10 $\mathrm{mg} \mathrm{dia}^{-1}$. A quantidade diária de poeira contida no carpete que pode ser ingerida por crianças é estimada em $100 \mu \mathrm{g} \mathrm{dia}^{-1}$.

Morawska (2003) reportou que as partículas maiores que $10 \mu \mathrm{m}$ ficam geralmente retidas no nariz, na garganta ou trato respiratório superior, ao passo que as menores que $2,5 \mu \mathrm{m}$, adentram no sistema respiratório e são mais difíceis de eliminação.

A literatura, nesses últimos, anos tem relatado muitos estudos sobre a exposição à poeira doméstica, cujo enfoque tem sido, especialmente, os teores de chumbo (Lisiewicz et al., 2000; Jabeen et al., 2001; Chattopadhyay et al., 2003; Turner e Simmonds et al., 2006; Spalinger et al., 2007), pesticidas, biocidas e retardadores de chama (Becker et al., 1998; Kersten e Reich, 2003; Abdallah et al., 2008). Trabalhos sobre a presença de ésteres ftálicos, também têm sido reportados (Kolarik et al., 2008; Abb et al., 2009), uma vez que, eles são classificados como substâncias carcinogênicas e mutagênicas (Schettler et al., 2006; Heudorf et al., 2007; Weschler et al., 2008). 


\subsubsection{Efeitos adversos provocados pela exposição à poeira}

Como mencionado anteriormente, por causa da adsorção de substâncias potencialmente tóxicas, a poeira doméstica tem sido objeto de estudo para avaliação de efeitos adversos provocados à saúde humana frente a sua exposição, uma vez que, a contaminação pode ocorrer por meio de absorção dérmica, inalação e ingestão.

Dentro deste contexto, a seguir é apresentada uma breve descrição sobre algumas enfermidades associadas à contaminação por metais ( $\mathrm{Pb}, \mathrm{Cr}, \mathrm{Ni}, \mathrm{Zn}$ e $\mathrm{Cu}$ ) e ésteres ftálicos (bis (2-etilhexil) ftalato (DEHP), di ( $n$-butil) ftalato (DnBP), (benzil butil ftalato (BBP), bis (2-etilhexil) adipato (DEHA), dietil ftalato (DEP) e dimetil ftalato (DMP)).

Os constituintes inorgânicos e os compostos orgânicos citados acima foram selecionados porque são os mais estudados e apresentam maiores correlações com as enfermidades.

- Chumbo

O chumbo é um elemento amplamente utilizado pelo homem, desde seus primórdios, e por causa de sua neurotoxicidade tem sido o enfoque de muitos estudos ao longo desses últimos anos.

A sua contaminação por exposição à poeira doméstica pode ocorrer por absorção dérmica, inalação e ingestão. Em razão do difícil metabolismo, acumulase no organismo humano e concentram-se especialmente, no fígado, rins, ossos, dentes e cérebro (Landrigan et al.,1985).

Os teores de $\mathrm{Pb}$, presente no sangue, acima de $60 \mu \mathrm{g} \mathrm{dL}^{-1}$ podem danificar os órgãos internos e o sistema nervoso central, provocando efeitos adversos a saúde como anemia, insuficiência renal e disfunção cerebral (Nriagu, 1988; 
Hammond e Dietrich, 1990). Os abaixo de $25 \mu \mathrm{g} \mathrm{dL}^{-1}$, não representam sintomas clínicos de toxicidade, entretanto, associado a massa corporal, são verificados desabilidades de aprendizagem, aumento do limiar auditivo, deficiência na inteligência psicométrica e outras consequências cognitivas e comportamentais em crianças jovens (Needleman et al., 1979, 1990; Schwartz e Otto, 1987; Fergusson et al., 1988a, b, c; Thacker et al., 1992; Dietrich et al., 1993; Schwartz, 1994; Bellinger, 1995).

Em virtude da onipresença de $\mathrm{Pb}$ e os efeitos subclínicos de intoxicação, os Centros de Controle de Doenças (1991) recomendaram o limite máximo aceitável no sangue, para a intervenção médica seja de $25 \mu \mathrm{g} \mathrm{dL}^{-1}$ a $10 \mu \mathrm{g} \mathrm{dL}^{-1}$ de sangue total.

A intoxicação por $\mathrm{Pb}$ na infância continua sendo um perigo toxicológico. Uma estimativa de crianças americanas (idade entre 1 e 5 anos) infectadas adversamente ou com valores acima de exposição foi de 1,7 milhões (ou 8,9\%) (Pirkle et al., 1998).

- Cromo

A principal via de contaminação por cromo presente em poeira doméstica ocorre por ingestão de alimentos e água. São descritos na literatura casos letais em humanos com doses de 1,5 gramas de dicromato de potássio e para o ácido crômico consideram-se 3,0 gramas como dose letal. Os íons $\mathrm{Cr}^{6+}$ são mais tóxicos que o $\mathrm{Cr}^{3+}$. A exposição aguda ao $\mathrm{Cr}^{6+}$ produz náuseas, diarréias, danos no fígado e rim, hemorragias internas, dermatites e problemas respiratórios, enquanto que $\circ \mathrm{Cr}^{3+}$ raramente reflete em efeitos tóxicos. A exposição aguda, geralmente está associada com alergias. Os envenenamentos por ingestão podem provocar necrose no fígado e rim. No caso de inalação pode provocar irritações do trato respiratório, ulceração ou perfurações no septo nasal. Os casos como bronquite, rinite e pneumonia, também, têm sido relatados. Muitas nações usam o padrão de potabilidade recomendado pela Organização Mundial de Saúde 
de $0,05 \mathrm{mg} \mathrm{L}^{-1}$, neste caso é assumido que o $\mathrm{Cr}^{+6}$ é a espécie dominante. A EPA (1989) desenvolveu padrão menos restritivo de $0,12 \mathrm{mg} \mathrm{L}^{-1}$, que foi derivado com base em ingestão crônica de água contendo $\mathrm{Cr}^{3+}$ e $\mathrm{Cr}^{6+}$. (CETESB, 2005).

- Níquel

A inalação é uma via importante de contaminação por níquel (nível de risco mínimo, MRL: 0,0002 $\mathrm{mg} / \mathrm{m}^{3}$ ) e a via gastrointestinal é menos importante. $\mathrm{O} \mathrm{Ni}$ está normalmente presente em tecidos humanos e sob condições de alta exposição, esses níveis podem aumentar significativamente. A ocorrência de toxicidade aguda é rara, mas pode provocar irritação de pele e olhos. As dermatites são resultados comuns à sua exposição, especialmente para as mulheres. A rinite, sinusite, perfurações no septo nasal e asma têm sido relatadas para trabalhadores de refinaria e siderúrgicas (CETESB, 2005).

- Zinco

A principal via de contaminação por zinco é a ingestão (MRL: 0,3 mg kg ${ }^{-1}$ por dia). A alta ingestão de zinco induz, no intestino, a síntese de uma proteína que liga o cobre chamado de metaloproteina. Essa proteína aprisiona o cobre nas células intestinais impedindo a sua absorção causando a hipocupremia. A deficiência de cobre pode provocar a síndrome de neutropenia, anemia e desmineralização dos ossos. Outros problemas que pode advir do excesso do elemento constituem de irritação gastrintestinal, dor abdominal, vômito e diarréia (King \& Keen (1999) apud SHUQAIR, 2002). O Zn não é considerado carcinogênico, aproximadamente $34 \%$ do total emitido na atmosfera são de fonte natural, o restante, $66 \%$, tem origem na produção do metal, fertilizantes e cimento, queima de carvão e óleo e outros (CETESB, 2005). 
- Cobre

O cobre é essencial para uma boa saúde, entretanto teores elevados no organismo podem ser prejudiciais. A exposição ao pó com Cu pode irritar o nariz, boca e olhos, e causar dores de cabeça, tonturas, náuseas e diarréia. A ingestão pode provocar náuseas, vômitos, cólicas estomacais, diarréias, danos aos rins e fígado, tornando-se letal. A contaminação de ambientes internos residenciais pode ocorrer por meio das mineradoras, fábricas que fazem uso de Cu metálico ou composto de $\mathrm{Cu}$, combustão de combustíveis fósseis e resíduos, produção de madeira, adubação fosfatada e de fontes naturais (solos, vulcões, vegetação em decomposição, incêndios florestais e brisa marítima). Muitas nações usam como limite máximo na água, para proteção à saúde humana, $1,0 \mathrm{mg} \mathrm{L}^{-1}$. Os valores de menor dose com efeito observado (LOAEL) para homens e animais é de $1,3 \mathrm{mg} \mathrm{L}^{-1}$ (U.S. EPA, 2009).

\section{- Ésteres ftálicos}

Testes realizados com animais, mostram diversos efeitos como diminuição da fertilidade em fêmeas, defeitos fetais, redução da sobrevivência dos filhotes, defeitos de nascimento, níveis de hormônio alterado e danos uterinos. Os ésteres ftálicos que podem desencadear um ou mais destes efeitos são BBP (Ema et al., 1992; Ema et al., 1994; Ema et al., 1995; Ema et al., 1998; Sharpe et al., 1995; Gray et al., 2000; Nagao et al., 2000), DnBP (40 Jones et al., 1993) e DEP (Field et al., 1993; Jones et al., 1993). Nos machos, causam danos da próstata, feminilidade como auréolas/mamilos e malformações reprodutivas em recémnascidos, incluindo os níveis hormonais alterados, atrofia testicular, produção reduzida de espermatozóides e motilidade, a hipospádia (defeito de nascimento da uretra), danos às células de Sertoli e tumores de células de Leydig (células do interior do testículo). Os ésteres ftálicos relacionados a um ou mais desses efeitos incluem BBP (Agarwal et al., 1985; Sharpe et al., 1995; Gray et al., 2000; Nagao et al., 2000; Piersma et al., 2000; Rochelle et al., 2004), DBP (Foster et al., 1983; Murature et al., 1987; Fredricsson et al., 1993; Mylchreest et al., 2000; Scarano et 
al., 2009), o DEHP (Fredricsson et al., 1993; Arcadi et al., 1998; Gray et al., 2000; Li et al., 2000; Berger et al., 2001; Borch et al., 2004; Borch et al., 2005), DEP (Lamb et al., 1987; Jones et al., 1993; Contzen et al., 2008).

\subsubsection{Avaliação da exposição a contaminantes}

A exposição é definida como o contacto de um organismo (humano, no caso da avaliação de risco para a saúde humana) com um agente físico, químico ou biológico (U.S. EPA, 1989) e sua magnitude é determinado por medição ou estimativa da quantidade de um agente disponível nas fronteiras de troca como pulmões, pele, intestino e outros órgãos internos, durante um período específico de tempo.

A avaliação de exposição é a determinação ou estimativa (qualitativa ou quantitativa) da magnitude, duração e percurso de exposição.

A estimativa da magnitude de exposição corresponde à quantificação das substâncias químicas de interesse que estarão em contato com o receptor durante o período de exposição. Essas magnitudes são estimadas usando os dados de monitoramento do ambiente em conjunto com os modelos matemáticos de transporte de contaminantes. Esta última é realizada em duas etapas: estimativa de concentrações de exposição e cálculo de entrada da substância química no organismo.

A estimativa de concentração de exposição - determina a concentração de substância química que terão contato com o ser vivo durante o período de exposição. Para tal, utilizam-se modelos de monitoramento de dados e/ou de transporte de químicos e de comportamento ambiental dessas substâncias, para situações atuais e predições futuras.

A entrada de substância química no organismo calcula as exposições específicas para cada percurso de exposição. As estimativas de exposição são 
expressas em termos de massa de substância em contato com o organismo por unidade de peso do corpo por unidade de tempo $\left(\mathrm{mg} \mathrm{kg}^{-1}\right.$ por dia).

Estas concentrações de "entrada" (intake) de substâncias químicas são calculadas utilizando concentrações de exposição, taxa de contacto, frequência de exposição, duração de exposição, peso do organismo e média temporal da exposição. Alguns destes valores dependem das condições do local e das características da população exposta.

A avaliação de exposição é concluída com uma síntese dos cálculos de ingestão para cada percurso avaliado. Assim, as decisões devem ser baseadas numa estimativa de exposição máxima razoável (RME - Reasonable Maximum Exposure) de ocorrência para condições de uso atuais e futuras. A exposição máxima razoável é definida como a exposição razoável mais elevada (que se espera que ocorra no local). As RMEs são valores estimados para os percursos individuais. A entrada de substâncias químicas é calculada pela equação geral (Eq. 1) (CETESB, 2005).

$$
I=C \times \frac{I R \times E F \times E D}{B W \times A T}
$$

Na qual,

I $\equiv$ quantidade (Ingresso) de contaminante que ingressa no organismo humano por uma via de exposição ( $\mathrm{mg} \mathrm{kg}^{-1}$ por dia);

$C$ E concentração do contaminante no meio enfocado ( $\mathrm{mg} \mathrm{L}^{-1}$ ou $\mathrm{mg} \mathrm{kg}^{-1}$ );

$\mathrm{IR} \equiv$ taxa de contato com o meio enfocado ( $\mathrm{L} \mathrm{dia}^{-1}$ ou $\mathrm{kg} \mathrm{dia}^{-1}$ );

$E F \equiv$ freqüência de exposição (dias $a n o^{-1}$ );

ED $\equiv$ duração da exposição (ano);

BW $\equiv$ peso corporal $(\mathrm{kg})$;

AT $\equiv$ período de exposição (dias). 


\subsection{Métodos de coleta}

As diferentes origens, quantidade e composição de amostras de poeira são fatores a serem considerados sobre a influência dos resultados finais de análises, assim como, os métodos de amostragem.

Os métodos de amostragem podem ser divididos entre passivo e ativo. Nos passivos são colocadas placas estacionárias que retém aproximadamente $99 \%$ de partículas com diâmetro $<50 \mu \mathrm{m}$ (Edwards et al., 1998). No ativo é utilizado à aspiração, esfregaço e escovação.

A Sociedade Americana de Testes e Materiais (ASTM) e a Associação de Engenheiros Alemães (VDI), para obtenção de informações mais confiáveis e de maior reprodutibilidade de resultados, estabeleceram dois métodos padrão para amostragem de poeira doméstica.

O método D 5438-00 (ASTM) utiliza um amostrador de alto volume para pequenas superfícies (High Volume Small Surface Sampler-HVS3), ou seja, um aspirador de pó modificado, que coleta partículas maiores que $5 \mu \mathrm{m}$ usando vários ciclones (ASTM, 2000).

O método VDI 4300 (VDI) descreve as técnicas de amostragem por aspirador de pó doméstico, esfregaço de superfície e coleta por deposição (VDI, 2001). A aspiração é o procedimento mais utilizado, já que, permite uma coleta em áreas definidas e de várias frações. Entretanto, a eficiência desta amostragem diminui para partículas $>250 \mu \mathrm{m}$. Por outro lado, este procedimento pode ser realizado pelos próprios ocupantes, com a restrição de coletar a poeira em um tempo mínimo de 14 dias, o qual garante um maior equilíbrio entre a amostra e o ambiente interno (Butte e Walker apud Morawska, 2003).

Uma série de estudos vem sendo realizada para se verificar os possíveis métodos de amostragem de poeira de ambientes interno. Lioy et al. (1992) verificaram que, apesar de se obter uma quantidade maior de poeira pelo método 
de esfregaço, em comparação com a vácuo, as concentrações de metais são semelhantes.

Os métodos de esfregaço e a vácuo são projetados para medir a quantidade de massa contaminada por unidade de área $\left(\mu \mathrm{g} \mathrm{m}^{-2}\right)$; no entanto, dentro do contexto de exposição e avaliação de riscos, as concentrações são expressas em massa por massa ( $\mu \mathrm{g} \mathrm{g}^{-1}$ poeira).

Os aspiradores de pó doméstico e seus específicos sacos (filtros de papel) são os mais usados para a coleta de amostras de poeira residencial (Lioy et al. 2002) e têm sido utilizados por diversos pesquisadores (Colt et al. 1998; Hysong et al. 2003 ; Hinwood et al. 2004). Contudo, este método, tem apresentado dificuldades em reter as partículas inferiores a $10 \mu \mathrm{m}$ (Morawska e Salthammer, 2003).

Zhipeng et al. (2003) avaliaram os métodos de esfregaço, etiqueta adesiva, filtro de papel C18, vácuo e lavagem das mãos, para a coleta de poeira interna residencial contaminada por chumbo, depositada sobre tapetes. Os autores concluíram que a amostragem por esfregaço apresentou melhor resultado para a determinação de chumbo, enquanto a vácuo, maior eficácia nas informações sobre o teor de chumbo total (concentração de longo período).

Que Hee et al. (1985) utilizaram um aspirador de pó com sacos (filtros de papel) descartáveis. A poeira contida no saco foi peneirada na fração $149 \mu \mathrm{m}$ e pesada $(10,20,30,40,50$ e $100 \mathrm{mg})$. As alíquotas foram colocadas sobre uma mesa e novamente aspiradas, porém utilizando um amostrador (suporte com filtro de papel acoplado ao tubo de aspiração). Por meio deste procedimento, verificaram a eficiência da amostragem e a correlação entre a concentração de chumbo e o tamanho de partículas. Os resultados obtidos foram: 44-149 $\mu \mathrm{m}$

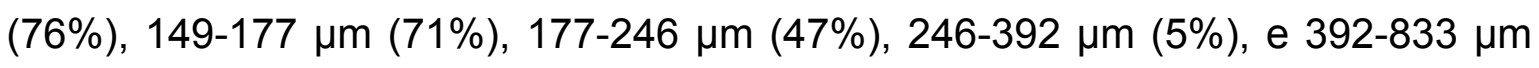
$(14 \%)$. 
A U.S. EPA (1989) utilizou o método F608-79 (ASTM, 1987), para testar a eficiência de coleta sobre o tapete. Foram realizadas simulações com duas composições diferentes de amostras, uma contendo $90 \%$ de areia e $10 \%$ de talco $(\mathrm{m} / \mathrm{m})$ e outra $45,45,9,5$ e $0,5 \%(\mathrm{~m} / \mathrm{m})$ de areia, talco, amido de milho e grafite, respectivamente. Estas, foram depositadas uniformemente sobre um tapete e os resultados mostraram que as partículas da primeira composição foram: $20 \%$, $>300 \mu \mathrm{m} ; 70 \%$, entre 300-150 $\mu \mathrm{m} ; 2 \%, 150-106 \mu \mathrm{m} ; 7 \%, 106-75 \mu \mathrm{m}$ e $1 \%<75$ $\mu \mathrm{m}$. A segunda foi inferior a $75 \mu \mathrm{m}$.

\subsubsection{Processamento e ensaios de amostras de poeira}

As amostras de poeira doméstica, após a coleta, são "processadas", ou seja, por meio de catação ou peneiramento, é realizada a separação das partículas de maiores tamanhos como cabelos, pelos, objetos atípicos e material grosso (grampos, brinquedos, botões e outros) do fino. De acordo com o procedimento de ensaio analítico, são utilizados também os processos de secagem e pesagem.

Nas determinações dos constituintes inorgânicos, cujos procedimentos utilizam agentes químicos no processo de preparação de amostras, como digestão por ácidos, cuidados especiais devem ser atentados, visto que, pode ocorrer a perda de analito por causa da volatilização e/ou solubilização incompleta.

Dentro deste contexto, a técnica de fluorescência de raios $X(X R F)$ tem se destacado, já que, procedimentos de tratamentos químicos prévios na preparação de amostras não são necessários, além disto, é uma técnica de análise multielementar e permite a determinação de elementos mais leves como o boro até os mais pesados, o urânio. O fato de ser não destrutiva é uma grande vantagem, já que, as amostras são preservadas quando adequadamente armazenadas, possibilitando a repetição do ensaio no mesmo testemunho. Outra vantagem refere-se à possibilidade de análises quantitativas sem a necessidade 
de curva de calibração individual. Atualmente, os espectrômetros de fluorescência de raios $X$ disponibilizam métodos de algoritmos matemáticos, como 0 de parâmetros fundamentais (Lachance e Claisse, 1995), que permite a determinação de maiores e menores constituintes e traços em diversos tipos de materiais, com acurácia comparáveis as técnicas de absorção atômica (AAS), espectrometria de emissão óptica acoplado com fonte de plasma induzido (ICPOES) e análise por ativação com nêutrons (NAA). Em razão desta e outras vantagens, a XRF nestes últimos anos tem sido amplamente utilizada para análise de materiais de interesse nuclear, geológicos, biológicos, ambientais e outros (Sato, 1988; Ribeiro, 2002; Ferreira, 2004; Scapin, 2004; Salvador, 2005; Scapin, e 2008; Marguí, 2009; Özdemir, 2009).

$\mathrm{Na}$ literatura, as técnicas analíticas mais utilizadas para a caracterização química de amostras de poeira doméstica são as destrutivas como AAS, ICPOES e ICPMS.

Com relação à determinação de compostos orgânicos, a literatura é razoavelmente ampla, demonstrando que as técnicas mais adequadas são as de cromatografia gasosa acoplada ao espectrômetro de massa (GCMS) e por ionização de chama (GCFID) (Colt et al., 1998; Hong et al., 2001; Butte e Heinzow, 2002; Clausen et al., 2003; Rudel et al., 2003; Butte, et al., 2004; Abb, 2009).

No Brasil, um único trabalho sobre a determinação de ésteres ftálicos refere-se ao de Greenpeace (2003). Neste estudo, foi realizada a coleta de quatro amostras de poeira doméstica em 15, 10, 10 e 15 residências das cidades de São Paulo, Campinas, Rio de Janeiro e Porto Alegre, respectivamente. Foram coletadas duas amostras em escritórios governamentais em Brasília, especificamente, 6 gabinetes de deputados federais, mais a poeira dos gabinetes de 2 senadores e diversas salas e corredores de diferentes andares do prédio do Ministério do Meio-Ambiente. Os ésteres ftálicos estudados foram: dimetil ftalato (DMP), dietil ftalato (DEP), di-iso-butil ftalato (DIBP), di-n-butil ftalato (DBP), butilbenzil ftalato (BBP), diciclohexilo ftalato (DCHP), di-(2-etil-exil) ftalato (DEHP), 
Di-n-pentyl ftalato (DPP), di-n-octil ftalato (DOP), di-isooctil ftalato (DIOP), di-isononil ftalato (DINP) e di-iso-decil ftalato (DIDP).

Os resultados mostraram que os 12 ésteres ftálicos analisados foram encontrados em todas as amostras de poeira, com exceção do DDP e DIOP. O éster ftálico mais abundante foi o DEHP $1018\left(\mu \mathrm{g} \mathrm{g}^{-1}\right)$, seguido do DINP $\left(151 \mu \mathrm{g} \mathrm{g}^{-1}\right)$ e DIDP $\left(174 \mu \mathrm{g} \mathrm{g}^{-1}\right)$. 


\section{OBJETIVO GERAL}

Determinar os teores de constituintes inorgânicos e os principais ésteres ftálicos em amostras de poeira doméstica, dos bairros de Pirituba, Freguesia do Ó, Jaraguá e Perus, da região metropolitana da cidade de São Paulo.

\subsection{Objetivos específicos}

- Estabelecer e avaliar uma metodologia de análise para determinar os elementos $\mathrm{Na}, \mathrm{Mg}, \mathrm{Al}$, Si, P, S, Cl, K, Ca, Ti, Cr, Mn, Fe, Ni, Cu, Zn, As, Br, $\mathrm{Rb}, \mathrm{Sr}, \mathrm{Zr}, \mathrm{Cd}, \mathrm{Ba}, \mathrm{Hg}$ e $\mathrm{Pb}$ e outros, utilizando a técnica de fluorescência de raios $X$ por dispersão de comprimento de onda (WDXRF);

- Adaptar e implantar uma metodologia de análise, do método EPA 525.5, para determinar os principais ésteres ftálicos (PAEs) (benzil butil ftalato (BBP), bis (2-etilhexil) adipato (DEHA), bis (2-etilhexil) ftalato (DEHP), di ( $n$ butil) ftalato (DnBP), dietil ftalato (DEP) e dimetil ftalato (DMP)), utilizando a técnica de cromatografia de fase gasosa acoplado ao espectrômetro de massa (CGMS);

- Analisar a morfologia das amostras por difração de raios X (XRD);

- Comparar os resultados obtidos com os publicados na literatura e avaliar o nível de contaminação;

- Avaliar os resultados por meio de ferramentas estatísticas como análises de Fatores e Cluster para identificar as prováveis fontes de contaminação;

- Avaliar o nível de exposição para os parâmetros de ingestão, inalação e contato dérmico por meio de modelos matemáticos. 


\section{CONTRIBUIÇÕES ORIGINAIS}

A abertura de mercado e a globalização no Brasil iniciado na década de noventa permitiram a aquisição de produtos importados com maior facilidade e ao mesmo tempo, criou uma competitividade entre estes países, disseminando uma busca por processos industriais menos dispendiosos.

Dentre os vários procedimentos que foram otimizados e criados para atender este propósito, é destacada a utilização de materiais reciclados, um conceito correto dentro do contexto político ambiental. No entanto, os estudos mais recentes mostraram que muitos produtos utilizados nos diversos setores industriais (automobilístico, eletro-eletrônico, eletro-doméstico e outros) apresentaram em sua composição química, compostos classificados como perigosos e carcinogênicos, consequentemente, uma correlação entre estes compostos e o aumento de algumas enfermidades foram estabelecidas.

Assim, os estudos relacionados às questões de impacto ambiental ganharam mais um enfoque, ou seja, a avaliação humana frente à exposição destes produtos "de menor custo". Os países mais desenvolvidos estão considerando como fonte amostral, o sedimento depositado em ambientes internos residenciais (poeira doméstica), já que, estes são promissores para diferenciar fontes potenciais de poluição. Contudo, a maioria dos trabalhos relaciona-se com os métodos de determinação de constituintes inorgânicos ou de compostos orgânicos e caracterização físico-química do material. Ainda, pouco trabalho é realizado utilizando tratamentos estatísticos para a identificação das fontes de contaminação e avaliação do nível de exposição de poeira doméstica.

Apesar de o Brasil possuir os parâmetros sobre a qualidade do ar, água e solo estabelecido, a ausência de um estudo sistemático sobre a qualidade da poeira doméstica é verificada. 
Neste trabalho, foram determinados os elementos dentre os quais se encontram Na, Mg, Al, Si, P, S, Cl, K, Ca, Ti, Cr, Mn, Fe, Ni, Cu, Zn, As, Br, Rb, Sr, $\mathrm{Zr}, \mathrm{Cd}, \mathrm{Ba}, \mathrm{Hg}, \mathrm{Pb}$ pela técnica de WDXRF. Os compostos orgânicos (benzil butil ftalato, bis (2-etilhexil) adipato, bis (2-etilhexil) ftalato, di ( $n$-butil) ftalato, dietil ftalato e dimetil ftalato) determinado por GCMS e a determinação de fases cristalinas por XRD. Além disso, os ensaios físicos como análise granulométrica e perda de massa por queima.

O estudo foi realizado na poeira doméstica dos bairros de Pirituba, Freguesia do Ó, Jaraguá e Perus integrantes da região metropolitana de São Paulo.

A contribuição inédita deste trabalho de pesquisa está na determinação conjunta dos parâmetros inorgânicos e orgânicos potencialmente tóxicos, em poeira doméstica, introduzindo as técnicas como XRF e XRD na sua caracterização; e na correlação com as suas prováveis fontes de emissão, assim como, o nível de exposição e mapeamento de distribuição de poluentes. $\mathrm{Na}$ interpretação dos dados obtidos foram usados os modelos matemáticos para a determinação do fator de enriquecimento, qualificação da poeira, determinação das fontes de contaminação por análise de fatores de cluster, avaliação da exposição por cálculos de ingestão, inalação e contato dérmico e para o mapeamento de distribuição dos poluentes.

Este estudo contribuirá para definição de valores de referência da qualidade da poeira, além de servir como um alerta para o governo brasileiro e aos cidadãos em relação a exposição de substâncias potencialmente tóxicas. 


\section{MATERIAIS E MÉTODOS}

A seguir são descritos os materiais e os métodos utilizados neste trabalho de pesquisa, nos seguintes tópicos:

- Local de estudo;

- Amostragem;

- Ensaios físicos:

- Análise granulométrica $(A G)$;

- Perda de massa por queima (PF);

- Ensaios Químicos:

- Determinação de constituintes inorgânicos por espectrometria de fluorescência de raios X (WDXRF);

- Determinação de ésteres ftálicos por cromatografia de fase gasosa acoplado ao espectrômetro de massa (GCMS);

- Determinação de fases cristalinas por difração de raios X (XRD);

- Modelos matemáticos:

- Determinação do fator de enriquecimento (FE);

○ Qualificação da poeira;

- Determinação das possíveis fontes de contaminação por Análise de Fatores (AF) e Cluster (AC);

- Avaliação da exposição para os parâmetros de ingestão; inalação e contato dérmico;

- Mapas de distribuição. 


\subsection{Local de estudo}

O local de estudo deste trabalho abrange parte norte da Região Metropolitana de São Paulo (RMSP) que compõe um dos maiores conglomerados de metrópoles do mundo e está localizado no estado de São Paulo na região sudeste do Brasil. Ela é constituída por 39 municípios que compõem uma área urbanizada de $2.209 \mathrm{~km}^{2}$ e em virtude do acentuado crescimento passa por um intenso processo de conurbação, o qual fez com que as cidades perdessem seus limites físicos dando origem a uma mancha urbana contínua.

A RMSP está localizada geograficamente na Bacia Sedimentar do Planalto Atlântico, possui uma extensão de $7.944 \mathrm{~km}^{2}$ com altitudes que variam de 650 a 1200 m. Estas altitudes máximas são caracterizadas por serras ao redor da região urbanizada tendo a Serra do Mar a leste, a Serra de Paranapiacaba ao sul, Serra da Cantareira ao norte e a oeste formando uma barreia à dispersão dos poluentes. O município de São Paulo está localizado a $23^{\circ} 32^{\prime} \mathrm{S}$ e $46^{\circ} 38^{\prime} \mathrm{W}$ e é drenado pela bacia do Rio Tietê com seus afluentes, rio Pinheiros, Tamanduateí e outros. Está a uma distância de $60 \mathrm{~km}$ a noroeste do litoral e a uma altitude média de $860 \mathrm{~m}$ do nível do mar. Possui uma população de 11 milhões de habitantes (IBGE, 2007), estando entre os seis maiores aglomerados urbanos do mundo.

O clima pode ser resumido em duas estações bem definidas com um verão chuvoso e um inverno seco. O inverno é caracterizado pela ocorrência de frequentes inversões térmicas com topo em baixas altitudes, o que é desfavorável à dispersão de poluentes (CETESB, (1997a); Andrade (1993) apud Castanho 1999).

A escolha dos locais de amostragem dentro de toda a cidade de São Paulo não é uma tarefa fácil. Desta forma, foram escolhidos os locais de amostragem que satisfizessem algumas prioridades como volumes de tráfego (leve e pesado); 
agrupamento residencial (apartamentos e casas); proximidades a estações ferroviárias, parques, aterros sanitários, cemitérios e renda per capita (estimada entre 2 a 20 salários mínimos).

Os bairros Freguesia do Ó (FO), Pirituba (PI), Jaraguá (JA) e Perus (PE) estiveram de acordo com os pré-requisitos. Estes, estão localizados na zona noroeste da cidade de São Paulo, com distâncias entre si de aproximadamente 10 $\mathrm{km}$. As principais vias que interligam estes bairros e as outras regiões da cidade são: Rod. Anhanguera, Rod. dos Bandeirantes, Rod. Castelo Branco, Rodoanel Mario Covas, Marginal Tietê e Pinheiros, caracterizando assim um tráfego intenso. Além disso, fazem parte cinco estações ferroviárias, Piqueri, Pirituba, Vila Clarice, Jaraguá e Perus; três cemitérios, da Freguesia do Ó, Jaraguá e Perus; um aterro sanitário "Bandeirantes", em Perus (desativado desde março de 2007) e um parque estadual "Jaraguá".

Os bairros FO, PI, JA e PE vêm se destacando em razão do seu crescimento populacional, assim como, a expansão do comércio e de indústrias de pequeno porte. De acordo com o censo de 2000, a população é de 1.044 .742 habitantes e a renda média de $\mathrm{R} \$ 751,60$ (prefeitura do município de SÃO PAULO, 2000). Na FIG. 7, é mostrado o mapa da Região Metropolitana de São Paulo e a localização dos bairros FO, PI, PE e JA. 


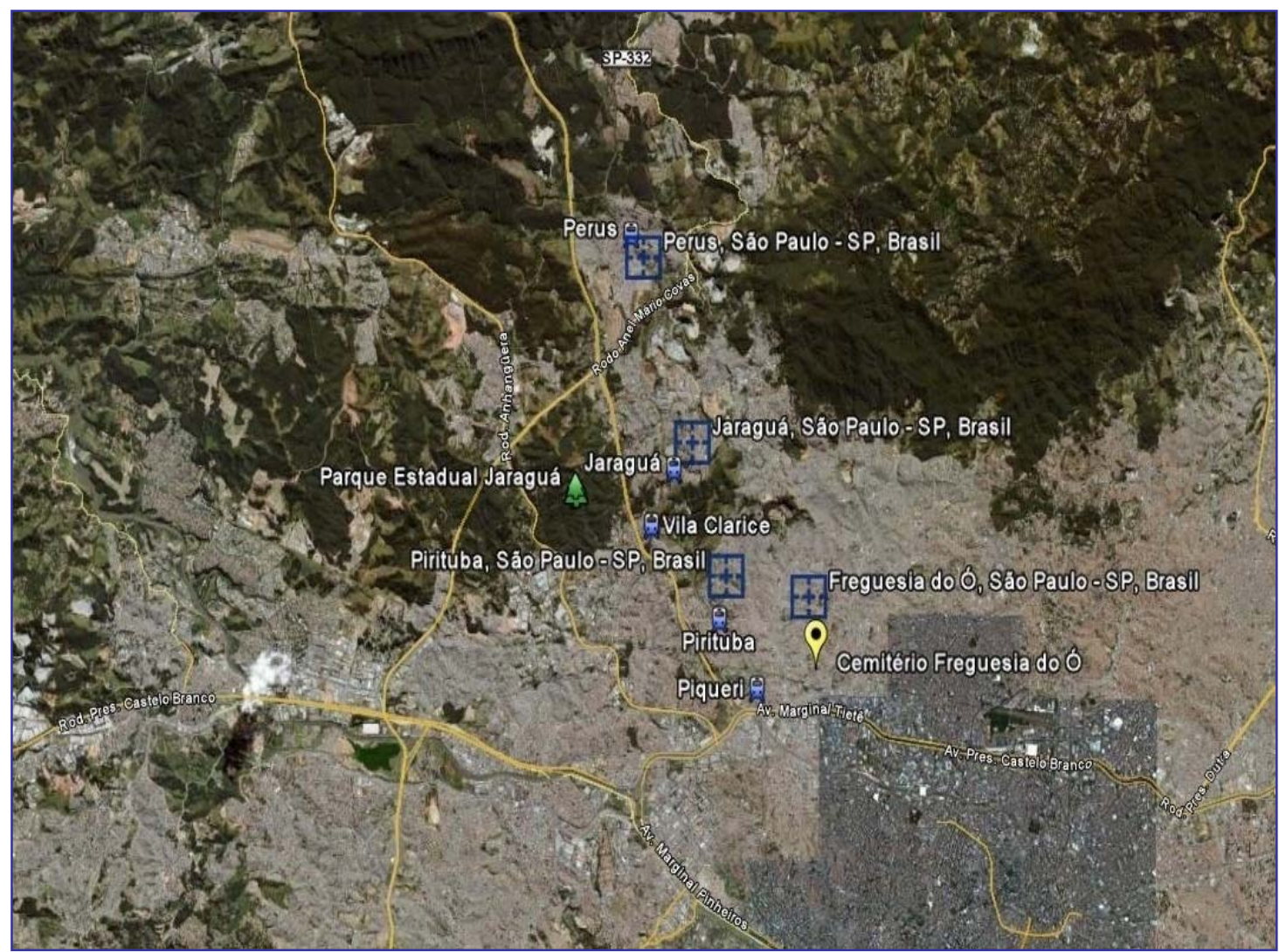

Fonte: Google Earth, 2009.

FIGURA 7 - Mapa da Região Metropolitana de São Paulo e os bairros Freguesia do Ó, Pirituba, Perus e Jaraguá

\subsection{Amostragem}

A amostragem foi realizada em 69 residências (FIG. 8), pelos próprios moradores, usando seus respectivos aspiradores e sacos de papel de filtro descartável, apropriado para cada modelo (FIG. 9). Para este trabalho, foi realizada uma campanha de amostragem que compreendeu o período de Janeiro de 2006 a Julho de 2008. 


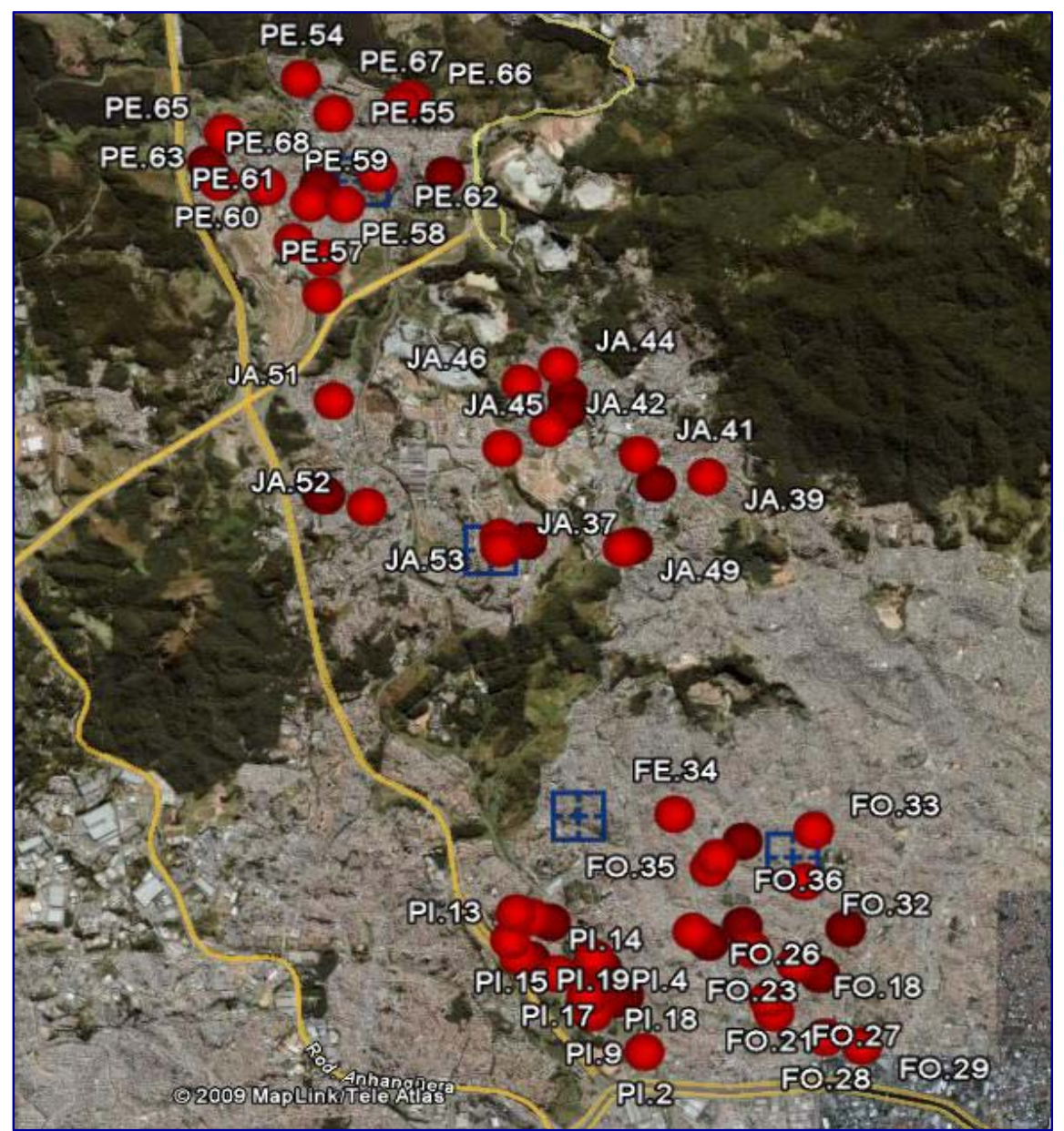

Fonte: Google Earth, 2009.

FIGURA 8 - Mapa da região em estudo com os pontos de coleta de amostras de poeira doméstica $(n=69)$ (APÊNDICE A, p. 129)

O procedimento de coleta seguiu um protocolo (APÊNDICE B, p. 133) elaborado com base nos documentos da Agência de Proteção Ambiental Americana (U.S. EPA, 2005). Os participantes foram instruídos a aspirar somente às áreas internas das residências, as quais incluem pisos com/sem tapetes, carpetes, mobílias, cortinas e outros. O tempo de acúmulo no reservatório foi de 14 meses, para que houvesse um equilíbrio entre o ambiente interno e o externo. As informações sobre as residências como a idade, a extensão, as características da construção, as fontes de aquecimento, os histórico sobre 
restauração/decoração, a proximidade entre a rua e a residência, o número de adultos, crianças e animais de estimação, hábitos ocupacionais, de fumar e outros foram registradas em um formulário (APÊNDICE C, p. 134).

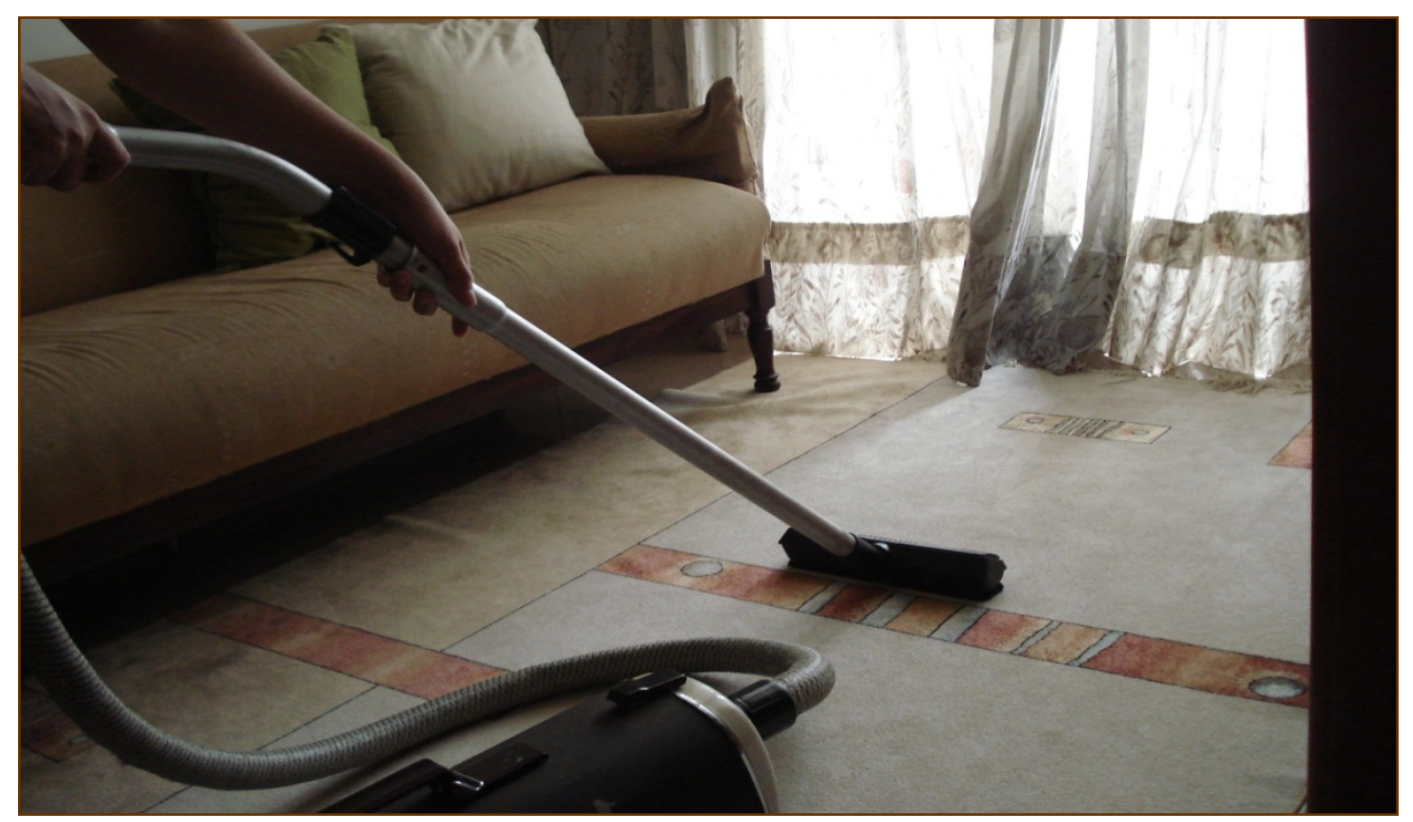

FIGURA 9 - Foto da coleta de amostras de poeira doméstica com aspiradores e sacos de papel de filtro descartável

Após a coleta, as amostras foram seladas e armazenadas para os ensaios posteriores.

\subsection{Análises granulométricas (AG)}

As análises granulométricas (ABNT/NBR 7181/82) foram realizadas em um agitador de peneiras eletromagnético Bertel, utilizando as peneiras de $30 \mathrm{~cm}$ de diâmetro, Tyler 20, 48, 100, 200 e 250 (850 $\mu \mathrm{m}$ (A), 850-300 $\mu \mathrm{m}$ (B), 300-150 $\mu \mathrm{m}$ (C), 150-75 $\mu \mathrm{m}$ (D), 75-63 $\mu \mathrm{m}$ (E) e <63 $\mu \mathrm{m}$ (F)) (ABNT/NBR 5734/80). As amostras foram previamente pesadas e adicionadas sobre a peneira A e 
posteriormente submetidas à agitação, sob uma frequência de $60 \mathrm{~Hz}$ por uma hora (FIG. 10).

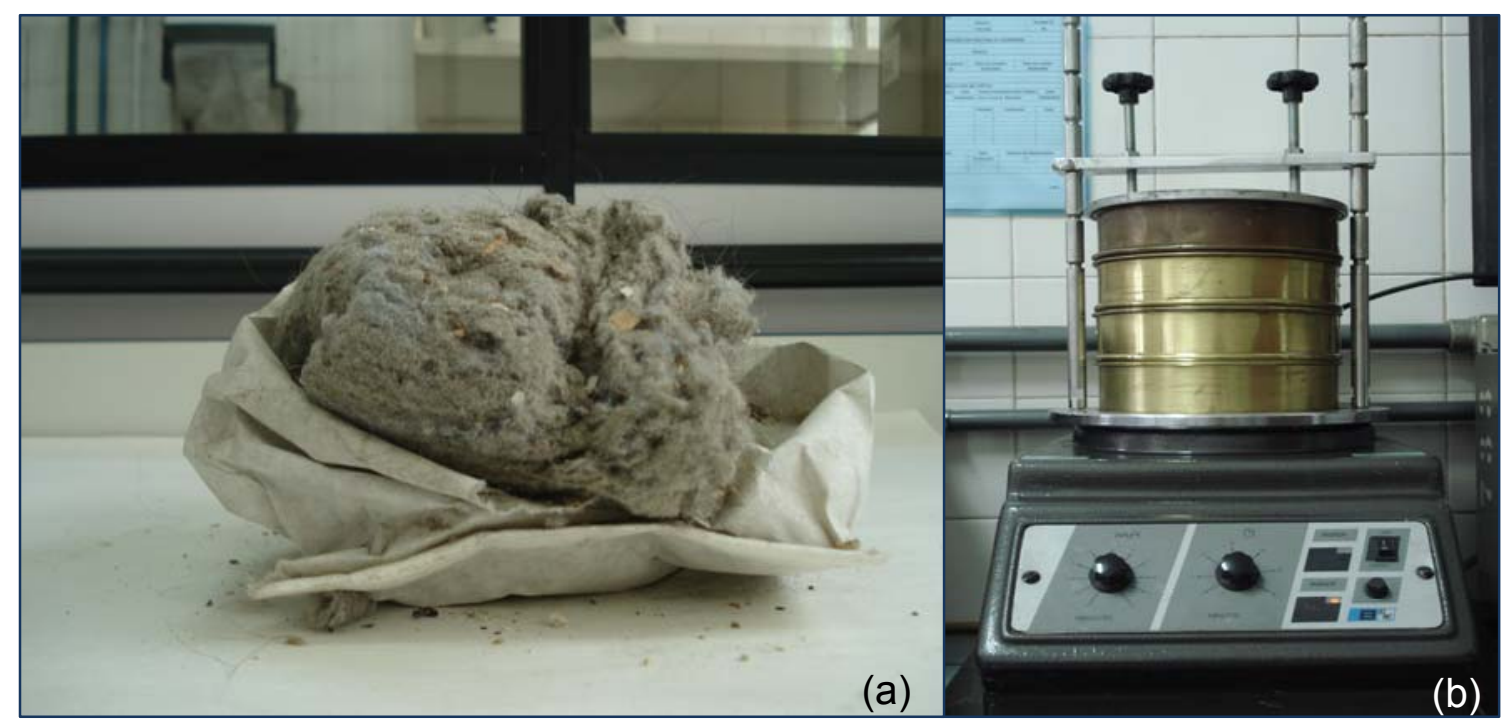

FIGURA 10 - Foto da amostra de poeira (a) e do agitador eletromagnético (b) para separação granulométrica

A distribuição do tamanho de grão foi calculada por meio da Eq. 2:

$$
\mathrm{Qg}=100 \times\left(\mathrm{M}_{\mathrm{r}} / \mathrm{M}_{\mathrm{t}}\right)
$$

Na qual,

$\mathrm{Qg} \equiv$ porcentagem de material passado em cada peneira;

$\mathrm{M}_{\mathrm{t}} \equiv$ massa total da amostra bruta;

$\mathrm{M}_{\mathrm{r}} \equiv$ massa do material retido acumulado em cada peneira. 


\subsection{Perda de massa por queima (PF)}

A perda de massa por queima $(F)$ foi realizada somente nas frações 150-75 $\mu \mathrm{m}$ (D), 75-63 $\mu \mathrm{m}$ (E) e <63 $\mu \mathrm{m}$ (F), uma vez que, a maior afinidade dos constituintes inorgânicos e ésteres ftálicos estarem presentes são nas partículas mais finas.

O procedimento consistiu em pesar cerca de $1 \mathrm{~g}$ de amostra de cada fração, separadamente; e posteriormente, transferiu-se para um cadinho de porcelana (previamente tarado) e a perda de massa foi realizada em forno mufla a $950 \pm 30{ }^{\circ} \mathrm{C}$ por 4 horas.

A perda de massa foi calculada de acordo com a Eq 3:

$$
\mathrm{PF}=100-\frac{\mathrm{n}_{2}}{\mathrm{n}_{1}} \times 100
$$

Na qual,

$\mathrm{PF} \quad=\quad$ porcentagem de massa queimada;

$\mathrm{n}_{1}=$ amostra inicial;

$\mathrm{n}_{2}=$ amostra restante após a queima. 


\subsection{Determinação dos constituintes inorgânicos por espectrometria de fluorescência de raios $X$ por dispersão de comprimento de onda (WDXRF)}

Para a determinação dos constituintes inorgânicos nas amostras de poeira doméstica utilizou-se um espectrômetro de fluorescência de raios $\mathrm{X}$ por dispersão de comprimento de onda (WDXRF), modelo RIX 3000, da RIGAKU Co. (FIG. 11); utilizando o método de parâmetros fundamentais (FP).

O espectrômetro possui os seguintes acessórios: tubo de Rh (3,0 kW), 6 diafragmas para o feixe dos raios $\mathrm{X}(35,30,25,20,10$ e $5 \mathrm{~mm}), 4$ filtros $(\mathrm{Zr}, \mathrm{Ti}, \mathrm{Al}$ e Ni), 3 colimadores $(160,460,520 \mu \mathrm{m}) 8$ cristais de difração ((LiF (200), PET (002), GE (111), TAP, RX 70, RX 80, RX 4)* e 2 detectores (SC e FPC)*. Além disso, encontram-se acoplados softwares de métodos de algoritmos como Parâmetros Fundamentais, Espalhamento Thomson, Espalhamento Compton e Regressão Linear, que permite executar correções de efeitos de matriz como sobreposição de linhas características, absorção, excitação e absorção/excitação.

Os recursos disponibilizados por este software, assim como, os acessórios mencionados acima, permitem estabelecer condições ótimas de análises e resultados confiáveis, bem como, limites de detecção suficientes para a determinação de constituintes inorgânicos.

*LIF 200, Fluoreto de Lítio; PET (002), Pentaeritritol; GE (111), Germânio; TAP, Fosfato de Tálio; RX, denominação RIGAKU Co.; SC, Detector de cintilação (Nal:TI); FPC, Detector proporcional de fluxo (mistura argônio/metano). 


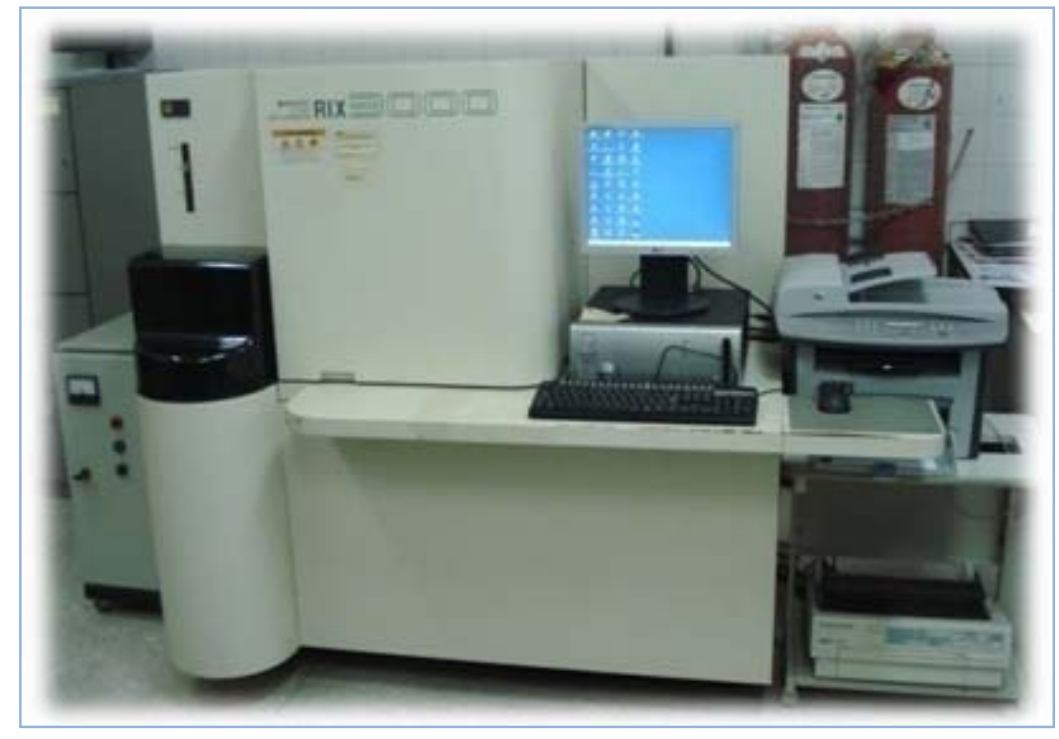

FIGURA 11 - Foto do espectrômetro de WDXRF, da RIGAKU Co., modelo RIX 3000

\subsubsection{Preparação de amostras para análises por WDXRF}

As amostras de poeira doméstica foram preparadas na forma de pó compactado. Cerca de $2 \mathrm{~g}$ a $3 \mathrm{~g}$ de ácido bórico $\left(\mathrm{H}_{3} \mathrm{BO}_{3}\right)$ foram previamente compactados em molde cilíndrico (da prensa hidráulica - B. Herzog, modelo HTP40) a 100 Pa por 1 minuto; sobre esta "base" cerca de 0,3 a 0,5g de cada amostra das frações D, E e F (separadamente) foram adicionadas e compactadas a uma pressão de $203 \mathrm{~Pa}$ por 1 minuto, obtendo-se uma pastilha de $20 \pm 1 \mathrm{~mm}$ de diâmetro e $10 \pm 1$ $\mathrm{mm}$ de espessura (FIG. 12).

Neste procedimento, há uma redução significativa no tempo de preparação de amostras, uma vez que, etapas de pesagem e dissolução das amostras não são necessárias. 


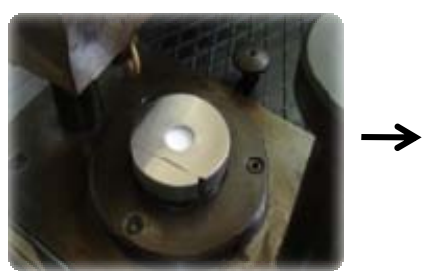

Compactação de ácido bórico $\left(\mathrm{H}_{3} \mathrm{BO}_{3}\right)$ em molde cilíndrico, obtendo-se uma "base"

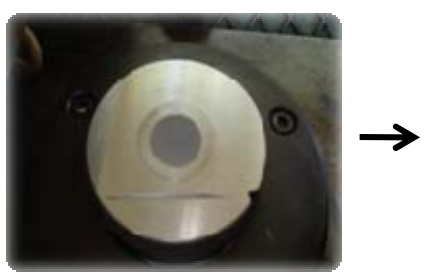

Compactação de poeira sobre a base

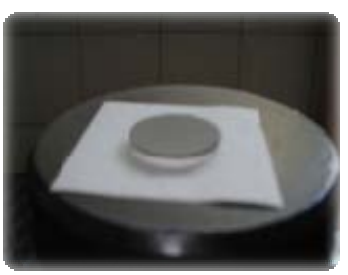

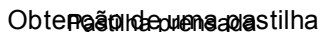

FIGURA 12 - Foto mostrando as etapas de preparação de pastilhas prensada de poeira para análises por WDXRF

\subsubsection{Método de parâmetros fundamentais (FP)}

A técnica de fluorescência de raios $X$ permite o uso de várias metodologias de análises químicas quantitativas, como as de método de regressão linear, padrão interno, efeito Compton, quimiométricos e de algoritmos. Entre os métodos de algoritmos, o de parâmetros fundamentais (FP) permite determinar a composição química de uma amostra, sem a utilização de padrões similares as amostras. A partir da medida da intensidade da linha de emissão do analito, em materiais e padrões certificados, com os valores tabelados de parâmetros fundamentais como distribuição espectral primária (fonte), coeficiente de absorção (fotoelétrico e de massa) e rendimento de fluorescência (Lachance, 1995; Scapin (2003) apud Scapin, 2008), é obtida curva de sensibilidade do espectrômetro.

O cálculo do algoritmo envolve duas etapas fundamentais, previsão e calibração. Na primeira etapa, a equação de FP é utilizada para prever a intensidade das linhas características de um padrão de calibração (um material com concentração conhecida e certificada). Os cálculos são realizados especificamente para condições de medidas, uma vez que, na equação de FP são computados aspectos de geometria, fonte e forma de excitação e condições instrumentais de medidas. As intensidades teoricamente calculadas são relacionadas com as 
intensidades medidas (experimentais) para cada linha característica e a sensibilidade instrumental (um fator de conversão) do equipamento é determinada para cada elemento analisado.

$\mathrm{Na}$ segunda etapa, o algoritmo estima inicialmente uma composição aproximada da amostra. O cálculo é realizado considerando a somatória de todas as intensidades relativas das linhas de emissão detectadas para cada elemento presente na matriz, assumindo uma composição total de $100 \%$ em massa.

A partir desta equação, o software, acoplado ao espectrômetro, calcula as intensidades observadas para a suposta composição, compara-as com os valores medidos, ajusta a composição assumida e calcula um novo conjunto de intensidades esperadas. Este processo de interação é repetido automaticamente até que a composição suposta forneça uma intensidade de raios $\mathrm{X}$ correspondente ao valor medido, dentro de uma faixa de erro de 0,05 \% de significância (Nagata et al (2001) apud Scapin, 2008).

A correlação entre a sensibilidade instrumental e o número atômico $(Z)$ do elemento fornece a curva de sensibilidade instrumental (Instrumental sensitivity curve, ISC), que é armazenada em uma biblioteca comum (Common Library, CL). A sensibilidade para os elementos não medidos é determinada por interpolação nesta curva (Scapin (2003) apud Scapin, 2008).

Por meio dos dados armazenados na CL é possível analisar do elemento boro ao urânio em concentrações que podem variar entre 0,001 a 100\%, independente do objeto de estudo, ou seja, materiais geológicos, biológicos, ambientais e outros (Scapin (2003) apud Scapin, 2008).

Entretanto, dependendo da complexidade da composição química da amostra e da concentração do analito, especialmente quando presente em traços $\left(\mu \mathrm{g} \mathrm{g}^{-1}\right)$, 
parâmetros como o erro relativo percentual (ER\%) pode variar até $100 \%$, numa faixa de concentração de 10 a $1 \mu \mathrm{g} \mathrm{g}^{-1}$.

Os ERs\% podem ser minimizados por meio de uma biblioteca auxiliar (Matching Library, $M L$ ) combinada à comum (CL), na qual é armazenada a sensibilidade instrumental, calculada para materiais com a composição química muito próxima das amostras de estudo.

Neste trabalho foram criadas duas ML, uma com o SRM 2584, Domestic Dust e a outra com o SRM 2781, Domestic Sludge, ambos do National Institute of Standard and Technology (NIST).

As condições de operação instrumental (posição do ângulo de Bragg para o pico e background, cristais analisadores, colimadores, detectores, potência do tubo de raios $X$ ), estabelecidas para a curva de sensibilidade são apresentadas no APÊNDICE D (p. 135) para os SRMs 2584 e 2781. Nos APÊNDICES E e F (p. 136 e 137) são apresentados as linhas de emissão características, intensidades experimentais (IEX) e teóricas (IT) e a sensibilidade para os elementos $\mathrm{Na}, \mathrm{Mg}, \mathrm{Al}$, $\mathrm{Si}, \mathrm{P}, \mathrm{K}, \mathrm{Ca}, \mathrm{Ti}, \mathrm{Cr}, \mathrm{Mn}, \mathrm{Ni}, \mathrm{Cu}, \mathrm{Zn}, \mathrm{As}$, Se, Rb, Sr, Ba, Hg e Pb. No APÊNDICE G e H (p. 138 e 139) são mostradas as curvas de sensibilidade instrumental (relação entre sensibilidade instrumental e número atômico para as linhas de emissão $\mathrm{K}$ e $\mathrm{L}$ ) do espectrômetro de fluorescência de raios $\mathrm{X}$ utilizado.

O limite de quantificação (LQ), para o método de parâmetros fundamentais, está correlacionado com a sensibilidade instrumental, aonde o espectro do contínuo e as linhas características emitidas dos elementos são parâmetros de cálculos para a sensibilidade $(m)$. No entanto, para cada linha de emissão, há uma área específica relacionada ao espectro do contínuo e uma parte do contínuo relacionada a intensidade de background (BG). Geralmente, o limite de quantificação para cada elemento expressa como uma concentração elementar $\left(\mu \mathrm{g} \mathrm{g}^{-1}\right)$, a um nível de 
significância 0,05; obtida de três vezes a intensidade líquida do background (Eq. 4) (Rousseau, 2001; Scapin, 2008)

$$
\mathrm{LQ}_{\mu \mathrm{g} \mathrm{g}}-1=\frac{3}{m} \cdot \frac{\sqrt{\mathrm{BG}}}{\mathrm{T}_{\mathrm{BG}}}
$$

Na qual,

$\mathrm{LQ}_{\mu \mathrm{g} \mathrm{g}} \mathrm{g}^{-1} \quad \equiv$ limite de quantificação;

$m \quad \equiv$ sensibilidade (quociente entre a intensidade teórica e experimental) extraída da curva de sensibilidade;

BG $\equiv$ intensidade de background na posição de pico, expressa em contagem por segundo (cps);

$\mathrm{T}_{\mathrm{BG}} \quad \equiv$ tempo total (tempo medido nas posições de background e pico $2 \theta$.

A intensidade de BG foi calculada de acordo com a Eq. 5:

$$
\mathrm{BG}=\frac{\mathrm{I}_{1}\left(2 \theta_{3}-2 \theta_{2}\right)+\mathrm{I}_{3}\left(2 \theta_{2}-2 \theta_{1}\right)}{2 \theta_{3}-2 \theta_{1}}
$$

$\mathrm{Na}$ qual,

$\mathrm{I}_{1}, \mathrm{I}_{3} \quad \equiv$ intensidade de background, a esquerda e direita do pico, respectivamente;

$2 \theta_{2}, 2 \theta_{1}, 2 \theta_{3} \equiv$ posição do ângulo de Bragg $2 \theta$ no pico, esquerdo e direito, respectivamente;

A metodologia foi avaliada utilizando os materiais de referência certificados (MCRs) 2781 - Domestic sludge, 1547 - Peach Leaves da National Institute of Standards and Technology (NIST) e Sargasso № 9 da National Institute for Environmental Studies (NIES). Réplicas de três amostras foram preparadas e para cada espécime foram realizadas quatro medidas, para cada elemento, totalizando 
um conjunto de doze medidas por elemento. As intensidades fluorescentes experimentais foram interpoladas na curva de sensibilidade e as concentrações de $\mathrm{Na}, \mathrm{Mg}, \mathrm{Al}, \mathrm{Si}, \mathrm{P}, \mathrm{S}, \mathrm{Cl}, \mathrm{K}, \mathrm{Ca}, \mathrm{Ti}, \mathrm{Cr}, \mathrm{Mn}, \mathrm{Fe}, \mathrm{Ni}, \mathrm{Cu}, \mathrm{Zn}, \mathrm{As}$, Se, Br, Sr e Pb determinadas. Os resultados foram avaliados por meio de testes estatísticos, descritos a seguir.

A precisão, em termos de repetitividade e a exatidão, erro percentual relativo, foram calculadas por meio de seguintes etapas (INMETRO, 1998; INMETRO, 2003; Scapin (2003) apud Scapin, 2008):

Primeiramente, foi aplicado o teste do critério de Chauvenet (Santos, 2001) para a eliminação dos valores dispersos (outliers), seguindo-se o procedimento descrito abaixo:

- mede-se a variável de número $\mathrm{N}$ de vezes e estima-se a média da distribuição (Eq 6) (Santos, 2001):

$$
\bar{x}=\frac{1}{N} \sum_{i=1}^{N} x_{i}=\frac{x_{1}+x_{2}+\ldots+x_{N}}{N}
$$

Na qual,

$\bar{X} \equiv$ valor médio;

$X_{i} \equiv$ valor de cada medida;

$N \equiv$ número de repetições.

- posteriormente o desvio padrão (Eq. 7) (Santos, 2001):

$$
\sigma=\left[\frac{1}{N-1} \sum_{i=1}^{N}\left(x_{i}-\bar{x}\right)^{2}\right]^{\frac{1}{2}}
$$


Na qual,

$\sigma \equiv$ desvio padrão;

$N \equiv$ número de repetições;

$X_{i} \equiv$ valor de cada medida;

$\bar{x} \equiv$ valor médio.

- calcula-se o desvio entre cada medida e a média dividindo-se o resultado por $\sigma$ (Eq. 8) (Santos, 2001):

$$
\left|\bar{d}_{i}\right|=\frac{1}{n} \sum_{i}^{n}\left|d_{i}\right|=\frac{1}{n} \sum_{i}^{n}\left|x_{i}-\bar{x}\right|
$$

Na qual,

$d_{i} \equiv$ desvio de cada medida;

$X_{i} \equiv$ valor de cada medida;

$\bar{x} \equiv$ valor médio.

- usando um número de leituras $\mathrm{N}$, compara-se o valor de $\mathrm{d}_{i} / \sigma \operatorname{com~} \mathrm{d}_{\max } / \sigma$ (ANEXO C, p. 167). Se for maior, rejeita-se o valor e recalcula-se a média e o desvio novamente. 
Após a eliminação dos outliers foi calculada a incerteza usando a Eq. 9 (Scapin, 2008):

$$
U= \pm t_{n-1\left(\frac{\alpha}{2}\right)} * \frac{\sigma}{\sqrt{n}}
$$

Na qual,

$$
\begin{array}{lll}
n & \equiv & \text { número de repetições; } \\
\sigma & \equiv & \text { desvio padrão; } \\
t_{n-1\left(\frac{\alpha}{2}\right)} & \equiv & \text { valor tabelado teste } t \text {-Student. }
\end{array}
$$

Em sequência, foi aplicado o teste Z-score, para a avaliação da exatidão usando a Eq. 10 (Scapin, 2008):

$$
Z=\frac{\bar{x}_{\mathrm{det}}-x_{c e r t}}{\sqrt{\sigma_{\mathrm{det}}^{2}+\sigma_{c e r t}^{2}}}
$$

Na qual,

$$
\begin{array}{lll}
\bar{x}_{\text {det }} \equiv & \text { valor médio determinado; } \\
x_{\text {cert }} \equiv & \text { valor certificado; } \\
\sigma_{\text {det }}^{2} \equiv & \text { variância calculada; } \\
\sigma_{\text {cert }}^{2} \equiv & \text { variância certificada. }
\end{array}
$$

A avaliação foi realizada de acordo com a classificação: valores $|Z| \leq 2$ são considerados satisfatório; $2<|Z| \leq 3$ valores questionáveis e $|Z|>3$ insatisfatório. 


\subsection{Determinação de ésteres ftálicos por cromatografia de fase gasosa acoplado ao espectrômetro de massa (GCMS)}

Para a determinação de ésteres ftálicos nas amostras de poeira doméstica utilizou-se um cromatógrafo gasoso acoplado ao espectrômetro de massa (GCMS), modelo QP2010 Plus (FIG. 13), da SHIMADZU Co. Este equipamento possui os seguintes acessórios: 1 injetor Split/splitless (SPL-2010), 1 coluna capilar de fase 5\% difenil e 95\% dimetil-polisiloxano (modelo RTX5ms, 30mx0,25mm id 0,25 $\mu \mathrm{m}$ ), 3 interfaces (microbore $(0,1 \mathrm{~mm})$ capilares $(0,25-0,32 \mathrm{~mm})$ ou megabore $(0,53 \mathrm{~mm}), 1$ fonte de íons, 1 analisador e 1 detector (MS). Um software permite o controle operacional (injetor e amostrador automático), gerenciamento (liga e desliga os sistemas de bombas, as unidades do MS, GC e periféricos), aquisição dos dados do detector de massas, integração da área do pico, quantificação por meio da normalização corrigida (padrão interno e externo), pesquisa os compostos em até 5 (cinco) bibliotecas simultaneamente e supre o background no espectro de massas. As condições instrumentais definidas, tais como: pressão; gás de arraste e temperatura são apresentadas no APÊNDICE I (p. 140). 


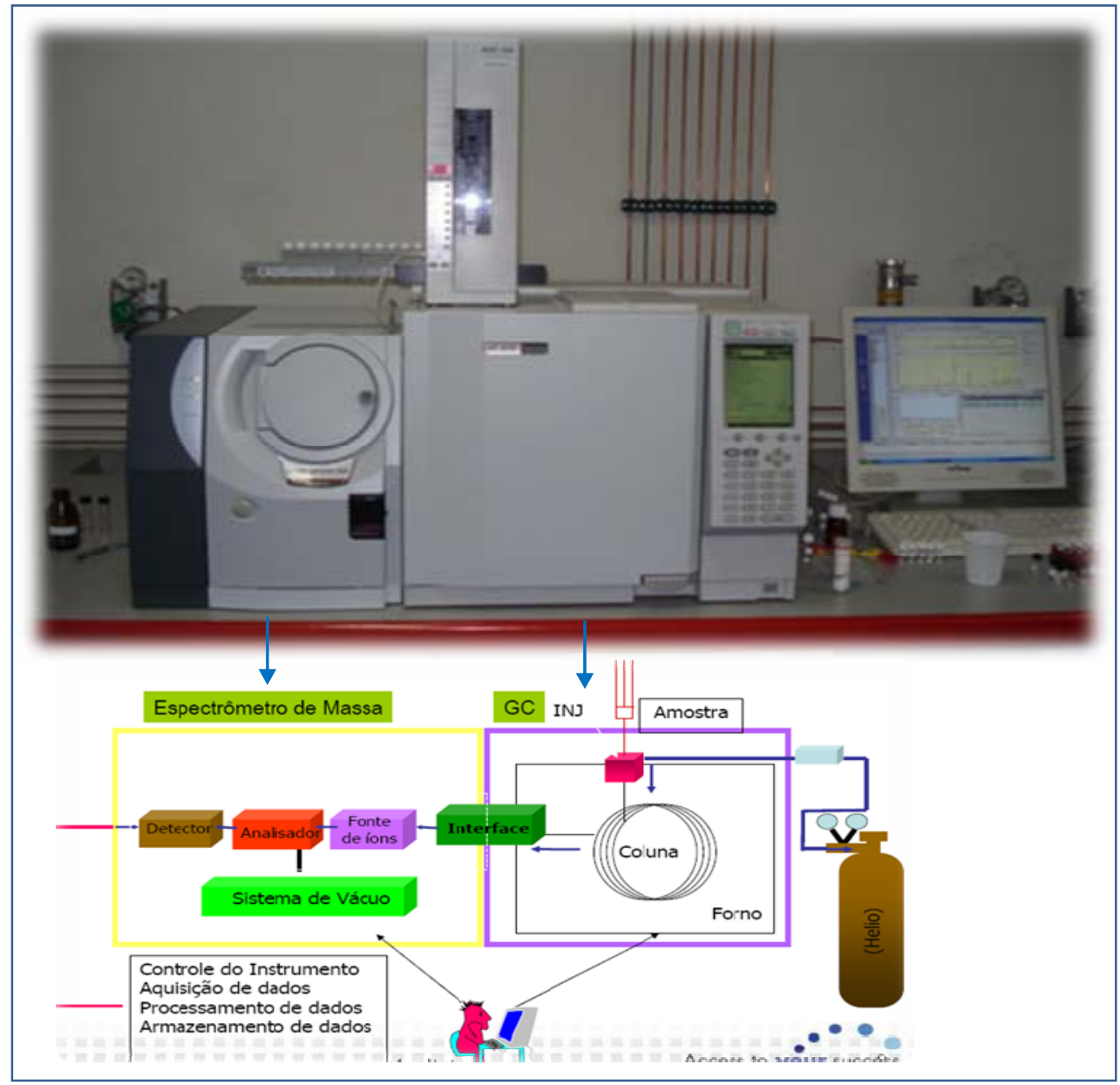

FIGURA 13 - Foto do equipamento GCMS, SHIMADZU Co., modelo QP2010 Plus

As análises quantitativas foram realizadas de acordo com o método EPA 525.5. O diclorometano e o metanol (PA) foram utilizados para a extração em fase sólida (SPE), de acordo com o método EPA 3535A.12. As curvas de calibração foram obtidas da solução certificada "EPA 525.5 update phthalate esters mix", contendo benzil butil ftalato (BBP), bis (2-etilhexil) adipato (DEHA), bis (2-etilhexil) ftalato (DEHP), di ( $n$-butil) ftalato (DnBP), dietil ftalato (DEP), dimetil ftalato (DMP) e pentaclorofenol, em um faixa de concentração de 0,1 a $10,0 \mu \mathrm{g} \mathrm{mL}^{-1}$. A solução de Extran neutro e Água Tipo I foram utilizadas para a descontaminação de todos os materiais de vidro utilizados na preparação de amostras. 


\subsubsection{Preparação de amostras para análises por GCMS}

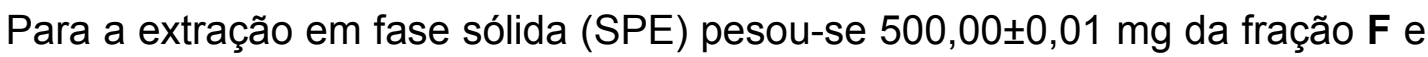
cada amostra foi transferida para um frasco de vidro de volume $20 \mathrm{~mL}$. Em cada frasco foram adicionados $10 \mathrm{~mL}$ de diclorometano que permaneceram em repouso por 48 horas a uma temperatura de $25+2{ }^{\circ} \mathrm{C}$. Posteriormente, os frascos foram centrifugados a $3000 \mathrm{rpm}$ por 2 minutos e alíquotas de $500 \mu \mathrm{L}$ do sobrenadante foram transferidas para um frasco de vidro de $5 \mathrm{~mL}$. Em cada frasco foi adicionado 1 $\mathrm{mL}$ de metanol. As amostras foram agitadas por 3 minutos em um agitador de tubos tipo Vortex (Biomixer) e armazenadas sob refrigeração até o momento de análise. $\mathrm{Na}$ FIG. 14 é mostrado o esquema de preparação de amostra para análise por cromatografia.

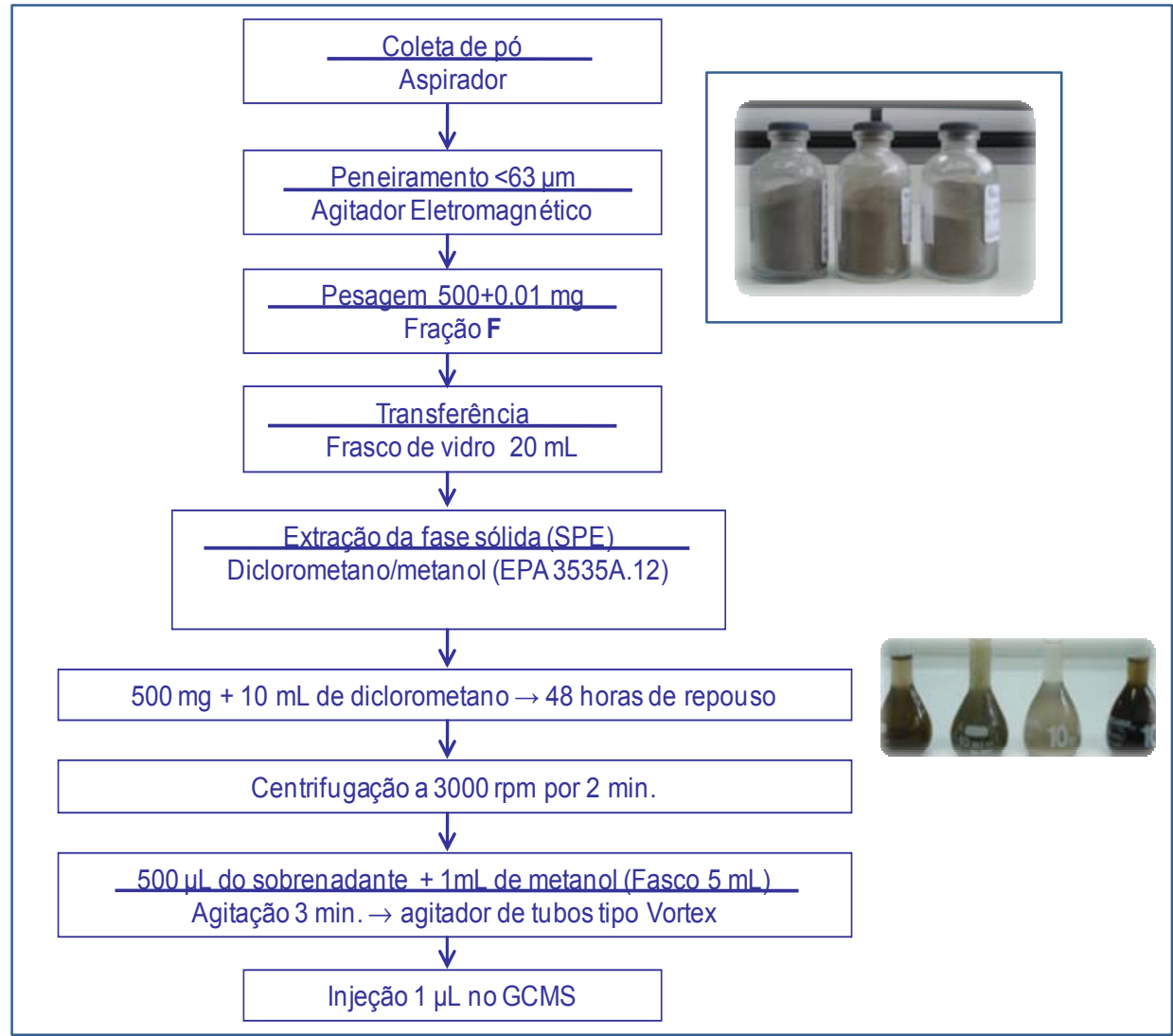

FIGURA 14 - Esquema das etapas de preparação das amostras de poeira para análise por GCMS 
A metodologia foi avaliada utilizando a solução certificada EPA 525.5 update phthalate esters mix (descrito p. 51). Foram preparadas três amostras e obtidas três medidas para cada éster ftálico, totalizando um conjunto de nove medidas por composto. As concentrações foram determinadas por meio de curvas de calibração para os compostos: DMP, DEP, DnBP, BBP, DEHA e DEHP. Os resultados foram avaliados por meio de testes estatísticos, recomendado pelo guia EURACHEM/CITAC.

A avaliação da precisão, em termos de repetitividade, foi realizada por meio de testes estatísticos como mencionados anteriormente (p. 49).

O limite de detecção foi determinado analisando sete vezes a menor concentração da curva analítica, e o desvio padrão foi multiplicado por 3, este limite é referente à alíquota de análise. Pode ser determinado pela Equação 11 (INMETRO, 2007):

$$
\mathrm{LD}=\frac{3 \times \sigma}{\mathrm{IC}}
$$

$\mathrm{Na}$ qual,

LD = limite de detecção;

$\sigma=$ desvio padrão (obtido a partir da curva de calibração proveniente da análise de uma amostra do branco, medidas sete vezes);

IC = inclinação da curva de calibração.

O limite de quantificação é estabelecido por meio da análise de soluções contendo concentrações decrescentes dos compostos até a menor concentração determinável com precisão e exatidão aceitáveis, expresso pela equação 12 (INMETRO, 2007):

$$
\mathrm{LQ}=\frac{10 \times \sigma}{\mathrm{IC}}
$$




\subsection{Determinação das fases cristalinas por difração de raios X (XRD)}

A determinação das fases cristalinas foi realizada por difração de raios $X$ em um difratômetro de raios X Multiflex, Rigaku Co. (FIG. 15).

Os acessórios usados neste equipamento foram: ângulo Theta/Theta, alinhamento automático, gerador de alta frequência $2 \mathrm{~kW}$, feixe monocromador de Grafite, divergência fixa antiespalhamento e detector "slits".

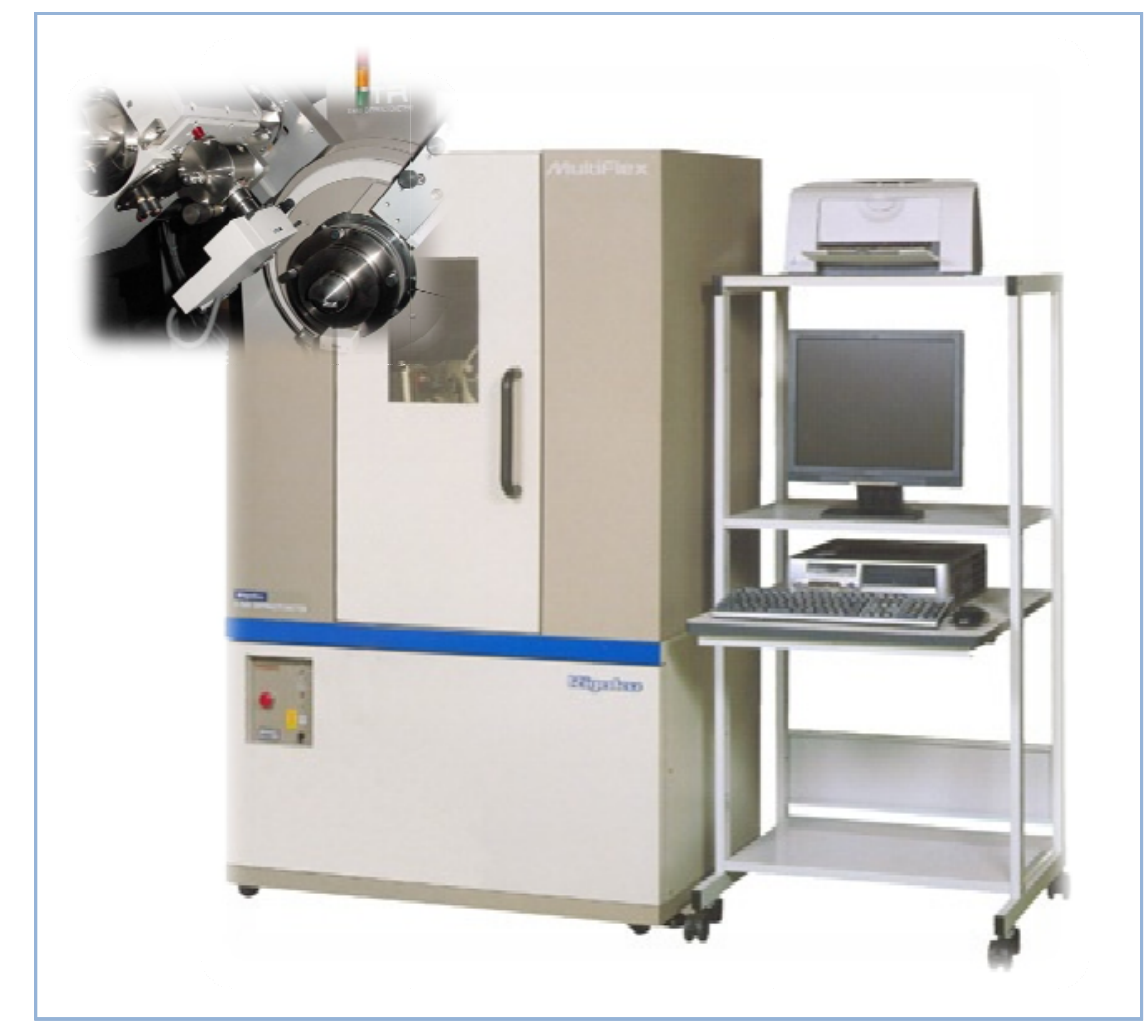

FIGURA - 15 - Foto do difratômetro de raios X Multiflex, Rigaku Co.

Nas análises de XRD, cada amostra foi colocada em um porta-amostra e pressionada suavemente para evitar possíveis orientações preferenciais. As condições de operação foram: extensão $(\theta-2 \theta): 5^{\circ}$ a $80^{\circ} ; 2,0^{\circ} / \mathrm{min}$; radiação Cu-K $\mathrm{K}_{\alpha}$ $(\lambda=1,5418 \AA) ; 40 \mathrm{kV} ; 20 \mathrm{~m} \AA$; fendas de: divergência $=1 / 2^{\circ}$; espalhamento $=1 / 2^{\circ}$; 
recepção $=0,03 \mathrm{~mm}$. O conjunto de dados $(P l o t)$ obtidos por XRD foram estudados utilizando o software Crystallographica (Search-Match), versão 3.0, da InstallShield Software Corporation, de reconhecimento automático de pico, identificação mineral e cálculos de intensidade de pico.

\subsection{Determinação do fator de enriquecimento (FE)}

A avaliação da contaminação por constituintes inorgânicos em amostras de poeira doméstica foi realizada por meio do cálculo do fator de enriquecimento (FE), que consiste na razão metal/normalizante observada dividida pela razão metal/normalizante de referência. O FE determina o fator de enriquecimento em relação aos teores considerados naturais (Salomons e Föstner, 1984; Fergusson et al., 1991). Os teores médios da crosta continental (CC) foram utilizados como referência. Os elementos normalizantes mais comumente usados são Al, Li, Fe e Mn, em razão da possibilidade de ocorrência de aportes antrópicos em relação a outros elementos.

A definição do marcador mais adequado foi realizada de acordo com os testes de distância de Mahalanobis e Shapiro-Wilk (W) (APÊNDICE J, p. 141), para se detectar os valores atípicos (outliers) (Harbottle, 1976) e análise de fatores (AF), para se verificar a correlação mais significante entre o metal normalizador e os demais elementos constituintes das amostras de poeira doméstica.

O cálculo do fator de enriquecimento (FE), é dado pela Eq. 13:

$$
\mathrm{FE}=\frac{\left(\frac{\mathrm{M}_{\mathrm{e}}}{\mathrm{Me}_{\text {normalizante }}}\right) \text { amostra }}{\left(\frac{\mathrm{M}_{\mathrm{e}}}{\mathrm{Me}_{\text {normalizante }}}\right) \text { background }}
$$


Na qual,

$$
\begin{array}{ll}
\mathrm{Me}_{\text {amostra }} & =\text { concentração do metal observado nas frações de poeira } \mathbf{D}, \mathbf{E} \text { e } \mathbf{F} ; \\
\mathrm{Me}_{\text {background }} & =\text { concentração do metal natural background (crosta continental); } \\
\mathrm{Me}_{\text {normalizante }} & =\text { concentração do metal identificado como normalizador. }
\end{array}
$$

\subsection{Qualificação da poeira}

Um procedimento estatístico para qualificar a poeira doméstica foi realizado por meio do cálculo da razão Al/Si para 109 materiais de referência certificados (argila, sedimento, areia e lodo da NIST, GSJ, BCS e IPT), e dos valores reportados na literatura referente à composição da crosta continental e os obtidos por WDXRF.

Os resultados foram avaliados estatisticamente por meio da análise de variância (ANOVA) e teste de Tukey, utilizando os softwares Microsoft EXCEL e Origin versão 7.5. Os valores outliers foram excluídos por meio do teste de intervalo interquartil (IQR). Após, a eliminação dos outliers foi aplicado novamente o teste de análise de variância (ANOVA).

A ANOVA foi aplicada para verificar se existe diferença significativa entre as médias e se os fatores exercem influência em alguma variável dependente. Considerando uma variável de interesse com média $(\mu)$ e variância $\left(\sigma^{2}\right)$ temos dois estimadores da variância:

O teste $F$ é aplicado com Eq. 14:

$$
F=\frac{S_{B}^{2}}{S_{W}^{2}}
$$


$\mathrm{Na}$ qual,

$S_{B}^{2} \quad=\quad$ dispersão entre os grupos;

$S_{W}^{2} \quad=\quad$ dispersão dentro dos grupos.

Com k-1 graus de liberdade no numerador e N-k no denominador, no qual $\mathrm{K}$ é o número de fatores ou grupos e $\mathrm{N}$ o número de observações, e $\mathrm{N}-1=(\mathrm{k}-1)+(\mathrm{k}-\mathrm{N})$.

O teste de ANOVA relata a diferença significativa entre as médias, dessa forma, a partir de um teste de comparações múltiplas foi verificada a magnitude das diferenças.

O teste de Tukey permite testar qualquer contraste, sempre, entre duas médias, ou seja, não permite comparar grupos entre si. $O$ teste baseia-se na Diferença Mínima Significativa (DMS) $\Delta$. A estatística do teste é dada de acordo com a Eq. 15:

$$
\Delta=\mathrm{q} \sqrt{\frac{\mathrm{QMRes}}{\mathrm{r}}}
$$

Na qual,

$$
\begin{array}{lll}
\Delta & \equiv \text { diferença mínima significativa; } \\
\mathrm{q} & \equiv \text { amplitude total studentizada; } \\
\text { QMRes } & \equiv \text { quadrado médio do resíduo; } \\
r & \equiv \text { número de repetições. }
\end{array}
$$




\subsection{Determinação das fontes de contaminação por Análises de Fatores (AF) e Cluster (AC)}

As prováveis fontes de contaminação foram estimadas por meio dos testes de análise de fatores (AF) e análise de Cluster (AC), ambos utilizando-se o software, "STATISTICA", version 6.

\subsubsection{Análise de fatores (AF)}

A análise de fatores (AF) é um método estatístico amplamente utilizado para a identificação de fontes poluidoras. Ela permite trabalhar com grupo grande de variáveis com unidades distintas e ordens de grandeza bastante díspares, agrupando-as sob uma mesma "tendência", não necessitando, a priori, do conhecimento do número e da composição das fontes de poluentes.

Para que os resultados da aplicação da AF sejam estatisticamente significativos é necessário, como condição mínima, um número considerável de amostras em relação ao número de variáveis (Eq. 16):

$$
N \geq 30+\frac{n+3}{2}
$$

$\mathrm{Na}$ qual,

$N \equiv$ número total de amostras;

$n \quad \equiv \quad$ número de variáveis.

A AF consiste de uma técnica de análise multivariada que trata das relações internas de um conjunto de variáveis, substituindo um conjunto inicial de variáveis correlacionadas por um conjunto menor de "fatores", que podem, ou não, ser correlacionados, justificando assim a maior parte da variância do conjunto original de 
dados. Desta forma, é estudada a estrutura de correlação de um conjunto inicial de "p" variáveis (X1, X2 ... Xp). Substituindo este por um conjunto menor de variáveis hipotéticas, os fatores comuns, com menor número e estrutura mais simples. A AF consiste de três etapas básicas: preparação da matriz de correlação; a extração dos Fatores e a possível rotação de dados para uma solução final à procura de fatores mais simples e interpretáveis. O procedimento mais detalhado de uma análise dos fatores é apresentado no APÊNDICE K (p. 143).

No presente estudo, o conjunto de 69 amostras de poeira doméstica foi empregado como matriz. As variáveis avaliadas $(n=23)$ foram os constituintes inorgânicos, a perda de massa por queima e massa total das amostras (análise granulométrica, AG) nas frações $\mathbf{D}$, E e F. 


\subsubsection{Análise de cluster (AC)}

A análise de cluster é uma técnica de análise multivariada bastante utilizada para interpretação de dados analíticos. O objetivo principal da Análise de Cluster (AC) é de identificar grupos de objetos com propriedades semelhantes dentro de um grande conjunto de dados (Johnson (1982) apud Castanho, 1999). Esta técnica de agrupamento surgiu exatamente da necessidade de se obter informações seguras estatisticamente de uma série de dados, os quais seriam muito extensos para serem analisados um a um.

Partindo-se do espaço de $\mathrm{N}$ dimensões (por exemplo, variáveis ou amostras) são calculadas as distâncias entre todos os pontos (objetos) deste espaço. Inicia-se agrupando os objetos com distâncias menores. Nestes grupos são calculadas, novamente, as distâncias entre eles formando um segundo nível de agrupamento. Sucessivamente, são criados níveis até que se tenha um último nível agrupando todos os elementos. Esta estrutura é representada na forma de dendograma o que promove uma fácil interpretação dos resultados. O método de agrupamento utilizado foi o método Ward, que é considerada uma das melhores estratégias para agrupamento hierárquico (Gerab (1996) apud Castanho, 1999).

Inicia-se preparando uma base de dados fazendo-se um escalonamento da matriz de dados para facilitar a interpretação destes. Neste caso, utilizou-se a Normalização Padrão como mostrado na Eq. 17.

$$
Z_{i j}=\frac{x_{i j}-\overline{x_{j}}}{\sigma_{j}}
$$


$\mathrm{Na}$ qual,

$Z_{i j} \equiv$ elementos da matriz normalizada;

$X_{i j} \equiv$ concentração elementar da amostra (i) e variável (j);

$X_{j} \equiv$ média das concentrações da variável (j);

$\sigma_{j} \quad \equiv$ desvio padrão das variáveis $(j)$ da variável (j).

Tem-se então a matriz que será utilizada nas análises de clusters. A medida entre dois pontos pode ser feita em distância Euclediana quadrática dada pela Eq. 18.

$$
d_{i j}^{2}=\sum_{k=1}^{n}\left(Z_{i k}-Z_{j k}\right)^{2}
$$

Este tipo de medida é geralmente utilizado quando as variáveis são independentes entre si.

Utilizando-se esta técnica por variável, cada cluster formado agrupa variáveis que possuem distância geométrica próxima. Cada cluster identifica a composição elementar caracterizando qualitativamente uma fonte ou um processo de emissão de poluente.

A AC foi calculada com rotação varimax para as 69 amostras (casos) versus os 22 elementos ( $\mathrm{Si}, \mathrm{Ca}, \mathrm{Al}, \mathrm{Mg}, \mathrm{Fe}, \mathrm{S}, \mathrm{K}, \mathrm{Cl}, \mathrm{Na}, \mathrm{Ti}, \mathrm{Zn}, \mathrm{Cu}, \mathrm{P}, \mathrm{Mn}, \mathrm{Pb}, \mathrm{Sr}, \mathrm{Cr}, \mathrm{Ni}, \mathrm{Zr}$, $\mathrm{Rb}, \mathrm{Br}$ - variáveis), além de dois parâmetros perda de massa por queima (PF) e massa relativa $(A G)$ nas frações $\mathbf{D}, \mathbf{E}$ e $\mathbf{F}$. 


\subsection{Avaliação do nível de exposição para os parâmetros de ingestão, inalação e contato dérmico}

$\mathrm{Na}$ maior parte dos projetos de avaliação de risco, os dados de monitoramento não são suficientes para estimar as concentrações nos pontos de exposição. Nestes casos é necessária a utilização de modelos matemáticos de transporte de contaminantes.

A utilização de modelos matemáticos para quantificação de concentrações em pontos de exposição de dificuldade ou não representativa a medição realizada em um determinado meio. Por exemplo, a concentração de compostos voláteis no ar, quando é calculado utilizando os resultados de monitoramento do solo ou água.

O modelo matemático de transporte e atenuação natural de contaminantes poderá simular uma concentração em um ponto de exposição, a partir de uma fonte secundária de contaminação. A fonte secundária de contaminação pode ser a fase dissolvida do contaminante no solo (CETESB, 2005).

O cálculo do ingresso por caminho de exposição é expresso como a quantidade do composto químico presente na interface de contato com o organismo exposto (pele, pulmões, intestino) e disponível para absorção. Nesta etapa é estimado o ingresso para todos os caminhos de exposição possíveis para uma determinada área de estudo.

O ingresso a partir da poeira contaminada, o receptor humano pode ser exposto a um composto químico pelas vias de ingestão, inalação e contato dérmico; os quais são considerados cenários de exposição diretos, ou seja, o receptor encontra-se em contato com o meio contaminado. As equações utilizadas para os cálculos deste ingresso são apresentados no APÊNDICE L (p. 147). No 
ANEXO D (p. 168) é apresentado os parâmetros de exposição utilizados para o cálculo da ingestão de poeira contaminado (CETESB, 2005 e U.S. EPA, 1997).

\subsection{Mapas de distribuição}

Os mapas de distribuição foram construídos a partir dos teores determinados para os constituintes inorgânicos. Para isto, foram utilizados o aplicativo Excel (Microsoft Office XP) e o programa de modelagem geoestatística Surfer 8.

O Surfer é um programa de mapeamento georreferenciado de superfície em 3D (tridimensional) e de contorno, desenvolvido pela Golden Software (http://www.goldensoftware.com), que cria ou importa e abre arquivos para que sejam internamente processados.

Os dados foram tabulados no programa de computador Microsoft Excel. Posteriormente estes dados foram transferidos para o programa Surfer 8, para avaliação dos teores determinados para os constituintes inorgânicos. Sendo que para isto utilizou-se como interpolador o método da Krigagem. A execução iniciase do seguinte modo: No menu File (arquivo) criou-se o arquivo na opção New (novo) na opção secundária Worksheet (planilha de trabalho). Em seguida este é salvo na extensão dat e este é fechado. Abre-se um novo arquivo desta vez na opção Plot (demarcação de pontos) e pode-se gerar o mapa com os pontos no menu Map (mapa) opção Post (e ainda um overlay com outras variáveis em forma de espacialização com preenchimento colorido ou com hachuras distintas por meio de linhas curvas). Para este passo faz-se necessário o Gridding do arquivo dat gerado anteriormente transformando-o em um arquivo com extensão grb. Este processo faz-se no menu Grid na opção Data, então se seleciona o arquivo dat e escolhe as colunas correspondentes para se gerar determinado cartograma e por fim pressiona-se $O K$, com um clique do mouse ou ainda pressionando a tecla 
<enter> no teclado. Após este processo pode-se gerar cartogramas e espacializar as informações que se desejar (georreferenciados em SIG Sistema Informação Geográfica) cada qual com a sua temática, desde que se faça o seu devido gridding da coluna e do arquivo, usando se a opção Data Columns e as opções X, Y e Z (X, posição do ponto no eixo da ordenada leste-oeste (latitude); Y na posição na abscissa norte-sul (longitude) e Z são os observados da variável nesse ponto) para se fazer a escolha da coluna, e em seguida a opção Gridding Method, Kriging e OK. Uma vez feito esse processo gera-se o cartograma usando-se o menu Map e a opção Contour e aí se escolhe o arquivo com extensão .grd. As coordenadas Geográficas são convertidas em coordenadas planas Universal Transversa de Mercator - UTM (Camponogara et al., 2005; Ribeiro, 2006). 


\section{RESULTADOS E DISCUSSÃO}

Os resultados e a discussão serão apresentados nos seguintes tópicos:

5.1 Ensaios físicos:

5.1.1 Análise granulométrica (AG);

5.1.2 Perda de massa por queima (PF);

5.2 Ensaios químicos:

5.2.1 Avaliação da metodologia WDXRF;

5.2.2 Resultados das análises dos constituintes inorgânicos;

5.2.3 Resultados das análises de ésteres ftálicos por GCMS;

5.2.4 Identificação das fases cristalinas por XRD;

5.3 Fator de enriquecimento (FE);

5.4 Qualificação da poeira doméstica;

5.5 Determinação das fontes de contaminação por análises de fatores (AF) e cluster (AC);

5.6 Determinação dos níveis de exposição para ingestão, inalação e contato dérmico;

5.7 Mapas de distribuição de contaminantes dos bairros estudados. 


\subsection{Ensaios físicos}

A seguir são apresentados os resultados das análises granulométricas (AG) e perda de massa por queima (PF), realizadas para as 69 amostras de poeira doméstica.

\subsubsection{Análises granulométricas (AG)}

Os resultados das análises granulométricas, mostrado na FIG 16, revelaram a predominância da fração A (67\%), fração mais grossa para todas as amostras analisadas. Assim, pode-se verificar que a maior parte do material coletado é constituída, especialmente, por fibras como de cabelo, de tapete, papéis e outros. Os $23 \%$ estão distribuídos nas frações intermediárias (B, C, D e E) e os $10 \%$ restantes, na fração mais fina $(\mathbf{F})$. Esta fração apresenta o maior poder de adsorção de substâncias potencialmente tóxicas, além de ácaros e fungos. Os resultados (APÊNDICE M, p. 150) confirmam a variabilidade nos diâmetros aerodinâmicos de partículas e massa relativa, e que as características da poeira variam consideravelmente, que podem ser atribuídas aos fatores sazonais, localidade, sistema de ventilação e aquecimento e outros.

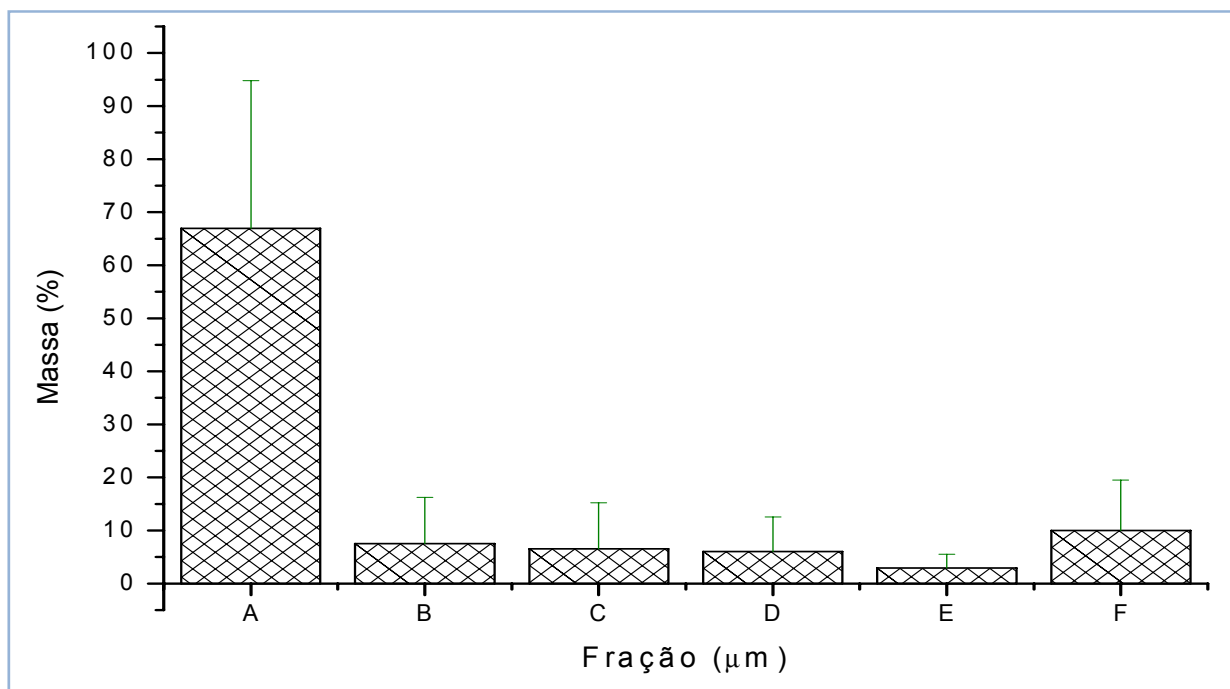

FIGURA 16 - Porcentagem em massa das frações A, B, C, D, E e F, de 69 amostras 
Na FIG. 17 são mostrados a distribuição das frações D, E e F,em termos de massa relativa percentual, referente aos bairros de coleta.
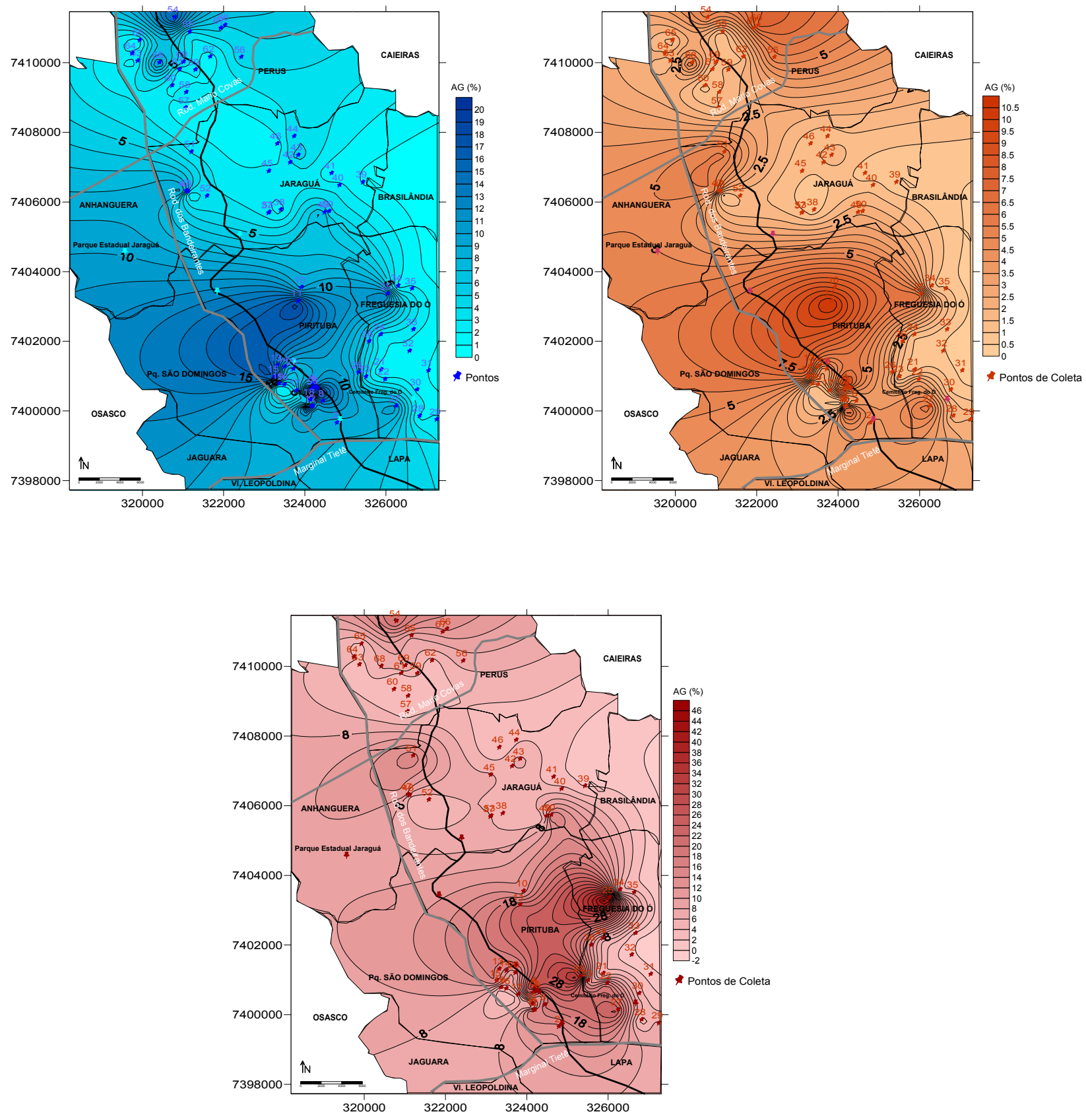

FIGURA 17 - Distribuição granulométrica nas frações D, E e F 
Os resultados mostram que o bairro de Pirituba detém a maior quantidade das frações D, E e F, seguido da Freguesia do Ó. O bairro do Jaraguá apresentou o menor valor. Este fato pode estar relacionado à proximidade dos pontos amostrados, no bairro de Pirituba, e as principais vias de tráfego como Rod. dos Bandeirantes e Anhanguera, Marginais Tietê e Pinheiros. Nestas localidades, de intenso tráfego a poeira da rua pode ser resuspensa e transportada para dentro das residências.

\subsubsection{Perda de massa por queima (PF)}

As análises de perda de massa por queima (PF) (Butte et al., 2004) realizada nas frações $\mathbf{D}$, E e $\mathbf{F}$, mostraram que $71 \%$ das amostras $(n=49)$ nas frações D e $\mathbf{E}$ perderam de 33 a $94 \%$ de massa. Para a fração $\mathbf{F}$, os $29 \%$ restante das amostras ( $n=20)$, ocorreu uma perda de massa de 22 a $76 \%$ (TAB. 4). Os resultados mostraram a menor perda para a fração $\mathbf{F}$; concordando com os valores reportados na literatura por Salthammer apud Morawska (2003) e Butte e Heinzow (2002). Os resultados confirmam a hipótese de quanto menor o tamanho de partícula menor a perda de massa, indicando que os maiores constituintes presentes nesta fração são inorgânicos. 
TABELA 4 - Perda de massa por queima de poeira (frações $\mathbf{D}$, E e F) de cada ponto de amostragem $(P A=69)$

\begin{tabular}{|c|c|c|c|c|c|c|c|}
\hline \multicolumn{8}{|c|}{ Perda de massa por queima (\%) } \\
\hline PA & D & $E$ & $\mathbf{F}$ & PA & D & $E$ & $\mathbf{F}$ \\
\hline 1 & 39,2 & 73,3 & 37,2 & 36 & 36,0 & 40,3 & 21,9 \\
\hline 2 & 47,3 & 66,5 & 45,6 & 37 & 66,4 & 79,9 & 60,4 \\
\hline 3 & 49,1 & 67,9 & 46,1 & 38 & 64,3 & 73,4 & 57,3 \\
\hline 4 & 48,8 & 71,2 & 50,9 & 39 & 67,2 & 76,0 & 63,7 \\
\hline 5 & 50,1 & 75,4 & 46,8 & 40 & 64,6 & 73,6 & 55,7 \\
\hline 6 & 46,3 & 65,3 & 42,0 & 41 & 62,7 & 70,4 & 60,2 \\
\hline 7 & 40,0 & 72,4 & 37,2 & 42 & 53,4 & 60,2 & 46,9 \\
\hline 8 & 44,5 & 68,9 & 41,4 & 43 & 55,6 & 64,1 & 48,9 \\
\hline 9 & 50,7 & 65,9 & 46,7 & 44 & 54,5 & 61,6 & 44,6 \\
\hline 10 & 60,0 & 72,1 & 55,1 & 45 & 47,1 & 54,2 & 42,3 \\
\hline 11 & 52,1 & 74,8 & 48,2 & 46 & 55,5 & 69,6 & 49,2 \\
\hline 12 & 49,8 & 69,9 & 47,0 & 47 & 44,9 & 53,5 & 39,4 \\
\hline 13 & 60,1 & 70,8 & 55,2 & 48 & 66,7 & 71,0 & 57,6 \\
\hline 14 & 63,0 & 73,0 & 58,0 & 49 & 64,7 & 67,9 & 56,2 \\
\hline 15 & 46,6 & 75,3 & 44,0 & 50 & 83,2 & 85,6 & 68,4 \\
\hline 16 & 48,4 & 71,1 & 45,3 & 51 & 84,5 & 88,4 & 73,8 \\
\hline 17 & 43,6 & 68,7 & 39,9 & 52 & 86,0 & 90,0 & 75,8 \\
\hline 18 & 51,2 & 70,3 & 50,5 & 53 & 88,3 & 89,7 & 69,8 \\
\hline 19 & 53,4 & 71,1 & 45,7 & 54 & 40,6 & 50,1 & 39,2 \\
\hline 20 & 52,8 & 74,7 & 48,9 & 55 & 40,2 & 47,9 & 34,8 \\
\hline 21 & 46,1 & 63,0 & 45,4 & 56 & 43,8 & 62,9 & 57,3 \\
\hline 22 & 43,0 & 62,7 & 38,3 & 57 & 69,3 & 90,2 & 53,9 \\
\hline 23 & 47,9 & 60,0 & 46,9 & 58 & 71,8 & 80,8 & 65,8 \\
\hline 24 & 38,8 & 59,1 & 44,9 & 59 & 61,3 & 82,1 & 55,6 \\
\hline 25 & 48,7 & 57,3 & 53,8 & 60 & 66,1 & 76,8 & 59,9 \\
\hline 26 & 50,0 & 60,0 & 53,0 & 61 & 65,6 & 61,2 & 56,3 \\
\hline 27 & 49,8 & 56,3 & 52,8 & 62 & 68,4 & 75,1 & 56,7 \\
\hline 28 & 63,1 & 69,8 & 56,7 & 63 & 60,0 & 67,4 & 55,7 \\
\hline 29 & 65,1 & 73,6 & 41,5 & 64 & 61,1 & 65,9 & 60,0 \\
\hline 30 & 57,8 & 61,0 & 53,1 & 65 & 84,6 & 88,6 & 66,8 \\
\hline 31 & 39,6 & 49,2 & 37,5 & 66 & 86,6 & 93,9 & 64,6 \\
\hline 32 & 61,6 & 65,5 & 54,7 & 67 & 85,4 & 90,0 & 65,7 \\
\hline 33 & 33,5 & 45,9 & 26,1 & 68 & 40,3 & 45,5 & 38,2 \\
\hline 34 & 41,6 & 57,0 & 47,9 & 69 & 46,3 & 50,5 & 39,5 \\
\hline 35 & 51,8 & 60,3 & 45,4 & & & & \\
\hline
\end{tabular}




\subsection{Ensaios químicos}

A seguir são apresentados os resultados para as analises químicas realizadas por WDXRF, GCMS e XRD.

\subsubsection{Avaliação da metodologia WDXRF}

A avaliação da metodologia foi realizada com os materiais de referência certificados (MRCs) NIST 2781 (Domestic Sludge), NIST 1547 (Peach Leaves) e NIES № 9 (Sargasso). Estes materiais foram selecionados porque apresentam composição química diferenciada, ou seja, são sedimento doméstico (NIST 2781), folhas de pêssego (NIST 1547) e algas (NIES № 9 ), permitindo assim, verificar a aplicabilidade do método de Parâmetros Fundamentais para diferentes matrizes e composições.

Os resultados obtidos para os elementos majoritários ( $\mathrm{Na}, \mathrm{Mg}, \mathrm{Al}, \mathrm{Si}, \mathrm{P}, \mathrm{K}$, $\mathrm{Ca}, \mathrm{Ti}, \mathrm{Fe}$ e $\mathrm{Sr}$ ), mostraram que a dispersão, em termos de desvio padrão relativo percentual (DPR\%) é satisfatória, visto que, para os três MRCs analisados, os valores são menores que $5 \%$, exceção ao $\mathrm{Na}$ e Ti, no NIST 2781 , cujos valores são 7,4 e 5,5\%, respectivamente. Os elementos minoritários $(\mathrm{Cr}, \mathrm{Ni}, \mathrm{Cu}, \mathrm{Zn}, \mathrm{Se}$, $\mathrm{Pb}, \mathrm{Cl}, \mathrm{Mn}, \mathrm{Zn}, \mathrm{S}$ e As) mostraram também dispersão satisfatória $(<5 \%)$ nos três MRCs, com exceção do Ni e Se no NIST 2781 e As no NIES № 9, cujos valores foram $5,9,5,9$ e $7,7 \%$, respectivamente (TAB.5).

A exatidão avaliada em termos de erro relativo percentual (ER\%), também se apresentou satisfatória, visto que, os valores calculados para todos os elementos, nos três MCRs são menores que 5\%, exceto $\mathrm{Cr}$ e Ni no NIST 2781, cujos valores são 5,4 e 6,0\%, respectivamente (TAB 5).

Os valores de $Z$ score dependem do material de referência usado. No caso do material de referência certificado MRC 2781, são satisfatórios: $\mathrm{Na}, \mathrm{Mg}, \mathrm{Al}, \mathrm{Si}$, 
$\mathrm{P}, \mathrm{K}, \mathrm{Ca}, \mathrm{Ti}, \mathrm{Fe}$, Ni e Se, porém, questionável para $\mathrm{Cr}, \mathrm{Cu}, \mathrm{Zn}$ e $\mathrm{Pb}$. No caso do MRC 1547, são satisfatórios: $\mathrm{Na}, \mathrm{Mg}, \mathrm{Al}, \mathrm{Si}, \mathrm{P}, \mathrm{S}, \mathrm{K}, \mathrm{Ca}, \mathrm{Mn}, \mathrm{Fe}, \mathrm{Ni}, \mathrm{Zn}, \mathrm{As}$ e Sr e para o MRC № 9, são satisfatórios: $\mathrm{Na}, \mathrm{Mg}, \mathrm{P}, \mathrm{S}, \mathrm{Cl}, \mathrm{K}, \mathrm{Ca}, \mathrm{Fe}, \mathrm{As}$ e $\mathrm{Sr}$ (FIG. 18).

Assim, pode ser constatado que a metodologia proposta é adequada e confiável para a determinação de constituintes inorgânicos em amostras de poeira doméstica.

TABELA 5 - Valores certificados, média aritmética $(\bar{X})$ e desvio padrão (DP) determinados, desvio padrão relativo percentual (DPR\%) e erro relativo percentual (ER\%) para os MCRs Domestic Sludge, Peach Leaves e Sargasso

\begin{tabular}{lllll}
\hline \multicolumn{5}{c}{ MRC - Domestic Sludge $-\mathbf{2 7 8 1}-\mathbf{N I S T}$} \\
Elemento & \multicolumn{1}{c}{$\begin{array}{c}\text { Valor } \\
\text { Certificado }\end{array}$} & \multicolumn{1}{c}{$\begin{array}{c}\text { Valor } \\
\text { Determinado }\end{array}$} & DPR & ER \\
& \multicolumn{5}{c}{$\overline{\mathrm{X} \pm \mathrm{DP}(\%)}$} \\
\hline $\mathrm{Na}$ & $0,21 \pm 0,02$ & $0,202 \pm 0,015$ & 7,4 & 3,8 \\
$\mathrm{Mg}$ & $0,59 \pm 0,04$ & $0,573 \pm 0,014$ & 2,4 & 2,9 \\
$\mathrm{Al}$ & $1,6,0 \pm 0,1$ & $1,595 \pm 0,038$ & 2,4 & 0,3 \\
$\mathrm{Si}$ & $5,1 \pm 0,2$ & $5,013 \pm 0,125$ & 2,5 & 1,7 \\
$\mathrm{P}$ & $2,42 \pm 0,09$ & $2,387 \pm 0,047$ & 2,0 & 1,4 \\
$\mathrm{~K}$ & $0,49 \pm 0,03$ & $0,513 \pm 0,018$ & 3,5 & 4,7 \\
$\mathrm{Ca}$ & $3,9 \pm 0,1$ & $3,966 \pm 0,106$ & 2,7 & 1,7 \\
$\mathrm{Ti}$ & $0,32 \pm 0,03$ & $0,311 \pm 0,017$ & 5,5 & 2,8 \\
$\mathrm{Fe}$ & $2,8 \pm 0,1$ & $2,916 \pm 0,082$ & 2,8 & 4,1 \\
$\mathrm{Cr}$ & $202 \pm 9$ & $213 \pm 4$ & 2,3 & 5,4 \\
$\mathrm{Ni}$ & $80,2 \pm 2,3$ & $85 \pm 5$ & 5,9 & 6,0 \\
$\mathrm{Cu}$ & $627 \pm 13$ & $639 \pm 2$ & 0,3 & 1,8 \\
$\mathrm{Zn}$ & $1273 \pm 53$ & $1296 \pm 6$ & 0,5 & 1,8 \\
$\mathrm{Se}$ & $16,0 \pm 1,6$ & $17 \pm 1$ & 5,9 & 6,3 \\
$\mathrm{~Pb}$ & $202,1 \pm 6,5$ & $211 \pm 8$ & 4,4
\end{tabular}


TABELA 5 - Valores certificados, média aritmética $(\bar{X})$ e desvio padrão (DP) determinados, desvio padrão relativo percentual (DPR\%) e erro relativo percentual (ER\%) para os MCRs Domestic Sludge, Peach Leaves e Sargasso

MRC - Peach Leaves - 1547 - NIST

\begin{tabular}{|c|c|c|c|c|}
\hline Elemento & $\begin{array}{c}\text { Valor } \\
\text { Certificado }\end{array}$ & $\begin{array}{c}\text { Valor } \\
\text { Determinado }\end{array}$ & DPR & $E R$ \\
\hline \multicolumn{5}{|c|}{$\%$} \\
\hline $\mathrm{Mg}$ & $0,432 \pm 0,008$ & $0,444 \pm 0,018$ & 4,2 & 2,7 \\
\hline$P$ & $0,137 \pm 0,007$ & $0,132 \pm 0,002$ & 1,7 & 3,8 \\
\hline $\mathrm{K}$ & $2,43 \pm 0,03$ & $2,453 \pm 0,038$ & 1,5 & 0,9 \\
\hline $\mathrm{Ca}$ & $1,56 \pm 0,02$ & $1,606 \pm 0,016$ & 1,0 & 2,9 \\
\hline \multicolumn{5}{|c|}{$\mu g g^{-1}$} \\
\hline $\mathrm{Al}$ & $249 \pm 8$ & $247 \pm 2$ & 0,8 & 0,8 \\
\hline $\mathrm{Cl}$ & $360 \pm 19$ & $363 \pm 2$ & 0,6 & 0,8 \\
\hline $\mathrm{Mn}$ & $98 \pm 3$ & $97,8+0,9$ & 0,9 & 0,2 \\
\hline $\mathrm{Fe}$ & $218 \pm 14$ & $224 \pm 3$ & 1,3 & 2,8 \\
\hline $\mathrm{Zn}$ & $17,9 \pm 0,4$ & $18,4 \pm 0,3$ & 1,7 & 2,8 \\
\hline $\mathrm{Sr}$ & $53 \pm 4$ & $55 \pm 1$ & 1,8 & 3,8 \\
\hline \multicolumn{5}{|c|}{ MRC - Sargasso - № 9 - NIES } \\
\hline Elemento & $\begin{array}{c}\text { Valor } \\
\text { Certificado }\end{array}$ & $\begin{array}{c}\text { Valor } \\
\text { Determinado }\end{array}$ & DPR & $E R$ \\
\hline \multicolumn{5}{|c|}{$\%$} \\
\hline $\mathrm{Na}$ & $1,70 \pm 0,08$ & $1,75 \pm 0,08$ & 4,6 & 2,9 \\
\hline $\mathrm{Mg}$ & $0,65 \pm 0,03$ & $0,64 \pm 0,03$ & 4,7 & 1,5 \\
\hline $\mathrm{K}$ & $6,1 \pm 0,2$ & $6,06 \pm 0,25$ & 4,1 & 1,5 \\
\hline $\mathrm{Ca}$ & $1,34 \pm 0,05$ & $1,35 \pm 0,05$ & 3,7 & 0,7 \\
\hline $\mathrm{Sr}$ & $0,100 \pm 0,003$ & $0,095 \pm 0,004$ & 4,2 & 5,0 \\
\hline$P$ & $0,260+0,003$ & $0,265 \pm 0,011$ & 4,2 & 1,9 \\
\hline \multicolumn{5}{|c|}{$\mu \mathrm{g} \mathrm{g}^{-1}$} \\
\hline$S$ & $1,2 \pm 0,1$ & $1,23 \pm 0,05$ & 4,1 & 2,5 \\
\hline $\mathrm{Cl}$ & $5,1 \pm 0,2$ & $5,2 \pm 0,2$ & 4,6 & 2,9 \\
\hline $\mathrm{Fe}$ & $187 \pm 6$ & $180 \pm 8$ & 4,4 & 3,7 \\
\hline As & $115+9$ & $117 \pm 9$ & 7,7 & 1,7 \\
\hline
\end{tabular}


Os valores calculados para o limite de quantificação (LQ) (TAB. 6) apresentaram valores adequados para a determinação de elementos constituintes $\mathrm{Na}, \mathrm{Mg}, \mathrm{Al}, \mathrm{Si}, \mathrm{P}, \mathrm{K}, \mathrm{Ca}, \mathrm{Ti}$ e Fe. Na determinação de menores constituintes, os valores de $\mathrm{LQ}$ determinados para $\mathrm{Cr}, \mathrm{Ni}, \mathrm{Cu}, \mathrm{Zn}$, Se, $\mathrm{Pb}, \mathrm{As}$ e $\mathrm{Hg}$, também se mostraram adequados (TAB. 6). Estes valores são suficientes para a avaliação de conteúdos de constituintes inorgânicos em amostras de poeira doméstica, conforme o objetivo deste trabalho; além disso, o método demonstra a grande potencialidade para as análises multi-elementares nestes materiais, de forma rápida, precisa e exata, sem a necessidade de tratamentos químicos prévios na preparação das amostras.

TABELA 6 - Valor certificado, determinado e o limite de determinação do método (LQ) para o MRC NIST 2781

\begin{tabular}{clcc}
\hline & \multicolumn{2}{c}{ MRC - Domestic Sludge - 2781 } & \\
Elemento & Valor Certificado & Valor Determinado & LQ \\
\hline $\mathrm{Na}$ & $\%$ & $\mathrm{Mg} \mathrm{g}^{-1}$ \\
$\mathrm{Mg}$ & $0,21 \pm 0,02$ & $0,202 \pm 0,015$ & 5 \\
$\mathrm{Al}$ & $0,59 \pm 0,04$ & $0,573 \pm 0,014$ & 5 \\
$\mathrm{Si}$ & $1,6,0 \pm 0,1$ & $1,595 \pm 0,038$ & 5 \\
$\mathrm{P}$ & $5,1 \pm 0,2$ & $5,013 \pm 0,125$ & 5 \\
$\mathrm{~K}$ & $2,42 \pm 0,09$ & $2,387 \pm 0,047$ & 5 \\
$\mathrm{Ca}$ & $0,49 \pm 0,03$ & $0,513 \pm 0,018$ & 5 \\
$\mathrm{Ti}$ & $3,9 \pm 0,1$ & $3,966 \pm 0,106$ & 6 \\
$\mathrm{Fe}$ & $0,32 \pm 0,03$ & $0,311 \pm 0,017$ & 15 \\
& $2,8 \pm 0,1$ & $2,916 \pm 0,082$ & 7 \\
$\mathrm{Cr}$ & & $\mu \mathrm{g}$ & \\
$\mathrm{Ni}$ & $202 \pm 9$ & $213 \pm 4$ & 7 \\
$\mathrm{Cu}$ & $80,2 \pm 2,3$ & $85 \pm 5$ & 8 \\
$\mathrm{Zn}$ & $627 \pm 13$ & $639 \pm 2$ & 9 \\
$\mathrm{Se}$ & $1273 \pm 53$ & $1296 \pm 6$ & 13 \\
$\mathrm{~Pb}$ & $16,0 \pm 1,6$ & $17 \pm 1$ & 12 \\
$\mathrm{Hg}$ & $202,1 \pm 6,5$ & $211 \pm 8$ & 10 \\
\hline
\end{tabular}



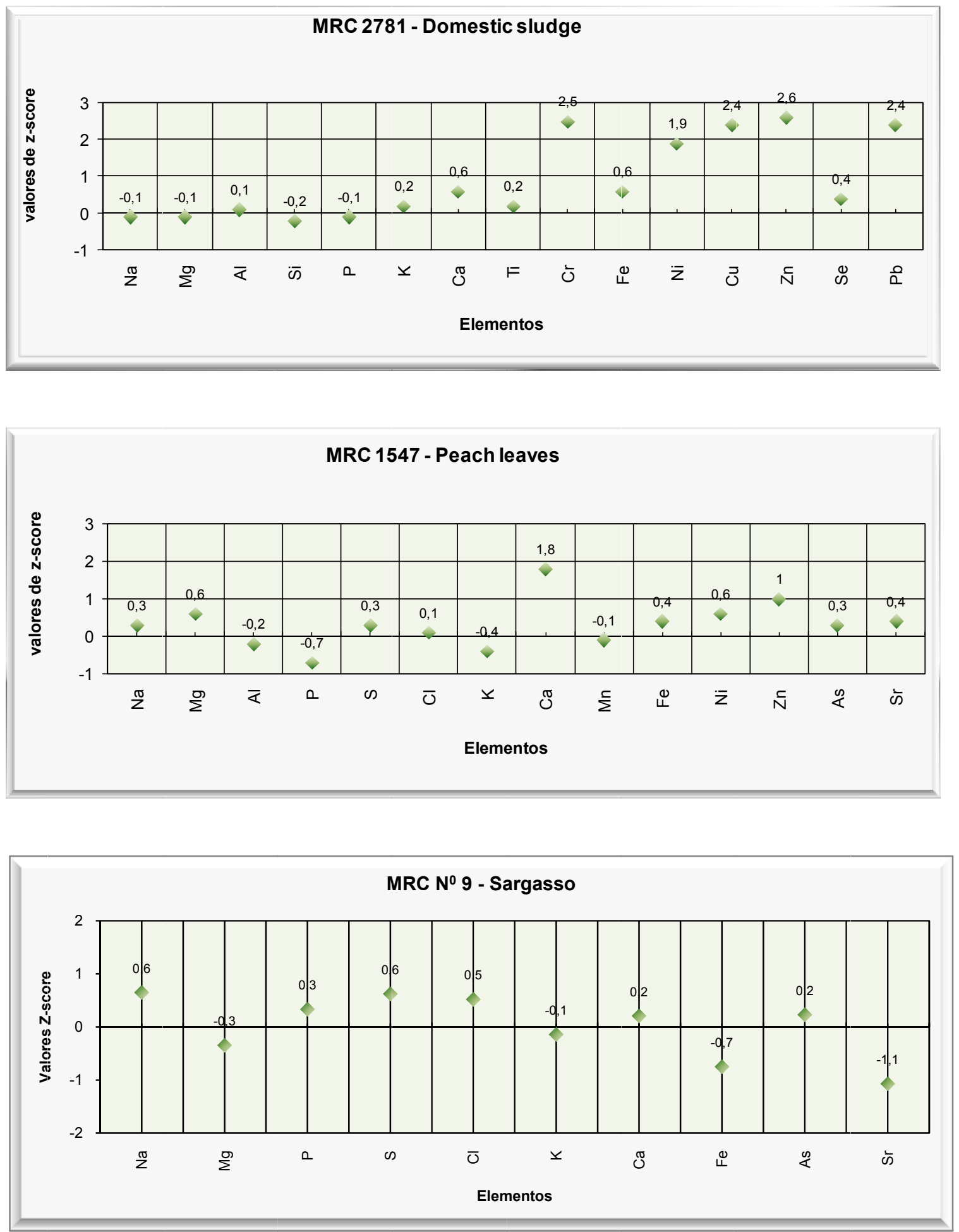

FIGURA 18 - Valores de Z-score calculados para os MRCs 2781, 1547 e № 9 


\subsubsection{Resultados das análises dos constituintes inorgânicos nas poeira doméstica}

A seguir são apresentados os resultados das análises dos constituintes inorgânicos que serão discutidos em relação a massa relativa, ou seja, a massa total acumulada no reservatório do aspirador de pó e a massa real. Os metais tem tendência a permanecerem retidos nas frações mais finas, desta forma, a massa relativa foi corrigida pelas porcentagens em massa das frações $\mathbf{D}$, E e F para cada ponto de amostragem, obtendo-se valores mais realísticos (massa real).

- Resultados em relação à massa relativa

As análises químicas realizadas para as frações D, E e F (APÊNDICES N, O e P, respectivamente, p. 152, 155 e 158) mostraram a presença de Si, Ca, Al, $\mathrm{Mg}, \mathrm{Fe}, \mathrm{S}, \mathrm{K}, \mathrm{Cl}$ e $\mathrm{Na}$, como elementos majoritários para as três frações. Na fração mais fina (F) a concentração destes elementos é significativamente maior, da ordem de 3 e 7 vezes em relação às frações $\mathbf{D}$ e $\mathbf{E}$, respectivamente, com exceção para o $\mathbf{S}$, cuja concentração, manteve-se praticamente constante entre $\mathbf{D}$, E e F ( $\bar{X}=0,97,0,91$ e $0,91 \%$, respectivamente) (TAB. 7). Este mesmo fato também é observado para $\mathrm{Cl}$ e $\mathrm{Na}$. Porém o $\mathrm{S}$ é o único que fornece evidências de contaminação ambiental, visto que, apresenta valores acima do background $(0,06 \%)$ e está relacionado com fontes de emissão veicular. 
Em relação aos elementos minoritários ( $\mathrm{Ti}, \mathrm{Zn}, \mathrm{Cu}, \mathrm{P}, \mathrm{Mn}, \mathrm{Pb}, \mathrm{Sr}, \mathrm{Cr}, \mathrm{Ni}, \mathrm{Zr}$, $\mathrm{Rb}$ e $\mathrm{Br}$ ) foi observado também que a fração mais fina $(\mathbf{F})$ detém a maior concentração, a qual varia entre 2 a 6 vezes em relação à fração $\mathbf{D}$, e 1 a 10 vezes para a E, com exceção do Ni que apresentou maior concentração $\left(10 \mu \mathrm{g} \mathrm{g}^{-1}\right)$ na fração $E$.

Uma avaliação geral da qualidade das amostras de poeira doméstica foi realizada por meio da comparação entre os elementos determinados acima com os valores da crosta continental (CC), conhecidos como valores de background (Swaine, 1955; Taylor e McLennan, 1985; Rudnick e Fountain, 1995). Em relação aos maiores constituintes observou-se que todos são consideravelmente menores, exceto o S, sugerindo serem provenientes de fontes naturais, não sendo classificados como contaminantes. Os elementos minoritários ( $\mathrm{Ti}, \mathrm{Zn}, \mathrm{Cu}, \mathrm{P}, \mathrm{Mn}$, $\mathrm{Pb}, \mathrm{Sr}, \mathrm{Cr}, \mathrm{Ni}, \mathrm{Zr}, \mathrm{Rb}$ e $\mathrm{Br}$ ) apresentaram teores menores que os do background; com exceção do $\mathrm{Zn}, \mathrm{Cu}, \mathrm{P}, \mathrm{Pb}, \mathrm{Cr}$ e Ni, com valores que variam de 13-29; 11-75; 1,2-1,6; 5-10; 1,2-1,3; e 1,6-1,9 vezes, respectivamente, acima dos valores de background; demonstrando que há um enriquecimento destes elementos nas amostras analisadas. As fontes antropogênicas podem ser atribuídas ao tráfego intenso de veículos; combustão de gás natural, gasolina e carvão; detritos de esgoto; spray marinho; desgaste de pneus; águas residuais (Reimann \& Caritat, 1998; Dias Cunha et al., 2004); atividades industriais, proximidades a aterros sanitários, estações ferroviárias, bem como, utensílios domésticos e atividades ocupacionais. 
TABELA 7 - Concentração média $(\bar{X})$ e intervalo de concentração de elementos (IC) (massa relativa) nas frações $\mathbf{D}, \mathbf{E}$ e $\mathbf{F}$ de amostras de poeira e os valores de background (CC)

\begin{tabular}{|c|c|c|c|c|c|c|c|}
\hline \multirow{2}{*}{ Elemento } & \multicolumn{3}{|c|}{$\bar{X}$} & \multicolumn{3}{|c|}{ IC } & \multirow{2}{*}{ CC } \\
\hline & D & E & $\mathbf{F}$ & D & $E$ & $\mathbf{F}$ & \\
\hline \multicolumn{8}{|c|}{$\%$} \\
\hline $\mathrm{Si}$ & $3,18 \pm 1,77$ & $3,49 \pm 1,49$ & $6,59 \pm 2,40$ & $0,60-9,58$ & $1,02-7,56$ & $0,89-12,98$ & 30,5 \\
\hline $\mathrm{Ca}$ & $2,76 \pm 1,80$ & $2,92 \pm 1,70$ & $4,74 \pm 3,29$ & $0,39-12,45$ & $0,47-12,39 \quad 0$ & $0,43-22,29$ & 2,0 \\
\hline $\mathrm{Al}$ & $1,07 \pm 0,62$ & $1,28 \pm 0,57$ & $2,02 \pm 0,75$ & $0,16-3,72$ & $0,31-3,72$ & $0,23-3,59$ & 7,8 \\
\hline $\mathrm{Mg}$ & $0,43 \pm 0,25$ & $0,37 \pm 0,57$ & $1,68 \pm 1,42$ & $0,06-1,09$ & $0,11-3,75 \quad 0$ & $0,09-6,00$ & 1,5 \\
\hline $\mathrm{Fe}$ & $0,96 \pm 0,45$ & $1,03 \pm 0,35$ & $1,42 \pm 0,57$ & $0,23-2,63$ & $0,38-1,87 \quad 0$ & $0,30-3,01$ & 4,1 \\
\hline$S$ & $0,97 \pm 1,05$ & $0,91 \pm 1,00$ & $0,91 \pm 0,97$ & $0,14-9,02$ & $0,15-9,02$ & $0,15-8,15$ & 0,06 \\
\hline K & $0,58+0,32$ & $0,63 \pm 0,36$ & $0,82 \pm 0,38$ & $0,04-2,25$ & $0,16-2,24$ & $0,05-2,47$ & 1,9 \\
\hline $\mathrm{Cl}$ & $0,98 \pm 0,49$ & $0,91 \pm 0,47$ & $0,74 \pm 0,47$ & $0,11-2,72$ & $0,17-2,31 \quad 0$ & $0,04-2,06$ & $* * *$ \\
\hline $\mathrm{Na}$ & $0,70 \pm 0,41$ & $0,67 \pm 0,36$ & $0,61 \pm 0,38$ & $0,03-2,74$ & $0,14-1,91 \quad 0$ & $0,06-1,80$ & 2,0 \\
\hline \multicolumn{8}{|c|}{$\mu \mathrm{g} \mathrm{g}^{-1}$} \\
\hline $\mathrm{Ti}$ & $1786 \pm 760$ & $1806 \pm 741$ & $2312 \pm 848$ & $803-446$ & 69 926-4105 & $973-4330$ & 4067 \\
\hline $\mathrm{Zn}$ & $839 \pm 539$ & $1182 \pm 771$ & $1890 \pm 3131$ & $119-364$ & $48 \quad 145-4882$ & $121-25415$ & 65 \\
\hline $\mathrm{Cu}$ & $263 \pm 513$ & $656 \pm 1259$ & $1734 \pm 6071$ & $29-4244$ & $4 \quad 67-8479$ & $41-48155$ & 23 \\
\hline$P$ & $964 \pm 971$ & $1029+601$ & $1203+694$ & $238-680$ & $07 \quad 293-4441$ & 207-5185 & 750 \\
\hline $\mathrm{Mn}$ & $128 \pm 11$ & $185 \pm 95$ & $309 \pm 176$ & $44-974$ & $62-659$ & $82-1177$ & 750 \\
\hline $\mathrm{Pb}$ & $67 \pm 231$ & $172 \pm 325$ & $145 \pm 141$ & $1-1346$ & 8-1884 & $17-1047$ & 14 \\
\hline $\mathrm{Sr}$ & $38+87$ & $56+90$ & $127 \pm 151$ & $9-739$ & $8-614$ & $16-872$ & 325 \\
\hline $\mathrm{Cr}$ & $75 \pm 118$ & $116 \pm 150$ & $104 \pm 37$ & $1-125$ & $12-878$ & $10-229$ & 85 \\
\hline $\mathrm{Ni}$ & $60 \pm 22$ & $62 \pm 21$ & $69 \pm 25$ & 20-154 & $26-126$ & $27-146$ & 37 \\
\hline $\mathrm{Zr}$ & $20 \pm 23$ & $31 \pm 29$ & $34 \pm 24$ & $4-184$ & $2-210$ & $9-177$ & 204 \\
\hline $\mathrm{Rb}$ & $6 \pm 5$ & $8+6$ & $22 \pm 28$ & $1-24$ & $2-31$ & $1-118$ & 90 \\
\hline $\mathrm{Br}$ & $12 \pm 17$ & $18 \pm 21$ & $17 \pm 26$ & $1-100$ & $1-105$ & $1-157$ & *** \\
\hline
\end{tabular}


De acordo com a literatura (Föstner e Salomons, 1980), os metais têm maior afinidade a ficarem retidos em frações mais finas, como pode ser observado na TAB. 7. Assim, os dados de concentrações totais obtidos para os elementos $\mathrm{Si}$, $\mathrm{Ca}, \mathrm{Al}, \mathrm{Mg}, \mathrm{Fe}, \mathrm{S}, \mathrm{K}, \mathrm{Cl}, \mathrm{Na}, \mathrm{Ti}, \mathrm{Zn}, \mathrm{Cu}, \mathrm{P}, \mathrm{Mn}, \mathrm{Pb}, \mathrm{Sr}, \mathrm{Cr}, \mathrm{Ni}, \mathrm{Zr}, \mathrm{Rb}$ e Br foram corrigidos pelas porcentagens das frações finas: 150-75 (D); 75-63 (E) e <63 $\mu \mathrm{m}$ $(\mathbf{F})$, em cada ponto de coleta, resultando em concentrações mais reais (massa real).

- Resultados em relação à massa real

Em relação aos maiores constituintes $\mathrm{Si}, \mathrm{Ca}, \mathrm{Al}, \mathrm{Mg}, \mathrm{Fe}, \mathrm{S}, \mathrm{K}, \mathrm{Cl}, \mathrm{Na}$ (TAB. 8), estes se encontram em concentração consideravelmente menores nas três frações (D, E e F). No entanto, o S ( $\bar{X}=0,06 \%)$ apresenta o mesmo valor médio, do valor de background $(0,06 \%)$ na fração F. Mas, os intervalos variam de 0,14 a $9,02 \%$, demonstrando que as amostras de poeira doméstica estão enriquecidas, possivelmente causadas por fontes antropogênicas como queima de combustível veicular.

Em relação aos elementos minoritários, $\mathrm{Ti}, \mathrm{Zn}, \mathrm{Cu}, \mathrm{P}, \mathrm{Mn}, \mathrm{Pb}, \mathrm{Sr}, \mathrm{Cr}, \mathrm{Ni}, \mathrm{Zr}$, $\mathrm{Rb}$ e $\mathrm{Br}$, provavelmente provêm de fontes naturais, uma vez que, os seus valores são menores que os do background (CC) para as três frações. No entanto, os elementos Zn (IC = 3-197, 4-81 e 9-966 $\left.\mu \mathrm{g} \mathrm{g}^{-1}\right)$, Cu (IC = 0,8-61,6, 1-85 e 2-963 $\mu \mathrm{g}$ $\left.\mathrm{g}^{-1}\right)$ e $\mathrm{Pb}\left(\mathrm{IC}=0,01-41,4,0,1-79\right.$ e 1-160 $\left.\mu \mathrm{g} \mathrm{g}^{-1}\right)$ apresentam intervalos de concentração superiores aos valores de CC (65 e $23 \mu \mathrm{g} \mathrm{g}^{-1}$, respectivamente) nas três frações $\mathbf{D}$, E e F (TAB. 8). Os elementos $P\left(I C=11-1090 \mu g^{-1}\right)$ e $\mathrm{Ni}(I C=$ 0,62-58 $\left.\mu \mathrm{g} \mathrm{g}^{-1}\right)$ apresentam intervalos acima dos valores de CC (750 e $37 \mu \mathrm{g} \mathrm{g}^{-1}$, respectivamente) apenas na fração F. Estes resultados, demonstram que há um enriquecimento destes elementos nas amostras analisadas, possivelmente 
causadas por tráfegos veicular, atividades industriais, proximidades a aterros sanitários, estações ferroviárias, bem como utensílios domésticos, produtos em geral e atividades ocupacionais

TABELA 8 - Concentração média $(\bar{X})$ e intervalo de concentração de elementos (IC) (massa real) nas frações $\mathbf{D}, \mathbf{E}$ e $\mathbf{F}$ de amostras de poeira e os valores de background (CC)

\begin{tabular}{|c|c|c|c|c|c|c|c|}
\hline \multirow{2}{*}{ Elemento } & \multicolumn{3}{|c|}{$(\bar{X})$} & \multicolumn{3}{|c|}{ IC } & \multirow[t]{2}{*}{ CC } \\
\hline & D & $E$ & $\mathbf{F}$ & D & $E$ & $\mathbf{F}$ & \\
\hline & \multicolumn{7}{|c|}{$\%$} \\
\hline $\mathrm{Si}$ & $0,16 \pm 0,41$ & $0,07 \pm 0,15$ & $0,65 \pm 1,86$ & $0,005-3,281$ & $0,007-1,257$ & $0,018-14,753$ & 30,5 \\
\hline $\mathrm{Ca}$ & $0,13 \pm 0,26$ & $0,06 \pm 0,11$ & $0,36 \pm 0,58$ & $0,004-1,829$ & $0,004-0,729$ & $0,009-3,613$ & 2,0 \\
\hline $\mathrm{Al}$ & $0,05 \pm 0,13$ & $0,03 \pm 0,05$ & $0,20 \pm 0,61$ & $0,002-0,989$ & $0,002-0,431$ & $0,005-4,996$ & 7,8 \\
\hline $\mathrm{Mg}$ & $0,02 \pm 0,04$ & $0,01 \pm 0,02$ & $0,12 \pm 0,23$ & $0,001-0,303$ & $0,001-0,120$ & $0,002-1,583$ & 1,5 \\
\hline $\mathrm{Fe}$ & $0,04 \pm 0,08$ & $0,02 \pm 0,03$ & $0,12 \pm 0,28$ & $0,002-0,541$ & $0,003-0,262$ & $0,009-2,148$ & 4,1 \\
\hline S & $0,04 \pm 0,03$ & $0,02 \pm 0,05$ & $0,06 \pm 0,08$ & $0,002-0,811$ & $0,003-0,414$ & $0,009-0,456$ & 0,06 \\
\hline $\mathrm{K}$ & $0,02 \pm 0,05$ & $0,01 \pm 0,03$ & $0,07 \pm 0,16$ & $0,001-0,350$ & $0,001-0,212$ & $0,003-1,248$ & 1,9 \\
\hline $\mathrm{Cl}$ & $0,03 \pm 0,03$ & $0,01 \pm 0,01$ & $0,05 \pm 0,07$ & $0,002-0,161$ & $0,003-0,068$ & $0,003-0,360$ & $* * *$ \\
\hline \multirow[t]{2}{*}{$\mathrm{Na}$} & $0,02 \pm 0,03$ & $0,01 \pm 0,01$ & $0,05 \pm 0,09$ & $0,001-0,149$ & $0,002-0,079$ & $0,004-0,665$ & 2,0 \\
\hline & \multicolumn{7}{|c|}{$\mu \mathrm{g} \mathrm{g}^{-1}$} \\
\hline $\mathrm{Ti}$ & $87 \pm 192$ & $39 \pm 68$ & $200 \pm 454$ & $7-1491$ & $5-514$ & $19-3502$ & 4067 \\
\hline $\mathrm{Zn}$ & $30 \pm 35$ & $18 \pm 18$ & $99 \pm 136$ & $3-197$ & $4-81$ & $9-866$ & 65 \\
\hline $\mathrm{Cu}$ & $10 \pm 12$ & $9 \pm 13$ & $57 \pm 126$ & $0,8-61,6$ & $1-85$ & $2-963$ & 23 \\
\hline$P$ & $40 \pm 57$ & $17 \pm 18$ & $92 \pm 178$ & 3-354 & 3-115 & $11-1090$ & 750 \\
\hline $\mathrm{Mn}$ & $6+14$ & $4 \pm 6$ & $28 \pm 60$ & $0,4-100,9$ & $0,4-49$ & $2-143$ & 750 \\
\hline $\mathrm{Pb}$ & $4 \pm 7$ & $4 \pm 10$ & $11+23$ & $0,01-41,4$ & $0,1-79$ & $1-160$ & 14 \\
\hline $\mathrm{Sr}$ & $3 \pm 9$ & $1 \pm 4$ & $10 \pm 21$ & $0,06-66,5$ & $0,1-30$ & $1-108$ & 325 \\
\hline $\mathrm{Cr}$ & $3+4$ & $2 \pm 5$ & $7 \pm 10$ & $0,03-19,6$ & $0,3-37$ & $1-58$ & 85 \\
\hline $\mathrm{Ni}$ & $2 \pm 4$ & $10 \pm 1$ & $5+9$ & $0,3-23,9$ & $0,2-8$ & $0,62-58$ & 37 \\
\hline $\mathrm{Zr}$ & $1+4$ & $0,8 \pm 3$ & $5 \pm 22$ & $0,04-34,2$ & $0,02-22$ & $0,20-179$ & 204 \\
\hline $\mathrm{Rb}$ & $0,3 \pm 0,5$ & $0,2 \pm 0,3$ & $1 \pm 3$ & $0,01-3,4$ & $0,01-2$ & $0,03-18$ & 90 \\
\hline $\mathrm{Br}$ & $0,6 \pm 1,0$ & $0,4 \pm 0,8$ & $2 \pm 3$ & $0,01-7,9$ & $0,01-5$ & $0,02-20$ & $* * *$ \\
\hline
\end{tabular}




\subsubsection{Resultados das análises de ésteres fálicos por cromatografia de fase gasosa acoplado ao espectrômetro de massa (GCMS)}

A determinação quantitativa dos ésteres ftálicos (DMP, DEP, DnBP, BBP, DEHA e DEHP) por GCMS, realizada de acordo com o procedimento EPA 525.5, por meio de curvas de calibração individuais, ajustadas pelo método de regressão linear, apresentou-se satisfatória. Os valores calculados para os coeficientes de correlação $\left(R^{2}\right)$ de cada curva estiveram entre 0,9988 e 0,9999, demonstrando uma excelente correlação.

A avaliação da precisão, em termos de desvio padrão relativo percentual (DPR\%), demonstrou repetitividade satisfatória para o DEP $(11,30 \%)$ e DEHP $(13,71 \%)$. Os outros 4 ésteres ftálicos apresentaram valores entre 20 a $37 \%$, consideravelmente altos, entretanto, estes valores são aceitos para o intervalo de concentração em que se realizaram as análises $\left(0,1\right.$ a $\left.10 \mu \mathrm{g} \mathrm{mL}^{-1}\right)$. Os limites de detecção (LD) e quantificação (LQ) demonstram uma sensibilidade satisfatória para a determinação dos compostos acima mencionados. Os valores calculados são apresentados na TAB. 9. 
TABELA 9 - Valores dos desvios padrão relativo percentual (DPR\%), intervalo de concentração (IC), limites de detecção (LD) e quantificação (LQ) para os ésteres ftálicos.

\begin{tabular}{lllll}
\hline $\begin{array}{l}\text { Ésteres } \\
\text { ftálicos }\end{array}$ & $\begin{array}{c}\text { IC } \\
\left(\mu \mathrm{g} \mathrm{mL}{ }^{-1}\right)\end{array}$ & DPR\% & $\begin{array}{c}\text { LD } \\
\left(\mu \mathrm{mL}^{-1}\right)\end{array}$ & $\begin{array}{c}\text { LQ } \\
\left(\mu \mathrm{mL}^{-1}\right)\end{array}$ \\
\hline DMP & $2-206$ & 29,9 & 0,001 & 0,1 \\
DEP & $4-522$ & 11,3 & 0,01 & 0,1 \\
DnBP & $191-5686$ & 23,8 & 0,01 & 0,1 \\
BBP & $5-86$ & 36,6 & 0,002 & 0,2 \\
DEHA & $18-393$ & 36,7 & 0,001 & 0,2 \\
DEHP & $407-19234$ & 13,7 & 0,002 & 0,1 \\
\hline
\end{tabular}

DMP: dimetil ftalato; DEP: dietil ftalato; DnBP: di-n-butil ftalalto; BBP: butil benzil ftalalto; DEHA: 2-etilhexil adipato; DEHP: 2-etilhexil ftalalto

Todas as 69 amostras de poeira doméstica (fração F) mostraram a presença de DEHP, DnBP, DEP, DEHA, BBP e DMP.

O teste de Shapiro-Wilk's W foi aplicado ao conjunto de dados para verificar o tipo de distribuição. Os resultados revelaram uma distribuição normal, permitindo um tratamento estatístico como dados paramétricos, assim foi aplicada a estatística descritiva. Os resultados obtidos para a média aritmética, calculada para cada composto mostrou que o mais abundante é o DEHP $(\bar{X}=5048 \pm 3066 \mu \mathrm{g}$ $\left.\mathrm{g}^{-1}\right)$, para um intervalo de 407 a $19234 \mu \mathrm{g} \mathrm{g}^{-1}$, seguido do DnBP $(\bar{X}=1541 \pm 1235$ $\mu \mathrm{g} \mathrm{g}^{-1}$ ), intervalo entre 191 a $5686 \mu \mathrm{g} \mathrm{g}^{-1}$. Os menos abundantes, de menor concentração são DEP, DEHA e DMP, $\bar{X}=150 \pm 107,89 \pm 49$ e $24 \pm 32 \mu \mathrm{g} \mathrm{g}^{-1}$, respectivamente (TAB. 10). 
TABELA 10 - Média aritmética $(\overline{\boldsymbol{X}})$ e intervalo de concentração (IC) (massa relativa) para os compostos DEHP, DnBP, DEP, DEHA, BBP e DMP determinados por GCMS, na fração $\mathbf{F}$

\begin{tabular}{|c|c|c|c|c|c|c|}
\hline \multirow{2}{*}{ PA } & DEHP & DnBP & DMP & DEP & BBP & DEHA \\
\hline & \multicolumn{6}{|c|}{$\mu \mathrm{g} \mathrm{g}^{-1}$} \\
\hline 1 & 4401 & 1767 & 4 & 413 & 49 & 32 \\
\hline 2 & 1867 & 940 & 4 & 406 & 79 & 55 \\
\hline 3 & 6414 & 1117 & 11 & 199 & 24 & 55 \\
\hline 4 & 4469 & 1383 & 14 & 120 & 47 & 39 \\
\hline 5 & 1952 & 820 & 4 & 362 & 46 & 87 \\
\hline 6 & 3732 & 863 & 18 & 91 & 41 & 75 \\
\hline 7 & 1656 & 681 & 4 & 407 & 52 & 97 \\
\hline 8 & 2048 & 767 & 4 & 349 & 74 & 72 \\
\hline 9 & 5142 & 1588 & 7 & 291 & 15 & 118 \\
\hline 10 & 2282 & 831 & 7 & 238 & 43 & 92 \\
\hline 11 & 2451 & 537 & 4 & 294 & 85 & 97 \\
\hline 12 & 3276 & 680 & 18 & 85 & 53 & 87 \\
\hline 13 & 2811 & 676 & 6 & 284 & 52 & 86 \\
\hline 14 & 3905 & 1281 & 8 & 203 & 34 & 76 \\
\hline 15 & 2848 & 787 & 2 & 522 & 60 & 93 \\
\hline 16 & 3945 & 210 & 27 & 283 & 53 & 76 \\
\hline 17 & 2524 & 902 & 22 & 101 & 34 & 75 \\
\hline 18 & 6769 & 973 & 18 & 93 & 38 & 62 \\
\hline 19 & 6022 & 1331 & 19 & 72 & 26 & 99 \\
\hline 20 & 4815 & 954 & 28 & 137 & 41 & 87 \\
\hline 21 & 407 & 5424 & 17 & 83 & 8 & 59 \\
\hline 22 & 2443 & 854 & 17 & 83 & 86 & 36 \\
\hline 23 & 6377 & 758 & 10 & 242 & 69 & 18 \\
\hline 24 & 6618 & 1200 & 19 & 93 & 62 & 29 \\
\hline 27 & 2806 & 1414 & 14 & 140 & 15 & 99 \\
\hline 25 & 3861 & 1356 & 11 & 263 & 10 & 114 \\
\hline 26 & 4374 & 908 & 18 & 89 & 33 & 90 \\
\hline 28 & 1623 & 1247 & 19 & 73 & 27 & 80 \\
\hline 29 & 5523 & 723 & 20 & 101 & 36 & 84 \\
\hline 30 & 3407 & 771 & 18 & 92 & 36 & 84 \\
\hline 31 & 4185 & 738 & 18 & 79 & 50 & 78 \\
\hline 32 & 3271 & 1752 & 14 & 118 & 14 & 95 \\
\hline 33 & 3287 & 934 & 17 & 83 & 33 & 91 \\
\hline 34 & 3632 & 5686 & 10 & 81 & 7 & 85 \\
\hline 35 & 19234 & 1488 & 30 & 309 & 5 & 94 \\
\hline
\end{tabular}


TABELA 10 - Média aritmética $(\overline{\boldsymbol{X}})$ e intervalo de concentração (IC) (massa relativa) para os compostos DEHP, DnBP, DEP, DEHA, BBP e DMP determinados por GCMS, na fração $\mathbf{F}$

\begin{tabular}{|c|c|c|c|c|c|c|}
\hline \multirow{2}{*}{ PA } & DEHP & DnBP & DMP & DEP & BBP & DEHA \\
\hline & \multicolumn{6}{|c|}{$\mu \mathrm{g} \mathrm{g}^{-1}$} \\
\hline 36 & 1523 & 1147 & 153 & 4 & 49 & 76 \\
\hline 37 & 3980 & 2412 & 22 & 80 & 13 & 158 \\
\hline 38 & 6973 & 1972 & 10 & 60 & 28 & 79 \\
\hline 39 & 5216 & 568 & 18 & 79 & 61 & 75 \\
\hline 40 & 3550 & 782 & 18 & 83 & 40 & 83 \\
\hline 41 & 4175 & 734 & 19 & 72 & 47 & 84 \\
\hline 42 & 9395 & 4942 & 20 & 97 & 5 & 86 \\
\hline 43 & 4732 & 771 & 17 & 67 & 65 & 70 \\
\hline 44 & 5850 & 1701 & 9 & 212 & 10 & 77 \\
\hline 45 & 4994 & 724 & 20 & 71 & 49 & 82 \\
\hline 46 & 6203 & 2325 & 15 & 67 & 25 & 59 \\
\hline 47 & 4148 & 3561 & 10 & 70 & 12 & 77 \\
\hline 48 & 5053 & 1736 & 25 & 64 & 20 & 75 \\
\hline 49 & 5779 & 1494 & 30 & 83 & 13 & 88 \\
\hline 50 & 7781 & 4912 & 9 & 92 & 22 & 27 \\
\hline 51 & 3107 & 5015 & 29 & 95 & 5 & 393 \\
\hline 52 & 8442 & 1660 & 21 & 86 & 20 & 76 \\
\hline 53 & 12133 & 1726 & 26 & 121 & 17 & 77 \\
\hline 54 & 14828 & 191 & 206 & 212 & 26 & 34 \\
\hline 55 & 5020 & 2803 & 11 & 165 & 9 & 84 \\
\hline 56 & 11663 & 307 & 112 & 210 & 17 & 49 \\
\hline 57 & 5943 & 3471 & 9 & 119 & 11 & 147 \\
\hline 58 & 6030 & 1411 & 19 & 100 & 21 & 103 \\
\hline 59 & 4205 & 2228 & 15 & 95 & 17 & 146 \\
\hline 60 & 7843 & 419 & 66 & 193 & 17 & 75 \\
\hline 61 & 6712 & 1018 & 65 & 108 & 9 & 137 \\
\hline 62 & 4098 & 2708 & 43 & 35 & 11 & 170 \\
\hline 63 & 4379 & 769 & 22 & 155 & 27 & 71 \\
\hline 64 & 6229 & 1431 & 30 & 97 & 16 & 97 \\
\hline 65 & 6354 & 1321 & 22 & 89 & 21 & 81 \\
\hline 66 & 2861 & 808 & 16 & 73 & 58 & 74 \\
\hline 67 & 7423 & 1320 & 23 & 149 & 14 & 134 \\
\hline 68 & 2372 & 2091 & 19 & 104 & 15 & 105 \\
\hline 69 & 4941 & 1495 & 23 & 96 & 22 & 189 \\
\hline $\bar{X}$ & $5048 \pm 3066$ & $1541 \pm 1235$ & $24 \pm 32$ & $150 \pm 107$ & $33 \pm 21$ & $89 \pm 49$ \\
\hline Mediana & 4379 & 1200 & 18 & 97 & 27 & 83 \\
\hline IC & $407-19234$ & $191-5686$ & 2-206 & 4-522 & $5-86$ & $18-393$ \\
\hline
\end{tabular}


Os valores de percentis (50-P e 95-P) calculados por meio da estatística descritiva foram comparados com os valores reportados nos 7 estudos realizados na Alemanha, por diferentes pesquisadores e regiões nos anos de 1991, 1998, 2001, 2003 e 2004. Estes trabalhos foram selecionados por apresentarem similaridade nos procedimentos de amostragem e métodos de análises (B.A.U.C.H., 1991; UBA, 1998; Butte et al.,2001; Mattulat, 2001; Kersten \& Reich, 2003; Bercker et al., 2004 e Fromme et al., 2004) (TAB. 11).

Em relação ao composto DEHP (o mais abundante neste estudo) 95-P = $11663 \mu \mathrm{g} \mathrm{g}^{-1}$ pode ser verificado que o valor determinado, é cerca de 4 vezes maior que o reportado por B.A.U.C.H. $\left(95-\mathrm{P}=3065 \mu \mathrm{g} \mathrm{g}^{-1}\right)$ e cerca de 10 vezes maior que o reportado por UBA (95-P $\left.=1190 \mu \mathrm{g} \mathrm{g}^{-1}\right)$, (TAB. 11). Os resultados mostram que as amostras deste estudo apresentam-se consideravelmente contaminadas e reforçam a hipótese de que a fonte mais provável de contaminação seja a migração deste composto para o ambiente interno por causa de desgaste de artefatos e/ou objetos, visto que, este composto é utilizado principalmente como aditivo de materiais plásticos. No aspecto de saúde humana, o resultado é muito preocupante, uma vez que, a literatura tem reportado, em muitos trabalhos, uma correlação entre doenças alérgicas por pessoas expostas a este composto (Bornehag et al., 2004; Bornehag et al., 2005; Calafat et al.,2006; Kolarik et al., 2008) e distúrbios endócrinos, cânceres e outros em animais de experimentação (Blount et al., 2000; ATSDR, 2002; Borch et al., 2004; Borch et al., 2005).

Com relação ao composto DnBP, valor determinado 95-P $=4942 \mu \mathrm{g} \mathrm{g}^{-1}$, apesar de apresentar menor concentração que o DEHP, o caso parece ser mais crítico, visto que este composto quando comparado aos valores da TAB. 4, apresenta-se cerca de 16 vezes maior que o valor superior (Mattulat, 95-P = 311 $\mu \mathrm{g} \mathrm{g}^{-1}$ ) e cerca de 38 vezes maior que o valor inferior (Fromme, 95-P = $130 \mu \mathrm{g} \mathrm{g}^{-1}$ ). Este resultado confirma a hipótese de contaminação da poeira doméstica por 
aditivos de materiais plásticos. Estes resultados alertam para problema toxicológico frente à exposição humana, por ésteres ftálicos.

O BBP é cerca de 4 vezes menor que os valores reportados na TAB. 10. Este resultado não descarta a hipótese da fonte de contaminação, apresentada anteriormente, já que, este composto é utilizado em menores proporções nos diversos artefatos e objetos.

TABELA 11 - Valores de percentis dos aos compostos DEHP, DnBP e BBP, reportados na literatura nos anos de 1991, 1998, 2001, 2003 e 2004, na Alemanha e neste estudo (NE)

\begin{tabular}{|c|c|c|c|c|c|c|c|c|}
\hline \multirow{3}{*}{ Pesquisador } & \multirow{3}{*}{ Fração } & \multirow{3}{*}{ Amostra } & \multicolumn{2}{|c|}{ DEHP } & \multicolumn{2}{|c|}{ DnBP } & \multicolumn{2}{|c|}{ BBP } \\
\hline & & & $50-P$ & 95-P & $50-P$ & 95-P & $50-P$ & 95-P \\
\hline & & & \multicolumn{6}{|c|}{$\left(\mu g^{-1}\right)$} \\
\hline $\begin{array}{l}\text { B.A.U.C.H., } \\
1991^{13}\end{array}$ & $\begin{array}{l}\text { não } \\
\text { especificado }\end{array}$ & 12 & 470 & 3065 & 30 & 301 & & \\
\hline UBA, $1998^{14}$ & $<2 \mathrm{~mm}$ & 199 & 416 & 1190 & 42 & 160 & 15 & 207 \\
\hline $\begin{array}{l}\text { Butte et } \\
\text { al.,2001 }\end{array}$ & $\leq 63 \mu \mathrm{m}$ & 286 & 740 & 2600 & 49 & 240 & 31 & 320 \\
\hline $\begin{array}{l}\text { Mattulat, } \\
2001^{16}\end{array}$ & $\begin{array}{l}\text { não } \\
\text { especificado }\end{array}$ & 600 & 699 & 3470 & 48 & 311 & & \\
\hline $\begin{array}{l}\text { Kersten \& } \\
\text { Reich, 2003 }\end{array}$ & $\leq 63 \mu \mathrm{m}$ & 65 & 600 & 1600 & 47 & 180 & 19 & 230 \\
\hline $\begin{array}{l}\text { Bercker et al., } \\
2004^{18}\end{array}$ & $63 \mu \mathrm{m}$ & 252 & 515 & 1840 & & & & \\
\hline $\begin{array}{l}\text { Fromme et al., } \\
2004^{8}\end{array}$ & fine dust & 30 & 703 & 1542 & 60 & 130 & & \\
\hline NE, 2009 & $\leq 63 \mu \mathrm{m}$ & 69 & 4379 & 11663 & 1200 & 4942 & 27 & 74 \\
\hline
\end{tabular}

De acordo com a literatura (Butte e Heizon, 2002), os ésteres ftálicos, assim como os constituintes inorgânicos, são adsorvidos às frações finas da poeira doméstica. Assim, os dados de concentrações totais obtidos para os compostos DEHP, DnBP, DMP, DEP, BBP e DEHA foram corrigidos das porcentagens da 
fração fina $(<63 \mu \mathrm{m})$ para massa total, resultando em concentrações mais reais (massa real) (TAB. 12).

TABELA 12 - Média aritmética $(\bar{X})$ e intervalo de concentração (IC) (massa real) para os compostos DEHP, DnBP, DEP, DEHA, BBP e DMP determinados por GCMS, na fração $F$ e valores orientadores (VO)

\begin{tabular}{llllll}
\hline $\begin{array}{l}\text { Ésteres } \\
\text { ftálicos }\end{array}$ & $\bar{X}$ & IC & $\begin{array}{l}\text { Valores orientadores } \\
\text { Referência* }^{*} \\
\left(\mu \mathrm{g} \mathrm{g}^{-1}\right)\end{array}$ & $\begin{array}{l}\text { Prevenção } \\
\text { Intervenção }\end{array}$ \\
\hline DEHP & $415,6 \pm 945,2$ & $33,1-7116,7$ & 0,6 & 1,2 & 4 \\
DnBP & $129,7 \pm 281,9$ & $4,2-2141,1$ & 0,25 & 0,5 & 1,6 \\
DEP & $9,4 \pm 17,4$ & $0,7-114,5$ & $* * *$ & $* * *$ & $* * *$ \\
DEHA & $6,8 \pm 17,3$ & $1,0-142,1$ & $* * *$ & $* * *$ & $* * *$ \\
BBP & $3,3 \pm 11,4$ & $0,1-91,5$ & $* * *$ & $* * *$ & $* * *$ \\
DMP & $5,4 \pm 34,3$ & $0,1-285,8$ & 0,7 & $* * *$ & $* * *$ \\
\hline
\end{tabular}

*Valores de referência $\equiv$ valores mínimos aceitáveis

Os resultados dos ésteres ftálicos DEHP, DnBP e DMP (TAB. 12) foram comparados com os valores orientadores para solo, publicados pela CETESB (2005) (TAB. 12). Em relação ao composto DEHP pode ser verificado que o valor determinado, é cerca de 693 vezes maior que os de referência, 346 de prevenção e 104 de intervenção. O DnBP também apresenta valores significantemente superiores aos de referência, prevenção e intervenção, cerca de 519, 294 e 81 vezes. O menos concentrado, mas tão importante quanto os outros se apresentou cerca de 7,7 vezes maior que os valores de referência. Estes fatos confirmam a hipótese, de desincorporação destes compostos para o ambiente, o que torna a poeira doméstica uma fonte de exposição para os seres humanos. 
Os valores de ésteres ftálicos determinados foram comparados com os valores orientadores da Comunidade Européia, que culturalmente abnegam a utilização de materiais plásticos em utensílios domésticos e brinquedos. No Brasil, pais em desenvolvimento, especialmente para a região metropolitana de São Paulo (renda mensal estimada de 2 a 20 salários mínimos) a utilização de materiais plásticos é abusiva em todos os aspectos domésticos. Apesar da existência de normativas para a utilização de aditivos em plásticos, ainda é precária a fiscalização de sua aplicabilidade.

\subsubsection{Identificação das fases cristalinas por difração de raios X (XRD)}

Das 69 amostras de poeira doméstica (fração F) foi selecionado um total de 23, dos bairros em estudo, como segue: quatro pontos de amostragem em Pirituba (PA1, PA19, PA10, PA14 e PA3); seis na Freguesia do Ó (PA33, PA31, PA26, PA36 PA27 e PA34); nove no Jaraguá (PA37, PA49, PA48, PA47, PA50, PA51, PA38 e PA45) e quatro em Perus (PA56, PA58, PA57 e PA65). Estas amostras foram escolhidas usando como critérios, as proximidades das residências com as vias de alto tráfego, estações ferroviárias e aterro sanitário.

As amostras foram analisadas por XRD, com o propósito de se determinar as fases cristalinas presentes. Os difratogramas experimentais foram comparados com os padrões de difração por meio do software Crystallographica (Package For The Web Stub).

Pelos resultados obtidos verificou-se que todas as amostras apresentaram picos de difração (cristalitos) e a presença majoritária foram: quartzo [ $\left.\mathrm{SiO}_{2}\right]$, dolomita $\left[\mathrm{CaMg}\left(\mathrm{CO}_{3}\right)_{2}\right]$, gibsita $\left[\mathrm{Al}(\mathrm{OH})_{3}\right]$, albita $\left[\mathrm{Na}\left(\mathrm{AlSi}_{3} \mathrm{O}_{8}\right)\right]$ e caulinita $\left[\mathrm{Al}_{2} \mathrm{Si}_{2} \mathrm{O}_{5}(\mathrm{OH})_{4}\right]$, seguidos de calcita $\left[\mathrm{CaCO}_{3}\right]$, rutilo $\left[\mathrm{TiO}_{2}\right]$, coesita $\left[\mathrm{SiO}_{2}\right]$,e sulfeto de silício [ $\left.\mathrm{SiS}_{2}\right]$ (FIGs. 19, 20 e 21). Estes resultados estão correlacionados com os 
valores determinados por XRF, demonstrando que os maiores constituintes são o $\mathrm{Si}, \mathrm{Al}, \mathrm{Ca}, \mathrm{Mg}$ e Na. Porém, foi verificada a presença de $\mathrm{S}$ na forma de sulfeto, indícios de contaminação; a entrada de $S$ no solo ou poeira pode ocorrer pelo intemperismo de minerais sulfatados, pela adsorção direta do $S$ atmosférico por causa do tráfego veicular.

Os resultados evidenciam a influência de fontes externas para os ambientes internos, já que, os elementos mais comuns na crosta terrestre são, oxigênio, silício, alumínio, ferro, cálcio, sódio, potássio e magnésio, assim como, os minerais compostos destes elementos - especialmente sílica e oxigênio - constituem a maior fração mineral da terra. Os componentes minerais mais comuns do solo são divididos em: quartzo $\left(\mathrm{SiO}_{2}\right)$, ortoclásio $\left(\mathrm{KAISi}_{3} \mathrm{O}_{8}\right)$, epidote $\left(4 \mathrm{CaO} .3(\mathrm{AlFe})_{2} \mathrm{O}_{3} .6 \mathrm{SiO}_{2} \cdot \mathrm{H} 2 \mathrm{O}\right)$, geothite $(\mathrm{FeO}(\mathrm{OH}))$, magnetita $\left(\mathrm{Fe}_{3} \mathrm{O}_{2}\right)$, carbonatos de cálcio e magnésio $\left(\mathrm{CaCO}_{3}\right.$ e $\left.\mathrm{MgCO}_{3}\right)$ e óxidos de manganês $\left(\mathrm{MnO}_{2}\right)$ e titânio $\left(\mathrm{TiO}_{2}\right)$.

De acordo com a literatura estima-se que a quantidade de solo que adentra para o ambiente interno pode ser da ordem de 20-30\% (Davies et al., 1985; Culbard et al., 1988; Rutz et al., 1997;) e 30-45\% (Fergusson e Kim, 1991; Trowbridge e Burmaster, 1997), e em alguns casos até 85\% (Roberts et al., 1991) de solo externo. Estes valores estão correlacionados com os determinados por análise granulométrica, uma vez que, a soma das três frações $\mathbf{D}, \mathbf{E}$ e $\mathbf{F}$, qualificadas como solo (APÊNDICE M, p. 150), é de $\bar{X}=19 \%$ e um intervalo de $\mathrm{IC}=0,2-51 \%$. 

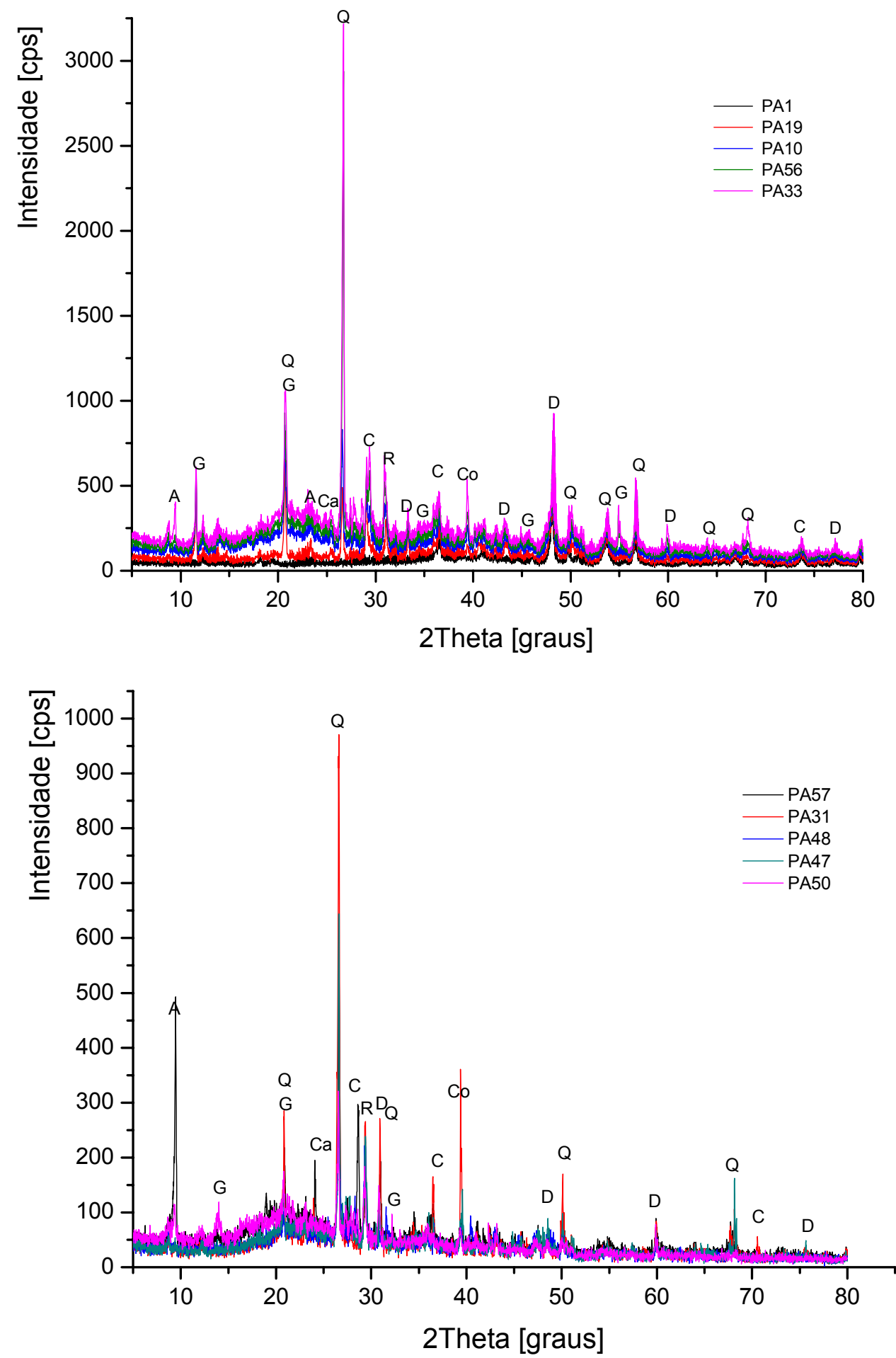

FIGURA 19 - Difratograma da análise direta em amostras de poeira doméstica. Quartzo (Q), Albita (A), Gibbsita (G), Rutile (R), Calcita (C), Dolomita (D), Caulinita (Ca), Coesita (Co) 

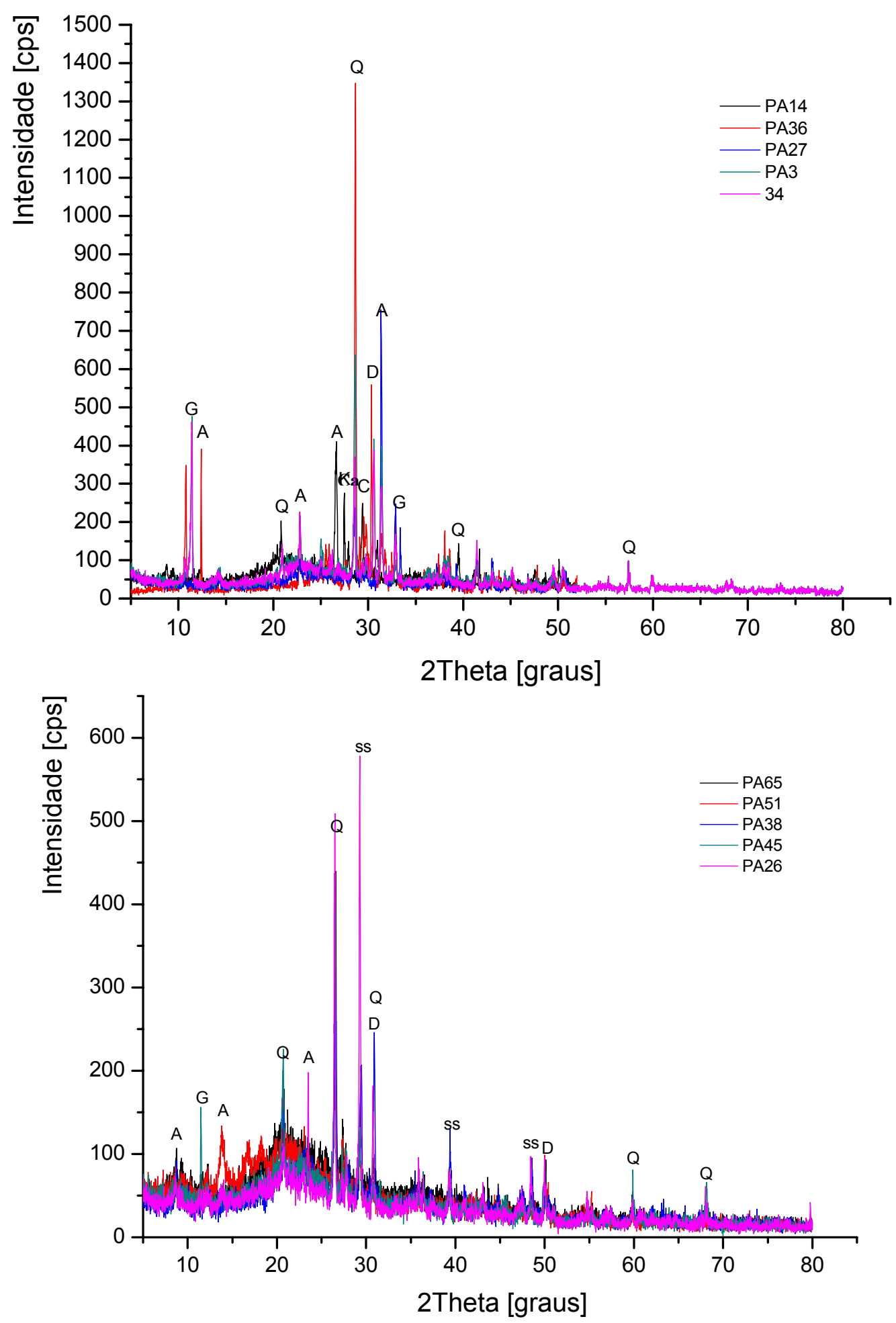

FIGURA 20 - Difratograma da análise direta em amostras de poeira doméstica. Quartzo (Q), Albita (A), Gibbsita (G), Dolomita (D), Calcita (C), Sulfeto de silício (SS) e Caulinita (Ca) 


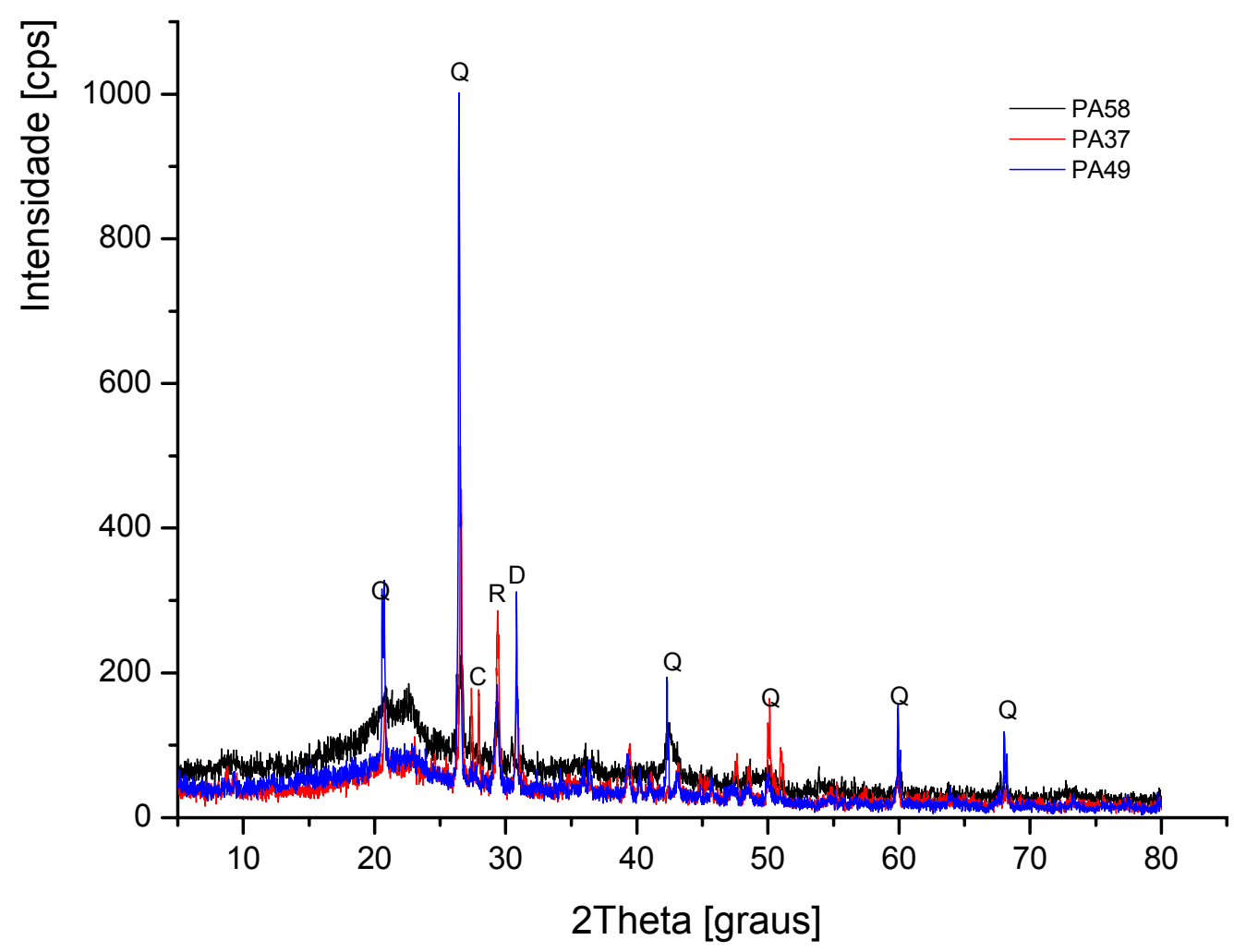

FIGURA 21 - Difratograma da análise direta em amostras de poeira doméstica. Quartzo (Q), Rutile (R), Dolomita (D) e Calcita (C) 


\subsection{Fator de enriquecimento (FE)}

O fator de enriquecimento é um método de normalização que permite identificar se um determinado elemento é contaminante ou constituinte. Normalmente, é utilizado em amostras de solo, sedimento e poeira. Para se aplicar este método é necessário identificar o elemento normalizante, um dos constituintes da crosta terrestre, isento de contaminação. De acordo com a literatura, os mais utilizados são o Al, Fe, Mn, Sc e Ti (Quevauviller et al., 1989; Fergusson et al., 1986; Lee et al., 1998; Mishra et al., 2004; Yongming et al., 2006e Zhang et al., 2009). A seleção do elemento normalizante é realizada por meio da avaliação da correlação deste elemento com os constituintes do material analisado.

Neste estudo, para a escolha do elemento normalizante mais apropriado, primeiramente foram descartados os valores outliers, por meio do teste de distância de Mahalanobis. Para o conjunto de 69 amostras não ocorreu nenhum valor aberrante (APÊNDICE K, p. 84). Em seguida, foi aplicado o teste de Shapiro Wilk W para se verificar a hipótese de normalidade. Posteriormente, foi utilizada a análise de fatores (AF) para se calcular as correlações entre as variáveis e extrair os fatores latentes, também chamados de loadings, utilizando uma matriz contendo as concentrações dos elementos (massa real) nas frações D, E e F (69 casos) versus os 23 elementos determinados (variáveis). O Al apresentou a maior correlação com os demais elementos constituintes; e este foi escolhido como elemento normalizador.

Foi calculado para cada amostra a razão da concentração de cada elemento com a concentração de Al. O mesmo cálculo foi realizado para as concentrações dos elementos constituintes da crosta terrestre.

O fator de enriquecimento (FE) foi obtido por meio do quociente entre a razão das amostras pela razão da crosta terrestre (Eq. 13, p. 57). O FE também 
calculado com a concentração da massa relativa, apresentou os mesmos resultados da massa real. $\mathrm{Na} T A B$. 13, são apresentados os valores de fator de enriquecimento e classe de contaminação, disponível na literatura (Salomons e Förstner, 1984; Sinex e Wright, 1988; Klerks e Levinton, 1989; Sutherland et al., 2000; Zhang e Liu, 2002; Loska e Wiechuła, 2003; Han et al., 2006).

TABELA 13 - Valores de fator de enriquecimento (FE) e classe de contaminação. (Salomons e Förstner, 1984; Sinex e Wright, 1988; Klerks e Levinton, 1989; Sutherland et al., 2000; Zhang e Liu, 2002; Loska e Wiechuła, 2003; Han et al., 2006)

\begin{tabular}{cc}
\hline Fator de enriquecimento (FE) & $\begin{array}{c}\text { Classe de contaminação de } \\
\text { enriquecimento }\end{array}$ \\
\hline$<2$ & mínimo \\
$2-5$ & moderado \\
$5-20$ & significante \\
$20-40$ & muito alto \\
$>40$ & extremamente alto \\
\hline
\end{tabular}

A comparação do fator de enriquecimento determinadas, neste estudo, com os disponíveis na literatura permitiram selecionar 7 elementos potencialmente enriquecidos, S, Zn, Cu, P, Cr, Pb e Ni (TAB. 14). Destes, pode-se verificar que S, $\mathrm{Zn}, \mathrm{Cu}$ e $\mathrm{Pb}$ apresentam-se classificados como extremamente alto (>40) em todas as frações $\mathbf{D}$, $\mathbf{E}$ e $\mathbf{F}$, exceto $\mathrm{Pb}$ na fração $\mathbf{E}$. O fator de enriquecimento do $\mathrm{Zn}$ mantém-se praticamente constante nas três frações (D, E e F), já o de $\mathbf{C u}$ aumentam consideravelmente da fração mais fina $(\mathbf{F})$. A fração mais contaminada por $\mathrm{P}, \mathrm{Cr}$ e Ni é na mais grossa e eles estão inseridos no grupo dos contaminantes significantes.

A hipótese mais provável para a fonte de contaminação está relacionada à frota veicular, não somente por causa das emissões de gases proveniente da combustão dos motores, mas pelo desgaste por mecanismos e acessórios destes 
veículos (pneus, freios e outros). Os estudos recentes sobre fontes de contaminação veicular têm utilizados estes elementos como traçadores.

TABELA 14 - Média $(\bar{x})$ e intervalo do fator de enriquecimento (IC) nas frações $\mathbf{D}$, $\mathbf{E}$ e $\mathbf{F}$, para a massa real

\begin{tabular}{|c|c|c|c|c|c|c|}
\hline \multirow{3}{*}{ Elementos } & \multicolumn{6}{|c|}{ Fator de enriquecimento (FE) } \\
\hline & \multicolumn{2}{|c|}{ Fração D } & \multicolumn{2}{|c|}{ Fração E } & \multicolumn{2}{|c|}{ Fração F } \\
\hline & $\overline{\mathbf{x}}$ & IC & $\overline{\mathbf{x}}$ & IC & $\overline{\mathbf{x}}$ & IC \\
\hline $\mathrm{S}$ & $165 \pm 18$ & $15-1144$ & $116 \pm 131$ & $14-752$ & $86 \pm 184$ & $7-1459$ \\
\hline $\mathrm{Zn}$ & $158 \pm 182$ & $12-897$ & $150 \pm 172$ & $13-935$ & $155 \pm 298$ & $8-2280$ \\
\hline $\mathrm{Cu}$ & $149 \pm 286$ & $10-2177$ & $255 \pm 628$ & $10-4564$ & $444+1555$ & $13-12144$ \\
\hline$P$ & $15 \pm 16$ & $2-88$ & $10 \pm 10$ & $2-48$ & $8+10$ & $2-84$ \\
\hline $\mathrm{Cr}$ & $12 \pm 20$ & $0-117$ & $12 \pm 26$ & $1-144$ & $6 \pm 3$ & $0-23$ \\
\hline $\mathrm{Pb}$ & $92+223$ & $0-1292$ & $12+8$ & 3-1829 & $42 \pm 38$ & $4-260$ \\
\hline $\mathrm{Ni}$ & $16 \pm 12$ & $2-64$ & $10 \pm 10$ & $2-53$ & $9 \pm 7$ & $2-53$ \\
\hline
\end{tabular}

\subsection{Qualificação da poeira doméstica}

A avaliação dos resultados de maneira rápida e eficiente para inclusão de outros elementos, não considerados enriquecidos pelo método $\mathrm{FE}$, foi realizada por outro modelo matemático.

Neste procedimento foi calculada a razão $\mathrm{Al} / \mathrm{Si}$ para as 69 amostras de poeira, 109 materiais de referência certificados (selecionados pelo critério de similaridade na composição química) e para os valores reportados para a composição da crosta continental (Swaine, 1955; Taylor e McLennan, 1985; Rudnick e Fountain, 1995). 
Os testes estatísticos (ANOVA e de Tukey) aplicados a este conjunto de dados demonstraram a desigualdade entre as médias. O teste de intervalo interquartil (IQR) foi aplicado para a eliminação dos outliers (primeiro, $Q_{1}$ e terceiro, $Q_{3}$ quartil). Os novos resultados foram avaliados novamente, pela ANOVA (para um nível de significância de 0,05) e estes mostram igualdade entre as médias, para as três frações testadas (D, E e F), mostrando que todas as amostras se apresentam, estatisticamente, uma composição química de solo.

Em vista disto, foi realizada uma comparação entre os valores médios obtidos (TAB. 14) e os valores orientadores para solo (TAB. 15) (CETESB, 2005). Os resultados mostraram que nenhum elemento foi acrescentado ao resultado anterior, porém, na fração mais fina $(\mathbf{F})$, pode ser observado que os valores médios de $\operatorname{Zn}\left(\bar{X}=99 \pm 136 \mu \mathrm{g} \mathrm{g}^{-1}\right)$ e $\mathrm{Cu}\left(\bar{X}=57 \pm 126 \mu \mathrm{g} \mathrm{g}^{-1}\right)$ estão acima dos valores de referência de qualidade (RQ) (60 e $35 \mu \mathrm{g} \mathrm{g}^{-1}$, respectivamente). Os valores do Cu próximo ao de prevenção ( $\mathrm{PR}, \bar{X}=60 \mu \mathrm{g} \mathrm{g}^{-1}$ ), enquanto que $\mathrm{Pb}, \mathrm{Cr}$ e Ni estão abaixo dos valores RQ. No entanto, estes elementos apresentam os níveis de concentração acima dos valores de referência de qualidade (RQ) e o de prevenção (PR) quando se observa a área pontuada (a localização da amostra coletada individual), com exceção do $\operatorname{Cr}\left(\mathrm{IC}=1-58 \mu \mathrm{g} \mathrm{g}^{-1}\right)$ para o valor de PR (75 $\left.\mu \mathrm{g} \mathrm{g}^{-1}\right)$. Os resultados demonstram que a fração $\mathbf{F}$ é a mais enriquecida, estando em concordância com os modelos anteriormente descritos (comparação com os valores de background e fator de enriquecimento) e demonstra a potencialidade deste material para monitoramento de contaminação ambiental por metais. 
TABELA 15 - Valores médios $(\bar{X})$ e intervalos (IC) determinados neste estudo (NE) e os orientadores de Referência de Qualidade (RQ) e Prevenção (PR) para solo no Estado de São Paulo. (CETESB, 2005)

\begin{tabular}{|c|c|c|c|c|c|c|c|c|}
\hline \multirow{3}{*}{ Elem. } & \multicolumn{3}{|c|}{$\overline{\bar{X}}$ (NE) } & \multicolumn{3}{|c|}{ IC (NE) } & \multirow{2}{*}{$\mathbf{R Q}$} & \multirow{2}{*}{ PR } \\
\hline & D & $E$ & $F$ & D & $E$ & $\mathbf{F}$ & & \\
\hline & \multicolumn{8}{|c|}{$\mu \mathrm{g} \mathrm{g}^{-1}$} \\
\hline $\mathrm{Zn}$ & $30 \pm 35$ & $18+18$ & $99 \pm 136$ & 3-197 & $4-81$ & $9-866$ & 60 & 300 \\
\hline $\mathrm{Cu}$ & $10 \pm 12$ & $9 \pm 13$ & $57 \pm 126$ & $0,8-62$ & $1-85$ & $2-963$ & 35 & 60 \\
\hline $\mathrm{Pb}$ & $4 \pm 7$ & $4+10$ & $11 \pm 23$ & $0,01-41$ & $0,1-79$ & $1-160$ & 17 & 72 \\
\hline $\mathrm{Cr}$ & $3 \pm 4$ & $2 \pm 5$ & $7 \pm 10$ & $0,03-20$ & $0,3-37$ & $1-58$ & 40 & 75 \\
\hline $\mathrm{Ni}$ & $2 \pm 4$ & $10 \pm 1$ & $5 \pm 22$ & $0,3-24$ & $0,2-8$ & $0,62-58$ & 13 & 30 \\
\hline
\end{tabular}

Cartas ou gráficos de controle foram construídos para ilustrar de maneira dinâmica a qualificação das amostras de poeira doméstica e informar se possuem características de solo/sedimento. As razões $(\mathrm{Al} / \mathrm{Si})$ das 69 amostras, de 36 materiais de referência certificados e da crosta continental, foram utilizadas como variáveis nos intervalos $\mu \pm \sigma ; \mu \pm 2 \sigma$ e $\mu \pm 3 \sigma(68 \%, 95 \%$ e $99,7 \%)$ estabelecidos (Figura 22).

Os gráficos mostram que as razões das amostras, dos materiais de referência certificados e da crosta continental encontram-se no intervalo de $\mu \pm 2 \sigma$ (95\%), com exceção das amostras 34, 38, 66 e 67 e os materiais de referência certificados $72,102,124,126,127,132,140,141,150,152$ e 154, que estão no intervalo de $\mu \pm 3 \sigma(99,7 \%)$. Contudo, todos os materiais estão compreendidos entre o limite superior e inferior estabelecido; assim, classificando todas as amostras como solo/sedimento. 

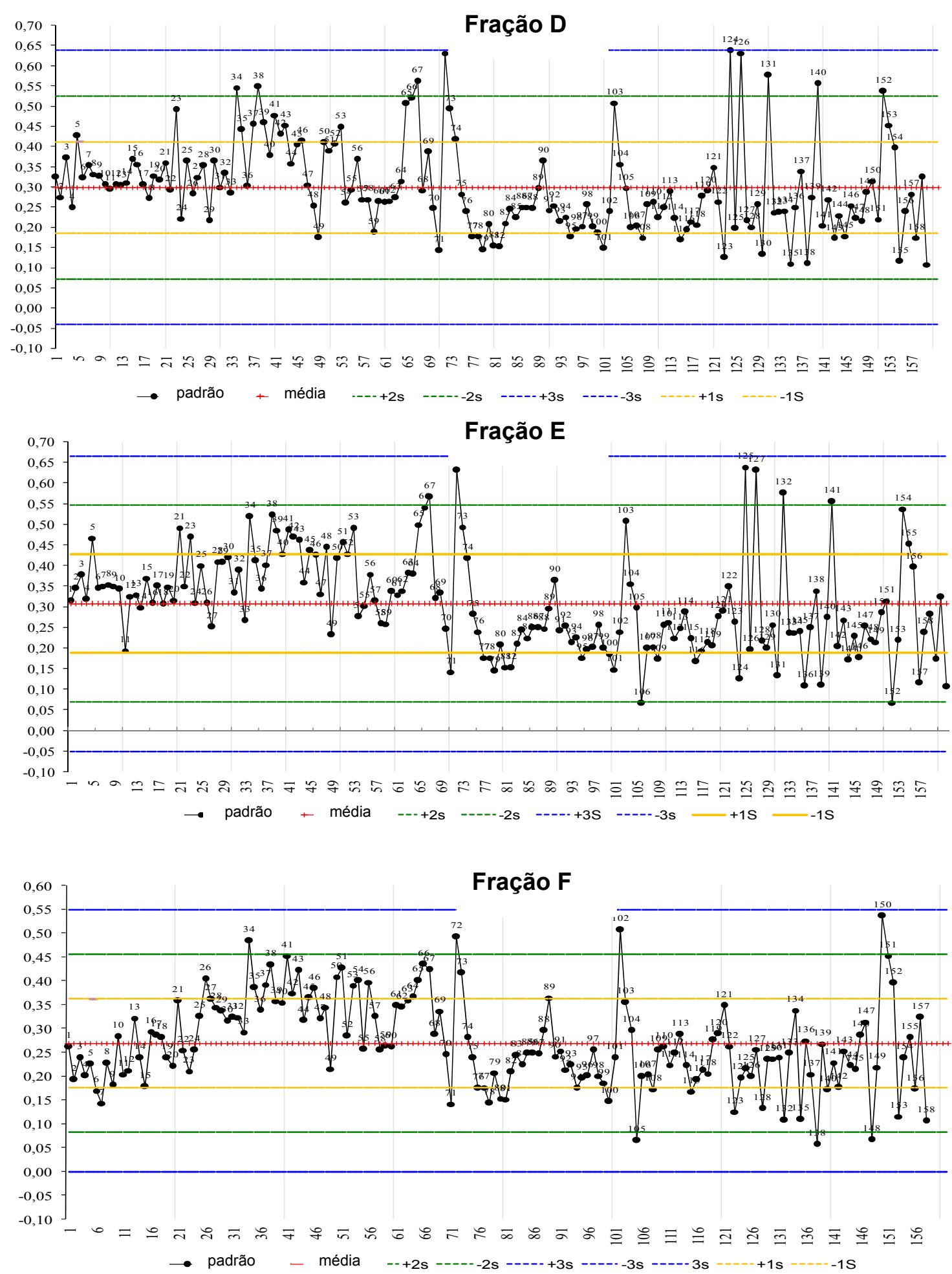

FIGURA 22 - Carta de controle das razões para as frações D, E e F 


\subsection{Determinação das fontes de contaminação por análises de fatores (AF) e cluster (AC);}

A análise de fatores (AF) foi aplicada para diferenciar fontes antropogênicas de naturais para as frações $\mathbf{D}, \mathbf{E}$ e $\mathbf{F}$, sobre base de dados com 23 variáveis (AG, $\mathrm{PF}, \mathrm{Si}, \mathrm{Ca}, \mathrm{Mg}, \mathrm{Al}, \mathrm{S}, \mathrm{Fe}, \mathrm{K}, \mathrm{Cl}, \mathrm{Na}, \mathrm{Zn}, \mathrm{Ti}, \mathrm{P}, \mathrm{Mn}, \mathrm{Cu}, \mathrm{Sr}, \mathrm{Cr}, \mathrm{Pb}, \mathrm{Zr}, \mathrm{Ni}, \mathrm{Br}$ e Rb) e 69 casos (amostras).

Com os dados da fração $\mathbf{D}$, os cálculos foram realizados para a extração dos autovalores da matriz de correlação, do número dos fatores loadings significantes, da porcentagem de variância e da comunalidade explicada por cada um dos parâmetros. Após a rotação VARIMAX, cinco fatores foram obtidos, explicando $81,5 \%$ da variabilidade dos dados. As comunalidades foram maiores que 0,7 ; o que indica que os fatores obtidos explicam maior parte da variabilidade de cada variável, porém isto não ocorreu para análise granulométrica, $A G(0,35)$ e perda de massa por queima, PF $(0,50)$. Cada fator é identificado como uma fonte ou processo de formação, pelas variáveis com loadings maiores que 0,7 (TAB. 16).

O fator 1 apresenta associação com os elementos $\mathrm{Si}, \mathrm{Ca}, \mathrm{Mg}, \mathrm{Al}, \mathrm{Fe}, \mathrm{K}, \mathrm{Ti}$, $\mathrm{Mn}$ e $\mathrm{Br}$ que são característicos de composição do solo (Mason, 1966). Portanto, pode ser classificado como fonte de resuspensão de solo ou transportado pelos moradores e ventilações. O fator 2 com $\mathrm{Cr}$ e $\mathrm{Pb}$ que são indicativos de contaminação por fontes antropogênicas, já que, são comumente utilizados em veículos automotores, baterias, soldas, pigmentos e outros aditivos de tintas (basicamente tintas anticorrosivas e de sinalização de segurança), vidros e cerâmicas, aditivos para PVC (ex. estearato de chumbo) e outros. O fator 3 apresenta associação dos elementos $\mathrm{S}, \mathrm{Cl}, \mathrm{Na}, \mathrm{Zn}, \mathrm{P}, \mathrm{Cu}$ e $\mathrm{Ni}$ são indícios de contaminação por fontes veiculares e contribuições marinhas. O fator 4, associação de $\mathrm{Sr}, \mathrm{Zr}$ e $\mathrm{Rb}$, característicos de fontes naturais do solo. $\mathrm{O}$ fator 5 , 
com análise granulométrica ( $A G$ ) e perda de massa por queima (PF), indica que quanto mais finas as frações menor a perda de massa.

TABELA 16 - Matriz de fatores loadings obtida a partir da análise de fatores (AF) da fração D

\begin{tabular}{|c|c|c|c|c|c|c|}
\hline \multirow{3}{*}{ Elementos } & \multicolumn{6}{|c|}{ Análise de fatores } \\
\hline & \multicolumn{6}{|c|}{ Fração D $(n=69)$} \\
\hline & 1 & 2 & 3 & 4 & 5 & Comunalidades \\
\hline$A G$ & $-0,237218$ & $-0,129435$ & $-0,194880$ & $-0,070731$ & $-0,645817$ & 0,35 \\
\hline PF & $-0,077789$ & 0,135155 & 0,181347 & 0,004757 & 0,814379 & 0,50 \\
\hline $\mathrm{Si}$ & 0,779860 & 0,076101 & 0,501352 & 0,127819 & $-0,009371$ & 0,97 \\
\hline $\mathrm{Ca}$ & 0,896468 & 0,121546 & 0,132497 & 0,117566 & 0,007021 & 0,94 \\
\hline $\mathrm{Mg}$ & 0,934417 & 0,009686 & 0,094327 & 0,148640 & $-0,013807$ & 0,97 \\
\hline $\mathrm{Al}$ & 0,782155 & 0,205629 & 0,471953 & 0,039372 & 0,059474 & 0,98 \\
\hline S & 0,393259 & 0,082334 & 0,653328 & 0,421648 & 0,139937 & 0,93 \\
\hline $\mathrm{Fe}$ & 0,740952 & 0,115108 & 0,549809 & 0,169763 & 0,042179 & 0,95 \\
\hline K & 0,655281 & 0,066691 & 0,576956 & $-0,009300$ & 0,097345 & 0,91 \\
\hline $\mathrm{Cl}$ & 0,400485 & 0,033017 & 0,794252 & 0,199283 & 0,202187 & 0,96 \\
\hline $\mathrm{Na}$ & 0,480817 & 0,084492 & 0,809244 & 0,089404 & 0,167897 & 0,97 \\
\hline $\mathrm{Zn}$ & 0,205767 & 0,076331 & 0,918257 & 0,147209 & 0,053319 & 0,97 \\
\hline $\mathrm{Ti}$ & 0,623034 & 0,514579 & 0,494410 & 0,125905 & 0,151130 & 0,97 \\
\hline$P$ & 0,339921 & 0,018493 & 0,767581 & 0,196479 & 0,152754 & 0,90 \\
\hline $\mathrm{Mn}$ & 0,752769 & 0,179023 & 0,471194 & 0,164139 & 0,103413 & 0,93 \\
\hline $\mathrm{Cu}$ & $-0,006042$ & 0,078709 & 0,789854 & $-0,104715$ & $-0,044140$ & 0,88 \\
\hline $\mathrm{Sr}$ & 0,532111 & $-0,045765$ & 0,334872 & 0,547395 & 0,146123 & 0,89 \\
\hline $\mathrm{Cr}$ & 0,141143 & 0,955923 & 0,099679 & 0,019286 & 0,049210 & 0,99 \\
\hline $\mathrm{Pb}$ & 0,038996 & 0,981826 & 0,033796 & 0,047011 & 0,075250 & 0,99 \\
\hline $\mathrm{Zr}$ & 0,068554 & 0,374156 & 0,151212 & 0,740041 & $-0,092513$ & 0,76 \\
\hline $\mathrm{Ni}$ & 0,537766 & 0,354456 & 0,621575 & 0,291903 & 0,008084 & 0,97 \\
\hline $\mathrm{Br}$ & 0,609852 & $-0,194290$ & 0,125704 & 0,367221 & $-0,058827$ & 0,76 \\
\hline $\mathrm{Rb}$ & 0,505830 & $-0,148073$ & 0,278499 & 0,646937 & 0,147040 & 0,83 \\
\hline Autovalor & 12,4 & 2,4 & 1,9 & 1,1 & 1,0 & Variância total \\
\hline \% Total de variância & 53,8 & 10,3 & 8,2 & 4,8 & 4,4 & 81,5 \\
\hline
\end{tabular}


A análise de fatores sobre base de dados da fração $E, 23$ variáveis ( $A G$, $\mathrm{PF}, \mathrm{Si}, \mathrm{Ca}, \mathrm{Mg}, \mathrm{Al}, \mathrm{S}, \mathrm{Fe}, \mathrm{K}, \mathrm{Cl}, \mathrm{Na}, \mathrm{Zn}, \mathrm{Ti}, \mathrm{P}, \mathrm{Mn}, \mathrm{Cu}, \mathrm{Sr}, \mathrm{Cr}, \mathrm{Pb}, \mathrm{Zr}, \mathrm{Ni}, \mathrm{Br}$ e Rb) e 69 amostras. Após a rotação VARIMAX, cinco fatores foram retidos, explicando $76,4 \%$ da variabilidade dos dados. As comunalidades foram sistematicamente maiores que 0,7 ; indicando que os fatores obtidos explicam a maior parte da variabilidade de cada variável, exceto para a análise granulométrica, $A G(0,39)$ e perda de massa por queima, $\operatorname{PF}(0,48)$, o $\operatorname{Zr}(0,51)$ e $\operatorname{Br}(0,62)$ (TAB. 17).

O fator 1 apresenta associação com Si, $\mathrm{Ca}, \mathrm{Mg}, \mathrm{Al}, \mathrm{Fe}, \mathrm{K}, \mathrm{Ti}, \mathrm{Mn}, \mathrm{Ni}$ e $\mathrm{Br}$, que são característicos de composição do solo (Mason, 1966). Portanto, pode-se classificar este fator como fonte de resuspensão de solo. $O$ fator 2 possui associação com os elementos $\mathrm{S}, \mathrm{Cl}, \mathrm{Na}, \mathrm{Zn}, \mathrm{P}$ e $\mathrm{Cu}$, os quais são indicativos de contaminação, que pode ter sido agregado à poeira por deposição seca ou úmida. Segundo a literatura o $\mathrm{Cu}$ foi identificado como produto de emissões em motores a diesel (Puri, et al., 1996); Cl e Na brisa marítima (Andrade, 1993); o Zn do desgaste das pastilhas de freio e pneus dos automóveis, bem como, das fachadas dos edifícios com revestimentos metálicos e o $\mathrm{S}$ da queima de combustíveis fósseis (Sweet e Gatz, 1998), um dos principais processos de formação destas partículas, na forma de sulfatos, sulfato de amônia e bissulfatos de amônia, é a partir da transformação gás partícula, na oxidação do $\mathrm{SO}_{2}$. $\mathrm{O}$ fator 3 apresenta associação com $\mathrm{Cr}$ e $\mathrm{Pb}$, indicando ser de uma fonte de poluição industrial, produto da queima de combustível veicular e/ou tintas de parede. O fator 4 é constituído por análise granulométrica e perda de massa por queima, indicando que as frações mais finas apresentam menor perda de massa. $O$ fator 5 possui associação com $\mathrm{Sr}$, $\mathrm{Zr}$ e $\mathrm{Rb}$ indicando ser de uma fonte natural. 
TABELA 17 - Matriz de fatores loadings obtida a partir da análise de fatores (AF) da fração $E$

\begin{tabular}{|c|c|c|c|c|c|c|}
\hline \multirow{3}{*}{ Elementos } & \multicolumn{6}{|c|}{ Análise de fatores } \\
\hline & \multicolumn{6}{|c|}{ Fração $E(n=69)$} \\
\hline & 1 & 2 & 3 & 4 & 5 & Comunalidades \\
\hline$A G$ & 0,096143 & $-0,379558$ & 0,009861 & $-0,635188$ & $-0,202387$ & 0,39 \\
\hline $\mathrm{PF}$ & $-0,071005$ & 0,206053 & $-0,057456$ & $-0,739222$ & 0,284149 & 0,48 \\
\hline $\mathrm{Si}$ & 0,899353 & 0,169826 & 0,033320 & $-0,139921$ & 0,251158 & 0,99 \\
\hline $\mathrm{Ca}$ & 0,837200 & 0,227393 & $-0,008790$ & 0,147700 & 0,149367 & 0,85 \\
\hline $\mathrm{Mg}$ & 0,832261 & $-0,095597$ & $-0,027571$ & $-0,257835$ & 0,101234 & 0,90 \\
\hline $\mathrm{Al}$ & 0,855800 & 0,252950 & 0,092059 & $-0,023410$ & 0,206215 & 0,99 \\
\hline$S$ & 0,329792 & 0,598392 & 0,016562 & 0,157661 & 0,212862 & 0,82 \\
\hline $\mathrm{Fe}$ & 0,825268 & 0,383762 & 0,078205 & 0,035337 & 0,277245 & 0,98 \\
\hline $\mathrm{K}$ & 0,591441 & 0,473949 & $-0,043051$ & 0,153950 & 0,275725 & 0,83 \\
\hline $\mathrm{Cl}$ & 0,311997 & 0,846757 & 0,033474 & 0,112252 & 0,243008 & 0,96 \\
\hline $\mathrm{Na}$ & 0,424490 & 0,821647 & 0,075104 & 0,137834 & 0,119481 & 0,96 \\
\hline $\mathrm{Zn}$ & 0,167328 & 0,923996 & $-0,001520$ & $-0,174923$ & $-0,051326$ & 0,97 \\
\hline $\mathrm{Ti}$ & 0,579627 & 0,532131 & 0,329151 & 0,152975 & 0,150820 & 0,91 \\
\hline $\mathrm{P}$ & 0,368220 & 0,708353 & 0,003145 & 0,193714 & 0,355506 & 0,89 \\
\hline $\mathrm{Mn}$ & 0,676039 & 0,360671 & 0,015235 & 0,086901 & 0,446849 & 0,88 \\
\hline $\mathrm{Cu}$ & $-0,108796$ & 0,790343 & $-0,038249$ & $-0,176504$ & $-0,269264$ & 0,94 \\
\hline $\mathrm{Sr}$ & 0,255638 & 0,069984 & $-0,141525$ & $-0,035533$ & 0,771545 & 0,86 \\
\hline $\mathrm{Cr}$ & 0,096988 & 0,076282 & 0,959993 & 0,054201 & 0,017084 & 0,95 \\
\hline $\mathrm{Pb}$ & $-0,071722$ & $-0,040285$ & 0,973525 & 0,001071 & 0,000060 & 0,95 \\
\hline $\mathrm{Zr}$ & 0,230586 & 0,068510 & 0,342387 & $-0,204565$ & 0,580305 & 0,51 \\
\hline $\mathrm{Ni}$ & 0,659290 & 0,491706 & 0,111191 & $-0,075060$ & 0,189331 & 0,92 \\
\hline $\mathrm{Br}$ & 0,588347 & 0,085393 & $-0,032870$ & 0,098860 & 0,096590 & 0,62 \\
\hline $\mathrm{Rb}$ & 0,404658 & 0,060199 & 0,039719 & 0,048819 & 0,752601 & 0,77 \\
\hline Autovalor & 10,1 & 2,8 & 2,1 & 1,3 & 1,3 & Variância total \\
\hline \% Total de variância & 44,1 & 12,0 & 9,2 & 5,6 & 5,5 & 76,4 \\
\hline
\end{tabular}


A análise de fatores sobre a base de dados da fração $F, 23$ variáveis (PF, $\mathrm{Si}, \mathrm{Ca}, \mathrm{Mg}, \mathrm{Al}, \mathrm{S}, \mathrm{Fe}, \mathrm{K}, \mathrm{Cl}, \mathrm{Na}, \mathrm{Zn}, \mathrm{Ti}, \mathrm{P}, \mathrm{Mn}, \mathrm{Cu}, \mathrm{Sr}, \mathrm{Cr}, \mathrm{Pb}, \mathrm{Zr}, \mathrm{Ni}, \mathrm{Br}$ e Rb) e 69 amostras. Após a rotação VARIMAX, cinco fatores foram retidos, explicando $79,1 \%$ da variabilidade dos dados. As comunalidades foram também sistematicamente maiores que 0,7 ; indicando que os fatores obtidos explicam a maior parte da variabilidade de cada variável, porém isto não ocorreu para análise granulométrica, $\operatorname{AG}(0,35)$ e perda de massa por queima, $\operatorname{PF}(0,47)$, o $\operatorname{Br}(0,60)$ e $\mathrm{Rb}(0,65)$. Cada fator é identificado como uma fonte ou processo de formação, pelas variáveis com loadings maiores que 0,7 (TAB. 18).

A associação dos elementos $\mathrm{Si}, \mathrm{Ca}, \mathrm{Al}, \mathrm{Fe}, \mathrm{Ti}, \mathrm{Mn}, \mathrm{Sr}$ e $\mathrm{Rb}$, também é verificado no fator 1 , que são característicos de composição do solo. O fator 2 é constituído por perda de massa por queima, $\mathrm{S}, \mathrm{K}, \mathrm{Cl}, \mathrm{Na}, \mathrm{P}, \mathrm{Zr}$ e $\mathrm{Ni}$, são indicativos de contaminação por fontes antropogênicas que estão agregados ao solo. O fator 3 apresenta associação com $\mathrm{Mg}, \mathrm{Cr}$ e $\mathrm{Br}$ atribuídos ao solo. $\mathrm{O}$ fator 4 com $\mathrm{Zn}$ e $\mathrm{Cu}$, indicativo de contaminação, já que, de acordo com a literatura foram identificados como produto de emissões em motores a diesel e desgaste de peças (Puri, et. al., 1996). O fator 5 análise granulométrica e $\mathrm{Pb}$, indicativo de contaminação por fontes antropogênicas como tintas utilizadas nas paredes das residências e está agregado na fração mais fina. 
TABELA 18 - Matriz de fatores loadings obtida a partir da análise de fatores (AF) da fração $\mathbf{F}$

\begin{tabular}{|c|c|c|c|c|c|c|}
\hline \multirow{3}{*}{ Elementos } & \multicolumn{6}{|c|}{ Análise de fatores } \\
\hline & \multicolumn{6}{|c|}{ Fração F $(n=69)$} \\
\hline & 1 & 2 & 3 & 4 & 5 & Comunalidades \\
\hline$A G$ & $-0,225081$ & $-0,325648$ & 0,318585 & $-0,077844$ & $-0,435595$ & 0,35 \\
\hline PF & 0,136204 & 0,582704 & $-0,047685$ & 0,018582 & 0,093903 & 0,47 \\
\hline $\mathrm{Si}$ & 0,682841 & 0,125754 & 0,611104 & 0,082667 & 0,303921 & 0,99 \\
\hline $\mathrm{Ca}$ & 0,907410 & 0,125487 & 0,191926 & $-0,024825$ & 0,122988 & 0,92 \\
\hline $\mathrm{Mg}$ & 0,203251 & $-0,230922$ & 0,843902 & 0,013375 & $-0,030749$ & 0,96 \\
\hline $\mathrm{Al}$ & 0,697141 & 0,284241 & 0,392841 & 0,100214 & 0,438244 & 0,99 \\
\hline S & 0,223350 & 0,617635 & 0,095231 & 0,032975 & 0,093283 & 0,87 \\
\hline $\mathrm{Fe}$ & 0,632354 & 0,468707 & 0,263632 & 0,172913 & 0,475579 & 0,98 \\
\hline K & 0,554323 & 0,607819 & 0,288917 & 0,083318 & 0,019679 & 0,90 \\
\hline $\mathrm{Cl}$ & 0,105623 & 0,884471 & 0,032925 & 0,284586 & 0,160639 & 0,98 \\
\hline $\mathrm{Na}$ & 0,126634 & 0,741947 & 0,040802 & 0,437025 & 0,318729 & 0,98 \\
\hline $\mathrm{Zn}$ & $-0,002294$ & 0,225668 & 0,007927 & 0,960320 & 0,056667 & 1,00 \\
\hline $\mathrm{Ti}$ & 0,658967 & 0,568805 & 0,169704 & 0,065673 & 0,394151 & 0,97 \\
\hline$P$ & 0,368012 & 0,811924 & 0,181779 & 0,141024 & 0,147976 & 0,90 \\
\hline $\mathrm{Mn}$ & 0,820322 & 0,461341 & 0,148974 & 0,007928 & 0,122453 & 0,95 \\
\hline $\mathrm{Cu}$ & $-0,021640$ & 0,153428 & $-0,053926$ & 0,969572 & 0,013698 & 1,00 \\
\hline $\mathrm{Sr}$ & 0,914785 & 0,185609 & $-0,044738$ & $-0,052526$ & 0,005868 & 0,94 \\
\hline $\mathrm{Cr}$ & 0,299110 & 0,386209 & 0,741840 & 0,054644 & 0,265249 & 0,92 \\
\hline $\mathrm{Pb}$ & 0,143562 & 0,207454 & 0,163814 & 0,051925 & 0,816970 & 0,71 \\
\hline $\mathrm{Zr}$ & 0,514665 & 0,534241 & 0,073896 & 0,076699 & 0,118722 & 0,84 \\
\hline $\mathrm{Ni}$ & 0,261582 & 0,609397 & 0,497964 & 0,227331 & 0,358196 & 0,96 \\
\hline $\mathrm{Br}$ & $-0,057118$ & 0,411700 & 0,660714 & $-0,207282$ & $-0,070128$ & 0,60 \\
\hline $\mathrm{Rb}$ & 0,569595 & 0,103152 & $-0,046713$ & $-0,061015$ & 0,501085 & 0,65 \\
\hline Autovalor & 11,0 & 2,9 & 1,9 & 1,4 & 1,0 & Variância total \\
\hline \% Total de variância & 47,7 & 12,6 & 8,2 & 6,1 & 4,4 & 79,1 \\
\hline
\end{tabular}


A análise por agrupamento (Cluster) de variáveis foi realizada sobre as mesmas bases de dados utilizadas para a AF. Os dendogramas (FIGs. 23, 24 e 25) mostram graficamente o resultado da análise por agrupamento, fornecendo uma idéia qualitativa do grau de associação entre os elementos da poeira doméstica, para as três frações.

Antes da análise de cluster (AC), as variáveis foram padronizadas pelas médias de Z-scores; e as distâncias Euclediana para similaridade nas variáveis foram calculadas. Finalmente, um agrupamento hierárquico por meio do método Ward's foi determinado com o conjunto de dados padronizados. A distância de cluster representa o grau de associação entre os elementos, quanto menor o valor mais significante a associação.

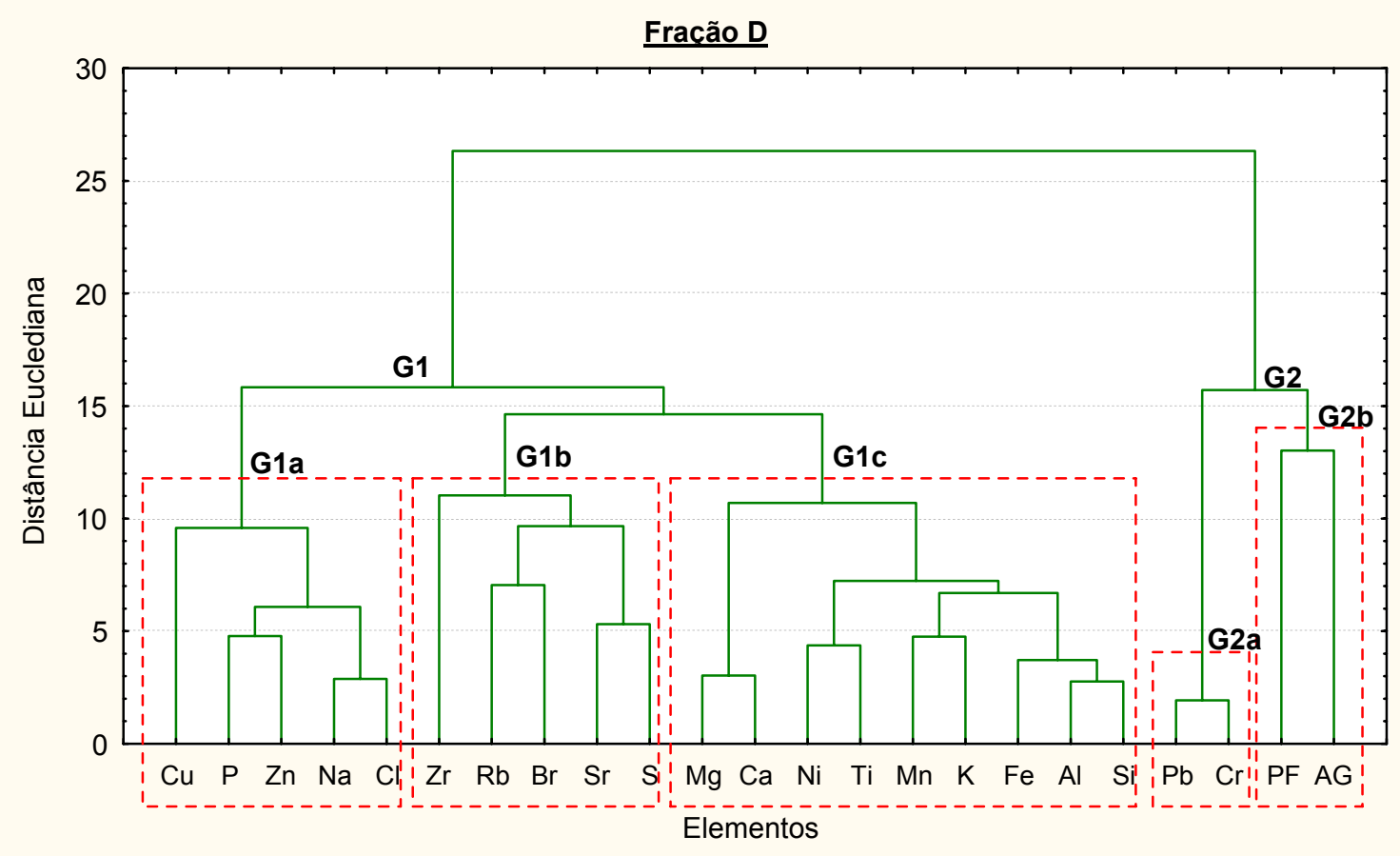

FIGURA 23 - Dendograma do resultado do método Ward's de análise de cluster hierárquico para as três frações $\mathbf{D}$ 


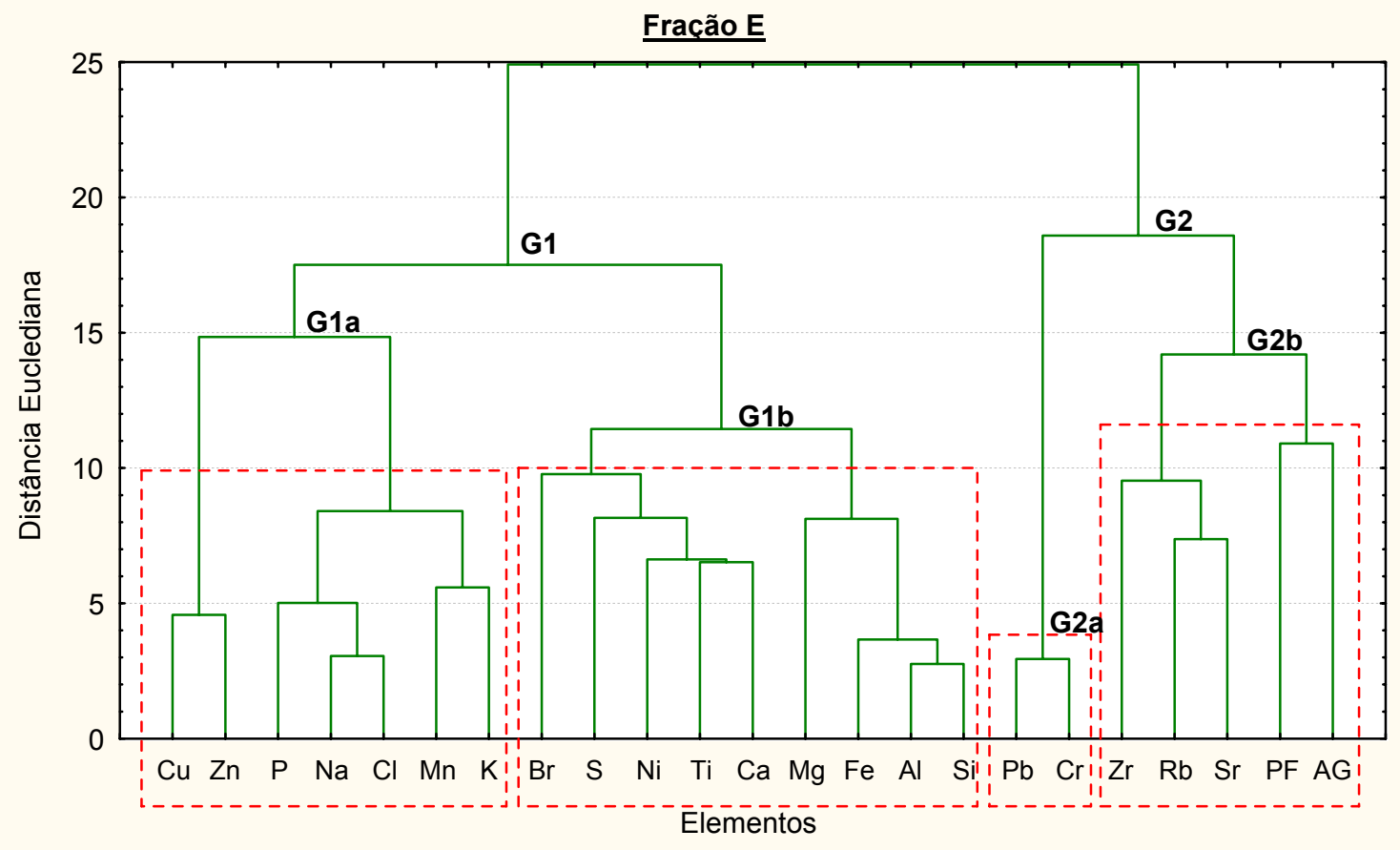

FIGURA 24- Dendograma do resultado do método Ward's de análise de cluster hierárquico para as três frações $\mathbf{E}$

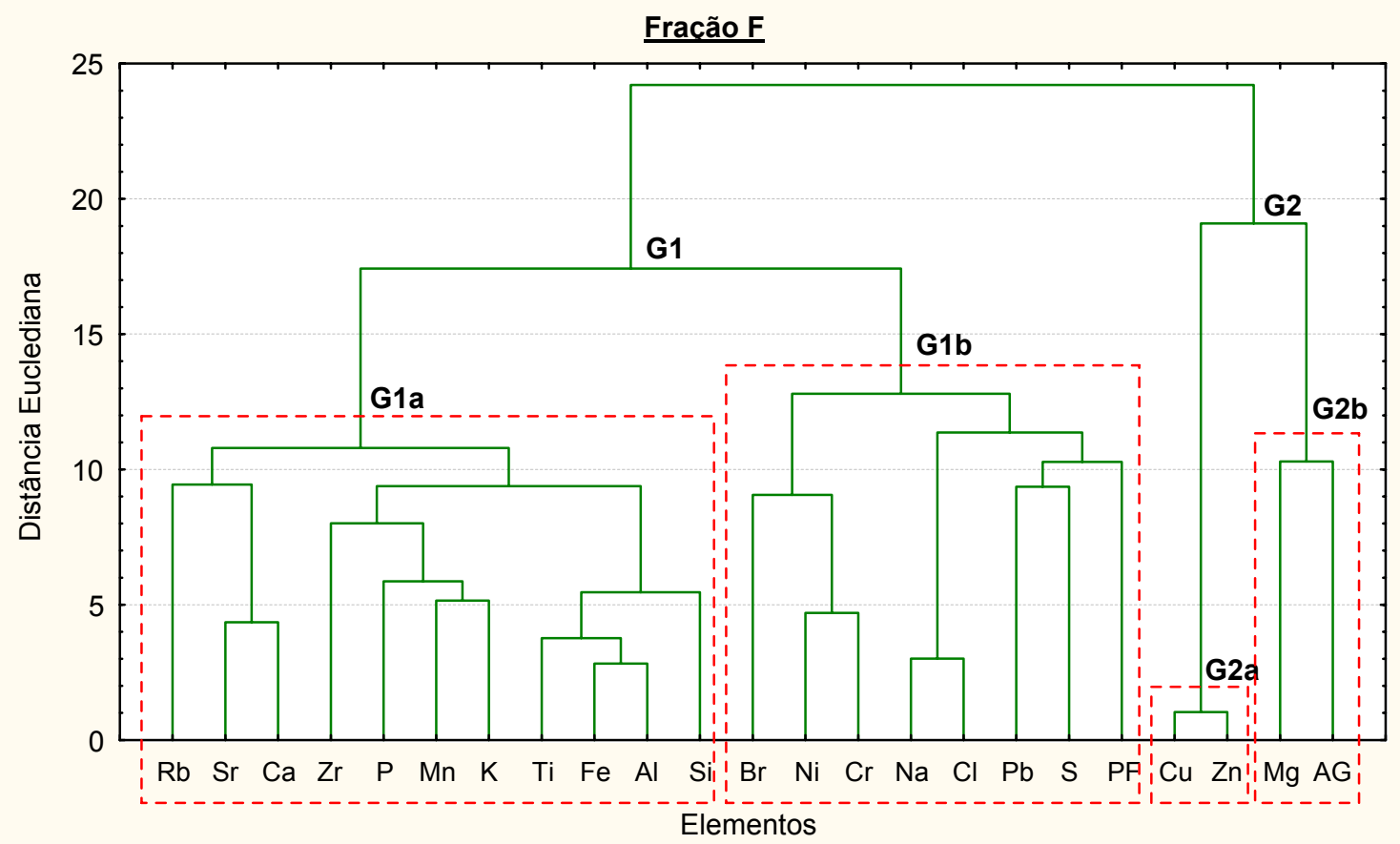

FIGURA 25- Dendograma do resultado do método Ward's de análise de cluster hierárquico para as três frações $\mathbf{F}$ 
A poeira doméstica, das frações $\mathbf{D}, \mathbf{E}$ e $\mathbf{F}$, foram identificadas por duas distâncias de cluster G1 e G2, subdividindo-se em, G1a, G1b, G1c, G2a e G2b.

\section{Fração D (FIG. 23)}

- G1a: contém Cu, P, Zn, Na e Cl. Este grupo de elementos reflete a grande influência de fontes antropogênicas como partículas geradas do tráfego veicular. Segundo Jiries et al., (2002 e 2003), o Zn e o Cu podem ser derivados do desgaste mecânico dos veículos (pneus, banhos metálicos, desgaste de pastilha de freios e queima de combustível). Além disso, o desgaste de aterfatos e/ou objetos domésticos a base de plásticos, borrachas, vidros e cerâmicas que podem influenciar no enriquecimento dos poluentes na poeira. Os elementos $\mathrm{Na}$ e $\mathrm{Cl}$ caracteriza a influência marítima que atravessa a cidade no final da tarde (Andrade et al., 1993).

- G1b: contém Zr, Rb, Br, Sr e S. Este grupo apresenta elementos característicos do solo, no entanto, a forte correlação entre $\mathrm{Sr}$ e $\mathrm{S}$ é um sinal de contaminação causada pela queima de combustíveis fósseis (Sweet e Gatz, 1998);

- G1c: Mg, Ca, Ni, Ti, Mn, K, Fe, Al e Si, estes elementos podem ser de origem natural, uma vez que, são constituintes da composição química do solo (Mason, 1966). No entanto, a associação entre Ti e Ni pode refletir a contribuição de algumas atividades antropogênicas e/ou natural, já que, comparando as concentrações com o do fator de enriquecimento, há contaminação do $\mathrm{Ni}$ nas amostras de poeira doméstica;

- G2a: contém $\mathrm{Pb}$ e $\mathrm{Cr}$, esta associação reflete a grande influência de fontes antropogênicas no ambiente domestico. Segundo a literatura (Lu et al., 2003; Imperato et al., 2003), isto pode ser atribuído a queima de gasolina, contendo uma 
substância anti-detonante, denominada chumbo tetraetila. No Brasil essa substância foi substituída pelo álcool, deixando de ser um dos principais responsáveis pela contaminação veicular. $\mathrm{O} \mathrm{Pb}$ é um dos metais tóxicos que apresenta menor mobilidade (Kabata-Pendias e Pendias, 1984) e as quantidades determinadas nas amostras de poeira podem estar relacionadas com as deposições no solo ocorridas antes da substituição do $\mathrm{Pb}$ da gasolina. Além disso, sua presença pode ser proveniente de produtos domésticos como inseticidas, tintas, cerâmicas, vidros, impermeabilização, soldas e baterias. O elemento $\mathrm{Cr}$ indica ser de origem antropogênica, uma vez que, ele é usado por várias indústrias na manufatura de porcelana, móveis de madeira, componentes eletroeletrônicos e outros;

- G2b: perda de massa por queima (PF) e análise granulométrica (AG), este grupo indica que de quanto menor a fração granulométrica, menor também a perda de massa por queima, já que, as amostras de poeira na fração $\mathbf{D}$ são qualificadas como solo e que seus maiores constituintes são inorgânicos.

\section{Fração E (FIG. 24)}

- G1a: contém $\mathrm{Cu}, \mathrm{Zn}, \mathrm{P}, \mathrm{Na}, \mathrm{Cl}, \mathrm{Mn}$ e K. Este apresenta elementos característicos do solo, no entanto, a correlação entre $\mathrm{Cu}$ e $\mathrm{Zn}$ é um sinal de contaminação (Galego et al., 2002; Manta et al., 2002; Li et al., 2004), o qual pode ter sido agregado à poeira por deposição úmida ou seca. A associação entre $\mathrm{Na} e$ $\mathrm{Cl}$, caracteriza a influência marítima na cidade;

- G1b: Br, S, Ni, Ti, Ca, Mg, Fe, Al e Si. Este grupo é típico da composição do solo, o qual pode ser transportado pelos calçados e roupas dos ocupantes de ambientes externos para os internos, bem como, as partículas depositadas trazidas pelo ar. A associação entre S e Ni dependendo de suas concentrações, 
estes elementos podem estar associados à contaminação antrópica dos solos urbanos;

- G2a: contém $\mathrm{Pb}$ e $\mathrm{Cr}$, estes elementos são fortes indicativos de fontes antropogênicas agregados a poeira;

- G2b: Zr, Rb, Sr, PF e AG, estes elementos são característicos da composição do solo; e suas associações com a perda de massa por queima e análise granulométrica condizem com a hipótese de que os metais tem maior afinidade com as frações mais finas;

\section{Fração F (FIG. 25)}

- G1a: contém Rb, Sr, Ca, Zr, P, Mn, K, Ti, Fe, Al e Si. Este grupo de elementos é constituinte da composição do solo;

- G1b: $\mathrm{Br}, \mathrm{Ni}, \mathrm{Cr}, \mathrm{Na}, \mathrm{Cl}, \mathrm{Pb}, \mathrm{S}$ e PF, este grupo apresenta elementos característicos do solo, entretanto, a associação entre $\mathrm{Ni}$ e $\mathrm{Cr}$, indica possíveis contaminação por fontes antropogênicas. Os elementos $\mathrm{Na}$ e $\mathrm{Cl}$ indica influência da brisa do mar;

- G2a: contém $\mathrm{Cu}$ e $\mathrm{Zn}$, este grupo reflete a grande influência das fontes antropogênicas na poeira. Isto, é corroborado pelas altas concentrações de massa relativa e real e o fator de enriquecimento;

- G2b: Mg e AG, esta associação confere a tendência de que os metais ficam retidos nas frações mais finas. 


\subsection{Determinação dos níveis de exposição para ingestão, inalação e contato dérmico}

Os tópicos anteriores permitiram verificar a ocorrência de contaminação no ambiente interno residencial por substâncias potencialmente tóxicas e associá-las as possíveis fontes de poluição. A exposição humana frente a estes contaminantes, seja por inalação, ingestão ou contacto com a pele, pode acarretar efeitos adversos à saúde, em especial as crianças, já que, em termos de absorção por peso corporal, elas ingerem maiores quantidades de metais quando comparadas a um adulto.

Em vista disso, os teores de $\mathrm{Ni}, \mathrm{Zn}, \mathrm{Cu}, \mathrm{Pb}$ e $\mathrm{Cr}$ (TAB. 7, p. 85) e dos ésteres ftálicos DEHP, DnBP, DEP, DEHA, BBP e DMP (TAB. 10, p. 88) foram convertidos para níveis de concentração por dia ( $\mu \mathrm{g} \mathrm{g}^{-1}$ dia) (TAB. 19). Estes valores foram comparados com os de exposição total (soma de todas as vias de contaminação), ingestão diária tolerável (TDI) e valores de risco.

A exposição total foi calculada somando as três vias de contaminação ingestão, inalação e contato dérmico (APÊNDICE L, p. 147, 148 e 149) para os ambientes internos. Os parâmetros utilizados para base de cálculos são os reportados pela CETESB (2005) (ANEXO D, p. 168). Na Tabela 20, são apresentados os valores de exposição total para adultos e crianças com massa corporal de 60 e $15 \mathrm{~kg}$, respectivamente, em ambientes internos, os de ingestão diária tolerável (TDI) e os valores de risco. 
TABELA 19 - Média aritmética $(\overline{\mathrm{X}})$ e intervalo de concentração (IC) de 69 amostras de poeira doméstica, nas frações $\mathbf{D}, \mathbf{E}$ e $\mathbf{F}$, em $\mu \mathrm{g} \mathrm{g}^{-1}$ por dia

\begin{tabular}{lcccccc}
\hline \multirow{2}{*}{ Elementos } & \multicolumn{7}{c}{$\overline{\mathbf{X}}$} \\
\cline { 2 - 7 } & $\mathbf{D}$ & $\mathbf{E}$ & $\mathbf{F}$ & $\mathbf{D}$ & $\mathbf{E}$ & $\mathbf{F}$ \\
\hline $\mathrm{Zn}$ & $0,71 \pm 0,87$ & $0,41 \pm 0,43$ & $1,9 \pm 2,0$ & $0,06-4,9$ & $0,04-3$ & $0,1-11$ \\
$\mathrm{Cu}$ & $0,24 \pm 0,36$ & $0,18 \pm 0,26$ & $1,2 \pm 2,3$ & $0,01-2,1$ & $0,02-1,4$ & $0,03-16$ \\
$\mathrm{~Pb}$ & $0,08 \pm 0,18$ & $0,08 \pm 0,19$ & $0,2 \pm 0,4$ & $0,0003-1,4$ & $0,002-1,3$ & $0,01-3$ \\
$\mathrm{Cr}$ & $0,06 \pm 0,07$ & $0,05 \pm 0,08$ & $0,1 \pm 0,1$ & $0,001-0,4$ & $0,003-0,6$ & $0,02-1$ \\
$\mathrm{Ni}$ & $0,06 \pm 0,12$ & $0,03 \pm 0,04$ & $0,1 \pm 0,2$ & $0,004-0,8$ & $0,003-0,3$ & $0,01-6$ \\
DEHP & $* * *$ & $* * *$ & $8,5 \pm 18,0$ & $* * *$ & $* * *$ & $0,3-118,6$ \\
DnBP & $* * *$ & $* * *$ & $3,04 \pm 8,76$ & $* * *$ & $* * *$ & $0,1-71,4$ \\
DEP & $* * *$ & $* * *$ & $0,2 \pm 0,3$ & $* * *$ & $* * *$ & $0,01-1,91$ \\
DEHA & $* * *$ & $* * *$ & $0,2 \pm 0,6$ & $* * *$ & $* * *$ & $0,02-4,74$ \\
BBP & $* * *$ & $* * *$ & $0,1 \pm 0,4$ & $* * *$ & $* * *$ & $0,002-3,049$ \\
DMP & $* * *$ & $* * *$ & $0,2 \pm 1,2$ & $* * *$ & $* * *$ & $0,002-9,53$ \\
\hline$* * *$ análises não realizadas por GCMS em amostras de poeira doméstica para as frações D e F &
\end{tabular}

Os teores determinados por dia de $\mathrm{Zn}, \mathrm{Cu}, \mathrm{Pb}, \mathrm{Cr}$ e Ni aumentam da fração grossa para a mais fina, permanecendo mais concentrados na fração $\mathbf{F}$. Este evento pode ser comparado com a literatura (Lisiewicz et al., 2000), aonde foi constatado que os teores desses elementos aumentam com a diminuição do tamanho de partícula da poeira. Este fato, confirma a hipótese da poeira ser um repositório de substâncias potencialmente tóxicas; tornando uma significante fonte de exposição aos seres humanos. 
TABELA 20 - Valores das vias de exposição total, ingestão diária tolerável (TDI) e risco para adultos e crianças (CETESB, 2001)

\begin{tabular}{|c|c|c|c|c|c|c|c|c|c|c|c|c|}
\hline \multirow{4}{*}{ Cont. } & \multirow{3}{*}{$\bar{X}$} & \multicolumn{8}{|c|}{ Vias de exposição } & \multirow{3}{*}{ TDI } & \multirow{2}{*}{\multicolumn{2}{|c|}{ Risco }} \\
\hline & & \multicolumn{2}{|c|}{ Contato dérmico } & \multicolumn{2}{|c|}{ Inalação } & \multicolumn{2}{|c|}{ Ingestão } & \multicolumn{2}{|c|}{ Exposição Total (TE) } & & & \\
\hline & & Adulto & Criança & Adulto & Criança & Adulto & Criança & Adulto & Criança & & Adulto & Criança \\
\hline & \multicolumn{12}{|c|}{$\mu \mathrm{g} \mathrm{g}^{-1}$ por dia } \\
\hline $\mathrm{Zn}$ & $1,9 \pm 2,0$ & $5,7810^{-01}$ & $1,7210^{-04}$ & $1,3510^{-06}$ & $5,2510^{-06}$ & $2,3910^{-05}$ & $2,4310^{-4}$ & $2,5810^{-05}$ & $4,2010^{-04}$ & 0,005 & 0,0006 & 0,008 \\
\hline $\mathrm{Cu}$ & $1,2 \pm 2,3$ & $2,8910^{-06}$ & $8,6010^{-04}$ & $2,3610^{-06}$ & $2,3610^{-06}$ & $1,1910^{-4}$ & $1,2210^{-3}$ & $1,2510^{-04}$ & $2,0810^{-03}$ & 1,0 & 0,0001 & 0,002 \\
\hline $\mathrm{Pb}$ & $0,2 \pm 0,4$ & $1,4410^{-06}$ & $4,3010^{-04}$ & $3,3710^{06}$ & $2,1910^{-06}$ & $5,9710^{-05}$ & $6,0810^{-4}$ & $6,4510^{-05}$ & $1,0410^{-03}$ & 0,14 & 0,0004 & 0,007 \\
\hline $\mathrm{Cr}$ & $0,1 \pm 0,1$ & $1,0110^{-06}$ & $3,0110^{-04}$ & $2,3610^{-06}$ & $1,5310^{-06}$ & $4,1810^{-05}$ & $4,2510^{-4}$ & $4,5210^{-05}$ & $7,3010^{-04}$ & 0,036 & 0,01 & 0,2 \\
\hline $\mathrm{Ni}$ & $0,1 \pm 0,2$ & $2,0210^{-06}$ & $6,0210^{-04}$ & $4,7210^{-06}$ & $1,8410^{-06}$ & $8,3610^{-05}$ & $8,5110^{-4}$ & $9,0310^{-05}$ & $1,4510^{-03}$ & 0,005 & 0,02 & 0,2 \\
\hline DEHP & $8,5 \pm 18,0$ & & & & & & & & & 50 & & \\
\hline $\mathrm{DnBP}$ & $3,04 \pm 8,76$ & & & & & & & & & 52 & & \\
\hline DEP & $0,2 \pm 0,3$ & & & & & & & & & 200 & & \\
\hline DEHA & $0,2 \pm 0,6$ & & & & & & & & & n.a.* & & \\
\hline BBP & $0,1 \pm 0,4$ & & & & & & & & & 500 & & \\
\hline DMP & $0,2 \pm 1,2$ & & & & & & & & & n.a.* & & \\
\hline
\end{tabular}


Os resultados indicam que os elementos $\mathrm{Zn}\left(1,9 \pm 2,0 \mu \mathrm{g} \mathrm{g}^{-1} \mathrm{dia}^{-1}\right)$, Cu $\left(1,2 \pm 2,3 \mu \mathrm{g} \mathrm{g}^{-1} \mathrm{dia}^{-1}\right), \mathrm{Pb}\left(0,2 \pm 0,4 \mu \mathrm{g} \mathrm{g}^{-1} \mathrm{dia}^{-1}\right), \mathrm{Cr}\left(0,1 \pm 0,1 \mu \mathrm{g} \mathrm{g}^{-1} \mathrm{dia}^{-1}\right)$ e $\mathrm{Ni}$ $\left(0,1 \pm 0,2 \mu \mathrm{g} \mathrm{g}^{-1} \mathrm{dia}^{-1}\right)$ apresentam valores maiores que o de exposição total para adultos (Zn: 2,58 10-05; Cu: 1,25 10- ${ }^{04}$; Pb: 6,45 10-05; Cr: 4,52 10-05 e Ni: 9,03 10-05 $\mu \mathrm{g} \mathrm{g}^{-1}$ dia $\left.^{-1}\right)$, variando da ordem de 664 a 3721 vezes maior; e crianças ( $\mathrm{Zn}: 4,20$

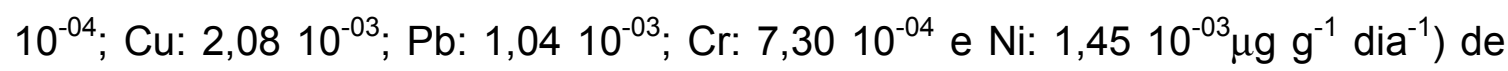
ambientes internos, da ordem de 34 a 1154 vezes maior (TAB. 20).

Em relação com os valores de ingestão diária tolerável (TDI), as concentrações diárias dos elementos citados acima se mostram também elevados, com exceção do $\mathrm{Cu}$ e $\mathrm{Pb}$ para as frações $\mathbf{D}\left(0,24\right.$ e $0,08 \mu \mathrm{g} \mathrm{g}^{-1}$ dia $\left.^{-1}\right)$ e $\mathbf{E}$ $\left(0,18\right.$ e $\left.0,08 \mu \mathrm{g} \mathrm{g}^{-1} \mathrm{dia}^{-1}\right)$; cujos valores são menores que TDI $\left(1,0\right.$ e $\left.0,14 \mu \mathrm{g} \mathrm{g}^{-1} \mathrm{dia}^{-1}\right)$.

Em relação aos valores de risco pode ser verificado que os teores dos elementos $\mathrm{Zn}, \mathrm{Cu}, \mathrm{Pb}, \mathrm{Cr}$ e $\mathrm{Ni}$ (três frações), estão acima para adultos ( $\mathrm{Zn}$ : 0,0006, Cu: 0,0001, Pb: 0,0004, Cr: 0,01 e Ni: 0,02 $\mu \mathrm{g} \mathrm{g}^{-1}$ dia $\left.^{-1}\right)$ e crianças (Zn: 0,008, $\mathrm{Cu}: 0,002$ e $\mathrm{Pb}: 0,007 \mu \mathrm{g} \mathrm{g}^{-1} \mathrm{dia}^{-1}$ ), enquanto que $\mathrm{Cr}$ e $\mathrm{Ni}$ são menores somente para as crianças.

Os cálculos para exposição total e de risco para os compostos orgânicos não foram possíveis de serem realizados, porque a CETESB não dispõe de dados. A comparação dos ésteres ftálicos somente foi realizada com os valores de TDI, a qual mostra que os valores de DEHP, DnBP, DEP, DEHA, BBP e DMP estão inferiores aos de TDI. Contudo, estes compostos encontram-se presentes em todas as amostras, confirmando o seu desprendendo dos artefatos domésticos aos quais as pessoas têm acesso diariamente. 


\subsection{Mapas de distribuição}

Os Mapas de distribuição construídos, por modelagem geoestatística (Surfer 8, p. 72), para as frações 150-75 $\mu \mathrm{m}$ (D) e <63 $\mu \mathrm{m}$ (F) mostram, por meio do gradiente de cor, os bairros que apresentam maior contaminação de $\mathrm{Ni}, \mathrm{Zn}, \mathrm{Cu}$, $\mathrm{Pb}, \mathrm{Cr}$, S e P (FIGs. 26, 27, 28, 29, 30, 31 e 32, respectivamente) e de DEHP e DnBP, DEP e DEHA e BBP e BMP sequencialmente os bairros de Pirituba (PI), Freguesia do Ó (FO), Jaraguá (JA) e Perus (PE) (FIGs. 33a e b, 34a e b e 35a e b, respectivamente).

Em relação à fração $D$, pode ser observado (FIGs 26, 27, 28, 29, 30 e 31), que o bairro de Perus apresenta contaminação de $\mathrm{Ni}, \mathrm{Zn}, \mathrm{Cu}, \mathrm{Pb}, \mathrm{Cr}$ e $\mathrm{S}$. Este fato, deve estar associado à sua proximidade com as rodovias dos Bandeirantes, Anhanguera e rodoanel Mario Covas, aonde o tráfego veicular é intenso e, consequentemente, a contaminação da poeira doméstica pode ser atribuída à quantidade de resíduos, a principal fonte de fragmentos provenientes do desgaste peças automotivos (pneus, freios e outros); bem como, da queima de combustível. Nesta mesma fração, pode ser observado (FIG. 32), o enriquecimento de P no bairro do Jaraguá. Este fato pode estar relacionado a uma reserva ecológica, consequentemente, uma área considerável não pavimentada e edificada; portanto, a principal fonte pode ser associada ao solo.

Em relação à fração $\mathbf{F}$, pode ser verificado que a contaminação por $\mathrm{Zn}, \mathrm{Cu}$ e S (FIGs 27, 28 e 31, respectivamente), ocorre no bairro de Perus; e a contaminação está associada à fonte veicular.

O bairro de Pirituba mostra a contaminação de Ni e Cr (FIGs. 26 e 30). Esta contaminação pode estar relacionada também a fontes veiculares, por situar-se muito próximos as marginais e a estação ferroviária. 
O bairro do Jaraguá apresenta contaminação de P e Pb (FIGs. 32 e 29). O $\mathrm{P}$ pode ser atribuído a reserva ecológica, ou seja, a principal fonte pode ser associada ao solo. No entanto, para o $\mathrm{Pb}$, a fonte mais provável de contaminação esteja relacionada com os artefatos interno das residências, especialmente nos produtos cerâmicos, tintas, vidros e outros.

Os mapas construídos para a avaliação da contaminação por ésteres ftálicos mostram que o bairro da Freguesia do Ó é o mais contaminado por DEHP, DEP e DEHA (FIGs 33a, 34a e 34b, respectivamente). A fonte mais provável de contaminação pode ser relacionada à migração destes compostos do desgaste de equipamentos eletro-eletrônicos, a forte indicação baseia-se no maior poder aquisitivo deste bairro e a existência de um número maior de equipamentos eletrônicos em suas residências.

Para os compostos DnBP, BBP e DMP, é verificada a contaminação nos bairros de Perus, Jaraguá e Pirituba (FIGs. 33b, 35a e 35b, respectivamente). A provável fonte de contaminação também está relacionada ao desprendimento destes compostos dos artefatos presentes nas residências. Estes compostos são normalmente utilizados em materiais plásticos mais baratos e os residentes destes bairros, possuem poder aquisitivo, consideravelmente, menor que os do bairro da Freguesia do Ó. 


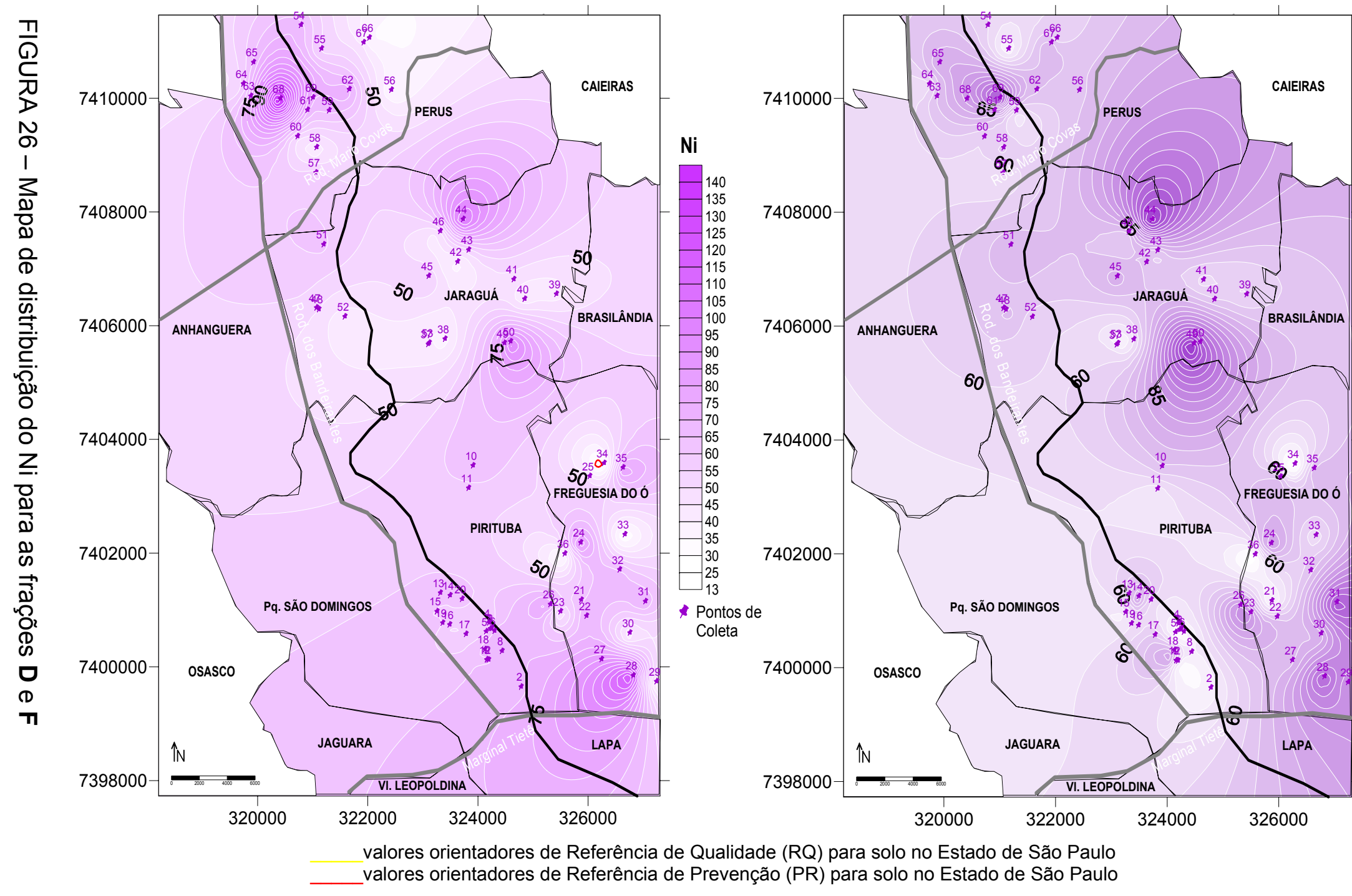

$\mathrm{Ni}$

\begin{tabular}{|l|l|}
\hline 135 \\
\hline 130 \\
125 \\
120 \\
120 \\
115 \\
110 \\
\hline 105 \\
\hline 100 \\
\hline 95 \\
\hline 90 \\
\hline 85 \\
\hline 80 \\
\hline 75 \\
\hline 70 \\
\hline 65 \\
\hline 60 \\
\hline 55 \\
\hline 50 \\
\hline 45 \\
\hline 40 \\
\hline 35 \\
\hline 30 \\
\hline 13 \\
\hline * Pontos de \\
Coleta
\end{tabular} 

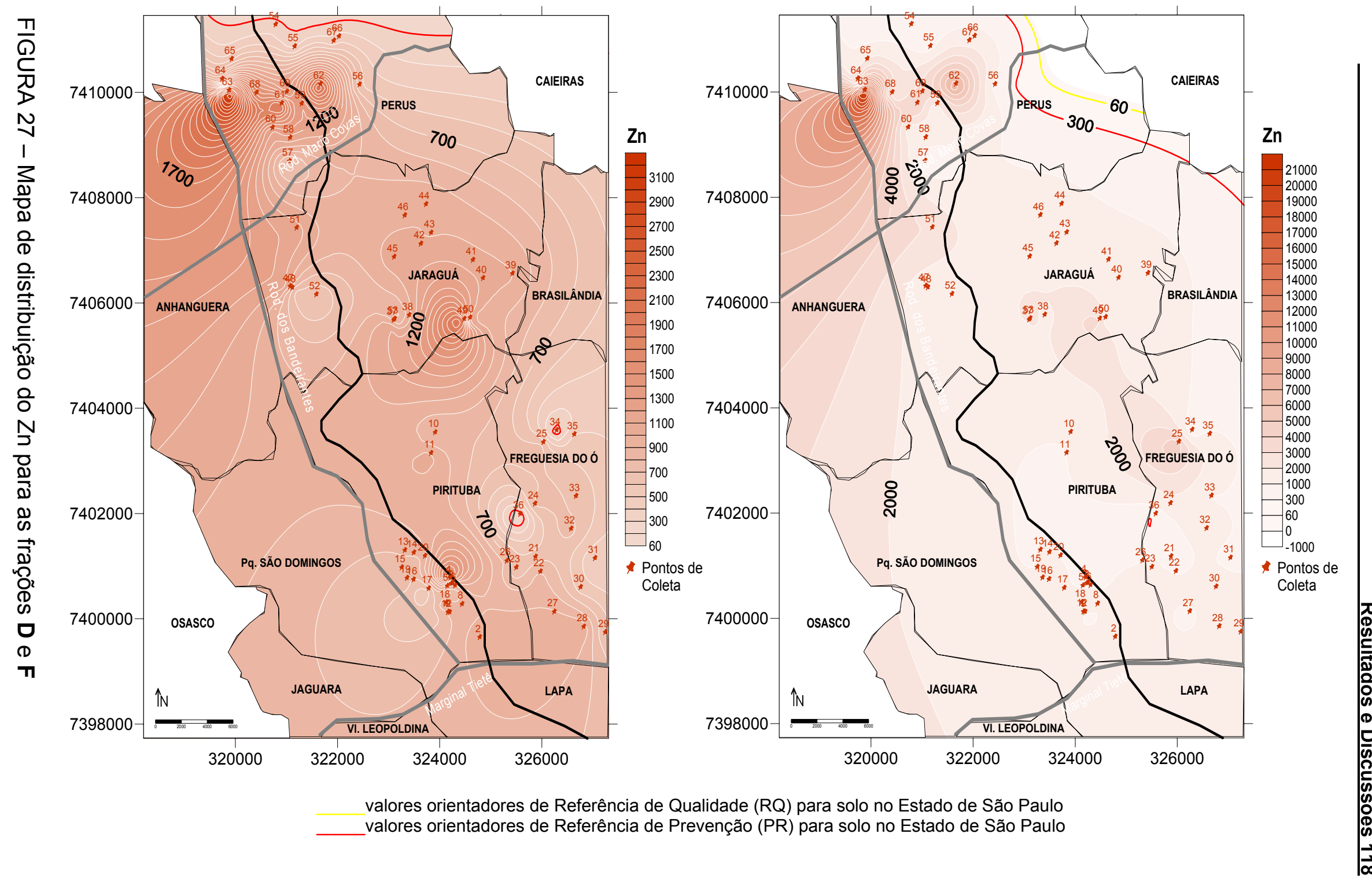

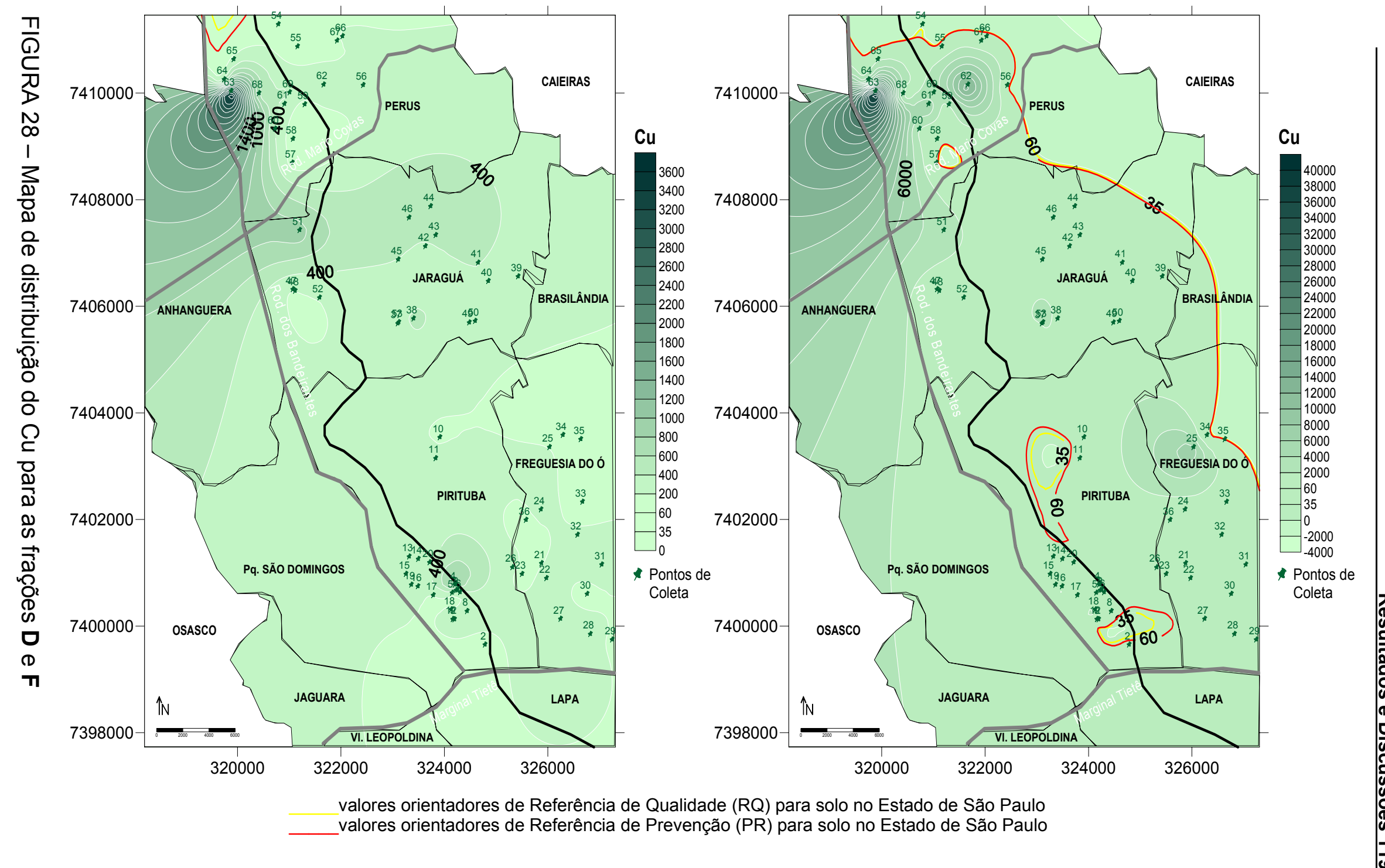

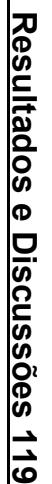




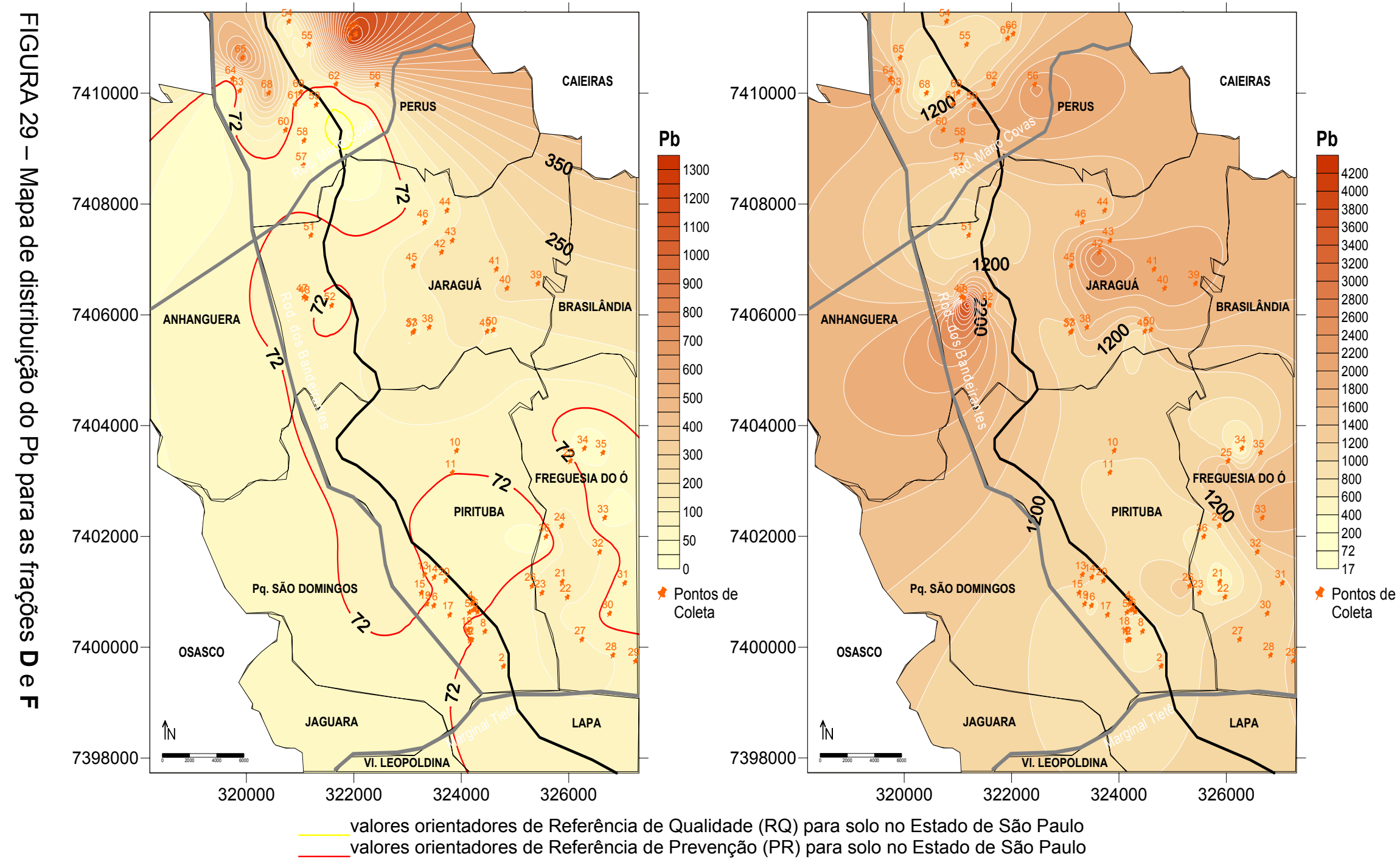



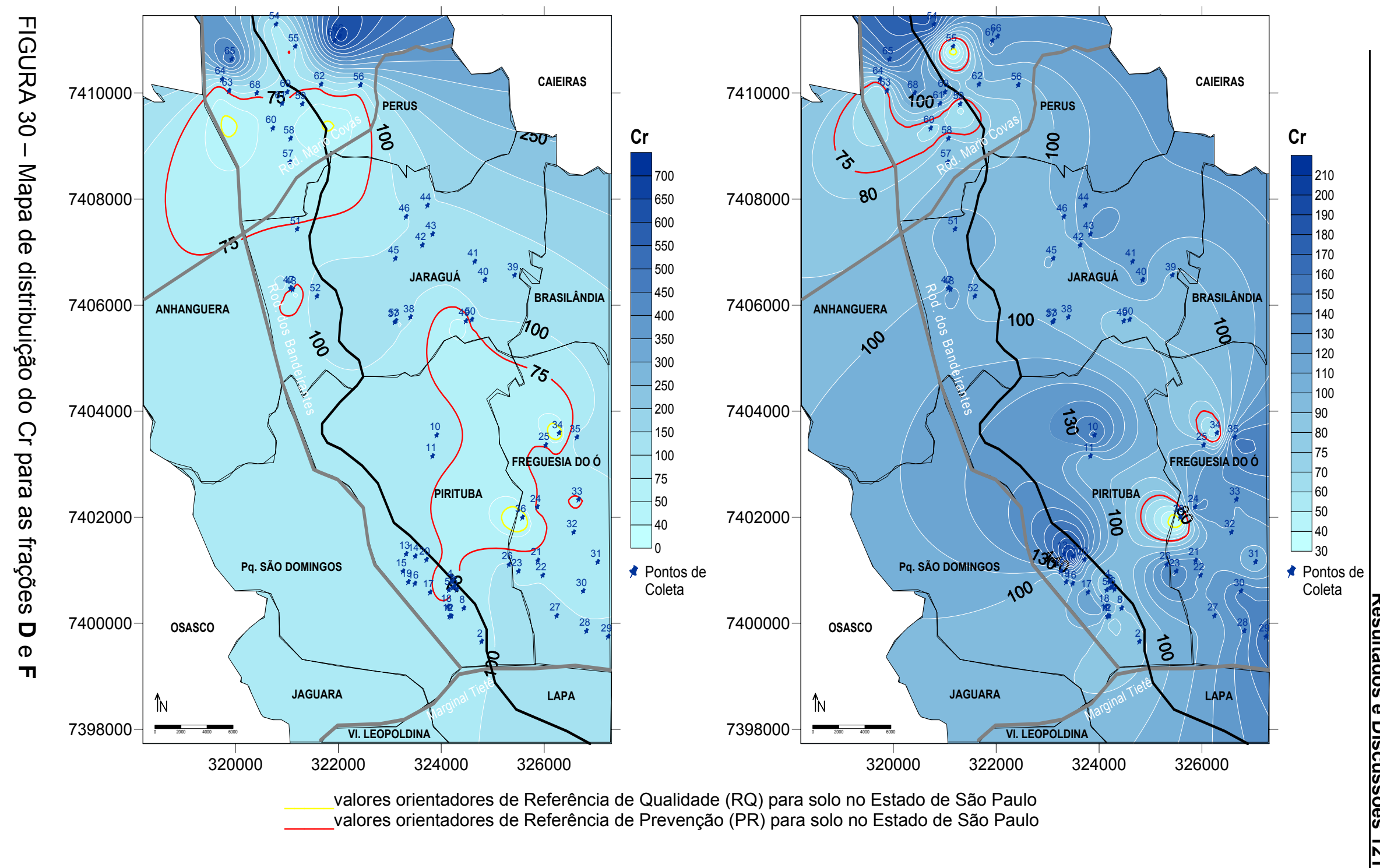

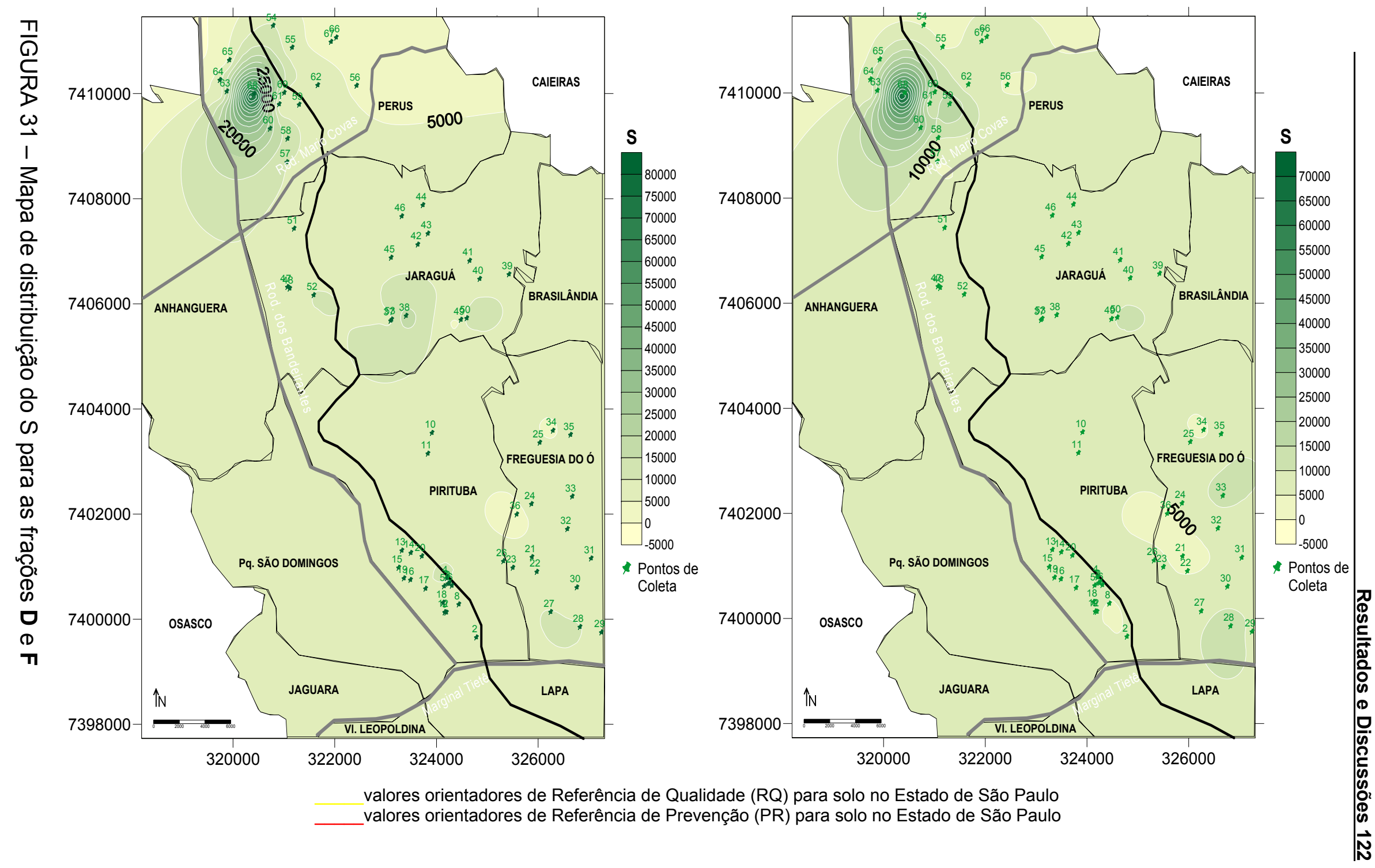

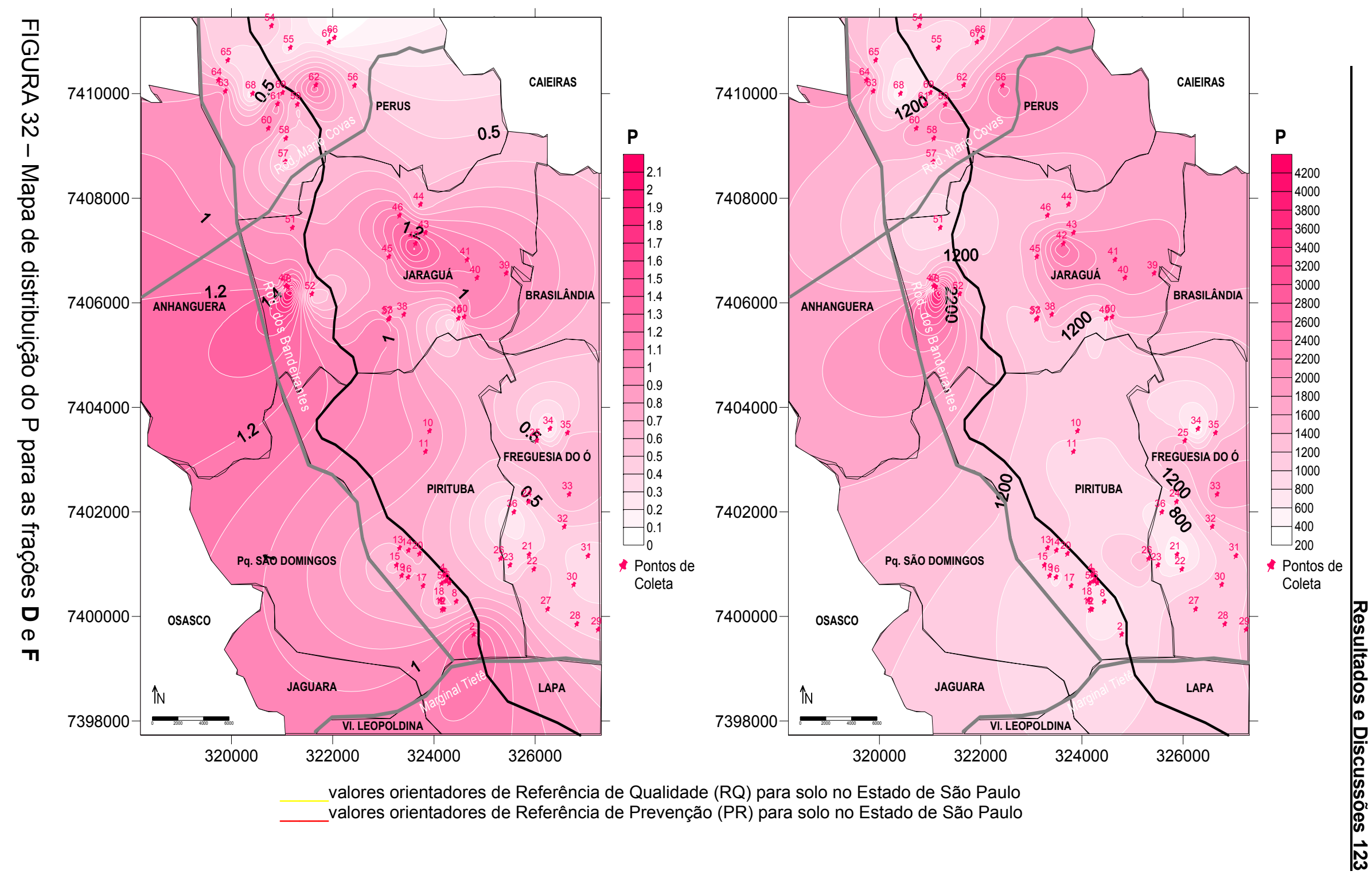

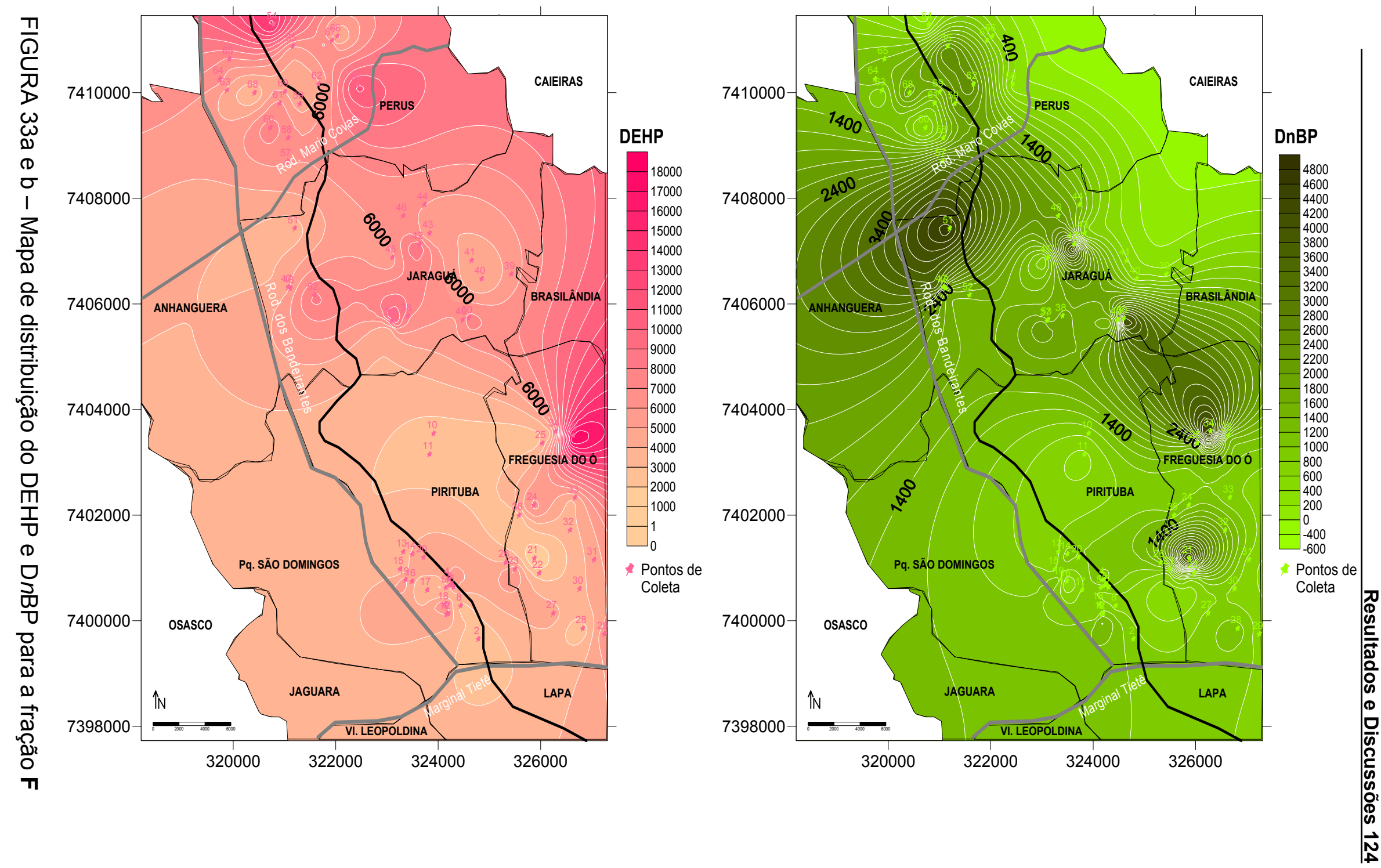

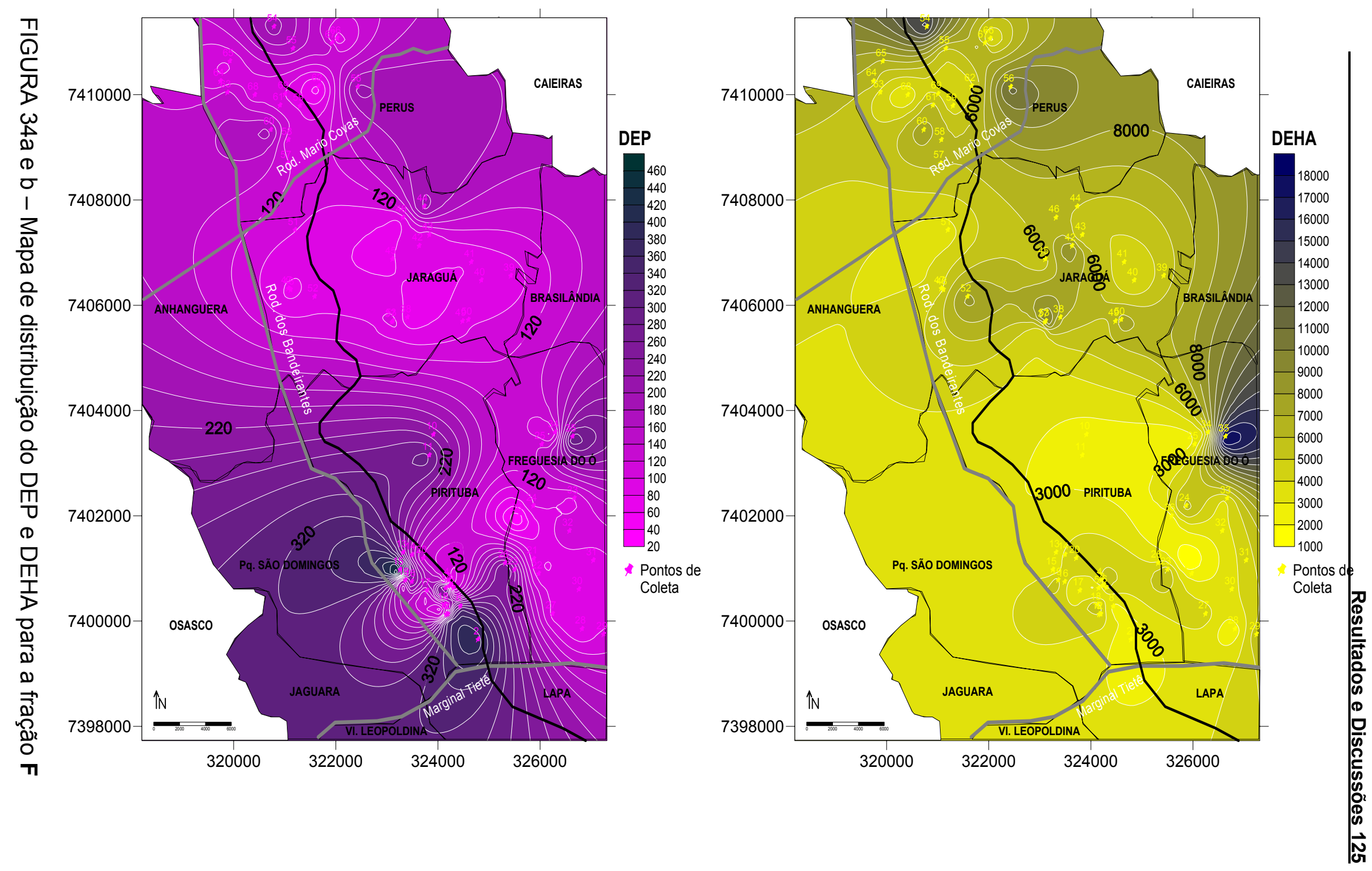

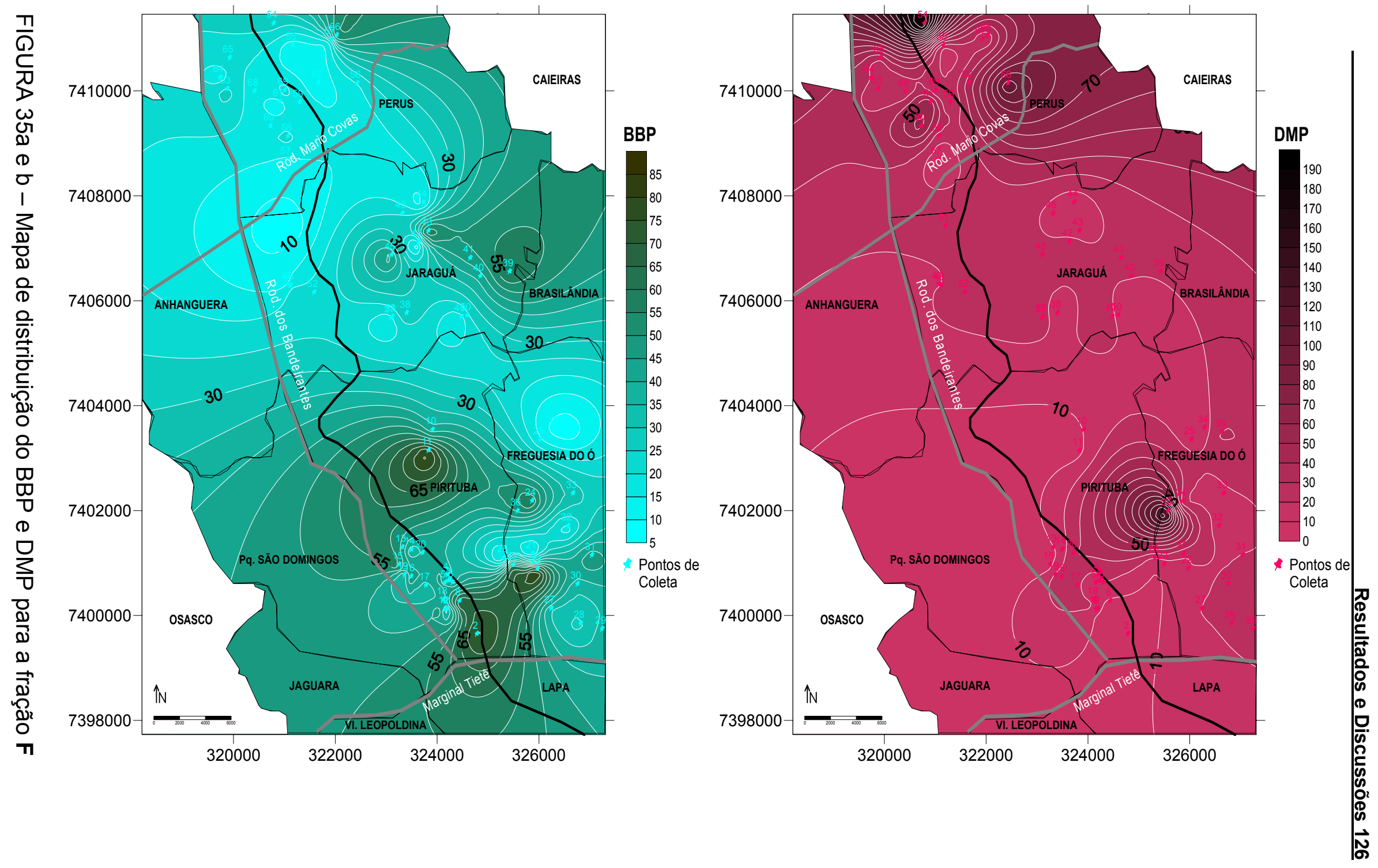


\section{CONCLUSÕES}

- As metodologias de análises químicas (WDXRF e GCMS) utilizadas para a caracterização de poeira doméstica (PD) foram estatisticamente avaliadas, demonstrando a confiabilidade dos resultados na caracterização química da poeira doméstica.

- As análises por $\mathrm{XRD}$, realizados para a fração $\mathbf{F}$, mostram que a poeira doméstica é constituída de materiais cristalinos, evidenciando a influência das fontes externas para os ambientes internos como os compostos presentes na crosta terrestre (óxidos de $\mathrm{Si}, \mathrm{Al}, \mathrm{Fe}, \mathrm{Ca}, \mathrm{Na}, \mathrm{K}$, e Mg).

- O tratamento matemático utilizado para a qualificação de poeira doméstica, mostrou que a sua composição química é muito semelhante á do solo, permitindo a comparação com os valores orientadores para solo, publicado pela CETESB. Os resultados mostram que as amostras estão enriquecidas pelos elementos $\mathrm{P}, \mathrm{S}, \mathrm{Cu}, \mathrm{Ni}, \mathrm{Cr}, \mathrm{Zn}$ e $\mathrm{Pb}$; concordantes com os obtidos por meio dos cálculos de fator de enriquecimento. Portanto, a utilização de dois modelos comprova a contaminação destes elementos em poeira doméstica.

- Nas frações $\mathbf{D}(150-75 \mu \mathrm{m}), \mathbf{E}(75-63 \mu \mathrm{m})$ e $\mathbf{F}(<63 \mu \mathrm{m})$ foram determinados os elementos majoritários $\mathrm{Si}, \mathrm{Ca}, \mathrm{Al}, \mathrm{Mg}, \mathrm{Fe}, \mathrm{S}, \mathrm{K}, \mathrm{Cl}$ e $\mathrm{Na}$ e os minoritários $\mathrm{Ti}, \mathrm{Zn}, \mathrm{Cu}, \mathrm{P}, \mathrm{Mn}, \mathrm{Pb}, \mathrm{Sr}, \mathrm{Cr}, \mathrm{Ni}, \mathrm{Zr}$, Rb e Br. Os resultados mostraram concentração, significativamente maior na fração F. A comparação dos valores dos elementos majoritários, das três frações, com os da crosta continental (CC), é menor, demonstrando que as presenças destes elementos provem de fontes naturais; com exceção do $S$, que apresentou valores superiores nas três frações. Assim, pode-se concluir que a amostras analisadas estão contaminadas por $\mathrm{S}$. Em relação aos elementos minoritários, foi verificado que $\mathrm{Zn}$ e $\mathrm{Cu}$ apresentam teores acima ao da 
crosta continental, demonstrando que a poeira doméstica está enriquecida por estes elementos.

- O fator de enriquecimento (FE) das frações D, E e F quando comparado com o reportado pela literatura, mostra o enriquecimento de $\mathrm{P}, \mathrm{S}, \mathrm{Cu}, \mathrm{Ni}$, $\mathrm{Cr}, \mathrm{Zn}$ e $\mathrm{Pb}$ e que as fontes antropogênicas são internas e externas. A hipótese mais provável de fonte interna, é a migração destes elementos de artefatos, objetos e produtos em geral dispostos nas residências; e para a fonte externa, oriundos de desgastes de resíduos e fragmentos oriundos de peças veiculares.

- As análises de fatores (AF) e cluster (AC), utilizadas para identificar as fontes de contaminação, das frações $\mathbf{D}, \mathbf{E}$ e $\mathbf{F}$ permitiram o agrupamento de constituintes inorgânicos, possibilitando a distinção entre fontes antropogênicas e naturais. Os resultados mostram que os elementos majoritários ( $\mathrm{Si}, \mathrm{Ca}, \mathrm{Al}, \mathrm{Mg}, \mathrm{Fe}, \mathrm{K}, \mathrm{Cl}$ e $\mathrm{Na}$ ) são provenientes de fontes naturais e os minoritários $(\mathrm{Zn}, \mathrm{Cu}, \mathrm{P}, \mathrm{Pb}, \mathrm{Cr}$ e $\mathrm{Ni}$ ) de antropogênicas. A fonte mais provável de contaminação antropogênica pode ser atribuída à frota veicular.

- Os teores $\mathrm{Zn}, \mathrm{Cu}, \mathrm{Pb}, \mathrm{Cr}$ e $\mathrm{Ni}$, determinados nas frações $\mathbf{D}, \mathbf{E}$ e F, comparados com os valores de exposição total, mostram-se significativamente superiores nas três frações. Em relação a ingestão diária de $\mathrm{Cu}$ e $\mathrm{Pb}$ são toleráveis, nas frações $\mathbf{D}$ e $\mathbf{E}$. Em relação aos valores de risco os teores dos elementos $\mathrm{Zn}, \mathrm{Cu}, \mathrm{Pb}, \mathrm{Cr}$ e $\mathrm{Ni}$, das três frações encontram-se superiores aos valores recomendados para adultos e crianças. O $\mathrm{Cr}$ e Ni são menores somente para as crianças.

- Os teores de DEHP, DnBP, DEP, DMP, DEHA e BBP, na fração F são mais elevados, o que demonstra a contaminação ( Decreto-Lei no 10/2007) por fonte interna, decorrente da migração destes compostos para o ambiente 
interno, por causa do desgaste natural e intempérie dos objetos e produtos dispostos nas residências. O estudo, aponta para a necessidade de normativas mais restritas de incorporação destes compostos em materiais, visto que, muitas enfermidades humanas estão associadas à sua exposição.

- Os mapas de distribuição construídos para identificar qual dos bairros estudados apresentam maior contaminação por constituintes inorgânicos e ésteres ftálicos. O bairro de Perus está mais contaminado por $\mathrm{Ni}, \mathrm{Zn}, \mathrm{Cu}$, $\mathrm{Pb}, \mathrm{Cr}$ e $\mathrm{S}$ (fração D); enquanto, que no Jaraguá por $\mathrm{P}$. Os teores de $\mathrm{Zn}, \mathrm{Cu}$ e $\mathbf{S}$, da fração $\mathbf{F}$, apresentam-se elevados no bairro de Perus. Nesta mesma fração, é verificada a contaminação por $\mathrm{Ni}$ e $\mathrm{Cr}$ em Pirituba, enquanto que $\mathrm{P}$ e $\mathrm{Pb}$, no Jaraguá. Em relação aos ésteres ftálicos, foi constatado o bairro da Freguesia do Ó é o mais contaminado por DEHP, DEP e DEHA e os compostos DnBP, BBP e DMP, nos bairros de Perus, Jaraguá e Pirituba, respectivamente. As prováveis fontes para a contaminação por constituintes inorgânicos são as proximidades com rodovias, visto que, os bairros com maiores teores destes compostos estão localizados próximos a vias de tráfego bastante intenso. Por outro lado, os teores de ftalatos podem ser atribuídos ao desprendimento destas substâncias, incorporadas aos artefatos, produtos de limpeza e higiene presentes nas residências.

- Os resultados indicam quão preocupante é a exposição do ser humano frente a poeira doméstica contaminada. Ainda, este material pode ser um excelente monitor para a avaliação de poluição ambiental e identificador de fontes antropogênicas. 


\section{SUGESTÕES PARA TRABALHOS FUTUROS}

Dando seguimento aos estudos, sugerem-se os seguintes tópicos para futuros trabalhos:

- Determinar a razão isotópica para se verificar a contribuição do chumbo de ambientes externos para o interno;

- Determinar outros compostos orgânicos como, pesticidas, retardadores de chama bromados (PBDEs), hidrocarbonetos aromáticos policíclicos (PAHs), bifenil policlorado (PCB) e éter difenil polibromado (PBDE) presentes na poeira;

- Avaliar a fração granulométrica e a composição química do solo de ambiente externo e relacionar com a poeira do ambiente interno residencial, usando modelos matemáticos;

- Avaliação toxicológica da poeira por ácaros, fungos e bactérias;

- Avaliar os teores de metais potencialmente tóxicos em outros bairros da zona leste, já que, esta é uma região diversificada (comercial e residencial com processos de urbanização e regularização de áreas risco, canalização de córregos, além da verticalização); bem como, estender o estudo para a zona central de São Paulo que conta com um alto grau de verticalização, além de integrar com um tráfego intenso de veículos.

- Avaliar os teores de constituintes inorgânicos e compostos orgânicos em creches, uma vez que, as crianças são mais suscetíveis em desencadear algum tipo de doenças. 
APÊNDICE A - Georreferenciamento dos pontos de coleta das amostras de poeira doméstica

\begin{tabular}{|c|c|c|c|c|}
\hline \multirow[b]{2}{*}{ PA } & Longitude & \multirow{2}{*}{ Latitude } & \multicolumn{2}{|c|}{ UTM (metro) } \\
\hline & & & Eixo $x$ & Eixo y \\
\hline 1 & $-46,722336$ & $-23,499961$ & 324130,9453 & 7400078,6948 \\
\hline 2 & $-46,716321$ & $-23,504343$ & 324751,0666 & 7399600,7812 \\
\hline 3 & $-46,721378$ & $-23,494973$ & 324222,1688 & 7400632,2440 \\
\hline 4 & $-46,721863$ & $-23,494101$ & 324171,4757 & 7400728,2166 \\
\hline 5 & $-46,722419$ & $-23,495481$ & 324116,5200 & 7400574,7132 \\
\hline 6 & $-46,720924$ & $-23,495421$ & 324269,1327 & 7400583,1875 \\
\hline 7 & $-46,721673$ & $-23,495047$ & 324192,1370 & 7400623,6881 \\
\hline 8 & $-46,719634$ & $-23,498632$ & 324405,1437 & 7400229,1758 \\
\hline 9 & $-46,722040$ & $-23,500004$ & 324161,2334 & 7400074,2954 \\
\hline 10 & $-46,724416$ & $-23,469121$ & 323877,8310 & 7403491,3920 \\
\hline 11 & $-46,725245$ & $-23,472674$ & 323797,5702 & 7403096,9205 \\
\hline 12 & $-46,722351$ & $-23,499948$ & 324129,3960 & 7400080,1161 \\
\hline 13 & $-46,730479$ & $-23,489273$ & 323285,0283 & 7401252,3032 \\
\hline 14 & $-46,728759$ & $-23,489694$ & 323461,2707 & 7401207,7956 \\
\hline 15 & $-46,731128$ & $-23,492204$ & 323222,6494 & 7400926,9219 \\
\hline 16 & $-46,728888$ & $-23,494327$ & 323454,2678 & 7400694,5728 \\
\hline 17 & $-46,725999$ & $-23,495865$ & 323751,3861 & 7400527,8005 \\
\hline 18 & $-46,722646$ & $-23,498323$ & 324097,1091 & 7400259,7091 \\
\hline 19 & $-46,730134$ & $-23,494044$ & 323326,6283 & 7400724,3807 \\
\hline 20 & $-46,726628$ & $-23,490285$ & 323679,7174 & 7401144,9644 \\
\hline 21 & $-46,705448$ & $-23,490666$ & 325843,5249 & 7401128,6059 \\
\hline 22 & $-46,704540$ & $-23,493213$ & 325939,6125 & 7400847,6507 \\
\hline 23 & $-46,709152$ & $-23,492459$ & 325467,5656 & 7400925,5534 \\
\hline 24 & $-46,705425$ & $-23,481554$ & 325833,9007 & 7402137,6990 \\
\hline 27 & $-23,491300$ & $-46,710946$ & 325997,6137 & 7403305,7862 \\
\hline 25 & $-46,710946$ & $-23,491300$ & 325282,8031 & 7401051,7210 \\
\hline 26 & $-46,701968$ & $-23,500132$ & 326211,3844 & 7400084,5529 \\
\hline 28 & $-46,696356$ & $-23,502769$ & 326787,9919 & 7399799,3111 \\
\hline 29 & $-46,692239$ & $-23,503745$ & 327209,7292 & 7399696,1887 \\
\hline 30 & $-46,696873$ & $-23,495965$ & 326726,2908 & 7400552,1630 \\
\hline 31 & $-46,694051$ & $-23,491021$ & 327008,0579 & 7401103,0624 \\
\hline 32 & $-46,698565$ & $-23,485929$ & 326540,3430 & 7401661,5080 \\
\hline 33 & $-46,697556$ & $-23,480346$ & 326636,1027 & 7402280,9866 \\
\hline 34 & $-46,701113$ & $-23,468994$ & 326257,8965 & 7403533,8115 \\
\hline 35 & $-46,697749$ & $-23,469745$ & 326602,5275 & 7403454,7065 \\
\hline 36 & $-46,708279$ & $-23,483300$ & 325544,6752 & 7401940,8850 \\
\hline 37 & $-46,732117$ & $-23,449753$ & 323065,0135 & 7405626,7762 \\
\hline 38 & $-46,729127$ & $-23,448952$ & 323369,4389 & 7405719,1526 \\
\hline 39 & $-46,709244$ & $-23,442043$ & 325391,8231 & 7406508,5179 \\
\hline 40 & $-46,714894$ & $-23,442766$ & 324815,4813 & 7406421,5882 \\
\hline 41 & $-46,716780$ & $-23,439628$ & 324618,6345 & 7406766,7942 \\
\hline 42 & $-46,726724$ & $-23,436740$ & 323598,7377 & 7407074,4635 \\
\hline 43 & $-46,724745$ & $-23,434871$ & 323798,4747 & 7407283,8605 \\
\hline 44 & $-46,725654$ & $-23,429972$ & 323699,0913 & 7407825,2650 \\
\hline
\end{tabular}


APÊNDICE A - Georreferenciamento dos pontos de coleta das amostras de poeira doméstica

\begin{tabular}{lrrrr} 
& \multicolumn{2}{c}{ Longitude } & Latitude & \multicolumn{2}{c}{ UTM (metro) } \\
& & Eixo (grau & Eixo $\mathbf{~}$ \\
\hline $\mathbf{4 5}$ & $-46,731886$ & $-23,438936$ & 323074,2047 & 7406824,9432 \\
$\mathbf{4 6}$ & $-46,729749$ & $-23,431847$ & 323283,1329 & 7407612,6077 \\
$\mathbf{4 7}$ & $-46,751894$ & $-23,443735$ & 321036,2603 & 7406268,7638 \\
$\mathbf{4 8}$ & $-46,751470$ & $-23,444018$ & 321079,9643 & 7406237,9511 \\
$\mathbf{4 9}$ & $-46,718589$ & $-23,449744$ & 324447,1671 & 7405644,3409 \\
$\mathbf{5 0}$ & $-46,717471$ & $-23,449498$ & 324561,0686 & 7405672,9464 \\
$\mathbf{5 1}$ & $-46,750488$ & $-23,433725$ & 321166,4446 & 7407379,0332 \\
$\mathbf{5 2}$ & $-46,746868$ & $-23,445208$ & 321551,7774 & 7406111,8818 \\
$\mathbf{5 3}$ & $-46,731932$ & $-23,449559$ & 323083,6566 & 7405648,4874 \\
$\mathbf{5 4}$ & $-46,754055$ & $-23,398823$ & 320754,9153 & 7411239,6920 \\
$\mathbf{5 5}$ & $-46,750461$ & $-23,402623$ & 321127,3690 & 7410823,3392 \\
$\mathbf{5 6}$ & $-46,738141$ & $-23,409307$ & 322395,4906 & 7410098,3805 \\
$\mathbf{5 7}$ & $-46,751738$ & $-23,422300$ & 321023,3297 & 7408642,7004 \\
$\mathbf{5 8}$ & $-46,751535$ & $-23,418271$ & 321038,6518 & 7409089,1291 \\
$\mathbf{5 9}$ & $-46,749234$ & $-23,412446$ & 321265,9758 & 7409737,0521 \\
$\mathbf{6 0}$ & $-46,754894$ & $-23,416508$ & 320692,9981 & 7409280,1901 \\
$\mathbf{6 1}$ & $-46,753073$ & $-23,412334$ & 320873,4777 & 7409744,6889 \\
$\mathbf{6 2}$ & $-46,745615$ & $-23,409138$ & 321631,4027 & 7410107,8666 \\
$\mathbf{6 3}$ & $-46,763124$ & $-23,410009$ & 319843,1089 & 7409989,6349 \\
$\mathbf{6 4}$ & $-46,764432$ & $-23,408040$ & 319706,7591 & 7410206,0496 \\
$\mathbf{6 5}$ & $-46,762572$ & $-23,404652$ & 319892,2725 & 7410583,5672 \\
$\mathbf{6 6}$ & $-46,741949$ & $-23,400992$ & 321995,1798 & 7411014,4919 \\
$\mathbf{6 7}$ & $-46,742966$ & $-23,401721$ & 321892,2091 & 7410932,5061 \\
$\mathbf{6 8}$ & $-46,757866$ & $-23,410469$ & 320381,1114 & 7409945,2562 \\
$\mathbf{6 9}$ & $-46,752076$ & $-23,410382$ & 320972,7443 & 7409962,0944 \\
\hline
\end{tabular}


APÊNDICE B - Protocolo sobre o procedimento de coleta das amostras de poeira doméstica

\section{Procedimento de amostragem}

1. Colocar o reservatório de papel dentro do saco do aspirador;

2. Anotar no formulário e no saco de papel a data do início da coleta;

Início da coleta:

Término da coleta:

3. A aspiração deverá ser realizada apenas no ambiente interno da residência;

4. Quando o reservatório de papel estiver cheio, retirar do saco do aspirador, fechar e colocá-lo dentro de um envelope;

5. Guardar o saco plástico em ambiente seco e levar ao local de coleta.

\begin{tabular}{|c|c|c|}
\hline $\begin{array}{l}\text { Substâncias } \\
\text { Tóxicas }\end{array}$ & De onde vem & Efeitos \\
\hline Cádmio & $\begin{array}{l}\text { fabricação de tubos para TV, pigmentos, esmaltes e } \\
\text { tinturas têxteis; baterias e pilhas. }\end{array}$ & $\begin{array}{l}\text { Câncer de pulmões e próstata; lesão nos } \\
\text { rins }\end{array}$ \\
\hline Chumbo & $\begin{array}{l}\text { proveniente de carros, pinturas, água contaminada, } \\
\text { indústrias. }\end{array}$ & $\begin{array}{l}\text { Afeta o cérebro, causando retardo mental } \\
\text { e outros graves efeitos na coordenação } \\
\text { motora e na capacidade de atenção. }\end{array}$ \\
\hline Cromo & $\begin{array}{l}\text { Indústrias de corantes, esmaltes, tintas, ligas com aço } \\
\text { e níquel; cromagem de metais. }\end{array}$ & Asma (bronquite); câncer \\
\hline Fósforo amarelo & $\begin{array}{l}\text { Veneno para baratas; rodenticidas (tipo de inseticida } \\
\text { usado na lavoura) e fogos de artifício. }\end{array}$ & $\begin{array}{l}\text { Náuseas; gastrite; odor de alho; fezes e } \\
\text { vômitos fosforescentes; dor muscular; } \\
\text { torpor; choque; coma e até morte }\end{array}$ \\
\hline Mercúrio & $\begin{array}{l}\text { tem origem em centrais elétricas e na incineração de } \\
\text { lixo. }\end{array}$ & Intoxicação do sistema nervoso central \\
\hline Níquel & $\begin{array}{l}\text { Baterias; aramados; fundição e niquelagem de metais; } \\
\text { refinarias. }\end{array}$ & Câncer de pulmão e seios paranasais \\
\hline Enxofre (S) & libertado na queima de combustíveis & $\begin{array}{l}\text { gás irritante para as mucosas dos olhos e } \\
\text { das vias respiratórias; }\end{array}$ \\
\hline $\begin{array}{l}\text { Benzeno, tolueno, } \\
\text { etil-benzeno e } \\
\text { xileno (BTEX) }\end{array}$ & $\begin{array}{l}\text { provenientes de poluição metropolitana, principalmente } \\
\text { do diesel }\end{array}$ & $\begin{array}{l}\text { agentes de câncer de pulmão e distúrbios } \\
\text { de via respiratória }\end{array}$ \\
\hline Ftalatos & $\begin{array}{l}\text { são aditivos aos plásticos, especialmente PVC, que } \\
\text { Ihes conferem uma variedade de características que } \\
\text { vão desde a flexibilidade até a retardação de chamas }\end{array}$ & $\begin{array}{l}\text { Por não estarem quimicamente ligados ao } \\
\text { plástico, os ftalatos podem vazar para o } \\
\text { meio-ambiente. Em animais silvestres e } \\
\text { de laboratórios, foram relacionados a } \\
\text { efeitos na saúde reprodutiva, aborto, } \\
\text { defeitos congênitos, contagem anormal de } \\
\text { esperma e dano testicular, como também } \\
\text { câncer do fígado e dos rins }\end{array}$ \\
\hline Dioxinas & provenientes de detritos e do lixo. & $\begin{array}{l}\text { podem causar câncer, má-formação de } \\
\text { fetos, doenças neurológicas }\end{array}$ \\
\hline
\end{tabular}


APÊNDICE C - Formulário para registro das informações sobre as características das residências e as atividades ocupacionais dos moradores

FORMULÁRIO

\begin{tabular}{|c|c|c|c|c|c|c|c|c|c|c|c|}
\hline \multicolumn{12}{|l|}{$\begin{array}{l}\text { Nome: } \\
\text { Endereço: }\end{array}$} \\
\hline \multicolumn{12}{|l|}{ Telefone: } \\
\hline \multicolumn{12}{|l|}{ Proximidades: } \\
\hline Localização dentro da cidade & \multicolumn{11}{|c|}{ Norte } \\
\hline \multicolumn{12}{|l|}{ Início da coleta } \\
\hline \multicolumn{12}{|l|}{ Término da coleta } \\
\hline \multirow{2}{*}{ Bairro: } & \multicolumn{4}{|c|}{ Freguesia do Ó } & \multicolumn{3}{|c|}{ Pirituba } & \multicolumn{2}{|c|}{ Jaraguá } & \multicolumn{2}{|c|}{ Perus } \\
\hline & & & & & & & & \\
\hline \multirow{2}{*}{ Características da residência } & \multicolumn{5}{|c|}{ Casa } & \multicolumn{6}{|c|}{ Apartamento } \\
\hline & \multicolumn{5}{|c|}{$\perp$} & \\
\hline \multicolumn{12}{|l|}{ Tamanho } \\
\hline \multirow{2}{*}{$\begin{array}{l}\text { Reformas/Decoração/Redecoração } \\
\text { Quantidade: } \\
\text { Período: }\end{array}$} & \multicolumn{5}{|c|}{ Sim } & \multicolumn{6}{|c|}{ Não } \\
\hline & \multicolumn{4}{|c|}{$\square$} & & \multicolumn{6}{|c|}{$\square$} \\
\hline Idade da residência & & & & & & & & & & & \\
\hline Número de cômodos & 0 & 1 & 2 & 3 & 4 & 5 & 6 & 7 & 8 & 9 & 10 \\
\hline Numero de comodos & $\square$ & $\square$ & 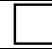 & $\square$ & $\square$ & $\square$ & L & $\square$ & $\mathrm{L}$ & $\square$ & $\square$ \\
\hline & & Carp & & & & Iade & & & & Frio & \\
\hline Tipo de piso & & & & & & $\square$ & & & & 1 & \\
\hline & 0 & 1 & 2 & 3 & 4 & 5 & 6 & 7 & 8 & 9 & 10 \\
\hline Adultos residentes & $\square$ & $\square$ & 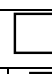 & $\square$ & $\square$ & $\square$ & $\square$ & $\square$ & L & $\square$ & $\square$ \\
\hline Idades & & $1-30$ & L & $31-4$ & $\mathrm{~L}$ & $\bar{~} \overline{41-}$ & & & $1-60$ & & $1-70$ \\
\hline & 0 & 1 & 2 & 3 & 4 & 5 & 6 & 7 & 8 & 9 & 10 \\
\hline Crianças residentes & $\square$ & $\square$ & $\square$ & $\square$ & $\square$ & $\square$ & $\square$ & $\square$ & $\square$ & $\square$ & $\square$ \\
\hline Idades & & $0-5$ & & $\square$ & $6-10$ & & & $11-15$ & & & $5-20$ \\
\hline & 0 & 1 & 2 & 3 & 4 & 5 & 6 & 7 & 8 & 9 & 10 \\
\hline Anımaıs de estımaçao & $\square$ & & 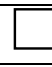 & $\square$ & $\square$ & $\square$ & $\square$ & $\square$ & $\square$ & $\square$ & $\square$ \\
\hline Quais? & & & & & & & & & & & \\
\hline Doencas pré-existentes & & & Sim & & & & & & Jão & & \\
\hline Doenças pre-existentes & & & & & & & & & & & \\
\hline Qual? & & & & & & & & & & & \\
\hline & 0 & 1 & 2 & 3 & 4 & 5 & 6 & 7 & 8 & 9 & 10 \\
\hline Fumantes & & & & & & & & & & & \\
\hline Ar condicionado & & & Sim & & & & & & Jão & & \\
\hline 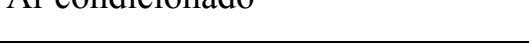 & & & & & & & & & & & \\
\hline Tipo de aspirador & & & & & & & & & & & \\
\hline & & diá & & & & mar & & & & nensa & \\
\hline Aspıraçao da poeıra & & $L$ & & & & & & & & $\square$ & \\
\hline Massa de poeira coletada & & & & & & & & & & & \\
\hline
\end{tabular}


APÊNDICE D - Condições de medidas utilizadas para a obtenção da curva de sensibilidade (Espectrômetro WDXRF RIGAKU, RIX 3000)

\begin{tabular}{|c|c|c|c|c|c|c|c|c|c|}
\hline $\begin{array}{l}\text { Elemento/ } \\
\text { Linha de } \\
\text { emissão }\end{array}$ & $\begin{array}{c}\text { Pico } 2 \theta \\
\text { grau }\end{array}$ & $\begin{array}{l}\text { BG(1) } \\
\text { grau }\end{array}$ & $\begin{array}{l}\text { BG(2) } \\
\text { grau }\end{array}$ & $\begin{array}{c}\text { Cristal } \\
\text { analisador }\end{array}$ & Colimador & Detector & $\begin{array}{l}\text { Potência } \\
\text { kV x mA }\end{array}$ & PHA & Filtro \\
\hline $\mathrm{Na}-\mathrm{K}_{\alpha}$ & 55.230 & 53.500 & 57.120 & TAP & $480 \mu \mathrm{m}$ & FPC & $50 \times 50$ & $100-300$ & $* * *$ \\
\hline $\mathrm{Mg}-\mathrm{K}_{\alpha}$ & 45.300 & 43.190 & 47.190 & TAP & $480 \mu \mathrm{m}$ & FPC & $50 \times 50$ & $100-300$ & $* * *$ \\
\hline $\mathrm{Al}-\mathrm{K}_{\alpha}$ & 144.700 & 139.610 & 146.810 & PET-001 & $480 \mu \mathrm{m}$ & FPC & $50 \times 50$ & $100-300$ & $* * *$ \\
\hline $\mathrm{Si}-\mathrm{K}_{\alpha}$ & 109.045 & 106.040 & 112.040 & PET-001 & $480 \mu \mathrm{m}$ & FPC & $50 \times 50$ & $100-300$ & $* * *$ \\
\hline $\mathrm{P}-\mathrm{K}_{\alpha}$ & 141.100 & 139.180 & 143.180 & GE & $480 \mu \mathrm{m}$ & FPC & $50 \times 50$ & $100-300$ & $* * *$ \\
\hline $\mathrm{K}-\mathrm{K}_{\alpha}$ & 70.000 & 68.000 & 72.000 & GE & $480 \mu \mathrm{m}$ & FPC & $50 \times 50$ & $100-300$ & $* * *$ \\
\hline $\mathrm{Ca}-\mathrm{K}_{\alpha}$ & 61.980 & 59.980 & 63.980 & GE & $480 \mu \mathrm{m}$ & FPC & $50 \times 50$ & $100-300$ & $* * *$ \\
\hline $\mathrm{Ti}^{-\mathrm{K}_{\alpha}}$ & 86.110 & 85.510 & 86.710 & LiF-200 & $480 \mu \mathrm{m}$ & $\mathrm{sc}$ & $50 \times 50$ & $100-300$ & $* * *$ \\
\hline $\mathrm{Cr}-\mathrm{K}_{\alpha}$ & 69.340 & 68.730 & 69.930 & LiF-200 & $480 \mu \mathrm{m}$ & SC & $50 \times 50$ & $100-300$ & $* * *$ \\
\hline $\mathrm{Mn}-\mathrm{K}_{\alpha}$ & 62.950 & 62.350 & 63.550 & LiF-200 & $480 \mu \mathrm{m}$ & $\mathrm{SC}$ & $50 \times 50$ & $100-300$ & $* * *$ \\
\hline $\mathrm{Fe}-\mathrm{K}_{a}$ & 57.500 & 56.900 & 58.000 & LiF-200 & $480 \mu \mathrm{m}$ & SC & $50 \times 50$ & $100-300$ & $* * *$ \\
\hline $\mathrm{Ni}-\mathrm{K}_{\alpha}$ & 48.660 & 48.050 & 49.250 & LiF-200 & $480 \mu \mathrm{m}$ & SC & $50 \times 50$ & $100-300$ & $* * *$ \\
\hline $\mathrm{Cu}-\mathrm{K}_{\alpha}$ & 45.020 & 44.410 & 45.610 & LiF-200 & $480 \mu \mathrm{m}$ & SC & $50 \times 50$ & $100-300$ & $* * *$ \\
\hline $\mathrm{Zn}-\mathrm{K}_{\alpha}$ & 41.780 & 41.180 & 42.380 & LiF-200 & $480 \mu \mathrm{m}$ & SC & $50 \times 50$ & $100-300$ & $* * *$ \\
\hline $\mathrm{Rb}-\mathrm{K}_{\alpha}$ & & & & LiF-200 & $480 \mu \mathrm{m}$ & SC & $50 \times 50$ & $100-300$ & $* * *$ \\
\hline $\mathrm{Sr}-\mathrm{K}_{\alpha}$ & 25.060 & 24.530 & 25.730 & LiF-200 & $480 \mu \mathrm{m}$ & SC & $50 \times 50$ & $100-300$ & $* * *$ \\
\hline $\mathrm{Ag}-\mathrm{K}_{\alpha}$ & 16.750 & 15.400 & 16.600 & LiF-200 & $480 \mu \mathrm{m}$ & SC & $50 \times 50$ & $100-300$ & $* * *$ \\
\hline $\mathrm{Ba}-\mathrm{L}_{\alpha}$ & 87.130 & 86.530 & 87.730 & LiF-200 & $480 \mu \mathrm{m}$ & SC & $50 \times 50$ & $100-300$ & $* * *$ \\
\hline $\mathrm{Pb}-\mathrm{L}_{\beta 1}$ & 28.240 & 27.640 & 28.840 & LiF-200 & $480 \mu \mathrm{m}$ & $\mathrm{sc}$ & $50 \times 50$ & $100-300$ & $* * *$ \\
\hline
\end{tabular}

TAP: fosfato de tálio; LiF: fluoreto de lítio e Ge: germânio. FPC: Detector proporcional com fluxo de gás; SC: Detector de cintilação (Nal (TI)). 
APÊNDICE E - Linhas de emissão, intensidades experimentais (I EX $)$ e teóricas $\left(\mathrm{I} \mathrm{T}^{* *}\right)$ e sensibilidade (S) determinada para o SRM 2584 e o espectrômetro Rigaku Co.; RIX 3000

\begin{tabular}{ccllll}
\hline № Atômico & Elemento & Linhas & \multicolumn{1}{c}{ I EX } & I T** & S \\
\hline 11 & $\mathrm{Na}$ & $\mathrm{Na}-\mathrm{K} \alpha$ & 0,956 & 2,971 & 3,109 \\
12 & $\mathrm{Mg}$ & $\mathrm{Mg}-\mathrm{K} \alpha$ & 2,130 & 3,979 & 1,868 \\
13 & $\mathrm{Al}$ & $\mathrm{Al}-\mathrm{K} \alpha$ & 10,595 & 11,793 & 1,113 \\
14 & $\mathrm{Si}$ & $\mathrm{Si}-\mathrm{K} \alpha$ & 40,729 & 111,321 & 2,733 \\
15 & $\mathrm{P}$ & $\mathrm{P}-\mathrm{K} \alpha$ & 8,525 & 3,098 & 0,363 \\
19 & $\mathrm{~K}$ & $\mathrm{~K}-\mathrm{K} \alpha$ & 13,713 & 21,140 & 1,542 \\
20 & $\mathrm{Ca}$ & $\mathrm{Ca}-\mathrm{K} \alpha$ & 133,178 & 198,929 & 1,494 \\
22 & $\mathrm{Ti}$ & $\mathrm{Ti}-\mathrm{K} \alpha$ & 2,472 & 17,852 & 7,220 \\
24 & $\mathrm{Cr}$ & $\mathrm{Cr}-\mathrm{K} \alpha$ & 0,334 & 0,985 & 2,953 \\
25 & $\mathrm{Mn}$ & $\mathrm{Mn}-\mathrm{K} \alpha$ & 1,036 & 3,256 & 3,144 \\
26 & $\mathrm{Fe}$ & $\mathrm{Fe}-\mathrm{K} \alpha$ & 63,743 & 182,315 & 2,860 \\
28 & $\mathrm{Ni}$ & $\mathrm{Ni}-\mathrm{K} \alpha$ & 0,817 & 1,362 & 1,667 \\
29 & $\mathrm{Cu}$ & $\mathrm{Cu}-\mathrm{K} \alpha$ & 2,862 & 5,475 & 1,913 \\
30 & $\mathrm{Zn}$ & $\mathrm{Zn}-\mathrm{K} \alpha$ & 30,538 & 52,954 & 1,734 \\
38 & $\mathrm{Sr}$ & $\mathrm{Sr}-\mathrm{K} \alpha$ & 2,682 & 7,057 & 2,631 \\
82 & $\mathrm{~Pb}$ & $\mathrm{~Pb}-\mathrm{L} \beta 1$ & 91,406 & 109,269 & 1,195 \\
\hline
\end{tabular}

I $\mathrm{EX}^{*}=$ Intensidade Experimental $(\mathrm{kcps})$;

$\mathrm{I} \mathrm{T}^{\star *}=$ Intensidade calculada - Método de Parâmetros Fundamentais (kcps). 
APÊNDICE F - Linhas de emissão, intensidades experimentais (I EX*) e teóricas (I $\mathrm{T}^{* *}$ ) e sensibilidade (S) determinada para o SRM 2781 e o espectrômetro Rigaku Co.; RIX 3000.

\begin{tabular}{llllll}
\hline № Atômico & Elemento & Linhas & I EX* & I T** & S \\
\hline 11 & $\mathrm{Na}$ & $\mathrm{Na}-\mathrm{K} \alpha$ & 0,060 & 0,215 & 3,577 \\
12 & $\mathrm{Mg}$ & $\mathrm{Mg}-\mathrm{K} \alpha$ & 0,871 & 1,504 & 1,727 \\
13 & $\mathrm{Al}$ & $\mathrm{Al}-\mathrm{K} \alpha$ & 8,323 & 5,586 & 1,032 \\
14 & $\mathrm{Si}$ & $\mathrm{Si}-\mathrm{K} \alpha$ & 26,231 & 58,347 & 2,226 \\
15 & $\mathrm{P}$ & $\mathrm{P}-\mathrm{K} \alpha$ & 119,622 & 45,794 & 0,383 \\
19 & $\mathrm{~K}$ & $\mathrm{~K}-\mathrm{K} \alpha$ & 9,183 & 13,612 & 1,482 \\
20 & $\mathrm{Ca}$ & $\mathrm{Ca}-\mathrm{K} \alpha$ & 115,655 & 159,296 & 1,377 \\
22 & $\mathrm{Ti}$ & $\mathrm{Ti}-\mathrm{K} \alpha$ & 2,696 & 18,720 & 6,944 \\
24 & $\mathrm{Cr}$ & $\mathrm{Cr}-\mathrm{K} \alpha$ & 0,576 & 2,052 & 3,561 \\
26 & $\mathrm{Fe}$ & $\mathrm{Fe}-\mathrm{K} \alpha$ & 164,114 & 418,071 & 2,547 \\
28 & $\mathrm{Ni}$ & $\mathrm{Ni}-\mathrm{K} \alpha$ & 0,864 & 1,450 & 1,679 \\
29 & $\mathrm{Cu}$ & $\mathrm{Cu}-\mathrm{K} \alpha$ & 7,308 & 12,815 & 1,753 \\
30 & $\mathrm{Zn}$ & $\mathrm{Zn}-\mathrm{K} \alpha$ & 17,741 & 31,131 & 1,755 \\
33 & $\mathrm{As}$ & $\mathrm{As}-\mathrm{K} \beta 1$ & 0,027 & 0,049 & 1,841 \\
34 & $\mathrm{Se}$ & $\mathrm{Se}-\mathrm{K} \alpha$ & 0,515 & 0,588 & 1,143 \\
42 & $\mathrm{Mo}$ & $\mathrm{Mo}-\mathrm{K} \alpha$ & 3,615 & 4,525 & 1,252 \\
47 & $\mathrm{Ag}$ & $\mathrm{Ag}-\mathrm{K} \alpha$ & 1,242 & 3,455 & 2,781 \\
48 & $\mathrm{Cd}$ & $\mathrm{Cd}-\mathrm{K} \alpha$ & 0,326 & 0,126 & 0,388 \\
80 & $\mathrm{Hg}$ & $\mathrm{Hg}-\mathrm{L} \alpha$ & 0,147 & 0,002 & 0,012 \\
82 & $\mathrm{~Pb}$ & $\mathrm{~Pb}-\mathrm{L} \beta 1$ & 2,276 & 2,854 & 1,254 \\
\hline
\end{tabular}

I $\mathrm{EX}^{*}=$ Intensidade Experimental $(\mathrm{kcps})$;

$\mathrm{I} \mathrm{T}^{* *}=$ Intensidade calculada - Método de Parâmetros Fundamentais (kcps). 
APÊNDICE G - Curva de sensibilidade instrumental, do SRM 2584, para as linhas de emissão $K$ e $L$ do espectrômetro de fluorescência de raios $X$, WDXRF RIGAKU Co., RIX 3000.

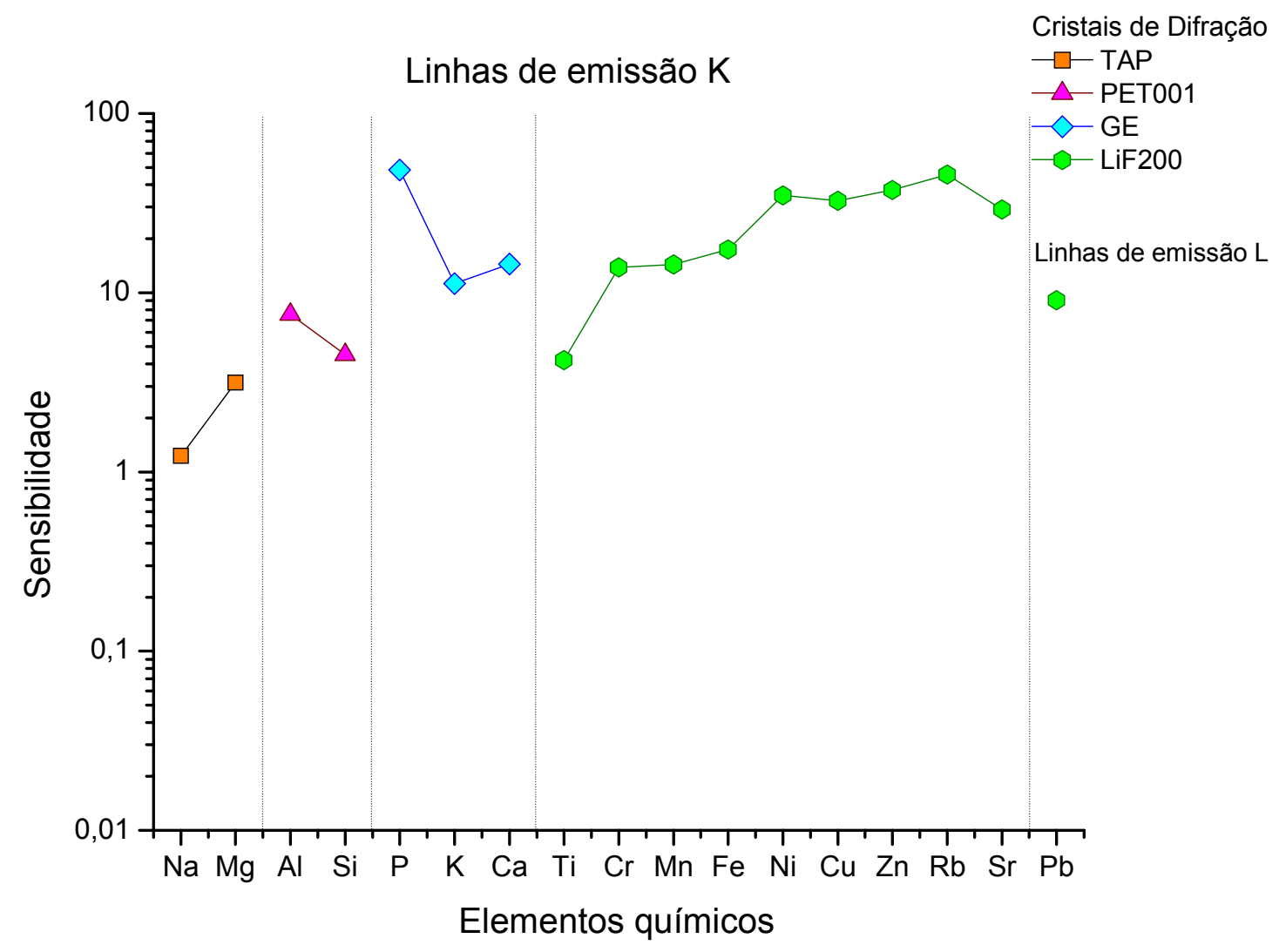


APÊNDICE H- Curva de sensibilidade instrumental, do SRM 2781, para as linhas de emissão $\mathrm{K}$ e $\mathrm{L}$ do espectrômetro de fluorescência de raios $X$, WDXRF RIGAKU Co., RIX 3000.

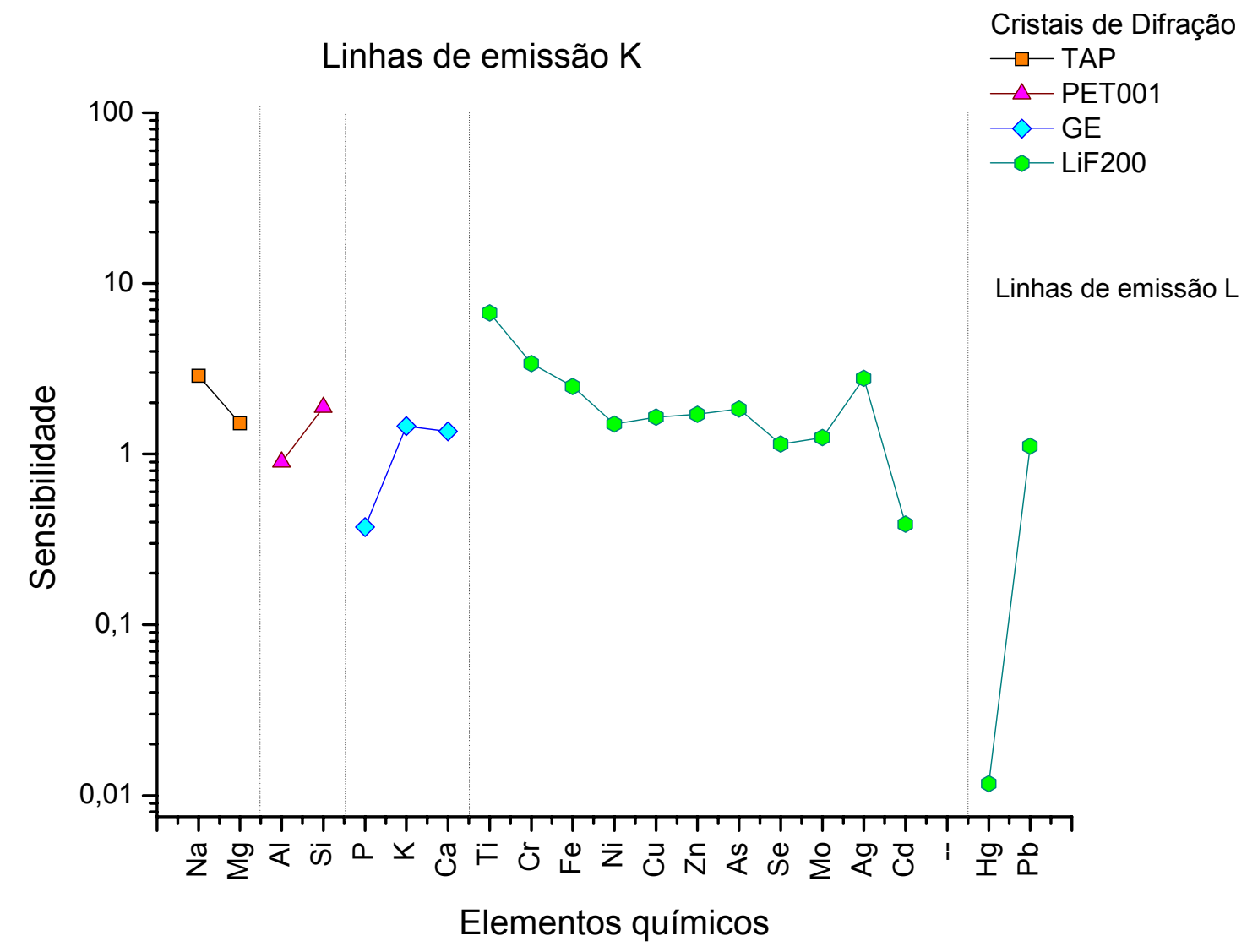


APÊNDICE I - Condições de medidas utilizadas para a obtenção das curvas de calibração (Cromatógrafo GCMS SHIMADZU, QP2010 Plus)

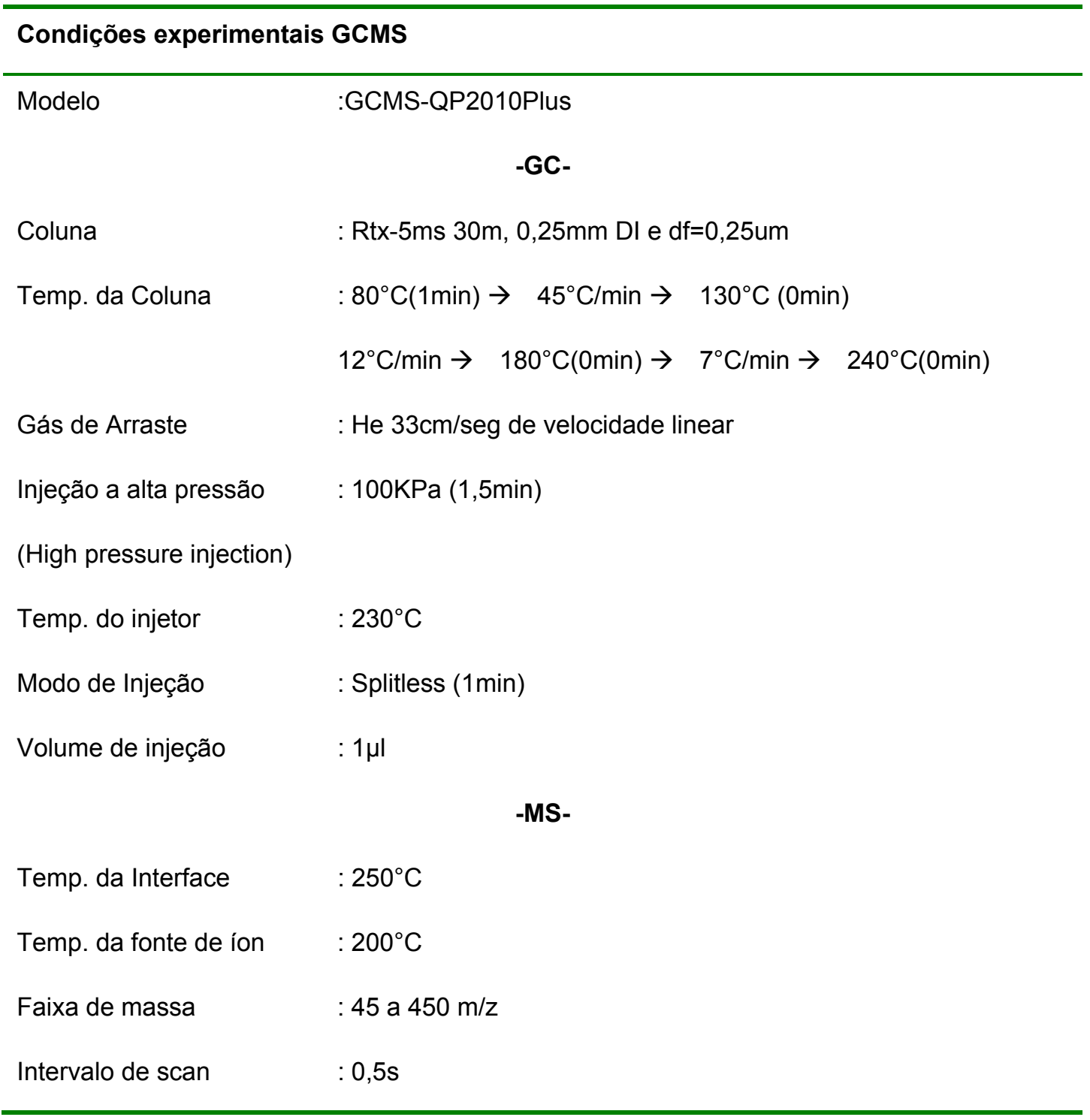


APENDICE J - Testes estatísticos para a determinação dos outliers

A distância de Mahalanobis quadrática é um método que se verifica a hipótese de aceitação ou rejeição dos dados a um determinado nível de confiança, a qual é dada pela Eq. abaixo:

$$
d_{M}^{2}(\vec{x}, \vec{y})=^{t}(\vec{x}-\vec{y}) S_{y}^{-1}(\vec{x}-\vec{y})
$$

$\mathrm{Na}$ qual,

$t \equiv$ matriz transposta;

$\vec{x} \equiv$ vetor da amostra no espaço m-dimensional que contém as concentrações de $\mathrm{m}$ elementos (vetor da média das amostras);

$\vec{y} \equiv$ vetor da média de todo o grupo;

$S_{y}^{-1} \equiv$ matriz de covariância do grupo que contem o quadrado da dispersão na diagonal.

Considerando as incertezas das medidas aplicou-se a distância de Mahalanobis modificada (Beier e Mommsen, 1994 apud Toyota):

$$
d_{M+U, n, c, \text { dil,red }}^{2}(\vec{x}, \vec{y})=\frac{1}{m-1} \sum_{k=1}^{m} \frac{\left(f_{o} x_{k}-y_{k}\right)^{2}}{f_{o}^{2} \sigma_{X k}^{2}+\sigma_{Y k}^{2}}
$$

Na qual,

$x_{K}$ e $y_{Y K} \quad \equiv$ valores das concentrações do elemento $\mathrm{k}$ nas amostras ou grupos $\mathrm{x}$ e y;

$\sigma_{X K}$ e $\sigma_{Y K} \quad \equiv$ incertezas correspondentes;

f $\quad \equiv$ fator de diluição;

O $f$ entre duas amostras $\mathrm{x}$ e y pode ser calculado por meio da Eq. que segue (Beier e Mommsen, 1994 apud Toyota): 


$$
\frac{\partial}{\partial f}=\left[{ }^{t}(f \vec{x}-\vec{y})\left(f^{2} S_{x}+S_{y}\right)^{-1}(f \vec{x}-\vec{y})\right]=0
$$

Posteriormente, foi aplicado o teste de Shapiro-Wilk (W) para testar a normalidade das amostras, o qual seguiu as etapas:

- Primeiramente foram consideradas duas hipóteses:

$\mathrm{H}_{0}$ : A amostra provém de uma população normal;

$\mathrm{H}_{1}$ : A amostra não provém de uma população normal.

- Em seguida, foram ordenados os números de observações $(N)$ da amostra:

$$
x_{1} \leq x_{2} \leq x_{3} \leq \cdots \leq x_{N}
$$

- Calculou-se:

$$
\sum_{i=1}^{N}\left(x_{i}-\bar{x}\right)^{2}=\sum_{i=1}^{n} x_{i}^{2}-\frac{\left(\sum_{i=1}^{N} x_{i}\right)^{2}}{N}=\sum_{i=1}^{N} x_{i}^{2}-N_{x}^{-2}
$$

- Posteriormente:

$$
b=\sum_{i=1}^{N / 2} \alpha_{N-i+1} \cdot\left(x_{N-i+1}-x_{i}\right)
$$

Os N sendo ímpares: desprezam-se as observações medianas

- Calculou-se o valor de W:

$$
W=\frac{b^{2}}{\sum\left(x_{i}-\bar{x}\right)^{2}}
$$

- Por fim, decidiu-se:

Rejeitar $\mathrm{H}_{0}$ ao nível de significância $\alpha$ ao passo que:

$$
W_{\text {calc }}<W_{\alpha}
$$


APÊNDICE K - Procedimento da análise dos fatores

O procedimento da análise dos fatores pode ser expresso por:

$$
X_{j}=\sum_{r=1}^{p} a_{j r} f_{r}+e_{j}
$$

Na qual,

$X_{j} \equiv$ variável original, existindo "m" $X_{j}$

$p \equiv$ número "especificado" de fatores;

$a_{j r} \equiv$ coeficiente que representa o carregamento da j'ésima variável sobre o r'ésimo fator;

$f_{r} \equiv$ r'ésimo fator;

$e_{j} \equiv$ variação casual única relativa a variável original $X_{j}$.

As variáveis, expressas em termos de vetores num sistema de coordenadas ortogonais, em que o comprimento representa a magnitude, agrupar-se-ão conforme o relacionamento entre si. Por esses agrupamentos de vetores poderão passar eixos, denominados fatores, que acusarão, pelo valor da projeção dos vetores sobre os eixos, a carga fatorial (factor loading) das variáveis sobre si. Esses fatores representam o número mínimo de causas que condicionam um máximo de variabilidade existente. A comunalidade (communallity), $\mathrm{h}^{2}$, isto é, a soma dos quadrados das cargas fatoriais das variáveis sobre cada fator indica a eficiência dos mesmos na explicação da variabilidade total.

Os fatores são encontrados fazendo com que o primeiro eixo esteja em tal posição que a soma dos quadrados dos pesos fatoriais em relação a ele seja maximizada, o que equivale a colocá-lo paralelamente ao principal agrupamento de vetores. O segundo eixo é colocado ortogonalmente, de modo que também 
seja maximizada a soma de quadrados dos pesos fatoriais para este segundo eixo, e assim por diante quanto aos demais fatores.

Uma das dificuldades resultantes deste procedimento é que o padrão de carregamento para cada componente pode não fornecer dimensões facilmente interpretáveis. Por exemplo, em uma matriz de coeficientes de correlação em que nenhum dos coeficientes é particularmente alto, o padrão de carregamento que pode ocorrer com respeito ao primeiro fator pode ser da mesma ordem relativa de magnitude que o existente em relação ao segundo fator, ao terceiro fator e assim por diante. Haverá necessidade, então, de uma rotação dos eixos fatoriais. A finalidade dessa rotação é maximizar colocando os eixos fatoriais numa única posição tal que cada fator possa ser interpretado pelos maiores carregamentos possível relacionados com o menor número de variáveis possível.

Quando se está interessada no relacionamento entre variáveis, o cálculo dos autovalores e autovetores são feitos a partir de uma matriz padronizada de variâncias-covariâncias, isto é, uma matriz de coeficientes de correlação entre "p" variáveis, tendo todas o mesmo peso.

Os autovetores são calculados de tal modo a definir "m" vetores com tamanho unitário. Isso é conseguido multiplicando cada elemento do autovetor normalizado pela raiz quadrada do correspondente autovalor. O resultado é um fator, ou seja, um vetor constituído por cargas fatoriais.

A matriz de variâncias e covariâncias observadas, $\left[S^{2}\right]$, é igual ao produto da matriz de carregamentos fatoriais (factor loading) $\left[\mathrm{A}^{\mathrm{R}}\right]$, de dimensões $\mathrm{m} \times \mathrm{p}$, multiplicada pelo seu transposto, mais uma matriz diagonal de variâncias únicas, [var $\mathrm{E}_{\mathrm{jj}}$ ].

$$
\left[S^{2}\right]=\left[A^{R}\right] \cdot\left[A^{R}\right]^{\prime}+\left[\operatorname{var} E_{j j}\right]
$$


Como na análise fatorial $p<m$, a variância nas $m$ variáveis é, portanto, derivada dos $p$ fatores, porém a contribuição é feita por fontes únicas que afetam independentemente as $\mathrm{m}$ variáveis originais. Esses $\mathrm{p}$ fatores subjacentes são conhecidos como fatores comuns e resumem a contribuição independente como um único fator.

Deve ser notado que $\mathrm{p}$ dever ser conhecido previamente à análise e isso implica numa restrição. Caso $p$ não seja especificado a partição de variáveis entre os fatores comuns e o fator único torna-se indeterminada. Os autovalores e, consequentemente, os fatores, representam a proporção da variância total explicada pelo respectivo autovetor e cada carga fatorial é proporcional à raiz quadrada da quantia de variância atribuída pela respectiva variável ao fator.

As comunalidades $\left(h_{j}^{2}\right)$ indicam quanto da variabilidade total está sendo explicada pelo conjunto de fatores. Para que os "p" fatores ortogonais situados no espaço "m" dimensional sejam mais facilmente entendidos é necessário que estejam em tal posição, de modo que as projeções de cada variável sobre o eixo fatorial situem-se o melhor possível, seja junto a extremidade, seja junto à origem. Em outras palavras, haverá necessidade de um critério de maximização da variância dos carregamentos sobre os fatores, o que é conseguido pela rotação dos eixos fatoriais.

$$
S_{K}^{2}=\frac{p \sum_{j=i}^{m}\left(a_{j p}^{2} / h_{j}^{2}\right)^{2}-\left(\sum_{j=i}^{m} a_{j p}^{2} / h_{j}^{2}\right)^{2}}{p^{2}}
$$


Na qual,

$S_{k}^{2} \equiv$ variância das cargas fatoriais;

$p \equiv$ número de fatores;

$m \equiv$ carregamento da variável j no fator $p$;

$a_{j p} \equiv$ comunidade da j'ésima variável;

$h_{j}^{2} \equiv$ comunidade da j'ésima variável;

A quantidade que se deseja maximizar é:

$$
V=\sum_{k=1}^{p} S_{k}^{2}
$$

Finalmente, depois de encontrada a matriz fatorial rotada se a mesma for multiplicada pela matriz inicial de dados obtêm-se uma matriz dos "factor score". Esses "factor score" representam estimações das contribuições dos vários fatores a cada observação original e podem ser utilizados na classificação de amostras. Maiores detalhes podem ser encontrados em Davis (1986) ou Reyment e Jöreskog (1993) 
APÊNDICE L - Equações para o cálculo do ingresso ao receptor a partir da ingestão, contato dérmico e inalação

Para o cálculo do ingresso a partir da ingestão de poeira contaminada aplicou-se a Eq. que se segue (CETESB, 2005).

$$
I=C_{S} \times \frac{I R \times F I \times E F \times E D \times C F}{B W} \times \frac{1}{A T}
$$

Na qual,

$$
\begin{array}{lll}
I\left(\mathrm{mg} \mathrm{kg}^{-1} \mathrm{dia}\right) & \equiv & \text { ingresso pela ingestão de poeira contaminada; } \\
C S\left(\mathrm{mg} \mathrm{kg}^{-1}\right) & \equiv & \text { concentração do contaminante na poeira; } \\
I R\left(\mathrm{mg} \mathrm{dia}^{-1}\right) & \equiv & \text { taxa de ingestão da poeira; } \\
F I & \equiv & \text { fração ingerida da fonte; } \\
E F\left(\text { dias } \mathrm{ano}^{-1}\right) & \equiv & \text { freqüência de exposição; } \\
E D(\text { ano }) & \equiv & \text { duração da exposição; } \\
C F\left(10^{-6} \mathrm{~kg} \mathrm{mg}^{-1}\right) & \equiv & \text { fator de conversão; } \\
B W(\mathrm{~kg}) & \equiv & \text { peso corpóreo; } \\
A T(\text { dias }) & \equiv & \text { período de exposição. }
\end{array}
$$


A equação utilizada para o cálculo do ingresso ao receptor a partir do contato dérmico com a poeira contaminada é (CETESB, 2005):

$$
I=C_{S} \times \frac{S A \times A F \times A B S \times E F \times E D \times C F}{B W} \times \frac{1}{A T}
$$

Na qual,

$\begin{array}{lll}I\left(\mathrm{mg} \mathrm{kg}^{-1} \mathrm{dia}\right) & \equiv & \text { dose de ingresso pela ingestão; } \\ C S\left(\mathrm{mg} \mathrm{L}^{-1}\right) & \equiv & \text { concentração do composto químico na poeira; } \\ S A\left(\mathrm{~cm}^{2}\right) & \equiv & \text { superfície da pele disponível para contato; } \\ A F\left(\mathrm{mg} \mathrm{cm}^{3}\right) & \equiv & \text { fator de aderência da poeira na pele; } \\ A B S & \equiv & \text { fator de absorção; } \\ E F\left(\text { dias ano }{ }^{-1}\right) & \equiv & \text { freqüência de exposição; } \\ E D(\mathrm{ano}) & \equiv & \text { duração da exposição; } \\ C F\left(10^{-6} \mathrm{~kg} \mathrm{mg}^{-1}\right) & \equiv & \text { fator de conversão; } \\ B W(\mathrm{~kg}) & \equiv & \text { peso corpóreo; } \\ A T(\text { dias }) & \equiv & \text { período de exposição. }\end{array}$

Um receptor humano pode ser exposto a um composto químico de interesse presente no ar pelas seguintes vias de ingresso: inalação de vapores e de partículas. 
Nos casos de exposição por via inalação de partículas, provenientes de poeiras contaminadas, deve ser considerado como meio contaminado o solo superficial. A Equação abaixo foi aplicada para o cálculo do ingresso ao receptor a partir da inalação de partículas presentes no ar (CETESB, 2005).

$$
I=C_{S} \times \frac{I P \times F R \times F A \times E T \times E R \times E D}{B W} \times \frac{1}{A T}
$$

$\mathrm{Na}$ qual,

$$
\begin{array}{llll}
I\left(\mathrm{mg} \mathrm{kg}^{-1} \mathrm{dia}\right) & \equiv & \begin{array}{l}
\text { ingresso a partir da inalação de vapores presentes no } \\
\mathrm{ar} ;
\end{array} \\
C S\left(\mathrm{mg} \mathrm{kg}^{-1}\right) & \equiv & \text { concentração do contaminante na poeira; } \\
I P\left(\mathrm{Kg} \mathrm{hora}^{-1}\right) & \equiv & \text { taxa de inalação de partículas; } \\
F R & \equiv & \text { fator de retenção de partículas no pulmão; } \\
F A & \equiv & \text { fator de absorção relativa; } \\
E T\left(\text { horas dia }{ }^{-1}\right) & \equiv & \text { tempo de exposição; } \\
E F\left(\text { dias ano }{ }^{-1}\right) & \equiv & \text { freqüência de exposição; } \\
E D(\text { ano }) & \equiv & \text { duração da exposição; } \\
B W(\mathrm{~kg}) & \equiv & \text { peso corpóreo; } \\
A T(\text { dias }) & \equiv & \text { período de exposição. }
\end{array}
$$


APÊNDICE M - Valores das massas, em porcentagem (\%), da análise por análise granulométrica

\begin{tabular}{|c|c|c|c|c|c|c|}
\hline \multirow{3}{*}{ PA } & \multicolumn{6}{|l|}{ Frações } \\
\hline & $\begin{array}{c}840 \mu \mathrm{m} \\
\text { (A) }\end{array}$ & $\begin{array}{c}840-300 \mu \mathrm{m} \\
\text { (B) }\end{array}$ & $\begin{array}{c}300-150 \mu \mathrm{m} \\
\text { (C) }\end{array}$ & $\begin{array}{l}150-75 \mu \mathrm{m} \\
\text { (D) }\end{array}$ & $\begin{array}{c}75-63 \mu \mathrm{m} \\
\text { (E) }\end{array}$ & $\begin{array}{c}<63 \mu \mathrm{m} \\
\text { (F) }\end{array}$ \\
\hline & \multicolumn{6}{|c|}{$\%$} \\
\hline 1 & 36,24 & 22,15 & 8,05 & 8,72 & 4,70 & 20,13 \\
\hline 2 & 47,70 & 21,76 & 5,86 & 8,37 & 3,77 & 12,55 \\
\hline 3 & 28,77 & 30,19 & 11,79 & 8,49 & 5,19 & 15,57 \\
\hline 4 & 19,30 & 19,30 & 8,77 & 11,40 & 8,77 & 32,46 \\
\hline 5 & 31,21 & 10,83 & 6,37 & 19,11 & 6,37 & 26,11 \\
\hline 6 & 23,91 & 12,50 & 23,37 & 25,00 & 4,35 & 10,87 \\
\hline 7 & 18,97 & 20,11 & 17,82 & 27,59 & 4,02 & 11,49 \\
\hline 8 & 27,67 & 19,50 & 18,24 & 12,58 & 3,14 & 18,87 \\
\hline 9 & 18,72 & 27,27 & 21,39 & 10,16 & 9,09 & 13,37 \\
\hline 10 & 25,32 & 35,44 & 8,86 & 8,86 & 8,86 & 12,66 \\
\hline 11 & 16,99 & 8,74 & 19,42 & 19,42 & 11,17 & 24,27 \\
\hline 12 & 23,78 & 1,62 & 25,95 & 25,95 & 1,62 & 21,08 \\
\hline 13 & 31,09 & 13,99 & 15,54 & 15,54 & 7,77 & 16,06 \\
\hline 14 & 22,52 & 41,44 & 9,01 & 9,01 & 4,50 & 13,51 \\
\hline 15 & 21,66 & 17,83 & 18,47 & 18,47 & 6,37 & 17,20 \\
\hline 16 & 87,67 & 2,24 & 2,24 & 2,24 & 1,12 & 4,48 \\
\hline 17 & 85,69 & 3,41 & 2,90 & 2,90 & 1,70 & 3,41 \\
\hline 18 & 95,59 & 0,59 & 0,42 & 0,59 & 0,42 & 2,38 \\
\hline 19 & 93,76 & 1,16 & 1,16 & 0,58 & 1,04 & 2,31 \\
\hline 20 & 70,85 & 5,18 & 6,93 & 6,87 & 2,36 & 7,81 \\
\hline 21 & 41,78 & 2,08 & 52,22 & 0,80 & 0,58 & 2,54 \\
\hline 22 & 37,45 & 10,51 & 25,49 & 2,50 & 3,42 & 20,63 \\
\hline 23 & 75,09 & 5,81 & 3,29 & 3,52 & 0,84 & 11,44 \\
\hline 24 & 87,93 & 1,87 & 1,45 & 1,96 & 0,94 & 5,87 \\
\hline 25 & 9,59 & 13,01 & 6,85 & 13,01 & 6,85 & 50,68 \\
\hline 26 & 32,33 & 9,77 & 8,65 & 7,89 & 3,01 & 38,35 \\
\hline 27 & 28,76 & 13,72 & 15,04 & 10,18 & 6,19 & 26,11 \\
\hline 28 & 92,40 & 1,60 & 1,04 & 1,32 & 1,57 & 2,07 \\
\hline 29 & 82,30 & 3,68 & 1,92 & 2,42 & 2,12 & 7,56 \\
\hline 30 & 87,73 & 2,95 & 1,47 & 1,64 & 0,82 & 5,40 \\
\hline 31 & 96,13 & 1,10 & 0,65 & 0,77 & 0,25 & 1,09 \\
\hline 32 & 88,06 & 5,70 & 3,48 & 1,74 & 0,45 & 0,56 \\
\hline 33 & 85,99 & 6,03 & 4,66 & 2,06 & 0,53 & 0,73 \\
\hline 34 & 92,52 & 1,24 & 0,80 & 1,24 & 0,75 & 3,45 \\
\hline 35 & 86,26 & 1,76 & 1,58 & 2,65 & 1,17 & 6,58 \\
\hline
\end{tabular}


APÊNDICE M - Valores das massas, em porcentagem (\%), da análise por análise granulométrica

\begin{tabular}{|c|c|c|c|c|c|c|}
\hline \multirow{3}{*}{ PA } & \multicolumn{6}{|l|}{ Frações } \\
\hline & $\begin{array}{l}840 \mu \mathrm{m} \\
\text { (A) }\end{array}$ & $\begin{array}{l}840-300 \mu \mathrm{m} \\
\text { (B) }\end{array}$ & $\begin{array}{c}300-150 \mu \mathrm{m} \\
(\mathrm{C})\end{array}$ & $\begin{array}{c}150-75 \mu \mathrm{m} \\
\text { (D) }\end{array}$ & $\begin{array}{c}\text { 75-63 } \mu \mathrm{m} \\
(\mathrm{E})\end{array}$ & $\begin{array}{c}<63 \mu \mathrm{m} \\
(\mathrm{F})\end{array}$ \\
\hline & \multicolumn{6}{|c|}{$\%$} \\
\hline 36 & 62,37 & 11,48 & 6,61 & 5,51 & 1,99 & 12,04 \\
\hline 37 & 87,72 & 1,22 & 1,10 & 2,56 & 1,18 & 6,22 \\
\hline 38 & 91,97 & 0,80 & 1,02 & 1,17 & 0,51 & 4,53 \\
\hline 39 & 96,21 & 0,53 & 0,38 & 0,68 & 0,46 & 1,75 \\
\hline 40 & 87,35 & 2,06 & 1,47 & 2,50 & 1,29 & 5,33 \\
\hline 41 & 94,30 & 1,12 & 0,75 & 0,84 & 0,56 & 2,43 \\
\hline 42 & 87,57 & 2,58 & 1,60 & 1,93 & 1,02 & 5,30 \\
\hline 43 & 77,59 & 4,87 & 3,65 & 4,54 & 2,10 & 7,24 \\
\hline 44 & 84,47 & 3,99 & 3,18 & 3,75 & 0,95 & 3,66 \\
\hline 45 & 84,45 & 3,93 & 1,80 & 2,29 & 0,98 & 6,55 \\
\hline 46 & 94,30 & 1,79 & 0,86 & 0,66 & 1,06 & 1,33 \\
\hline 47 & 64,41 & 4,43 & 4,32 & 9,98 & 5,43 & 11,42 \\
\hline 48 & 91,20 & 1,42 & 1,15 & 1,30 & 0,42 & 4,51 \\
\hline 49 & 66,64 & 9,96 & 8,70 & 7,89 & 2,42 & 4,39 \\
\hline 50 & 61,50 & 9,28 & 4,57 & 4,19 & 2,41 & 18,04 \\
\hline 51 & 63,16 & 5,85 & 5,85 & 2,92 & 5,85 & 16,37 \\
\hline 52 & 82,90 & 4,99 & 2,85 & 3,33 & 1,43 & 4,51 \\
\hline 53 & 86,22 & 1,76 & 1,59 & 2,66 & 1,18 & 6,59 \\
\hline 54 & 44,44 & 5,90 & 6,60 & 16,32 & 5,21 & 21,53 \\
\hline 55 & 83,51 & 3,16 & 2,21 & 2,78 & 0,77 & 7,57 \\
\hline 56 & 76,76 & 3,20 & 3,41 & 4,48 & 5,33 & 6,82 \\
\hline 57 & 92,13 & 1,70 & 1,02 & 1,09 & 1,36 & 2,71 \\
\hline 58 & 87,71 & 3,16 & 2,49 & 2,66 & 1,50 & 2,49 \\
\hline 59 & 84,30 & 4,96 & 2,89 & 2,07 & 1,65 & 4,13 \\
\hline 60 & 92,20 & 2,49 & 1,35 & 1,35 & 0,52 & 2,08 \\
\hline 61 & 93,54 & 1,45 & 0,78 & 0,89 & 1,11 & 2,23 \\
\hline 62 & 93,21 & 1,28 & 0,77 & 0,90 & 1,28 & 2,56 \\
\hline 63 & 92,13 & 1,20 & 1,33 & 1,33 & 1,33 & 2,67 \\
\hline 64 & 86,52 & 2,25 & 2,25 & 2,25 & 2,25 & 4,49 \\
\hline 65 & 94,15 & 0,97 & 0,97 & 0,49 & 0,97 & 2,44 \\
\hline 66 & 72,10 & 1,73 & 1,73 & 4,68 & 7,28 & 12,48 \\
\hline 67 & 72,36 & 3,11 & 3,11 & 5,28 & 5,28 & 10,87 \\
\hline 68 & 60,27 & 10,05 & 7,79 & 10,16 & 5,42 & 6,32 \\
\hline 69 & 80,00 & 3,06 & 2,50 & 4,17 & 1,39 & 8,89 \\
\hline $\bar{X}$ & $67 \pm 28$ & $8 \pm 9$ & $7 \pm 9$ & $6 \pm 7$ & $3 \pm 3$ & $10 \pm 9$ \\
\hline $50-P$ & 82 & 4 & 3 & 3 & 2 & 7 \\
\hline IC & $9,6-96,2$ & $0,5-41,4$ & $0,4-52,2$ & $0,5-27,6$ & $0,2-11,2$ & $0,6-50,7$ \\
\hline
\end{tabular}


APÊNDICE N - Valores das concentrações totais dos constituintes inorgânicos determinados em poeira por WDXRF, de cada ponto de amostragem na Fração D

\begin{tabular}{|c|c|c|c|c|c|c|c|c|c|c|c|c|c|c|c|c|c|c|c|c|c|}
\hline \multirow{3}{*}{ PA } & \multicolumn{21}{|c|}{ Concentração de elementos } \\
\hline & \multicolumn{9}{|c|}{$(\%)$} & \multicolumn{12}{|c|}{$\left(\mu g^{-1}\right)$} \\
\hline & Si & $\mathrm{Ca}$ & Mg & Al & $\mathbf{S}$ & $\mathrm{Fe}$ & K & $\mathrm{Cl}$ & $\mathrm{Na}$ & $\mathrm{Zn}$ & $\mathrm{Ti}$ & $\mathbf{P}$ & Mn & $\mathrm{Cu}$ & $\mathrm{Sr}$ & $\mathrm{Cr}$ & $\mathbf{P b}$ & $\mathbf{Z r}$ & $\mathrm{Ni}$ & $\mathrm{Br}$ & $\mathbf{R b}$ \\
\hline 1 & 2,87 & 3,32 & 0,48 & 0,93 & 0,91 & 0,95 & 0,41 & 0,69 & 0,49 & 647 & 1493 & 784 & 149 & 196 & 47 & 77 & 65 & 33 & 80 & 29 & 7 \\
\hline 2 & 3,02 & 2,23 & 0,47 & 0,83 & 0,67 & 1,12 & 1,11 & 1,49 & 1,33 & 996 & 1090 & 797 & 140 & 138 & 48 & 83 & 73 & 27 & 69 & 40 & 9 \\
\hline 3 & 2,88 & 2,51 & 0,38 & 1,07 & 0,53 & 0,84 & 0,79 & 0,92 & 0,54 & 542 & 1244 & 959 & 174 & 212 & 50 & 75 & 32 & 24 & 61 & 21 & 5 \\
\hline 4 & 1,31 & 0,92 & 0,14 & 0,32 & 1,29 & 0,51 & 0,36 & 1,34 & 0,63 & 2060 & 1117 & 1640 & 73 & 1093 & 35 & 46 & 42 & 27 & 55 & 11 & 5 \\
\hline 5 & 1,30 & 1,61 & 0,19 & 0,56 & 0,77 & 0,44 & 0,35 & 0,77 & 0,53 & 800 & 1084 & 660 & 84 & 111 & 18 & 45 & 51 & 10 & 59 & 12 & 7 \\
\hline 6 & 2,92 & 2,69 & 0,44 & 0,94 & 0,70 & 0,97 & 0,77 & 1,03 & 0,79 & 728 & 1276 & 847 & 150 & 182 & 48 & 79 & 57 & 28 & 70 & 30 & 7 \\
\hline 7 & 2,49 & 3,26 & 0,35 & 0,88 & 0,74 & 0,64 & 0,55 & 0,87 & 0,61 & 625 & 1220 & 775 & 124 & 151 & 34 & 64 & 44 & 16 & 59 & 16 & 5 \\
\hline 8 & 3,90 & 2,92 & 0,58 & 1,29 & 0,85 & 1,17 & 0,59 & 0,76 & 0,56 & 847 & 1932 & 953 & 136 & 275 & 40 & 80 & 76 & 28 & 70 & 30 & 7 \\
\hline 9 & 2,66 & 2,79 & 0,39 & 0,87 & 0,82 & 0,81 & 0,60 & 0,98 & 0,69 & 864 & 1310 & 902 & 124 & 277 & 39 & 69 & 54 & 23 & 65 & 24 & 6 \\
\hline 10 & 3,40 & 3,61 & 0,52 & 1,04 & 0,82 & 0,98 & 0,74 & 1,06 & 0,88 & 792 & 1451 & 819 & 130 & 182 & 41 & 79 & 66 & 20 & 66 & 35 & 6 \\
\hline 11 & 2,63 & 2,88 & 0,39 & 0,77 & 0,90 & 0,81 & 0,69 & 1,20 & 0,88 & 1079 & 1204 & 997 & 119 & 286 & 43 & 70 & 55 & 24 & 58 & 27 & 7 \\
\hline 12 & 3,16 & 4,32 & 0,55 & 0,97 & 0,78 & 2,63 & 0,47 & 0,83 & 0,67 & 720 & 1625 & 853 & 109 & 265 & 29 & 79 & 45 & 12 & 60 & 9 & 3 \\
\hline 13 & 3,07 & 2,91 & 0,71 & 0,93 & 0,79 & 1,34 & 0,60 & 0,93 & 0,69 & 851 & 1368 & 894 & 128 & 266 & 38 & 74 & 58 & 24 & 62 & 22 & 6 \\
\hline 14 & 2,96 & 3,33 & 0,52 & 0,92 & 0,77 & 0,86 & 0,58 & 0,93 & 0,72 & 829 & 1464 & 890 & 119 & 258 & 35 & 75 & 51 & 17 & 61 & 19 & 5 \\
\hline 15 & 5,55 & 3,08 & 0,68 & 2,04 & 0,75 & 1,20 & 0,64 & 0,71 & 0,53 & 710 & 2375 & 974 & 141 & 222 & 45 & 74 & 83 & 36 & 60 & 19 & 6 \\
\hline 16 & 2,50 & 1,12 & 0,35 & 0,89 & 0,75 & 0,65 & 0,45 & 0,89 & 0,71 & 664 & 1664 & 818 & 67 & 373 & 9 & 86 & 26 & 6 & 54 & 9 & 2 \\
\hline 17 & 3,29 & 5,67 & 0,49 & 1,00 & 0,93 & 0,64 & 0,52 & 0,93 & 0,76 & 534 & 1332 & 705 & 113 & 131 & 34 & 73 & 50 & 14 & 57 & 2 & 3 \\
\hline 18 & 3,69 & 6,17 & 0,82 & 1,00 & 0,64 & 0,78 & 0,45 & 0,67 & 0,54 & 963 & 1880 & 1037 & 147 & 291 & 43 & 78 & 59 & 15 & 70 & 2 & 5 \\
\hline 19 & 2,93 & 2,96 & 0,44 & 0,96 & 0,81 & 0,79 & 0,56 & 0,93 & 0,67 & 879 & 1.476 & 931 & 121 & 308 & 36 & 71 & 53 & 21 & 63 & 16 & 5 \\
\hline 20 & 3,02 & 3,19 & 0,50 & 0,96 & 0,80 & 1,13 & 0,62 & 0,95 & 0,72 & 815 & 1.428 & 881 & 127 & 238 & 39 & 74 & 56 & 21 & 63 & 24 & 6 \\
\hline 21 & 7,37 & 3,03 & 0,89 & 2,65 & 0,74 & 1,38 & 0,59 & 0,47 & 0,34 & 668 & 3336 & 947 & 132 & 194 & 44 & 76 & 154 & 51 & 66 & 15 & 7 \\
\hline 22 & 4,14 & 4,23 & 0,70 & 1,21 & 0,89 & 1,47 & 0,59 & 0,77 & 0,64 & 858 & 2161 & 1014 & 148 & 274 & 40 & 89 & 85 & 22 & 72 & 27 & 7 \\
\hline 23 & 7,56 & 2,28 & 1,09 & 3,72 & 0,70 & 1,83 & 0,45 & 0,40 & 0,28 & 606 & 4105 & 1094 & 114 & 107 & 37 & 83 & 96 & 53 & 41 & 18 & 6 \\
\hline 24 & 7,18 & 3,77 & 0,69 & 1,59 & 0,78 & 0,92 & 0,73 & 0,53 & 0,41 & 729 & 2567 & 799 & 149 & 280 & 51 & 69 & 118 & 48 & 90 & 11 & 7 \\
\hline
\end{tabular}


APÊNDICE N - Valores das concentrações totais dos constituintes inorgânicos determinados em poeira por WDXRF, de cada ponto de amostragem na Fração D

Concentração de elementos

\begin{tabular}{|c|c|c|c|c|c|c|c|c|c|c|c|c|c|c|c|c|c|c|c|c|c|}
\hline \multirow[t]{2}{*}{ PA } & \multicolumn{9}{|c|}{$(\%)$} & \multicolumn{12}{|c|}{$\left(\mu g^{-1}\right)$} \\
\hline & $\mathrm{Si}$ & $\mathrm{Ca}$ & $\mathrm{Mg}$ & $\mathrm{Al}$ & $S$ & $\mathrm{Fe}$ & $\mathrm{K}$ & $\mathrm{Cl}$ & $\mathrm{Na}$ & $\mathrm{Zn}$ & $\mathrm{Ti}$ & $\mathrm{P}$ & $\mathrm{Mn}$ & $\mathrm{Cu}$ & $\mathrm{Sr}$ & $\mathrm{Cr}$ & $\mathrm{Pb}$ & $\mathrm{Zr}$ & $\mathrm{Ni}$ & $\mathrm{Br}$ & $\mathrm{Rb}$ \\
\hline 25 & 3,94 & 3,82 & 0,77 & 1,11 & 0,98 & 1,68 & 0,51 & 0,51 & 0,47 & 832 & 2134 & 1018 & 155 & 273 & 39 & 102 & 81 & 20 & 82 & 52 & 9 \\
\hline 26 & 3,88 & 3,81 & 0,74 & 1,25 & 1,09 & 1,74 & 0,55 & 0,56 & 0,49 & 957 & 2115 & 989 & 167 & 375 & 39 & 109 & 92 & 21 & 89 & 68 & 11 \\
\hline 27 & 4,84 & 2,83 & 0,59 & 1,76 & 0,75 & 1,17 & 0,64 & 0,90 & 0,69 & 756 & 2330 & 1401 & 140 & 232 & 43 & 74 & 84 & 31 & 51 & 17 & 5 \\
\hline 28 & 3,82 & 3,57 & 0,64 & 1,35 & 1,10 & 1,63 & 0,58 & 0,53 & 0,48 & 1040 & 2323 & 1081 & 168 & 396 & 38 & 100 & 89 & 29 & 130 & 57 & 6 \\
\hline 29 & 4,06 & 4,07 & 0,90 & 0,88 & 0,86 & 1,72 & 0,44 & 0,49 & 0,47 & 624 & 1945 & 954 & 141 & 149 & 40 & 104 & 72 & 11 & 34 & 47 & 12 \\
\hline 30 & 2,27 & 4,59 & 0,94 & 0,83 & 0,77 & 0,56 & 0,40 & 0,42 & 0,39 & 580 & 2421 & 1197 & 92 & 94 & 48 & 66 & 44 & 17 & 38 & 54 & 11 \\
\hline 31 & 6,80 & 3,59 & 0,50 & 2,03 & 0,61 & 1,03 & 0,70 & 0,44 & 0,29 & 403 & 1781 & 1012 & 212 & 343 & 59 & 64 & 41 & 34 & 72 & 2 & 6 \\
\hline 32 & 4,91 & 3,60 & 0,80 & 1,63 & 0,87 & 1,41 & 0,55 & 0,56 & 0,46 & 765 & 2544 & 1049 & 141 & 237 & 42 & 87 & 91 & 30 & 69 & 33 & 8 \\
\hline 33 & 9,58 & 2,68 & 0,50 & 2,73 & 1,04 & 0,95 & 1,15 & 1,23 & 0,72 & 688 & 3772 & 1761 & 191 & 112 & 80 & 58 & 24 & 34 & 27 & 21 & 3 \\
\hline 34 & 0,97 & 0,50 & 0,10 & 0,53 & 0,37 & 0,23 & 0,04 & 0,11 & 0,05 & 189 & 1961 & 238 & 44 & 29 & 27 & 1 & 1 & 11 & 20 & 2 & 2 \\
\hline 35 & 1,25 & 1,26 & 0,13 & 0,55 & 0,84 & 0,54 & 0,50 & 1,08 & 0,61 & 536 & 1178 & 705 & 150 & 182 & 10 & 104 & 31 & 5 & 83 & 3 & 1 \\
\hline 36 & 3,84 & 2,14 & 0,35 & 1,16 & 0,14 & 0,63 & 0,41 & 0,15 & 0,17 & 119 & 1744 & 323 & 118 & 72 & 42 & 1 & 1 & 40 & 28 & 3 & 4 \\
\hline 37 & 3,85 & 4,53 & 0,71 & 1,75 & 1,13 & 1,40 & 0,79 & 1,52 & 1,19 & 1163 & 3363 & 1555 & 187 & 357 & 43 & 98 & 150 & 20 & 42 & 1 & 6 \\
\hline 38 & 0,92 & 1,36 & 0,12 & 0,50 & 1,95 & 0,91 & 0,52 & 1,41 & 0,81 & 955 & 1603 & 953 & 99 & 461 & 18 & 95 & 119 & 14 & 36 & 6 & 4 \\
\hline 39 & 2,64 & 2,90 & 0,48 & 1,21 & 0,99 & 1,11 & 0,67 & 1,51 & 1,05 & 1052 & 2338 & 1392 & 137 & 342 & 32 & 106 & 210 & 20 & 43 & 9 & 3 \\
\hline 40 & 4,34 & 3,74 & 0,58 & 1,64 & 0,95 & 1,41 & 0,76 & 1,30 & 1,12 & 1119 & 2575 & 1880 & 166 & 345 & 36 & 125 & 223 & 26 & 41 & 11 & 22 \\
\hline 41 & 3,38 & 2,60 & 0,37 & 1,61 & 0,91 & 1,36 & 0,75 & 1,50 & 1,14 & 1083 & 2098 & 1561 & 191 & 418 & 39 & 103 & 160 & 19 & 48 & 15 & 6 \\
\hline 42 & 3,94 & 2,90 & 0,41 & 1,70 & 0,82 & 1,43 & 0,74 & 1,72 & 1,63 & 1064 & 2468 & 5153 & 157 & 353 & 34 & 120 & 183 & 20 & 37 & 12 & 1 \\
\hline 43 & 2,77 & 2,01 & 0,31 & 1,25 & 0,76 & 1,10 & 0,70 & 1,80 & 1,24 & 1023 & 1790 & 1487 & 144 & 455 & 28 & 95 & 171 & 12 & 49 & 13 & 5 \\
\hline 44 & 5,28 & 4,71 & 0,73 & 1,89 & 0,88 & 1,32 & 0,73 & 0,56 & 0,61 & 1038 & 2344 & 969 & 215 & 565 & 56 & 140 & 98 & 25 & 108 & 100 & 20 \\
\hline 45 & 2,77 & 2,75 & 0,36 & 1,12 & 0,94 & 0,99 & 0,62 & 1,24 & 0,92 & 1094 & 1897 & 1477 & 137 & 405 & 30 & 96 & 129 & 16 & 58 & 18 & 6 \\
\hline 46 & 2,56 & 1,62 & 0,19 & 1,06 & 0,75 & 0,84 & 0,83 & 2,15 & 1,22 & 1014 & 1898 & 1346 & 120 & 576 & 21 & 79 & 72 & 12 & 43 & 10 & 4 \\
\hline 47 & 4,51 & 3,22 & 0,33 & 1,37 & 1,06 & 1,08 & 0,71 & 1,20 & 1,09 & 1165 & 2264 & 1245 & 199 & 173 & 54 & 101 & 80 & 13 & 53 & 15 & 7 \\
\hline
\end{tabular}


APÊNDICE N - Valores das concentrações totais dos constituintes inorgânicos determinados em poeira por WDXRF, de cada ponto de amostragem na Fração D

Concentração de elementos

\begin{tabular}{|c|c|c|c|c|c|c|c|c|c|c|c|c|c|c|c|c|c|c|c|c|c|}
\hline \multirow{3}{*}{ PA } & \multicolumn{21}{|c|}{ Concentração de elementos } \\
\hline & \multicolumn{9}{|c|}{$(\%)$} & \multicolumn{12}{|c|}{$\left(\mu g^{-1}\right)$} \\
\hline & $\mathrm{Si}$ & $\mathrm{Ca}$ & $\mathrm{Mg}$ & $\mathrm{Al}$ & $S$ & $\mathrm{Fe}$ & $\mathrm{K}$ & $\mathrm{Cl}$ & $\mathrm{Na}$ & $\mathrm{Zn}$ & $\mathrm{Ti}$ & $P$ & $\mathrm{Mn}$ & $\mathrm{Cu}$ & $\mathrm{Sr}$ & $\mathrm{Cr}$ & $\mathrm{Pb}$ & $\mathrm{Zr}$ & $\mathrm{Ni}$ & $\mathrm{Br}$ & $\mathrm{Rb}$ \\
\hline 48 & 4,72 & 3,72 & 0,95 & 1,19 & 0,49 & 1,97 & 2,24 & 2,72 & 2,74 & 722 & 1318 & 6807 & 974 & 173 & 142 & 1 & 78 & 14 & 49 & 12 & 22 \\
\hline 49 & 2,07 & 1,15 & 0,21 & 0,36 & 0,26 & 0,51 & 0,32 & 0,41 & 0,23 & 2239 & 823 & 363 & 71 & 261 & 21 & 16 & 157 & 12 & 82 & 1 & 2 \\
\hline 50 & 2,27 & 1,84 & 0,26 & 0,93 & 1,26 & 0,88 & 0,78 & 1,33 & 1,03 & 1030 & 2345 & 1308 & 154 & 272 & 21 & 81 & 69 & 10 & 103 & 15 & 2 \\
\hline 51 & 2,45 & 1,76 & 0,25 & 0,96 & 0,79 & 0,67 & 0,50 & 1,42 & 0,91 & 1209 & 2112 & 790 & 114 & 958 & 27 & 67 & 78 & 11 & 62 & 12 & 3 \\
\hline 52 & 1,49 & 2,02 & 0,27 & 0,61 & 1,10 & 0,51 & 0,39 & 0,66 & 0,46 & 602 & 869 & 848 & 102 & 197 & 21 & 124 & 34 & 12 & 42 & 11 & 3 \\
\hline 53 & 1,70 & 6,01 & 0,34 & 0,76 & 0,61 & 0,64 & 0,53 & 1,25 & 0,77 & 712 & 1404 & 1024 & 90 & 227 & 23 & 85 & 41 & 8 & 42 & 13 & 4 \\
\hline 54 & 1,29 & 0,54 & 0,11 & 0,34 & 1,18 & 0,66 & 0,17 & 1,68 & 0,50 & 370 & 997 & 530 & 108 & 170 & 54 & 58 & 35 & 44 & 70 & 13 & 14 \\
\hline 55 & 1,50 & 0,72 & 0,29 & 0,44 & 0,70 & 0,57 & 0,14 & 0,59 & 0,22 & 367 & 825 & 567 & 130 & 62 & 68 & 58 & 56 & 55 & 54 & 10 & 13 \\
\hline 56 & 3,59 & 2,34 & 0,44 & 1,32 & 0,43 & 1,18 & 0,63 & 0,49 & 0,54 & 641 & 2227 & 620 & 153 & 215 & 43 & 73 & 150 & 30 & 35 & 1 & 5 \\
\hline 57 & 1,37 & 1,03 & 0,18 & 0,37 & 1,06 & 0,58 & 0,22 & 1,21 & 0,45 & 636 & 980 & 912 & 104 & 142 & 52 & 54 & 44 & 42 & 60 & 11 & 11 \\
\hline 58 & 0,60 & 0,39 & 0,06 & 0,16 & 1,42 & 0,36 & 0,14 & 1,46 & 0,50 & 1200 & 803 & 1170 & 49 & 110 & 23 & 41 & 31 & 15 & 40 & 9 & 7 \\
\hline 59 & 1,18 & 0,39 & 0,09 & 0,22 & 1,03 & 0,46 & 0,12 & 1,21 & 0,51 & 1260 & 992 & 1860 & 63 & 107 & 36 & 44 & 34 & 55 & 67 & 11 & 5 \\
\hline 60 & 2,83 & 2,68 & 0,19 & 0,74 & 2,44 & 0,84 & 0,53 & 1,34 & 0,93 & 1204 & 2181 & 1892 & 108 & 437 & 94 & 47 & 68 & 15 & 50 & 10 & 4 \\
\hline 61 & 3,12 & 1,06 & 0,19 & 0,81 & 0,74 & 0,71 & 0,47 & 1,18 & 1,03 & 2165 & 1520 & 2441 & 70 & 349 & 26 & 50 & 38 & 11 & 71 & 11 & 10 \\
\hline 62 & 3,07 & 1,11 & 0,18 & 0,81 & 1,06 & 0,75 & 0,62 & 1,19 & 1,26 & 2328 & 1564 & 2492 & 93 & 381 & 28 & 65 & 31 & 15 & 76 & 8 & 4 \\
\hline 63 & 2,43 & 1,07 & 0,16 & 0,66 & 0,94 & 0,73 & 0,43 & 1,31 & 0,98 & 3648 & 1536 & 1941 & 82 & 4244 & 25 & 54 & 56 & 13 & 71 & 9 & 2 \\
\hline 64 & 1,15 & 2,23 & 0,47 & 0,36 & 0,88 & 0,52 & 1,50 & 1,41 & 0,76 & 959 & 949 & 1834 & 128 & 128 & 17 & 59 & 1 & 4 & 53 & 18 & 2 \\
\hline 65 & 1,08 & 1,42 & 0,12 & 0,55 & 0,48 & 0,38 & 0,27 & 0,38 & 0,38 & 595 & 2290 & 544 & 76 & 275 & 11 & 539 & 719 & 7 & 65 & 1 & 1 \\
\hline 66 & 1,10 & 1,07 & 0,12 & 0,57 & 0,37 & 0,40 & 0,23 & 0,29 & 0,03 & 476 & 2268 & 511 & 64 & 235 & 12 & 725 & 1346 & 5 & 35 & 1 & 1 \\
\hline 67 & 1,00 & 0,99 & 0,11 & 0,56 & 0,35 & 0,41 & 0,22 & 0,31 & 0,25 & 441 & 2207 & 464 & 67 & 118 & 10 & 614 & 1263 & 184 & 47 & 1 & 1 \\
\hline 68 & 4,90 & 12,45 & 0,54 & 1,42 & 9,02 & 1,09 & 0,55 & 0,21 & 0,17 & 1631 & 4469 & 301 & 146 & 602 & 739 & 63 & 460 & 19 & 154 & 9 & 24 \\
\hline 69 & 1,34 & 1,38 & 0,17 & 0,52 & 0,73 & 0,43 & 0,38 & 1,27 & 0,75 & 1202 & 1294 & 589 & 75 & 461 & 22 & 73 & 60 & 11 & 71 & 12 & 10 \\
\hline $\bar{X}$ & 3,2 & 2,8 & 0,4 & 1,1 & 10 & 10 & 06 & 10 & 07 & 938 & 1.856 & 1.196 & 138 & 339 & 48 & 98 & 125 & 24 & 61 & 18 & 7 \\
\hline 50-P & 2,9 & 2,8 & 0,4 & 1,0 & 0,8 & 0,9 & 0,6 & 0,9 & 0,6 & 831 & 1.786 & 964 & 129 & 260 & 38 & 76 & 67 & 20 & 60 & 13 & 6 \\
\hline Min & 0,6 & 0,4 & 0,1 & 0,2 & 0,1 & 0,2 & 0,04 & 0,1 & 0,03 & 119 & 803 & 238 & 44 & 29 & 9 & 1 & 1 & 4 & 20 & 1 & 1 \\
\hline Max & 9,6 & 12,5 & 1,1 & 3,7 & 9,0 & 2,6 & 2,2 & 2,7 & 2,7 & 3.648 & 4.469 & 6.807 & 974 & 4.244 & 739 & 725 & 1.346 & 184 & 154 & 100 & 24 \\
\hline
\end{tabular}


APÊNDICE O - Valores das concentrações totais dos constituintes inorgânicos determinados em poeira por WDXRF, de cada ponto de amostragem na Fração $\mathbf{E}$

\begin{tabular}{|c|c|c|c|c|c|c|c|c|c|c|c|c|c|c|c|c|c|c|c|c|c|}
\hline \multirow{3}{*}{ PA } & \multicolumn{21}{|c|}{ Concentração de elementos } \\
\hline & \multicolumn{9}{|c|}{$(\%)$} & \multicolumn{12}{|c|}{$\left(\mu g^{-1}\right)$} \\
\hline & $\mathrm{Si}$ & $\mathrm{Ca}$ & $\mathrm{Mg}$ & $\mathrm{Al}$ & $S$ & $\mathrm{Fe}$ & $\mathrm{K}$ & $\mathrm{Cl}$ & $\mathrm{Na}$ & $\mathrm{Zn}$ & $\mathrm{Ti}$ & $P$ & $\mathrm{Mn}$ & $\mathrm{Cu}$ & $\mathrm{Sr}$ & $\mathrm{Cr}$ & $\mathrm{Pb}$ & $\mathrm{Zr}$ & $\mathrm{Ni}$ & $\mathrm{Br}$ & $\mathrm{Rb}$ \\
\hline 1 & 4,41 & 3,07 & 1,12 & 1,39 & 1,01 & 1,45 & 0,58 & 0,66 & 0,49 & 1077 & 1288 & 745 & 122 & 103 & 39 & 81 & 70 & 35 & 75 & 60 & 12 \\
\hline 2 & 4,34 & 3,60 & 0,58 & 1,49 & 0,75 & 1,20 & 0,65 & 0,62 & 0,49 & 850 & 1072 & 856 & 158 & 123 & 53 & 95 & 94 & 28 & 79 & 57 & 7 \\
\hline 3 & 4,24 & 2,65 & 0,42 & 1,60 & 0,73 & 1,28 & 0,78 & 1,20 & 0,83 & 1169 & 1221 & 1060 & 168 & 154 & 50 & 72 & 80 & 37 & 76 & 15 & 7 \\
\hline 4 & 3,65 & 2,17 & 0,44 & 1,16 & 0,75 & 1,02 & 0,59 & 0,72 & 0,67 & 1172 & 1092 & 875 & 169 & 332 & 46 & 96 & 131 & 20 & 81 & 12 & 9 \\
\hline 5 & 2,12 & 2,08 & 0,30 & 0,99 & 0,99 & 0,81 & 0,56 & 1,20 & 0,81 & 1507 & 1110 & 805 & 134 & 136 & 19 & 105 & 78 & 12 & 53 & 10 & 3 \\
\hline 6 & 4,33 & 3,11 & 0,71 & 1,49 & 0,83 & 1,31 & 0,67 & 0,83 & 0,60 & 1032 & 1194 & 887 & 149 & 127 & 47 & 83 & 81 & 33 & 77 & 44 & 9 \\
\hline 7 & 4,01 & 3,06 & 0,55 & 1,40 & 0,81 & 1,09 & 0,68 & 0,93 & 0,72 & 1109 & 1023 & 680 & 222 & 114 & 45 & 96 & 102 & 24 & 74 & 14 & 7 \\
\hline 8 & 4,81 & 2,63 & 0,62 & 1,70 & 0,92 & 1,22 & 0,78 & 1,01 & 0,59 & 803 & 1011 & 892 & 201 & 213 & 47 & 100 & 86 & 33 & 76 & 23 & 11 \\
\hline 9 & 4,38 & 2,93 & 0,63 & 1,53 & 0,85 & 1,21 & 0,71 & 0,92 & 0,64 & 981 & 1076 & 820 & 191 & 151 & 46 & 93 & 90 & 20 & 66 & 27 & 9 \\
\hline 10 & 5,83 & 3,03 & 1,99 & 2,00 & 0,53 & 1,49 & 0,65 & 0,41 & 0,34 & 557 & 1060 & 928 & 356 & 181 & 71 & 89 & 168 & 75 & 70 & 3 & 11 \\
\hline 11 & 6,24 & 2,40 & 3,75 & 1,21 & 0,52 & 0,81 & 0,51 & 0,29 & 0,26 & 894 & 1166 & 698 & 144 & 174 & 40 & 78 & 73 & 14 & 41 & 11 & 4 \\
\hline 12 & 3,38 & 3,18 & 0,80 & 1,10 & 0,71 & 0,79 & 0,52 & 0,74 & 0,58 & 991 & 1481 & 666 & 186 & 590 & 31 & 82 & 70 & 13 & 58 & 10 & 4 \\
\hline 13 & 4,13 & 2,90 & 0,95 & 1,36 & 0,77 & 1,07 & 0,62 & 0,78 & 0,58 & 739 & 1216 & 794 & 184 & 192 & 42 & 88 & 89 & 25 & 67 & 23 & 7 \\
\hline 14 & 4,37 & 2,76 & 1,47 & 1,30 & 0,64 & 0,98 & 0,56 & 0,63 & 0,50 & 880 & 1209 & 732 & 189 & 329 & 42 & 80 & 91 & 27 & 60 & 10 & 6 \\
\hline 15 & 6,17 & 3,68 & 1,83 & 2,28 & 0,62 & 1,36 & 0,56 & 0,41 & 0,30 & 712 & 2286 & 939 & 196 & 213 & 51 & 92 & 101 & 50 & 64 & 11 & 9 \\
\hline 16 & 2,51 & 1,17 & 0,69 & 0,77 & 0,58 & 0,62 & 0,44 & 0,72 & 0,47 & 955 & 1156 & 545 & 86 & 821 & 16 & 68 & 40 & 6 & 37 & 10 & 3 \\
\hline 17 & 4,15 & 4,37 & 0,79 & 1,45 & 0,95 & 0,97 & 0,66 & 0,85 & 0,65 & 988 & 1654 & 706 & 329 & 455 & 39 & 121 & 94 & 15 & 65 & 3 & 5 \\
\hline 18 & 3,48 & 4,01 & 0,90 & 1,07 & 0,61 & 0,80 & 0,45 & 0,66 & 0,61 & 1029 & 1632 & 748 & 143 & 493 & 39 & 58 & 75 & 17 & 73 & 3 & 3 \\
\hline 19 & 3,90 & 2,98 & 0,79 & 1,36 & 0,78 & 1,06 & 0,59 & 0,78 & 0,59 & 1.051 & 1.390 & 809 & 167 & 314 & 39 & 88 & 85 & 24 & 67 & 20 & 6 \\
\hline 20 & 4,61 & 2,89 & 1,27 & 1,46 & 0,73 & 1,11 & 0,63 & 0,73 & 0,53 & 887 & 1.159 & 788 & 202 & 230 & 46 & 88 & 94 & 29 & 66 & 18 & 7 \\
\hline 21 & 7,56 & 2,28 & 1,09 & 3,72 & 0,70 & 1,83 & 0,45 & 0,40 & 0,28 & 606 & 4105 & 1094 & 114 & 107 & 37 & 83 & 96 & 53 & 41 & 18 & 6 \\
\hline 22 & 3,78 & 3,45 & 0,88 & 1,32 & 0,81 & 1,27 & 0,58 & 0,65 & 0,58 & 1035 & 1911 & 840 & 225 & 468 & 45 & 94 & 155 & 32 & 75 & 36 & 8 \\
\hline 23 & 5,32 & 2,26 & 1,89 & 2,50 & 0,77 & 1,51 & 0,44 & 0,48 & 0,32 & 1036 & 3132 & 896 & 143 & 175 & 40 & 120 & 113 & 66 & 58 & 17 & 18 \\
\hline 24 & 3,93 & 3,64 & 0,69 & 1,22 & 0,68 & 0,98 & 0,59 & 0,58 & 0,44 & 1082 & 1921 & 555 & 220 & 388 & 53 & 103 & 115 & 26 & 66 & 9 & 6 \\
\hline
\end{tabular}


APÊNDICE O - Valores das concentrações totais dos constituintes inorgânicos determinados em poeira por WDXRF, de cada ponto de amostragem na Fração $\mathbf{E}$

\section{Concentração de elementos}

\begin{tabular}{|c|c|c|c|c|c|c|c|c|c|c|c|c|c|c|c|c|c|c|c|c|c|}
\hline \multirow[t]{2}{*}{ PA } & \multicolumn{9}{|c|}{$(\%)$} & \multicolumn{12}{|c|}{$\left(\mu g^{-1}\right)$} \\
\hline & $\mathrm{Si}$ & $\mathrm{Ca}$ & $\mathrm{Mg}$ & $\mathrm{Al}$ & $S$ & $\mathrm{Fe}$ & $\mathrm{K}$ & $\mathrm{Cl}$ & $\mathrm{Na}$ & $\mathrm{Zn}$ & $\mathrm{Ti}$ & $\mathrm{P}$ & $\mathrm{Mn}$ & $\mathrm{Cu}$ & $\mathrm{Sr}$ & $\mathrm{Cr}$ & $\mathrm{Pb}$ & $\mathrm{Zr}$ & $\mathrm{Ni}$ & $\mathrm{Br}$ & $\mathrm{Rb}$ \\
\hline 25 & 3,54 & 3,89 & 0,91 & 1,10 & 0,96 & 1,25 & 0,59 & 0,60 & 0,59 & 906 & 2004 & 1092 & 166 & 320 & 45 & 111 & 108 & 47 & 113 & 49 & 19 \\
\hline 26 & 4,87 & 5,69 & 1,46 & 1,22 & 0,61 & 0,80 & 0,46 & 0,43 & 0,40 & 626 & 1507 & 757 & 132 & 141 & 53 & 113 & 86 & 20 & 53 & 2 & 6 \\
\hline 27 & 2,91 & 3,35 & 0,49 & 1,16 & 0,84 & 1,03 & 0,62 & 1,06 & 0,82 & 1056 & 1897 & 994 & 173 & 555 & 34 & 98 & 103 & 21 & 59 & 16 & 10 \\
\hline 28 & 3,76 & 3,79 & 0,69 & 1,54 & 1,31 & 1,87 & 0,63 & 0,65 & 0,51 & 1206 & 2077 & 933 & 193 & 579 & 39 & 124 & 115 & 24 & 103 & 101 & 14 \\
\hline 29 & 3,17 & 3,72 & 0,61 & 1,29 & 0,98 & 1,48 & 0,59 & 0,76 & 0,70 & 1000 & 2325 & 934 & 331 & 454 & 39 & 109 & 113 & 14 & 62 & 105 & 2 \\
\hline 30 & 2,13 & 3,70 & 0,68 & 0,89 & 0,62 & 0,70 & 0,41 & 0,57 & 0,51 & 802 & 1790 & 804 & 136 & 445 & 31 & 61 & 75 & 17 & 46 & 67 & 2 \\
\hline 31 & 5,91 & 3,45 & 0,45 & 1,97 & 0,59 & 1,15 & 0,76 & 0,50 & 0,31 & 468 & 1969 & 1080 & 222 & 428 & 67 & 74 & 55 & 44 & 110 & 5 & 7 \\
\hline 32 & 4,10 & 3,58 & 0,94 & 1,60 & 0,83 & 1,27 & 0,54 & 0,62 & 0,51 & 935 & 2267 & 890 & 183 & 363 & 42 & 102 & 108 & 32 & 68 & 42 & 9 \\
\hline 33 & 7,41 & 7,59 & 1,63 & 1,98 & 1,23 & 1,41 & 1,96 & 1,09 & 0,51 & 1333 & 3083 & 1897 & 476 & 305 & 485 & 81 & 43 & 54 & 63 & 32 & 31 \\
\hline 34 & 2,33 & 2,19 & 0,32 & 1,21 & 0,87 & 0,51 & 0,20 & 0,25 & 0,14 & 357 & 2891 & 493 & 91 & 67 & 49 & 47 & 21 & 16 & 37 & 13 & 3 \\
\hline 35 & 1,79 & 1,56 & 0,19 & 0,74 & 0,78 & 0,73 & 0,57 & 1,03 & 0,67 & 737 & 1391 & 794 & 182 & 201 & 20 & 83 & 46 & 9 & 52 & 9 & 3 \\
\hline 36 & 4,07 & 2,36 & 0,39 & 1,39 & 0,15 & 0,85 & 0,69 & 0,17 & 0,25 & 145 & 1664 & 373 & 159 & 96 & 51 & 12 & 8 & 70 & 27 & 3 & 6 \\
\hline 37 & 3,11 & 2,33 & 0,49 & 1,25 & 0,71 & 1,52 & 0,58 & 0,81 & 0,83 & 1508 & 2789 & 867 & 208 & 739 & 39 & 73 & 478 & 37 & 56 & 7 & 6 \\
\hline 38 & 1,78 & 2,11 & 0,26 & 0,93 & 1,34 & 0,99 & 0,64 & 1,59 & 1,03 & 1304 & 2025 & 1042 & 151 & 1095 & 20 & 91 & 127 & 14 & 38 & 4 & 4 \\
\hline 39 & 2,91 & 2,83 & 0,49 & 1,41 & 0,69 & 1,20 & 0,68 & 1,40 & 1,01 & 1370 & 2180 & 1266 & 181 & 1006 & 32 & 81 & 137 & 26 & 51 & 17 & 2 \\
\hline 40 & 4,28 & 3,31 & 0,57 & 1,83 & 0,77 & 1,47 & 0,83 & 1,32 & 1,14 & 1199 & 2412 & 1581 & 227 & 424 & 48 & 81 & 151 & 27 & 64 & 14 & 17 \\
\hline 41 & 4,14 & 2,78 & 0,44 & 2,01 & 0,72 & 1,43 & 0,79 & 1,43 & 1,13 & 1257 & 2239 & 1476 & 247 & 758 & 41 & 88 & 132 & 28 & 41 & 17 & 14 \\
\hline 42 & 4,29 & 2,81 & 0,49 & 2,01 & 0,80 & 1,52 & 0,88 & 1,68 & 1,51 & 1298 & 2515 & 2544 & 428 & 539 & 43 & 103 & 173 & 25 & 65 & 17 & 7 \\
\hline 43 & 5,22 & 3,03 & 0,55 & 2,41 & 0,87 & 1,70 & 0,96 & 1,78 & 1,59 & 1501 & 2890 & 1720 & 234 & 622 & 51 & 127 & 210 & 24 & 60 & 21 & 23 \\
\hline 44 & 3,72 & 3,71 & 0,58 & 1,33 & 0,82 & 1,22 & 0,60 & 0,55 & 0,58 & 979 & 1968 & 850 & 191 & 515 & 46 & 104 & 124 & 21 & 92 & 15 & 15 \\
\hline 45 & 3,12 & 2,90 & 0,42 & 1,36 & 0,81 & 1,10 & 0,67 & 1,20 & 0,95 & 1433 & 2045 & 1213 & 189 & 847 & 32 & 89 & 118 & 18 & 64 & 13 & 8 \\
\hline 46 & 3,70 & 2,17 & 0,32 & 1,57 & 0,88 & 1,17 & 1,02 & 2,31 & 1,35 & 1530 & 1906 & 1232 & 194 & 195 & 44 & 68 & 92 & 29 & 62 & 15 & 8 \\
\hline 47 & 4,75 & 3,69 & 0,39 & 1,57 & 1,10 & 1,26 & 0,78 & 16 & 15 & 1364 & 2483 & 1285 & 217 & 200 & 64 & 88 & 7 & 1 & 64 & 12 & 8 \\
\hline
\end{tabular}


APÊNDICE O - Valores das concentrações totais dos constituintes inorgânicos determinados em poeira por WDXRF, de cada ponto de amostragem na Fração $\mathbf{E}$

Concentração de elementos

\begin{tabular}{|c|c|c|c|c|c|c|c|c|c|c|c|c|c|c|c|c|c|c|c|c|c|}
\hline \multirow{2}{*}{ PA } & \\
\hline & $\mathrm{Si}$ & $\mathrm{Ca}$ & $\mathrm{Mg}$ & $\mathrm{Al}$ & $\mathrm{S}$ & $\mathrm{Fe}$ & $\mathrm{K}$ & $\mathrm{Cl}$ & $\mathrm{Na}$ & $\mathrm{Zn}$ & $\mathrm{Ti}$ & $P$ & $\mathrm{Mn}$ & $\mathrm{Cu}$ & $\mathrm{Sr}$ & $\mathrm{Cr}$ & $\mathrm{Pb}$ & $\mathrm{Zr}$ & $\mathrm{Ni}$ & $\mathrm{Br}$ & $\mathrm{Rb}$ \\
\hline 48 & 2,64 & 3,73 & 0,80 & 1,17 & 0,47 & 1,05 & 1,93 & 1,95 & 1,91 & 1159 & 1229 & 4441 & 659 & 476 & 148 & 96 & 72 & 35 & 57 & 22 & 20 \\
\hline 49 & 2,49 & 2,10 & 0,35 & 0,58 & 0,34 & 0,58 & 0,38 & 0,45 & 0,29 & 2981 & 926 & 490 & 98 & 280 & 28 & 22 & 172 & 18 & 86 & 10 & 3 \\
\hline 50 & 2,85 & 2,12 & 0,31 & 1,19 & 1,31 & 1,08 & 0,86 & 1,38 & 1,09 & 1283 & 2836 & 1458 & 178 & 353 & 26 & 73 & 70 & 11 & 126 & 14 & 4 \\
\hline 51 & 2,65 & 1,77 & 0,29 & 1,21 & 0,70 & 0,80 & 0,57 & 1,32 & 0,90 & 2621 & 2352 & 645 & 125 & 3547 & 19 & 78 & 66 & 14 & 73 & 17 & 2 \\
\hline 52 & 1,93 & 2,35 & 0,36 & 0,83 & 0,93 & 0,64 & 0,48 & 0,69 & 0,51 & 595 & 1053 & 729 & 126 & 324 & 18 & 145 & 40 & 7 & 49 & 2 & 2 \\
\hline 53 & 1,19 & 5,85 & 0,31 & 0,59 & 0,41 & 0,52 & 0,36 & 0,75 & 0,59 & 804 & 1148 & 759 & 82 & 702 & 15 & 73 & 9 & 4 & 26 & 3 & 4 \\
\hline 54 & 2,54 & 0,95 & 0,35 & 0,70 & 0,82 & 0,86 & 0,18 & 0,99 & 0,39 & 500 & 1300 & 809 & 229 & 181 & 94 & 74 & 66 & 72 & 53 & 6 & 18 \\
\hline 55 & 2,26 & 1,00 & 0,46 & 0,68 & 0,66 & 0,74 & 0,17 & 0,66 & 0,25 & 488 & 1090 & 692 & 174 & 83 & 92 & 67 & 69 & 67 & 37 & 7 & 16 \\
\hline 56 & 3,85 & 3,34 & 0,53 & 1,46 & 0,64 & 1,02 & 0,60 & 0,84 & 0,68 & 827 & 2554 & 939 & 183,5 & 418 & 45 & 98 & 478 & 54 & 42 & 2 & 6 \\
\hline 57 & 3,88 & 4,04 & 0,84 & 1,22 & 0,99 & 1,52 & 0,55 & 0,57 & 0,51 & 899 & 1094 & 970 & 182 & 86 & 42 & 66 & 59 & 23 & 32 & 68 & 11 \\
\hline 58 & 1,29 & 0,54 & 0,11 & 0,34 & 1,18 & 0,66 & 0,17 & 1,68 & 0,50 & 1730 & 997 & 1530 & 108 & 170 & 54 & 58 & 35 & 44 & 70 & 13 & 14 \\
\hline 59 & 1,18 & 0,47 & 0,11 & 0,31 & 1,16 & 0,56 & 0,16 & 1,45 & 0,47 & 1800 & 968 & 1340 & 72 & 761 & 36 & 76 & 55 & 43 & 76 & 12 & 11 \\
\hline 60 & 1,32 & 2,26 & 0,16 & 0,44 & 2,40 & 0,80 & 0,53 & 1,38 & 0,88 & 1629 & 1544 & 982 & 109 & 1164 & 54 & 59 & 60 & 12 & 65 & 13 & 3 \\
\hline 61 & 2,74 & 1,43 & 0,26 & 0,90 & 0,87 & 0,90 & 0,66 & 1,74 & 1,47 & 2086 & 1382 & 1671 & 129 & 1728 & 22 & 67 & 57 & 96 & 75 & 11 & 3 \\
\hline 62 & 2,36 & 1,46 & 0,23 & 0,80 & 0,82 & 0,75 & 0,51 & 1,33 & 1,09 & 4182 & 1276 & 2282 & 122 & 5780 & 20 & 76 & 51 & 16 & 48 & 13 & 2 \\
\hline 63 & 1,66 & 1,15 & 0,20 & 0,63 & 0,92 & 0,53 & 0,54 & 1,29 & 0,98 & 4882 & 1122 & 1143 & 85 & 8479 & 11 & 51 & 41 & 2 & 37 & 3 & 2 \\
\hline 64 & 1,27 & 2,94 & 0,65 & 0,48 & 0,85 & 0,43 & 2,24 & 1,60 & 0,85 & 690 & 976 & 1968 & 173 & 471 & 12 & 68 & 11 & 3 & 40 & 15 & 2 \\
\hline 65 & 1,02 & 0,97 & 0,13 & 0,51 & 0,39 & 0,38 & 0,24 & 0,30 & 0,34 & 494 & 2380 & 484 & 62 & 324 & 8 & 794 & 1452 & 7 & 33 & 1 & 6 \\
\hline 66 & 1,05 & 0,82 & 0,12 & 0,57 & 0,31 & 0,39 & 0,20 & 0,20 & 0,23 & 372 & 2530 & 435 & 71 & 170 & 11 & 878 & 1884 & 6 & 36 & 2 & 3 \\
\hline 67 & 1,19 & 0,97 & 0,13 & 0,67 & 0,31 & 0,44 & 0,22 & 0,26 & 0,27 & 424 & 2587 & 477 & 86 & 144 & 11 & 730 & 1481 & 210 & 34 & 2 & 2 \\
\hline 68 & 4,67 & 12,39 & 0,59 & 1,50 & 8,63 & 0,98 & 0,62 & 0,22 & 0,16 & 1612 & 4068 & 293 & 181 & 409 & 614 & 87 & 456 & 37 & 75 & 11 & 14 \\
\hline $\begin{array}{l}69 \\
\bar{X}\end{array}$ & $\begin{array}{r}2,77 \\
3,5\end{array}$ & $\begin{array}{r}2,25 \\
2,9\end{array}$ & $\begin{array}{r}0,29 \\
\mathbf{0 , 7}\end{array}$ & $\begin{array}{r}0,92 \\
1,3\end{array}$ & $\begin{array}{c}0,70 \\
\mathbf{0 , 9}\end{array}$ & $\begin{array}{r}0,76 \\
1,0\end{array}$ & $\begin{array}{r}0,50 \\
\mathbf{0 , 6}\end{array}$ & $\begin{array}{c}1,15 \\
\mathbf{0 , 9}\end{array}$ & $\begin{array}{r}0,80 \\
\mathbf{0 , 7}\end{array}$ & $\begin{array}{c}1949 \\
1.181\end{array}$ & $\begin{array}{c}1819 \\
1.799\end{array}$ & $\begin{array}{l}707 \\
1.025\end{array}$ & $\begin{array}{c}137 \\
184\end{array}$ & $\begin{array}{r}1154 \\
648\end{array}$ & $\begin{array}{c}27 \\
56\end{array}$ & $\begin{array}{l}91 \\
116\end{array}$ & $\begin{array}{l}76 \\
170\end{array}$ & $\begin{array}{c}16 \\
31\end{array}$ & $\begin{array}{c}99 \\
62\end{array}$ & $\begin{array}{c}17 \\
19\end{array}$ & $\begin{array}{l}3 \\
8\end{array}$ \\
\hline $50-P$ & 3,7 & 2,9 & 0,6 & 1,3 & 0,8 & 1,0 & 0,6 & 0,8 & 0,6 & 1.030 & 1.643 & 881 & 176 & 330 & 42 & 87 & 90 & 25 & 64 & 13 & 7 \\
\hline Min & 1,0 & 0,5 & 0,1 & 0,3 & 0,2 & 0,4 & 0,2 & 0,2 & 0,1 & 145 & 926 & 293 & 62 & 67 & 8 & 12 & 8 & 2 & 26 & 1 & 2 \\
\hline Max & 7,6 & 12,4 & 3,7 & 3,7 & 8,6 & 1,9 & 2,2 & 2,3 & 1,9 & 4.882 & 4.105 & 4.441 & 659 & 8.479 & 614 & 878 & 1.884 & 210 & 126 & 105 & 31 \\
\hline
\end{tabular}


APÊNDICE P - Valores das concentrações totais dos constituintes inorgânicos determinados em poeira por WDXRF, de cada ponto de amostragem na Fração $\mathbf{F}$

\begin{tabular}{|c|c|c|c|c|c|c|c|c|c|c|c|c|c|c|c|c|c|c|c|c|c|}
\hline \multirow{3}{*}{ PA } & \multicolumn{21}{|c|}{ Concentração de elementos } \\
\hline & & & & & $(\%)$ & & & & & & & & & & $(\mu \mathrm{g} \mathrm{g})^{-1}$ & & & & & & \\
\hline & $\mathrm{Si}$ & $\mathrm{Ca}$ & $\mathrm{Mg}$ & Al & $S$ & $\mathrm{Fe}$ & $\mathrm{K}$ & $\mathrm{Cl}$ & $\mathrm{Na}$ & $\mathrm{Zn}$ & $\mathrm{Ti}$ & $P$ & $\mathrm{Mn}$ & $\mathrm{Cu}$ & $\mathrm{Sr}$ & $\mathrm{Cr}$ & $\mathrm{Pb}$ & $\mathrm{Zr}$ & $\mathrm{Ni}$ & $\mathrm{Br}$ & $\mathrm{Rb}$ \\
\hline 1 & 5,13 & 3,19 & 2,37 & 1,35 & 0,71 & 0,90 & 0,68 & 0,42 & 0,35 & 1264 & 1388 & 863 & 160 & 115 & 57 & 92 & 83 & 13 & 52 & 32 & 6 \\
\hline 2 & 5,84 & 3,09 & 3,38 & 1,13 & 0,52 & 0,76 & 0,54 & 0,42 & 0,35 & 1474 & 1203 & 802 & 138 & 117 & 44 & 82 & 90 & 26 & 45 & 9 & 16 \\
\hline 3 & 5,77 & 3,05 & 2,83 & 1,38 & 0,58 & 0,95 & 0,62 & 0,36 & 0,32 & 1084 & 1464 & 837 & 182 & 183 & 50 & 97 & 65 & 16 & 50 & 9 & 5 \\
\hline 4 & 6,26 & 2,68 & 3,47 & 1,26 & 0,52 & 0,81 & 0,55 & 0,30 & 0,29 & 701 & 1158 & 890 & 164 & 150 & 44 & 71 & 62 & 15 & 43 & 9 & 6 \\
\hline 5 & 5,79 & 2,53 & 3,04 & 1,31 & 0,54 & 0,89 & 0,64 & 0,34 & 0,30 & 864 & 1270 & 864 & 195 & 196 & 46 & 76 & 56 & 22 & 43 & 9 & 5 \\
\hline 6 & 6,38 & 2,50 & 3,96 & 1,08 & 0,56 & 0,77 & 0,46 & 0,24 & 0,24 & 921 & 1157 & 709 & 143 & 201 & 45 & 76 & 95 & 10 & 35 & 15 & 3 \\
\hline 7 & 6,30 & 2,26 & 4,34 & 0,90 & 0,43 & 0,64 & 0,42 & 0,27 & 0,23 & 752 & 973 & 536 & 138 & 126 & 30 & 72 & 115 & 15 & 31 & 6 & 3 \\
\hline 8 & 6,60 & 1,84 & 3,95 & 1,50 & 0,48 & 0,94 & 0,51 & 0,27 & 0,22 & 1060 & 1167 & 581 & 115 & 262 & 35 & 87 & 57 & 19 & 49 & 17 & 4 \\
\hline 9 & 6,14 & 2,08 & 3,92 & 1,12 & 0,55 & 0,72 & 0,49 & 0,28 & 0,23 & 744 & 1077 & 633 & 123 & 119 & 33 & 66 & 43 & 9 & 40 & 9 & 3 \\
\hline 10 & 7,31 & 4,27 & 2,91 & 2,07 & 0,75 & 1,05 & 0,72 & 0,47 & 0,33 & 1096 & 1633 & 1062 & 232 & 171 & 61 & 157 & 94 & 18 & 69 & 12 & 5 \\
\hline 11 & 9,76 & 3,14 & 5,14 & 1,99 & 0,75 & 1,00 & 0,68 & 0,45 & 0,30 & 963 & 1485 & 799 & 183 & 147 & 53 & 94 & 49 & 18 & 49 & 20 & 6 \\
\hline 12 & 9,53 & 3,94 & 3,69 & 2,02 & 0,91 & 0,89 & 0,84 & 0,37 & 0,39 & 1067 & 1518 & 775 & 188 & 127 & 95 & 95 & 89 & 30 & 84 & 3 & 8 \\
\hline 13 & 6,84 & 6,04 & 2,33 & 2,20 & 0,78 & 1,21 & 0,76 & 0,39 & 0,37 & 989 & 2071 & 1188 & 241 & 173 & 78 & 178 & 97 & 18 & 63 & 1 & 6 \\
\hline 14 & 7,30 & 2,99 & 3,40 & 1,74 & 0,85 & 0,99 & 0,67 & 0,50 & 0,33 & 1336 & 1385 & 968 & 196 & 182 & 57 & 229 & 88 & 26 & 89 & 55 & 6 \\
\hline 15 & 10,62 & 2,65 & 6,00 & 1,90 & 0,66 & 0,93 & 0,63 & 0,43 & 0,28 & 969 & 1405 & 729 & 187 & 134 & 49 & 87 & 63 & 12 & 47 & 12 & 6 \\
\hline 16 & 5,62 & 2,38 & 1,40 & 1,65 & 0,65 & 1,19 & 0,58 & 0,63 & 0,47 & 2162 & 1909 & 681 & 212 & 2619 & 54 & 94 & 110 & 15 & 56 & 2 & 6 \\
\hline 17 & 9,85 & 6,85 & 1,47 & 2,83 & 0,96 & 1,99 & 0,98 & 0,64 & 0,62 & 1196 & 2680 & 903 & 474 & 629 & 248 & 120 & 103 & 28 & 68 & 13 & 118 \\
\hline 18 & 8,42 & 6,26 & 1,70 & 2,37 & 0,72 & 1,75 & 0,69 & 0,58 & 0,49 & 2588 & 2666 & 907 & 296 & 3157 & 206 & 113 & 110 & 26 & 82 & 2 & 30 \\
\hline 19 & 7,03 & 3,63 & 2,85 & 1,68 & 0,65 & 1,13 & 0,66 & 0,46 & 0,39 & 1.367 & 1683 & 831 & 223 & 811 & 89 & 92 & 82 & 19 & 54 & 11 & 22 \\
\hline 20 & 7,35 & 3,23 & 3,74 & 1,63 & 0,67 & 0,91 & 0,62 & 0,36 & 0,29 & 992 & 1385 & 806 & 173 & 168 & 54 & 117 & 81 & 18 & 57 & 15 & 5 \\
\hline 21 & 1,87 & 22,29 & 3,46 & 0,67 & 0,17 & 0,30 & 0,21 & 0,04 & 0,08 & 121 & 1368 & 227 & 156 & 43 & 66 & 125 & 143 & 14 & 39 & 21 & 17 \\
\hline 22 & 11,48 & 6,18 & 4,38 & 2,92 & 0,53 & 1,37 & 0,79 & 0,31 & 0,22 & 1032 & 2163 & 781 & 366 & 145 & 74 & 114 & 197 & 31 & 73 & 1 & 8 \\
\hline 23 & 12,98 & 5,03 & 4,00 & 2,74 & 0,80 & 2,05 & 0,71 & 0,47 & 0,29 & 2188 & 3193 & 784 & 370 & 257 & 207 & 143 & 235 & 59 & 96 & 15 & 26 \\
\hline 24 & 10,82 & 9,34 & 1,88 & 2,77 & 0,82 & 2,13 & 0,99 & 0,54 & 0,47 & 1641 & 3194 & 803 & 579 & 594 & 431 & 133 & 254 & 74 & 90 & 14 & 44 \\
\hline
\end{tabular}


APÊNDICE P - Valores das concentrações totais dos constituintes inorgânicos determinados em poeira por WDXRF, de cada ponto de amostragem na Fração $\mathbf{F}$

\section{Concentração de elementos}

\begin{tabular}{|c|c|c|c|c|c|c|c|c|c|c|c|c|c|c|c|c|c|c|c|c|c|}
\hline \multirow[t]{2}{*}{ PA } & \multicolumn{9}{|c|}{$(\%)$} & \multicolumn{12}{|c|}{$\left(\mu g^{-1}\right)$} \\
\hline & $\mathrm{Si}$ & $\mathrm{Ca}$ & $\mathrm{Mg}$ & $\mathrm{Al}$ & $S$ & $\mathrm{Fe}$ & $\mathrm{K}$ & $\mathrm{Cl}$ & $\mathrm{Na}$ & $\mathrm{Zn}$ & $\mathrm{Ti}$ & $P$ & $\mathrm{Mn}$ & $\mathrm{Cu}$ & $\mathrm{Sr}$ & $\mathrm{Cr}$ & $\mathrm{Pb}$ & $\mathrm{Zr}$ & $\mathrm{Ni}$ & $\mathrm{Br}$ & $\mathrm{Rb}$ \\
\hline 25 & 3,53 & 5,28 & 1,00 & 1,43 & 0,87 & 1,34 & 0,87 & 0,54 & 0,52 & 943 & 2241 & 1400 & 277 & 541 & 61 & 134 & 107 & 31 & 95 & 80 & 8 \\
\hline 26 & 7,24 & 5,43 & 1,84 & 2,62 & 0,87 & 1,31 & 0,87 & 0,36 & 0,34 & 742 & 2103 & 1171 & 266 & 165 & 87 & 111 & 80 & 22 & 72 & 10 & 28 \\
\hline 27 & 6,25 & 4,45 & 1,34 & 2,04 & 0,78 & 1,57 & 0,90 & 0,81 & 0,71 & 5109 & 2206 & 1521 & 388 & 8143 & 166 & 110 & 114 & 33 & 73 & 8 & 27 \\
\hline 28 & 7,90 & 7,95 & 1,17 & 2,72 & 1,38 & 3,01 & 0,95 & 0,55 & 0,53 & 1397 & 3180 & 1130 & 320 & 983 & 206 & 127 & 131 & 43 & 115 & 3 & 42 \\
\hline 29 & 7,92 & 7,18 & 0,99 & 2,67 & 0,93 & 2,80 & 0,86 & 0,79 & 0,68 & 1532 & 3184 & 1205 & 402 & 968 & 257 & 162 & 155 & 35 & 91 & 131 & 99 \\
\hline 30 & 6,34 & 5,16 & 1,76 & 2,01 & 0,81 & 1,49 & 0,75 & 0,70 & 0,58 & 1974 & 2035 & 1076 & 268 & 1968 & 101 & 146 & 100 & 28 & 75 & 14 & 15 \\
\hline 31 & 9,63 & 6,34 & 0,94 & 3,12 & 0,55 & 1,45 & 1,00 & 0,34 & 0,32 & 628 & 2432 & 1109 & 490 & 463 & 114 & 96 & 80 & 60 & 123 & 2 & 9 \\
\hline 32 & 5,97 & 4,77 & 1,67 & 1,93 & 0,76 & 1,34 & 0,80 & 0,74 & 0,60 & 1774 & 2054 & 1152 & 282 & 1788 & 94 & 118 & 108 & 27 & 67 & 17 & 15 \\
\hline 33 & 11,13 & 14,18 & 2,00 & 3,25 & 1,14 & 2,01 & 1,65 & 0,65 & 0,40 & 935 & 4013 & 1764 & 872 & 363 & 700 & 117 & 38 & 68 & 54 & 2 & 29 \\
\hline 34 & 2,06 & 0,91 & 0,25 & 1,00 & 0,31 & 0,44 & 0,05 & 0,07 & 0,06 & 190 & 2023 & 207 & 82 & 41 & 41 & 36 & 62 & 13 & 27 & 11 & 3 \\
\hline 35 & 6,28 & 4,69 & 0,62 & 2,43 & 0,94 & 1,57 & 1,02 & 0,95 & 0,72 & 1316 & 2765 & 1303 & 506 & 219 & 95 & 156 & 184 & 26 & 74 & 1 & 9 \\
\hline 36 & 7,90 & 1,94 & 0,44 & 2,68 & 0,15 & 1,15 & 0,67 & 0,12 & 0,36 & 169 & 1876 & 584 & 221 & 142 & 58 & 10 & 17 & 96 & 31 & 1 & 8 \\
\hline 37 & 5,67 & 4,17 & 0,92 & 2,22 & 0,96 & 1,94 & 0,82 & 0,97 & 1,02 & 1686 & 3851 & 1036 & 322 & 527 & 65 & 98 & 1047 & 44 & 56 & 21 & 0 \\
\hline 38 & 5,87 & 5,28 & 0,87 & 2,55 & 0,90 & 1,68 & 0,90 & 1,30 & 1,12 & 1720 & 3388 & 1651 & 262 & 1328 & 65 & 94 & 182 & 33 & 50 & 12 & 23 \\
\hline 39 & 8,71 & 7,00 & 1,29 & 3,12 & 0,87 & 2,28 & 1,14 & 1,14 & 0,98 & 1561 & 3696 & 1886 & 340 & 1006 & 214 & 94 & 210 & 47 & 59 & 14 & 100 \\
\hline 40 & 8,89 & 6,18 & 0,94 & 3,15 & 0,81 & 2,32 & 1,07 & 1,08 & 0,95 & 1334 & 3637 & 1927 & 443 & 623 & 225 & 112 & 205 & 43 & 67 & 1 & 47 \\
\hline 41 & 7,09 & 4,18 & 0,66 & 3,21 & 0,72 & 2,05 & 0,99 & 1,19 & 1,04 & 1421 & 3141 & 1942 & 581 & 795 & 77 & 109 & 196 & 30 & 57 & 13 & 25 \\
\hline 42 & 9,58 & 4,93 & 0,77 & 3,59 & 0,94 & 2,63 & 1,32 & 1,39 & 1,27 & 1555 & 3812 & 2788 & 550 & 683 & 246 & 90 & 241 & 60 & 70 & 16 & 112 \\
\hline 43 & 7,28 & 3,96 & 0,65 & 3,08 & 0,82 & 2,07 & 1,04 & 1,46 & 1,38 & 1361 & 3327 & 1874 & 318 & 539 & 73 & 122 & 218 & 47 & 62 & 14 & 27 \\
\hline 44 & 8,37 & 7,67 & 1,00 & 2,66 & 0,95 & 2,03 & 1,00 & 0,56 & 0,52 & 1404 & 2758 & 1278 & 379 & 1042 & 206 & 114 & 119 & 28 & 141 & 157 & 2 \\
\hline 45 & 6,9 & 5,1 & 0,8 & 2,5 & 0,8 & 1,8 & 0,9 & 1,1 & 0,9 & 1875 & 2925 & 1557 & 360 & 1324 & 131 & 99 & 184 & 35 & 79 & 25 & 33 \\
\hline 46 & 5,48 & 3,11 & 0,43 & 2,11 & 0,86 & 1,58 & 1,05 & 2,06 & 1,42 & 1614 & 2546 & 1353 & 240 & 449 & 54 & 95 & 70 & 35 & 64 & 10 & 8 \\
\hline 47 & 6,42 & 5,07 & 0,52 & 2,06 & 1,01 & 1,60 & 0,88 & 0,97 & 1,04 & 1387 & 2732 & 1356 & 305 & 245 & 90 & 93 & 100 & 39 & 66 & 14 & 9 \\
\hline
\end{tabular}


APÊNDICE P - Valores das concentrações totais dos constituintes inorgânicos determinados em poeira por WDXRF, de cada ponto de amostragem na Fração $\mathbf{F}$

\begin{tabular}{|c|c|c|c|c|c|c|c|c|c|c|c|c|c|c|c|c|c|c|c|c|c|}
\hline \multirow{2}{*}{ PA } & \\
\hline & $\mathrm{Si}$ & $\mathrm{Ca}$ & $\mathrm{Mg}$ & $\mathrm{Al}$ & $\mathrm{S}$ & $\mathrm{Fe}$ & $\mathrm{K}$ & $\mathrm{Cl}$ & $\mathrm{Na}$ & $\mathrm{Zn}$ & $\mathrm{Ti}$ & $\mathrm{P}$ & $\mathrm{Mn}$ & $\mathrm{Cu}$ & $\mathrm{Sr}$ & $\mathrm{Cr}$ & $\mathrm{Pb}$ & $\mathrm{Zr}$ & $\mathrm{Ni}$ & $\mathrm{Br}$ & $\mathrm{Rb}$ \\
\hline 48 & 6,59 & 6,64 & 1,17 & 2,27 & 0,60 & 1,78 & 2,47 & 1,99 & 1,80 & 1657 & 1910 & 5185 & 1177 & 472 & 598 & 122 & 101 & 31 & 74 & 21 & 100 \\
\hline 49 & 5,38 & 4,33 & 0,70 & 1,16 & 0,46 & 0,93 & 0,52 & 0,55 & 0,42 & 3699 & 1610 & 676 & 181 & 1128 & 71 & 77 & 349 & 29 & 146 & 1 & 5 \\
\hline 50 & 4,64 & 2,79 & 0,44 & 1,89 & 1,24 & 1,61 & 0,95 & 1,17 & 1,03 & 1426 & 2977 & 1560 & 242 & 373 & 52 & 82 & 128 & 15 & 122 & 14 & 9 \\
\hline 51 & 4,29 & 2,44 & 0,41 & 1,84 & 0,80 & 1,32 & 0,79 & 1,47 & 1,17 & 3034 & 2380 & 730 & 358 & 3417 & 50 & 105 & 174 & 32 & 75 & 16 & 1 \\
\hline 52 & 9,49 & 7,11 & 1,24 & 2,70 & 0,82 & 1,84 & 0,96 & 0,60 & 0,54 & 1129 & 2747 & 1405 & 500 & 979 & 238 & 90 & 114 & 37 & 62 & 15 & 36 \\
\hline 53 & 3,05 & 5,94 & 0,59 & 1,19 & 0,62 & 0,93 & 0,70 & 1,13 & 0,96 & 2861 & 1627 & 971 & 169 & 3973 & 50 & 95 & 70 & 20 & 41 & 21 & 6 \\
\hline 54 & 5,74 & 5,77 & 1,60 & 2,30 & 0,54 & 1,56 & 0,82 & 0,37 & 0,32 & 643 & 1944 & 1001 & 504 & 127 & 102 & 182 & 130 & 44 & 61 & 3 & 6 \\
\hline 55 & 5,56 & 1,57 & 0,82 & 1,43 & 0,50 & 1,11 & 0,21 & 0,29 & 0,23 & 505 & 1360 & 899 & 301 & 76 & 16 & 12 & 85 & 177 & 42 & 3 & 24 \\
\hline 56 & 6,13 & 5,32 & 1,11 & 2,43 & 0,47 & 2,12 & 0,83 & 0,48 & 0,50 & 611 & 2967 & 2330 & 396 & 92 & 100 & 89 & 400 & 34 & 68 & 1 & 8 \\
\hline 57 & 5,42 & 4,61 & 0,70 & 1,76 & 0,47 & 1,16 & 0,94 & 0,44 & 0,32 & 426 & 2032 & 1157 & 286 & 102 & 68 & 86 & 79 & 49 & 53 & 52 & 10 \\
\hline 58 & 2,82 & 0,91 & 0,25 & 0,72 & 0,97 & 0,99 & 0,18 & 1,32 & 0,53 & 1500 & 1510 & 1580 & 283 & 278 & 105 & 81 & 62 & 76 & 68 & 11 & 19 \\
\hline 59 & 2,83 & 0,86 & 0,27 & 0,74 & 2,44 & 0,84 & 0,53 & 1,34 & 0,93 & 1204 & 2181 & 1896 & 108 & 437 & 94 & 47 & 68 & 15 & 50 & 10 & 13 \\
\hline 60 & 0,89 & 0,43 & 0,09 & 0,23 & 2,61 & 0,46 & 0,98 & 1,46 & 0,48 & 1523 & 2231 & 1877 & 233 & 1478 & 103 & 58,5 & 43 & 23 & 59 & 21 & 9 \\
\hline 61 & 4,14 & 2,04 & 0,38 & 1,44 & 0,85 & 1,40 & 0,70 & 1,62 & 1,32 & 4883 & 1770 & 1378 & 182 & 6975 & 50 & 83 & 82 & 27 & 77 & 12 & 17 \\
\hline 62 & 3,75 & 2,03 & 0,36 & 1,29 & 0,83 & 1,23 & 0,63 & 1,32 & 1,12 & 8642 & 1674 & 1332 & 215 & 14940 & 40 & 98 & 77 & 20 & 71 & 1 & 4 \\
\hline 63 & 3,76 & 1,86 & 0,35 & 1,35 & 0,94 & 1,22 & 0,70 & 1,33 & 1,23 & 25415 & 1617 & 1357 & 168 & 48155 & 47 & 63 & 96 & 33 & 70 & 1 & 4 \\
\hline 64 & 2,70 & 3,90 & 0,79 & 0,99 & 0,89 & 1,09 & 2,31 & 1,60 & 0,91 & 1809 & 1601 & 2107 & 409 & 1716 & 44 & 66 & 34 & 13 & 54 & 31 & 5 \\
\hline 65 & 5,74 & 3,87 & 0,62 & 2,30 & 0,95 & 1,46 & 0,89 & 0,66 & 0,70 & 2279 & 3091 & 1004 & 297 & 1883 & 56 & 156 & 186 & 17 & 81 & 10 & 7 \\
\hline 66 & 5,72 & 3,55 & 0,53 & 2,49 & 0,84 & 1,53 & 0,87 & 0,69 & 0,67 & 1581 & 3039 & 1065 & 406 & 605 & 76 & 118 & 250 & 38 & 62 & 11 & 27 \\
\hline 67 & 5,95 & 3,69 & 0,55 & 2,52 & 0,68 & 1,53 & 0,74 & 0,67 & 0,59 & 1671 & 3058 & 969 & 265 & 769 & 71 & 139 & 204 & 31 & 77 & 12 & 23 \\
\hline 68 & 6,89 & 12,81 & 0,84 & 1,99 & 8,15 & 1,32 & 0,82 & 0,23 & 0,19 & 1780 & 4330 & 345 & 224 & 594 & 872 & 122 & 501 & 30 & 86 & 13 & 32 \\
\hline 69 & 7,79 & 6,11 & 0,81 & 2,62 & 1,26 & 2,18 & 1,09 & 1,09 & 0,82 & 3502 & 3600 & 980 & 379 & 2897 & 236 & 124 & 158 & 22 & 132 & 17 & 85 \\
\hline$\overline{\boldsymbol{X}}$ & $6 G$ & 17 & 1,7 & & & & & & & 1012 & 2.287 & 1.203 & 307 & 1.835 & 127 & 104 & 142 & 33 & 68 & 17 & 22 \\
\hline $50-P$ & 6,3 & 4,2 & 1,1 & 2,0 & 0,8 & 1,3 & 0,8 & 0,6 & 0,5 & 1.377 & 2.087 & 1.064 & 267 & 468 & 72 & 97 & 101 & 29 & 65 & 12 & 9 \\
\hline Min & 0,9 & 0,4 & 0,1 & 0,2 & 0,2 & 0,3 & 0,05 & 0,04 & 0,1 & 121 & 973 & 207 & 82 & 41 & 16 & 10 & 17 & 9 & 27 & 1 & 1 \\
\hline Max & 13,0 & 22,3 & 6,0 & 3,6 & 8,1 & 3,0 & 2,5 & 2,1 & 1,8 & 25.415 & 4.330 & 5.185 & 1.177 & 48.155 & 872 & 229 & 1.047 & 177 & 146 & 157 & 118 \\
\hline
\end{tabular}




\title{
ANEXO A - Directiva 2005/84/CE do Parlamento Europeu e do Conselho de 14 de Dezembro de 2005
}

\begin{tabular}{l|lll}
\hline L $344 / 40$ & Jornal Oficial da União Europeia & 27.12 .2005 \\
\hline
\end{tabular}

\author{
DIRECTIVA 2005/84/CE DO PARLAMENTO EUROPEU E DO CONSELHO \\ de 14 de Dezembro de 2005
}

que altera, pela vigésima segunda vez, a Directiva 76/769/CEE do Conselho relativa à aproximação das disposiçōes legislativas, regulamentares e administrativas dos Estados-Membros respeitantes à limitação da colocação no mercado e da utilização de determinadas substâncias e preparaçôes perigosas (ftalatos nos brinquedos e artigos de puericultura)

O PARLAMENTO EUROPEU E O CONSELHO DA UNIÃO EUROPEIA,

Tendo em conta o Tratado que institui a Comunidade Europeia, nomeadamente o artigo $95 .^{\circ}$,

Tendo em conta a propost a da Comissão $\left({ }^{1}\right)$,

Tendo em conta o parecer do Comité Económico e Social Europeu ( ${ }^{2}$,

Deliberando nos termos do artigo $251 .^{\circ}$ do Tratado (3),

Considerando o seguinte:

(1) $\mathrm{O}$ artigo $14 .^{\circ}$ do Tratado estabelece um espaço sem fronteiras internas no qual é assegurada a livre circulação das mercadorias, das pessoas, dos serviços e dos capitais.

(2) As iniciativas no domínio do mercado interno devem melhorar a qualidade de vida, a protecção da saúde e a segurança dos consumidores. A presente directiva cumpre a exigência de um elevado nível de proteccão da saúde e dos consumidores na definição e execução de todas as políticas e acções comu nitárias.

(3) Deverá proibir-se a utilização de determinados ftalatos em brinquedos e artigos de puericultura em material plastificado ou incluindo componentes de material plastificado, dado que a sua presença apresenta ou pode eventualmente apresentar riscos para a saúde das crianças. Os brinquedos e artigos de puericultura que, embora não se destinem a essa finalidade, possam entrar em contacto com a boca podem, em determinadas circunstâncias, implicar riscos podem, em determinadas circunstâncias, implicar riscos
para a saúde das crianças pequenas se forem fabricados em material plastificado ou incluírem componentes nesse material que contenha certos ftalatos.

(4) Consultado pela Comissão, o Comité Científico da Toxicidade, Ecotoxicidade e do Ambiente (CCTEA) apresentou pareceres sobre os riscos que os referidos ftalatos apresentam para a saúde.

(1) JO C 116 E de 26.4 .2000 , p. 14

(2) JO C 117 de 26.4.2000, p. 59.
(3) Parecer do Parlamento Europeu de 6 de Julho de 2000 (JO C 121 de 24.4.2001 p. 410), posição comum do Conselho de 4 de Abril de 2005 (JO C 144 E de 14.6.2005, p. 24), posição do Parlamento Europeu de 5 de julho de 2005 (ainda não publicada no
(5) A Recomendação 98/485/CE da Comissão, de 1 de Julho de 1998, relativa aos artigos de puericultura e brinquedos destinados a ser postos na boca por crianças com menos de três anos de idade, fabricados em PVC maleável que de três anos de idade, fabricados em contenha certos ftalatos $\left({ }^{4}\right)$, convidou os Estados-Membros
a tomarem medidas que garantissem um nível elevado de protecção da saúde das crianças relativamente aos produtos em causa.

(6) A utilização de seis ftalatos em brinquedos e artigos de puericultura destinados a ser postos na boca por crianças com menos de três anos de idade está sujeita, desde 1999 , a uma proibição temporária a nível da União Europeia, na sequência da aprovação da Decisão 1999/815/CE da Comissão (5), no âmbito da Directiva 92/59/CEE do Conselho, de 29 de Junho de 1992, relativa à segurança geral dos produtos $(6)$. Esta decisão tem sidı regularmente prorrogada.

(7) As restrições já adoptadas por determinados Estados-Membros em relação à colocação no mercado de brinquedos e artigos de puericultura devido à presença de ftalatos afectam directamente a realização e o funcionamento do mercado interno, pelo que ế necessário aproximar as legismercado interno, pelo que é necessário aproximar as legis-
lações dos Estados-Membros no domínio em causa e, por lações dos Estados-Membros no domínio em causa e, por
conseguinte, alterar o anexo I à Directiva 76/769/CEE (7).

(8) Quando a avaliação científica não permite a determinação do risco com suficiente certeza, deve ser aplicado o princípio da precaução, a fim de assegurar um elevado nível de protecção da saúde, especialmente das crianças.

(9) As crianças, enquanto seres em desenvolvimento, são particularmente vulneráveis a substâncias tóxicas para a reprodução, pelo que deve ser reduzida o mais possível a sua exposição a todas as fontes, que na prática sejam evitáveis, de emissão dessas substâncias, especialmente as provenientes de artigos que elas põem na boca.

(4) JO L 217 de 5.8.1998, p. 35

(5) JO L 315 de 9.12 .1999$, p. 46. Decisão com a última redacção que the foi dada pela Decisão 2004/781/CE JO L 344 de 20.11.2004, p. 35). 2001/95/CE do Parlanento 15.1 .2002 .

(7) JO L 262 de 27.9.1976, p. 201. Directiva com a última redacção que The foi dada pela Directiva 2004/98/CE da Comissão JO L 305 de 1.10.2004, p. 63)

Fonte: http://eur-lex.europa.eu/LexUriServ/LexUriServ.do?uri=OJ:L:2005:344:0040:0043:PT:PDF 


\section{ANEXO A - Directiva 2005/84/CE do Parlamento Europeu e do Conselho de 14 de Dezembro de 2005}

(10) Durante as avaliaç̃es de risco e/ou no âmbito da Directiva 67/548/CEE do Conselho, de 27 de Junho de 1967, relativa à aproximação das disposições legislativas, regulamentares e administrativas respeitantes à classificação, embalagem e rotulagem das substâncias perigosas $(1)$, o di(2-etil-hexilo) ftalato (DEHP), o ftalato de dibutilo (DBP) e o ftalato de benzilbutilo (BBP) foram identificados como substâncias tóxicas para a reprodução, tendo por isso sido classificados como substâncias tóxicas para a reprodução de cat egoria 2

(11) As informações científicas relativas ao ftalato de di-isononilo (DINP), ao ftalato de di-isodecilo (DIDP) e ao ftalato de di-n-octilo (DNOP) ou são insuficientes ou contraditórias, embora não se possa excluir que apresentem um risco potencial se utilizados em brinquedos e artigos de puericultura, os quais são, por definição, produzidos para crianças.

(12) As incertezas na avaliação da exposição a estes ftalatos, nomeadamente a quantidade de vezes que são postos na boca e a exposição a emissões provenientes de outras fontes, exigem que se atenda a considerações de precaução, devendo, por isso, ser introduzidas restrições à utilização desses ftalatos em brinquedos e artigos de puericultura e à colocação desses artigos no mercado. Todavia, por razões de proporcionalidade, as restrições em relação aos DINP. DIDP e DNOP devem ser menos rígidas do que as propostas para os DEHP, DBP e BBP.

13) A Comissão deverá reexaminar as restantes aplicações dos produtos fabricados em material plastificado ou contendo componentes fabricados nesse material que possam apresentar riscos para a saúde humana, em particular os utilizados em instrum entos médicos.

(14) Em conformidade com a comunicação da Comissão relativa ao princípio da precaução, as medidas baseadas neste princí pio deverão ser reexaminadas à luz das novas informações científicas.

(15) A Comissão, em cooperação com as autoridades dos Estados-Membros responsáveis pela vigilância do mercado e pela aplicação da lei em matéria de brinquedos e artigos de puericultura, e em consulta com as organizações competentes de produtores e importadores, deverá vigiar a utilização de ftalatos e de outras substâncias plastificantes em brinquedos e artigos de puericultura.

(16) Para efeitos da Directiva 76/769/CEE, deverá definir-se a expressão *artigo de puericultura*. (1) JO 196 de 16.8 .1967 , p. 1 . Directiva com a última redacção que the
foi dada pela Directiva $2004 / 73 / \mathrm{CE}$ da Comissåo (JO L 152 de 30.4 .2004 , p. 1).
(17) Nos termos do ponto 34 do Acordo Interinstitucional Legislar melhor* (2), os Estados-Membros são encorajados a elaborarem, para si próprios e no interesse da Comunidade, os seus próprios quadros, que ilustrem, na medida do possível, a concordância entre a presente directiva e as medidas de transposicão, e a publicá-los.

(18) A Comissão vai rever a utilização noutros produtos dos talatos enumerados no anexo I à Directiva 76/769/CEE, quando estiver concluída a avaliação do risco nos termos do Regulamento (CEE) n. ${ }^{\circ} 793 / 93$ do Conselho, de 23 de Março de 1993, relativo à avaliação e controlo dos riscos ambientais associados às substâncias existentes ( ${ }^{3}$ ).

(19) A presente directiva é aplicável sem prejuízo da legislação comunitária que est abelece requisitos mínimos para a protecção dos trabalhadores, incluídos na Directiva 89/391/CEE do Conselho, de 12 de Junho de 1989, relativa à aplicação de medidas destinadas a promover a melhoria da segurança e da saúde dos trabalhadores no trabalho $\left({ }^{4}\right)$, e nas directivas específicas nela baseadas, nomeadamente a Directiva 90/394/CEE do Conselho, de 28 de Junho de 1990 , relativa à protecção dos trabalhadores contra riscos ligados à exposição a agentes cancerígenos durante o trabalho (5), e a Directiva 98/24/CE do Conselho, de 7 de Abril de 1998, relativa à protecção da segurança e da saúde dos trabalhadores contra os riscos ligados à exposição a agentes químicos no trabalho $(\%)$,

ADOPTARAM A PRESENTE DIRECTIVA:

Artigo $1 .^{\circ}$

A Directiva 76/769/CEE é alterada do seguinte modo:

1. No artigo $10^{\circ}$ é aditada a seguinte alínea ao n. ${ }^{\circ} 3$ :

"c) “Artigo de puericultura", qualquer produto destinado a facilitar o sono, o relaxamento, a higiene, a alimentação e a sucção das crianças.*

O anexo I é alterado nos termos do anexo da presente directiva.

(2) JO C 321 de 31.12.2003, p. 1.

(3) JO L 84 de 5.4.1993, p. 1. Regulamento alterado pelo Regulamento (CE) n. $1882 / 2003$ do Parlamento Europeu e do Conselho (JO L. 284 de 31.10 .2003 , p. 1).

(4) JO L. 183 de 29.6.1989, p. 1. Directiva alterada pelo Regulamento (CE) n. ${ }^{\circ} 1882 / 2003$.

(5) JO L 196 de 26.7 .1990 , p. 1. Directiva revogada pela Directiva 2004/37/CE do Parlamento Europeu e do Conselho (JO L 158 de 30.4 .2004$, p. 50).

(ब) JO L 131 de 5.5.1998, p. 11

${ }^{1}$ Fonte: http://eur-lex.europa.eu/LexUriServ/LexUriServ.do?uri=OJ:L:2005:344:0040:0043:PT:PDF 


\section{ANEXO A - Directiva 2005/84/CE do Parlamento Europeu e do Conselho de 14 de Dezembro de 2005}

\begin{abstract}
L 344/42 PT
Artigo $2^{\circ}$

A Comissão reavalia, até 16 de Janeiro de 2010 , as medidas previstas na Directiva 76/769/CEE, com a redacção que lhe é dada pela presente directiva, à luz das novas informações científicas relativas às substâncias, e seus substitutos, descritas no anexo da presente directiva e, se se justificar, essas medidas serão alteradas nesse sentido.
\end{abstract}

\section{Artigo $3{ }^{\circ}$}

1. Os Estados-Membros devem aprovar e publicar as disposições legislativas, regulamentares e administrativas necessárias para dar cumprimento à presente directiva até 16 de Julho de 2006 e informar imediatamente a Comissão desse facto.

Os Estados-Membros devem aplicar essas disposições a partir de 16 de Janeiro de 2007.

Quando os Estados-Membros aprovarem essas disposições, estas devem incluir uma referência à presente directiva ou ser dela acompanhadas aquando da sua publicação oficial. As modalidades dessa referência serão aprovadas pelos Estados-Membros. das principais disposições de direito interno que aprovarem nas matérias reguladas pela presente directiva.

Artigo $4 .^{\circ}$

A presente directiva entra em vigor no vigésimo dia seguinte ao da sua publicação no Jornal Oficial da União Europeia.

\section{Artigo $5^{\circ}$}

Os Estados-Membros são os destinatários da presente directiva.

Feito em Estrasburgo, em 14 de Dezembro de 2005.

$\begin{array}{cc}\text { Pelo Parlamento Europeu } & \text { Pelo Conselho } \\ \text { O Presidente } & \text { O Presidente } \\ \text { J. BORRELL. FONTELLES } & \text { C. CL.ARKE }\end{array}$

${ }^{1}$ Fonte: http://eur-lex.europa.eu/LexUriServ/LexUriServ.do?uri=OJ:L:2005:344:0040:0043:PT:PDF 


\section{ANEXO A - Directiva 2005/84/CE do Parlamento Europeu e do Conselho de 14 de Dezembro de 2005}

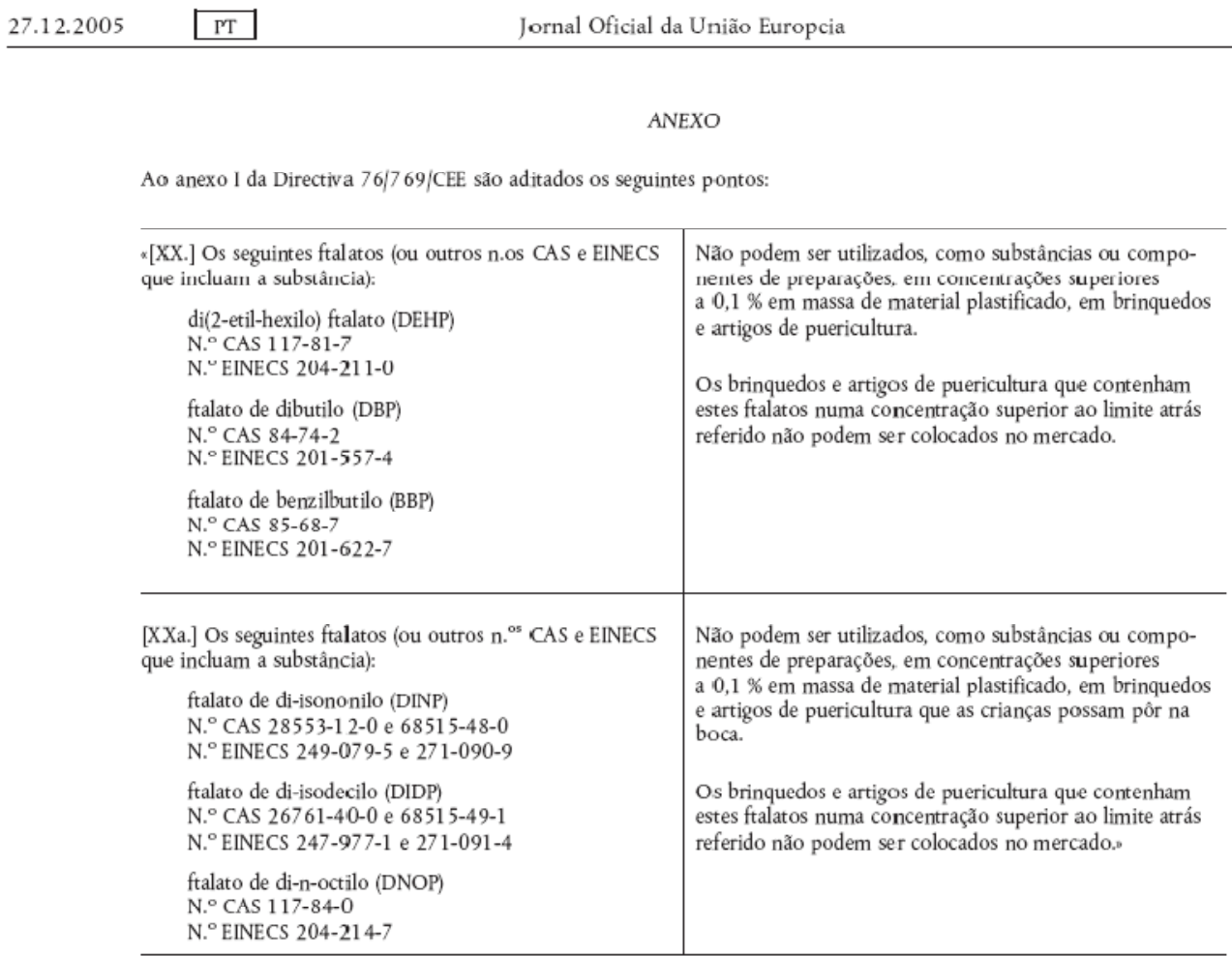




\section{ANEXO B - Decreto-Lei n. ${ }^{\circ}$ 10/2007 do Ministério da Economia e da Inovação de 18 de Janeiro de 2007}

\section{Diário da República, $1 .^{a}$ série $-N{ }^{\circ} 13-18$ de Janeiro de 2007 \\ MINISTÉRIO DA ECONOMIA E DA INOVAÇÃOO \\ Decreto-Lei n. ${ }^{\circ}$ 10/2007 \\ de 18 de Janeiro}

A Directiva n. ${ }^{\circ}$ 76/769/CEE, do Conselho, de 27 de Julho, introduziu limitações à colocação no mercado e à utilização de substâncias e preparações perigosas, com o objectivo de salvaguardar a saúde humana e o com o object

$\mathrm{Na}$ sequência da Recomendação n. ${ }^{\circ} 98 / 485 / \mathrm{CE}$, da Comissão, de 1 de Julho, no âmbito da Directiva n. ${ }^{\circ}$ 92/59/CEE, do Conselho, de 29 de Junho, referente à segurança geral dos produtos, os Estados membros foram convidados a tomar medidas que garantissem um nível elevado de protecção da saúde das crianças relativamente aos artigos de puericultura e brinquedos, que contenham certos ftalatos, destinados a ser postos na boca por crianças com menos de 3 anos de idade.

Em resultado da aprovaçáo da Decisão n. ${ }^{\circ}$ 1999/ $815 / \mathrm{CE}$, da Comissão, de $7^{3}$ de Dezembro, no âmbito da mesma directiva, desde o ano de 1999 que a utilização de seis ftalatos em brinquedos e artigos de puericultura destinados a ser postos na boca por crianças com menos de 3 anos de idade ficou sujeita a uma proibição temporária a nível da União Europeia, decisão essa que tem sido regularmente prorrogada.

Considerando que as restrições já adoptadas por determinados Estados membros em relação à colocação no mercado de brinquedos e artigos de puericultura, devido à presença de ftalatos, afectam directamente a realizaçáo e o funcionamento do mercado interno e que urgia pôr termo à situação de proibição temporária imposta pela Decisão n. ${ }^{\circ}$ 1999/815/CE, da Comissão, foi adoptada a Directiva n. ${ }^{\circ} 2005 / 84 / C E$, do Parlamento Europeu e do Conselho, de 14 de Dezembro, que aproxima as legislações dos Estados membros no domínio em causa e altera a Directiva $n .^{\circ} 76 / 769 / \mathrm{CEE}$, que importa agora transpor.

A exemplo de outros Estados membros, a nível nacional foram publicadas as Portarias n. ${ }^{\text {os }} 116-\mathrm{A} / 2000$, de 3 de Março, e 1201/2000, de 21 de Dezembro, no quadro do Decreto-Lei n. ${ }^{3} 11 / 95$, de 20 de Novembro, relativo à segurança geral dos produtos, cuja aplicação se mantém no direito interno sob a forma de regime transitório até 16 de Janeiro de 2007, data em que serão revogadas, face à harmonização legislativa imposta por aquela directiva.

Acresce que, face ao progresso científico e técnico alcançado no domínio da saude humana e do ambiente, foram ainda adoptadas as Directivas n. ${ }^{\text {os }} 2005 / 59 / \mathrm{CE}$, do Parlamento Europeu e do Conselho, de 26 de Outubro, 2005/69/CE, do Parlamento Europeu e do Conselho, de 16 de Novembro, e 2005/90/CE, do Parlamento Europeu e do Conselho, de 18 de Janeiro de 2006, que alteram igualmente a Directiva $n .^{\circ} 76 / 769 / \mathrm{CEE}$ e que se torna igualmente necessário transpor.

Em conformidade com a metodologia seguida em relação às anteriores transposições de directivas que alteram ou adaptam ao progresso científico e técnico a Directiva n. ${ }^{\circ} 76 / 769 / \mathrm{CEE}$, o presente decreto-lei vem introduzir novas alteraçōes ao Decreto-Lei n. ${ }^{\circ}$ 264/98, de 19 de Agosto, republicado pelo Decreto-Lei n. ${ }^{\circ}$ 446/99, de 3 de Novembro, na redacção que lhe foi conferida pelos Decretos-Leis n. ${ }^{\text {os }} 256 / 2000$, de 17 de Outubro, 238/2002, de 5 de Novembro, 141/2003,

${ }^{2}$ Fonte: http://dre.pt/pdf1s/2007/01/01300/04470483.pdf de 2 de Julho, 208/2003, de 15 de Setembro, 123/2004, de 24 de Maio, 72/2005, de 18 de Março, 73/2005, de 18 de Março, 101/2005, de 23 de Junho, e 222/2005, de 27 de Dezembro.

Pretende-se, deste modo, minorar os efeitos prejudiciais para a saúde humana e para o ambiente, associados à utilização de tolueno e do triclorobenzeno, de hidrocarbonetos aromáticos policíclicos, de alguns ftalatos e de algumas substâncias classificadas como cancerígenas, mutagénicas ou tóxicas para a reprodução. Assim:

Nos termos da alínea $a$ ) do n. ${ }^{\circ} 1$ do artigo $198 .^{\circ}$ da Constituição, o Governo decreta o seguinte:

\section{Artigo $10^{\circ}$}

Objecto

O presente decreto-lei transpõe para a ordem jurídica interna as Europeu e do Conselho, de 26 de Outubro, 2005/69/CE, do Parlamento Europeu e do Conselho, de 16 de Novembro, 2005/84/CE, do Parlamento Europeu e do Conselho, de 14 de Dezembro, e 2005/90/CE, do Parlamento Europeu e do Conselho, de 18 de Janeiro de 2006, relativas à limitação da colocação no mercado e da utilização de algumas substâncias e preparações perigosas.

\section{Artigo 2. ${ }^{\circ}$ \\ Definiçốes}

Para efeitos do disposto no presente decreto-lei, entende-se por:

a) «Artigo de puericultura» qualquer produto destinado a facilitar o sono, o relaxamento, a higiene, a alimentação e a sucção das crianças;

b) «Brinquedo» qualquer produto concebido ou manifestamente destinado a ser utilizado com fins lúdicos por crianças com menos de 14 anos.

\section{Artigo $3 .^{\circ}$}

Alteraçáo ao anexo I do Decreto-Let $n .^{\circ}$ 264/98, de 19 de Agosto

São aditados os n. ${ }^{\circ} 17,18,19,20$ e 21 ao anexo 1 do Decreto-Lei n. ${ }^{\circ}$ 264/98, de 19 de Agosto, republicado pelo Decreto-Lei n. ${ }^{\circ} 446 / 99$, de 3 de Novembro, na redaccão que lhe foi conferida pelos Decretos-Leis n. $^{\text {os }} 256 / 2000$, de 17 de Outubro, 238/2002, de 5 de Novembro, 141/2003, de 2 de Julho, 208/2003, de 15 de Setembro, $123 / 2004$, de 24 de Maio, $72 / 2005$, de 18 de Marco, 73/2005, de 18 de Março, 101/2005, de 23 de Junho, e 222/2005, de 27 de Dezembro, com a seguinte redacção:

«ANEXO I 


\section{ANEXO B - Decreto-Lei n. ${ }^{\circ}$ 10/2007 do Ministério da Economia e da Inovação de 18 de Janeiro de 2007}

448

$$
\begin{aligned}
& 9-[\ldots] \\
& 10-[\ldots] \\
& 11-[\ldots] \\
& 12-[\ldots] \\
& 13-[\ldots] \\
& 14-[\ldots] \\
& 15-[\ldots] \\
& 16-[\ldots] \\
& 17-\text { Tolueno: }
\end{aligned}
$$

17.1 - É proibida a colocação no mercado e a utilização de tolueno, constante do n. ${ }^{\circ} 19$ do anexo II, como substância ou componente de preparações numa concentração igual ou superior a $0,1 \%$ em massa, em produtos adesivos e tintas para pulverização, destinados à venda ao público em geral.

18 - Triclorobenzeno:

18.1 - É proibida a colocação no mercado e a utilização de triclorobenzeno, constante do n. $^{\circ} 20$ do anexo II, como substância ou componente de preparações numa concentração igual ou superior a $0,1 \%$ em massa, para qualquer utilização, salvo

a) Como produto intermédio de síntese, ou

b) Como solvente de processo em aplicações químicas fechadas para reacções de cloração, ou

c) $\mathrm{Na}$ produção de 1,3,5-trinitro-2,4,6-triaminobenzeno (TATB)

19 - Hidrocarbonetos aromáticos policíclicos (HAP):

19.1 - É proibida a colocação no mercado dos óleos de diluição que contenham as substâncias constantes do n. $^{\circ} 21$ do anexo II e a sua utilização no fabrico de pneumáticos ou partes de pneumáticos se contiverem:

a) Mais de $1 \mathrm{mg} / \mathrm{kg}$ de $\mathrm{BaP}$, ou

b) Mais de $10 \mathrm{mg} / \mathrm{kg}$ da soma de todos os HAP indicados.

Estes limites são considerados observados, caso a massa do extracto de aromáticos policíclicos (APC) seja inferior a $3 \%$, em conformidade com a norma IP346:1998 do Instituto do Petróleo (Determinação dos APC nos óleos de base para lubrificação não usados e em amostras de petróleo sem asfalteno — método do índice refractivo de extracção de sulfóxido de dimetilo), desde que a conformidade com os valores-limite de $\mathrm{BaP}$ e dos HAP indicados, bem como a correlação dos valores medidos com o extracto de APC, sejam controlados pelo fabricante ou pelo importador de seis em seis meses ou após cada alteração operacional importante, consoante o que ocorrer primeiro.

19.2 - Além disso, os pneumáticos e as bandas de rodagem para recauchutagem fabricadas após 1 de Janeiro de 2010 não podem ser colocados no mercado se contiverem óleos de diluição que excedam os limites indicados no n. ${ }^{\circ} 19.1$.

Consideram-se observados esses limites, caso os componentes de borracha vulcanizada não ultrapassem o limite de $0,35 \%$ Hbay, tal como medidos e calculados pela norma ISO 21461 (Borracha vulcanizada -
Diário da República, $1 .{ }^{a}$ série $-N{ }^{\circ} 13-18$ de Janeiro de 2007

Determinação da aromaticidade do óleo nos componentes de borracha vulcanizada).

19.3 - Por derrogação, o n. ${ }^{\circ} 19.2$ não se aplica aos pneumáticos recauchutados, caso as suas bandas de rodagem não contenham óleos de diluição que ultrapassem os limites indicados no $\mathrm{n}^{\circ} 19.1$.

20 - Ftalato de di(2-etil-hexilo) (DEHP), ftalato de dibutilo (DBP) e ftalato de benzilbutilo (BBP):

20.1 - É proibida a utilização dos ftalatos constantes do n. ${ }^{\circ} 22$ do anexo II, como substâncias ou componentes de preparaç̃es, em concentrações superiores a $0,1 \%$ em massa de material plastificado, em brinquedos e artigos de puericultura.

20.2 - É proibida a colocação no mercado de brinquedos e artigos de puericultura que contenham estes ftalatos numa concentração superior ao limite referido em 20.1.

21 - Ftalato de di-isononilo (DINP), ftalato de diisodecilo (DIDP) e ftalato de di-n-octilo (DNOP):

21.1 - É proibida a utilização dos ftalatos constantes do n०23 do anexo II, como substâncias ou componentes de preparações, em concentrações superiores a $0,1 \%$ em massa de material plastificado, em brinquedos e artigos de puericultura que as crianças possam pôr na boca.

21.2 - É proibida a colocação no mercado de brinquedos e artigos de puericultura que contenham estes ftalatos numa concentração superior ao limite referido em 21.1.»

Artigo $4 .^{\circ}$

Alteração ao anexo n do Decreto-Lei n. ${ }^{\circ}$ 264/98, de 19 de Agosto

O anexo II do Decreto-Lei n. ${ }^{\circ} 264 / 98$, de 19 de Agosto, republicado pelo Decreto-Lei $n .^{\circ} 446 / 99$, de 3 de Novembro, na redacção que lhe foi conferida pelos Decretos-Leis n. ${ }^{\circ} 256 / 2000$, de 17 de Outubro, 238/ 2002, de 5 de Novembro, 141/2003, de 2 de Julho, 208/ 2003 , de 15 de Setembro, 123/2004, de 24 de Maio, 72/2005, de 18 de Março, 73/2005, de 18 de Março, $101 / 2005$, de 23 de Junho, e 222/2005, de 27 de Dezembro, é alterado da seguinte forma:

1 - São aditadas aos n. ${ }^{\infty} 1,2$ e 3 as substâncias constantes do anexo I do presente diploma, que é parte integrante do presente acto.

2 - São alteradas, nos $n^{\circ} 1,2$ e 3 , as substâncias constantes do anexo II do presente diploma, que é parte integrante do presente acto.

3 - São suprimidas do n. ${ }^{\circ} 1$, categoria 2 , as substâncias constantes do anexo III do presente diploma, que é parte integrante do presente acto.

4 - São aditados os n. os $19,20,21,22$ e 23 , com a seguinte redacção:

ANEXO II

$[\cdots]$

${ }^{2}$ Fonte: http://dre.pt/pdf1s/2007/01/01300/04470483.pdf 
ANEXO C - Coeficientes de Chauvenet

Número de leituras, $n$

Razão entre o máximo desvio aceitável

e o desvio padrão, $d_{\max } / \sigma$

\begin{tabular}{ll}
\hline 3 & 1,38 \\
\hline 4 & 1,54 \\
\hline 5 & 1,65 \\
\hline 7 & 1,73 \\
\hline 10 & 1,80 \\
\hline 15 & 1,96 \\
\hline 25 & 2,13 \\
\hline 50 & 2,33 \\
\hline 100 & 2,57 \\
\hline 300 & 2,81 \\
\hline 500 & 3,14 \\
\hline 1000 & 3,29 \\
\hline
\end{tabular}

${ }^{3}$ Fonte: Scapin (2003) apud Scapin, 2008. 
ANEXO D - Parâmetros para o cálculo da exposição total em ambientes internos

\begin{tabular}{|c|c|c|c|c|c|c|c|c|c|}
\hline Cenário: Residencial & & & & & & & & & \\
\hline Adultos & Unidade & Chumbo & risco(1) & Cobalto & risco(1) & Cobre & risco(1) & Cromo & risco(1) \\
\hline \multicolumn{10}{|l|}{ Ambiente Interno } \\
\hline Contato dermal & $\begin{array}{l}\mathrm{mg} / \mathrm{kg} \\
\mathrm{dia}\end{array}$ & & & & & & & & \\
\hline Inalação de partículas & $\begin{array}{l}\mathrm{mg} / \mathrm{kg} \\
\mathrm{dia}\end{array}$ & $2,36 \mathrm{E}-06$ & & $5,39 \mathrm{E}-07$ & & $3,37 \mathrm{E}-06$ & & $4,72 \mathrm{E}-06$ & \\
\hline \multicolumn{10}{|l|}{ Criança } \\
\hline \multicolumn{10}{|l|}{ Ambiente Interno } \\
\hline Contato dermal & $\begin{array}{l}\mathrm{mg} / \mathrm{kg} \\
\mathrm{dia}\end{array}$ & & & & & & & & \\
\hline Inalação de partículas & $\begin{array}{l}\mathrm{mg} / \mathrm{kg} \\
\mathrm{dia}\end{array}$ & $9,19 \mathrm{E}-06$ & & $2,10 \mathrm{E}-06$ & & 1,31E-05 & & 1,84E-05 & \\
\hline \multicolumn{10}{|l|}{ Meios de Contato } \\
\hline Solo & $\mathrm{mg} / \mathrm{kg}$ & $3,50 \mathrm{E}+02$ & & $\begin{array}{l}8,00 \mathrm{E}+0 \\
1\end{array}$ & & $5,00 E+02$ & & $7,00 \mathrm{E}+02$ & \\
\hline $\begin{array}{l}\text { Poeira em ambiente } \\
\text { interno }\end{array}$ & $\mu g / m^{3}$ & $1,47 \mathrm{E}-02$ & & $3,36 \mathrm{E}-03$ & & $2,10 \mathrm{E}-02$ & & 2,94E-02 & \\
\hline TDI & $\begin{array}{l}\mathrm{mg} / \mathrm{kg} \\
\mathrm{dia}\end{array}$ & $3,60 \mathrm{E}-03$ & & $1,40 \mathrm{E}-03$ & & $1,40 \mathrm{E}-01$ & & $5,00 \mathrm{E}-03$ & \\
\hline $\begin{array}{l}\begin{array}{l}\text { Fator } \\
\text { carcinogenicidade }\end{array} \\
\text { de }\end{array}$ & $\begin{array}{l}\mathrm{mg} / \mathrm{kg} \\
\mathrm{dia}\end{array}$ & $\# \mathrm{~N} / \mathrm{D}$ & & \#N/D & & \#N/D & & $\# \mathrm{~N} / \mathrm{D}$ & \\
\hline Risco de câncer & $\begin{array}{l}\mathrm{mg} / \mathrm{kg} \\
\mathrm{dia}\end{array}$ & $\# \mathrm{~N} / \mathrm{D}$ & & \#N/D & & $\# \mathrm{~N} / \mathrm{D}$ & & $\# \mathrm{~N} / \mathrm{D}$ & \\
\hline Adultos & Unidade & Mercúrio & risco(1) & $\begin{array}{l}\text { Molibdê } \\
\text { nio }\end{array}$ & risco(1) & Níquel & risco(1) & Prata & risco(1) \\
\hline \multicolumn{10}{|l|}{ Ambiente Interno } \\
\hline Contato dermal & $\mathrm{mg} / \mathrm{kg}$ dia & & & & & & & & \\
\hline Inalação de partículas & $\mathrm{mg} / \mathrm{kg}$ dia & 3,37E-08 & & $6,74 \mathrm{E}-07$ & & $1,35 \mathrm{E}-06$ & & 3,37E-07 & \\
\hline \multicolumn{10}{|l|}{ Criança } \\
\hline \multicolumn{10}{|l|}{ Ambiente Interno } \\
\hline Contato dermal & $\mathrm{mg} / \mathrm{kg}$ dia & & & & & & & & \\
\hline Inalação de partículas & $\mathrm{mg} / \mathrm{kg}$ dia & 1,31E-07 & & $2,63 \mathrm{E}-06$ & & $5,25 \mathrm{E}-06$ & & 1,31E-06 & \\
\hline Exposição & $\mathrm{mg} / \mathrm{kg}$ dia & $6,52 \mathrm{E}-05$ & 0,107 & $3,73 \mathrm{E}-02$ & 3,7339 & $8,44 \mathrm{E}-03$ & 0,17 & $6,17 \mathrm{E}-03$ & 1,235 \\
\hline \multicolumn{10}{|l|}{ Meios de Contato } \\
\hline Solo & $\mathrm{mg} / \mathrm{kg}$ & $5,00 \mathrm{E}+00$ & & $1,00 \mathrm{E}+02$ & & $2,00 E+02$ & & $5,00 \mathrm{E}+01$ & \\
\hline $\begin{array}{l}\text { Poeira em ambiente } \\
\text { interno }\end{array}$ & $\mu g / m^{3}$ & $2,10 \mathrm{E}-04$ & & $4,20 \mathrm{E}-03$ & & $8,40 \mathrm{E}-03$ & & $2,10 \mathrm{E}-03$ & \\
\hline TDI & $\mathrm{mg} / \mathrm{kg}$ dia & $6,10 \mathrm{E}-04$ & & $1,00 \mathrm{E}-02$ & & $5,00 \mathrm{E}-02$ & & $5,00 \mathrm{E}-03$ & \\
\hline $\begin{array}{l}\text { Fator } \\
\text { carcinogenicidade de }\end{array}$ & $\mathrm{mg} / \mathrm{kg}$ dia & $\# \mathrm{~N} / \mathrm{D}$ & & $\# \mathrm{~N} / \mathrm{D}$ & & $\# \mathrm{~N} / \mathrm{D}$ & & $\# \mathrm{~N} / \mathrm{D}$ & \\
\hline Risco de câncer & $\mathrm{mg} / \mathrm{kg}$ dia & $\# N / D$ & & $\# \mathrm{~N} / \mathrm{D}$ & & $\# \mathrm{~N} / \mathrm{D}$ & & $\# \mathrm{~N} / \mathrm{D}$ & \\
\hline
\end{tabular}


ANEXO D - Parâmetros para o cálculo da exposição total em ambientes internos

\begin{tabular}{|c|c|c|c|c|c|}
\hline Adultos & Unidade & Zinco & risco(1) & Níquel & risco(1) \\
\hline \multicolumn{6}{|l|}{ Ambiente Interno } \\
\hline Contato dermal & $\mathrm{mg} / \mathrm{kg} \mathrm{dia}$ & & & & \\
\hline Inalação de partículas & $\mathrm{mg} / \mathrm{kg}$ dia & $6,74 \mathrm{E}-06$ & & $1,35 \mathrm{E}-06$ & \\
\hline \multicolumn{6}{|l|}{ Criança } \\
\hline \multicolumn{6}{|l|}{ Ambiente Interno } \\
\hline Contato dermal & $\mathrm{mg} / \mathrm{kg}$ dia & & & & \\
\hline Inalação de partículas & $\mathrm{mg} / \mathrm{kg}$ dia & $2,63 E-05$ & & $5,25 \mathrm{E}-06$ & \\
\hline \multicolumn{6}{|l|}{ Meios de Contato } \\
\hline Solo & $\mathrm{mg} / \mathrm{kg}$ & $1,00 \mathrm{E}+03$ & & $2,00 \mathrm{E}+02$ & \\
\hline Poeira em ambiente interno & $\mu \mathrm{g} / \mathrm{m}^{3}$ & $4,20 \mathrm{E}-02$ & & $8,40 \mathrm{E}-03$ & \\
\hline TDI & $\mathrm{mg} / \mathrm{kg}$ dia & $1,00 \mathrm{E}+00$ & & $5,00 \mathrm{E}-02$ & \\
\hline Fator de carcinogenicidade & $\mathrm{mg} / \mathrm{kg}$ dia & $\# \mathrm{~N} / \mathrm{D}$ & & \#N/D & \\
\hline Risco de câncer & $\mathrm{mg} / \mathrm{kg}$ dia & $\# \mathrm{~N} / \mathrm{D}$ & & $\# \mathrm{~N} / \mathrm{D}$ & \\
\hline
\end{tabular}




\section{REFERÊNCIAS BIBLIOGRÁFICAS}

ABB, M.; HEINRICH, T.; SORKAU, E.; LORENZ, W. Phthalates in house dust. Environment International. v. 35, p. 965-970, 2009.

ABDALLAH, M. A-E.; IBARRA, C.; NEELS, H.; HARRAD, S.; COVACI, A. Comparative evaluation of liquid chromatography-mass spectrometry versus gas chromatography-mass spectrometry for the determination of hexabromocyclododecanes and their degradation products in indoor dust. The Journal of Chromatography A. v. 1190, p. 333-41, 2008.

AGARWAL, D. K; MARONPOT, R. R.; LAMB, J. C.; KLUWE, W. M. Adverse effects of butyl benzyl phthalate on the reproductiveand hematopoietic systems of male rats. Toxicology. v. 35, p. 189-206, 1985.

AHRENS A.; BÖHM E.; HEITMANN K.; HILLENBRAND T. Leitfaden zur Anwendung umweltvertragliche Stoffe. Berlin: Umweltbundesamt; 2003.

AL BITAR, F.; Hazardous chemicals in Belgian house dust. Report on chemical content in house dust samples collected in Belgian homes and offices. Greenpeace, 2004.

ANDRADE, M. F.; ORSINI, C.; MAENHAUT, W. Relation between aerosol sources and meteorological parameters for inhalable atmospheric particles in São Paulo city, Brazil. Atmospheric Environment. v. 28, n. 14, p. 2307-2315.

ARCADI, R. A.; COSTA. C. E.; IMPERATORE, C. Oral toxicity of DEHP during pregnancy and suckling in the Long-Evans rat. Food and Chemical Toxicology. v. 36, p. 963-970, 1998. 
ASTM D 5438-00. Standard Practice for collection of floor dust for chemical analysis. Book of Standards. ASTM International, West Conshohocken, PA. 2000.

ATSDR, 2002. Toxicological Profile for Di(2-ethylhexyl) Phthalate. Agency for Toxic Substances and Disease, Atlanta, GA. Disponível em: http://www.atsdr.cdc.gov/toxprofiles/tp9.html. Acesso em: 17 out 2009.

B.A.U.C.H. Fachbericht zum Projekt Berlin. 1991.

BECKER K.; KAUS S.; SEIFERT M.; HEIDRICH F.; ROSSKAMP E.; SCHULZ C. Umwelt-Survey 1998 Band V: Hausstaub Stoffgehalte im Hausstaub aus Haushalten der Bevölkerung in Deutschland; 1998.

BECKER, K., SEIWERT, M., ANGERER, J.; HEGER, W.; KOCH, H. M.; NAGORKA, R. International Journal of Hygiene and Environmental Health. v. 207, 409-417, 2004.

BECKER, K.; SEIWERT, M.; KAUS, S.; KRAUSE, C.; SCHULZ, C.; SEIFERT, B. German Environmental Survey (GERES III): Pesticides and other pollutants in house dust. In: Proceedings of the 9th International Conference on Indoor Air Quality and Climate. Indoor Air. v. 4, p. 883-887, 2002.

BELLINGER, D. Neuropsychologic function in children exposed to environmental lead. Epidemiology. v. 6, p. 101- 103, 1995.

BERGER, M. R. Combination effect of three non-genotoxic carcinogens in male SD rats. In: American Association for Cancer Research annual meeting, 1995. Proceedings... 2001. v. 36p. 133.

BLOUNT, B. C.; SILVA, M. J.; CAUDILL, S. P.; NEEDHAM, L. L.; PIRKLE, J. L.; SAMPSON, E. J.; LUCIER, G. W.; JACKSON, R. K.; BROCK, J. W. Levels of Seven Urinary Phthalate Metabolites in a Human Reference Population. Environmental Health Perspectives. v. 108, n. 10, p. 979-952, 2000. 
BORCH, J., DALGAARD, M.; LADEFOGED, O. Early testicular effects in rats perinatally exposed to DEHP in combination with DEHA-apoptosis assessment and immunohistochemical studies. Reproductive Toxicology. v. 19, n. 4, p. 517525, 2005.

BORCH, J.; LADEFOGED, O.; HASS, U.; VINGGAARD, A. M. Steroidogenesis in fetal male rats is reduced by DEHP and DINP, but endocrine effects of DEHP are not modulated by DEHA in fetal, prepubertal and adult male rats. Reproductive Toxicology. v. 18, n. 1, p. 53-61, 2004.

BORNEHAG, C.; LUNDGREN, B.; WESCHLER, C. J.; SIGSGAARD, T.; ENGMAN, L. H.; SUNDELL, J. Phthalates in indoor dust and their association with building characteristics. Environmental Health Perspectives. v. 113, n. 10, p. 1399-1404, 2005.

BORNEHAG, C.; SUNDELL, J.; WESCHLER, C. J.; SIGSGAARD, T.; LUNDGREN, B.; HASSELGREN, M.; ENGMAN, L. H. The association between asthma and allergic symptoms in children and phthalates in house dust: a nested case-control study. Environmental Health Perspectives. v. 112, n. 14, p. 13931397, 2004.

BRICKUS, L. S. R.; NETO AQUINO, F. R. A qualidade do ar de interiores e a química. Química Nova. v. 22, n. 1, p. 65-74, 1999.

BUTTE W.; HEINZOW B. Pollutants in House Dust as Indicators of Indoor Contamination. Reviews of Environmental Contamination \& Toxicology. v. 175, p. 1-46, 2002.

BUTTE, W. Sources and impacts of pesticides in indoor environments. The Handbook of Environmental Chemistry. v. 4, Berlin: Springer-Verlag Berlin Heidelberg, 2004. 
BUTTE, W.; HOFFMANN, W.; HOSTRUP, O.; SCHMIDT, A.; WALKER, G. Endocrine disrupting chemicals in house dust: results of a representative monitoring. Gefahrstoffe Reinhaltung Der Luft. v. 61, p. 19-23, 2001.

BUTTE, W.; WALKER, G. Sinn und unsinn von hausstaubunteruchungen - das für und wider. Hausstaub als meßparameter zu erkenn einer innenraumbelastung mit permethrin, pentachlorphenol und linden (Sense and nonsense of analyzing house dust - pro and contra - house dust as an indicator for an indoor pollution with permethrin, pentachlophenol and lindane) VDI-Ber 1122:535546, 1994.

CALAFAT, A. M.; NEEDHAM, L. L.; SILVA, M. J.; LAMBERT, G. Exposure to di-(2ethylhexyl) phthalate among premature neonates in a neonatal intensive care unit. Pediatrics. v. 113, p. 429-434, 2004.

CALIFORNIA ENVIRONMENTAL PROTECTION AGENCY. Indoor air pollution in California. Draft report submitted by California Air Resources Board. 2005

CAMPONOGARA, I.; MAZIERO, L.; FRANTZ, L. C.; SILVA, J. L. S. Exemplo de utilização do aplicativo surfer 8.0 na análise de parâmetros hidrodinâmico tendo como área de estudo Quaraí-BR e Artigas-YV. $1^{\circ}$ Simpósio de Recursos Hídricos do Sul/Santa Maria-RS (20 a 23 de Março 2005). Disponível em: http://jararaca.ufsm.br/websites/labhidro/659f2cd218c170d485c5445210605ec1.ht m. Acesso em: 20 jan. 2009.

CASTANHO, A. D. A. A determinação quantitativa de fontes de material particulado na atmosfera da cidade de São Paulo. Dissertação (Mestrado). 1999. Instituto de Física - Universidade de São Paulo (USP), São Paulo.

CENTROS DE CONTROLE DE DOENÇAS (CDC). Preventing lead poisoning in yong children: A statement by the centers for disease control. Atlanta, GA: U.S. Department of Health and Human Services, Public health service, 1991. 
CETESB Companhia de Tecnologia de Saneamento Ambiental. Valores Orientadores para Solos e Águas Subterrâneas no Estado de São Paulo. n. 195-2005- E, de 23 de nov. 2005.

CETESB. Uso das águas subterrâneas para abastecimento público no Estado de São Paulo. p. 48, 1997a.

CHÁFER-PERICÁS C.; CAMPÍNS-FALCÓ P.; PRIETO-BLANCO M. C. Automatic in-tube SPME and fast liquid chromatography: a cost-effective method for the estimation of dibuthyl and di-2-ethylhexyl phthalates in environmental water samples. Analytica Chimica Acta. v. 610, p. 268-73, 2008.

CHATTOPADHYAY G.; LIN K. C; FEITZ A. J. Household dust metal levels in the Sydney metropolitan area. Environmental Research. v. 93, p. 301-307, 2003

CHEN H,WANG C.; WANG X.; HAO N.; LIU J. Determination of phthalate esters in cosmetics by gas chromatography with flame ionization detection and mass spectrometric detection. International Journal of Cosmetic Science. v. 27, p. 205-10, 2005.

CLAUSEN, P. A.; BILLE, R. L. L.; NILSSON, T.; HANSEN V; SVENSMARK B.; BØWADT, S. Simultaneous extraction of di(2-ethylhexyl) phthalate and nonionic surfactants from house dust concentrations in floor dust from 15 Danish schools. Journal of Chromatography. v. 986, p. 179-190, 2003.

COLT, J.S., ZIHM, S.H., CAMANN, D.E., HART, J.A. Comparison of pesticides and other components in carpet dust samples collected from used vacuum cleaner bags and from a high volume surface sampler. Environmental Health Perspectives. v. 106, p. 721-724, 1998.

COMMISION DIRECTIVE 2004/93/EC of 21 September 2004 amending Council Directive 76/768/EEC for the purpose of adapting its Annexes II and III to technical progress.

Disponível

em: 
http://jckspaqi.aqsiq.gov.cn/hzpiyiy/gwxgfgibz/200610/P020061030409732588991. pdf. Acesso em: 04 set 2009.

CONTZEN PEREIRA, KRANTI MAPUSKAR, C. VAMAN RAO. Effect of diethyl phthalate on rat testicular antioxidant system: A dose-dependent toxicity study. Pesticide Biochemistry and Physiology. v. 90, n. 1, p. 52-57, 2008.

COSTNER, P.; BUTCHER, J. Substâncias químicas tóxica na poeira de lares e ambientes de trabalho no Brasil como indicador de exposição química nas residências e escritórios. Veneno doméstico. Greenpeace. Disponível em: http://www.greenpeace.com.br/toxicos/pdf/venenodomestico relatorio.pdf. Acesso em: 11 out 2005.

COSTNER, P.; THORPE, B.; MCPHERSON A. Sick of Dust Chemicals in Common Products-A Needless Health Risk in Our Homes. (2005). Disponível em: <http://www.cleanproduction.org/library/Dust\%20Report.pdf>. Acesso em: 04 set 2009.

COSTNER, P.; THORPE, B.; MCPHERSON, A. Sick of dust chemicals in common products - a needless health risk in our homes. Disponível em: < http://www.cleanproduction.org/library/Dust\%20Report.pdf. Acesso em: 11 mar. 2009.

CULBARD, E. B.; THORNTON, I.; WATT, J. M.; WHEATLEY, M. MOORCROFT, S.; THOMPSON, M. Metal contamination in British urban dusts and soil. Journal of Environmental Quality. v. 17, n. 2, p. 226-234, 1988.

DAVIES, B. E.; ELWOOD, J.; GALLACHER, J.; GINNERVER, R. C. The relationship between heavy metals in garden soils and house dusts in an old mining area of North Wales, Great Britain. Environmental Pollution. v. 9, p. 255266, 1985.

DE BLAY, F.; SANCHEZ, J.; HEDELIN, G.; PEREZ-INFANTE, A.; VEROT, A.; CHAPMAN, M.; Dust and airborne exposure to allergens derived from cockroach 
(Blattella germanica) in low-cost public housing in Strasbourg (France). Journal of Allergy and Clinical Immunology . v. 99, p.107-12, 1999.

DE LUCCA, S. D.; TAYLOR, D. J.; O'MEARA, T. J.; JONES, A. S.; TOVEY, E. R. Measurement and characterization of cockroach allergens detected during normal domestic activity. Journal of Allergy and Clinical Immunology . v. 104, p. 67280, 1999.

DE ORSI, D.; GAGLIARDI, L.; PORRÀ, R.; BERRI, S.; CHIMENTI, P.; GRANESE A. An environmentally friendly reversed-phase liquid chromatography method for phthalates determination in nail cosmetics. Analytica Chimica Acta. v. 555, p. 238-41, 2006.

DI BellA, G.; SAITTA, M.; PELlegRINO, M.; SALVO, F.; DUGO, G. Contamination of Italian citrus essential oils: presence of phthalate esters. Journal of Agricultural and Food Chemistry . v. 47, p. 1009-12, 1999.

DIAS DA CUNHA, K. D.; RICKMAN, R. D.; LEITE, C. V. B. Characterization of environmental exposure to mineral sands by PMDS technique. Nuclear Instruments and Methods in Physics Research B. v. 201, p. 615-622, 2003.

DIETRICH, K .N.; BERGER, O. G.; SUCCOP, P. A. Lead exposure and the motor developmental status of urban 6-year old children in the Cincinnati perspective study. Pediatrics. v. 80, p. 721-730, 1993.

Directive 2005/84/EC of the European Parliament and of the Council of 14 December 2005 amending for the 22nd time Council Directive 76/769/EEC on the approximation of the laws, regulations and administrative provisions of the Member States relating to restrictions on the marketing and use of certain dangerous substances and preparations (phthalates in toys and childcare articles).

DUTY, M. S.; CALAFAT, A. M.; SILVA, M. J.; RYAN, L.; HAUSER, R. Phthalate exposure and reproductive hormones in adult men. Human Reproduction. v. 20, n. 3, p. 604-610, 2005. 
DWARDS, R. D.; YURKOW, E. J.; LIOY, P. J. Seasonal deposition of house dusts onto household surfaces. Science of the Total Environment. v. 224, p. 69-80, 1998.

EGGLESTON, P. A.; ROSENSTREICH, D.; LYNN, H.; GERGEN, P.; BAKER, D.; KATTAN, M. Relationship of indoor allergen exposure to skin test sensitivity in inner-city children with asthma. Journal of Allergy and Clinical Immunology . v. 102, p. 563-70, 1998.

EMA, M.; ITAMI, T.; KAWASAKI, H. Teratogenic evaluation of butyl benzyl phthalate in rats by gastric intubation. Toxicology Letters. v. 61, p. 1-7, 1992.

EMA, M.; KUROSAKA, R.; AMANO, H.; OGAWA, Y. Comparative developmental toxicity of n-butyl benzyl phthalate and di-nbutyl phthalate in rats. Archives of Environmental Contamination and Toxicology . v. 28, p. 223-228, 1995.

EMA, M.; KUROSAKA, R.; AMANO, H.; OGAWA, Y. Embryolethality of butyl benzyl phthalate during early pregnancy in rats. Reproductive Toxicology. v. 8, p. 231-236, 1994.

EMA, M.; MIYAWAKI, E.; KAWASHIMA, K. Reproductive effects of butyl benzyl phthalate in pregnant and pseudopregnant rats. Reproductive Toxicology. v. 12, p. 127-132, 1998.

EURACHEM/CITAC. Incertezas de Quantificação em Medidas Analíticas. Guide 4715-92, 2 ed., 2000.

FARFEL, M. R.; LEES, P. S.; ROHDE, C. A.; LIM, B. S.; BANNON, D.; CHISOLM Jr., J. J. Comparison of a wipe and vacuum collection method for the determination of lead in residential dusts. Environmental Research. v. 65, n. 2, p. 291-301, 1994.

FERGUSSON, D. M.; FERGUSSON, J. E.; HORWOOD, L. J.; KINZETT, N. G. A longitudinal study of lead levels, intelligence, school performance and behavior. 
Part I. Dentine lead levels and exposure to environmental risk factors. Journal of Child Psychology and Psychiatry. v. 29, p. 781-792, 1988a.

FERGUSSON, D. M.; FERGUSSON, J. E.; HORWOOD, L. J.; KINZETT, N. G. A longitudinal study of lead levels, intelligence, school performance and behavior. Part II. Dentine lead levels and cognitive ability. Journal of Child Psychology and Psychiatry. v. 29, p. 793-809, 1988 b.

FERGUSSON, D. M.; FERGUSSON, J. E.; HORWOOD, L. J.; KINZETT, N. G. A longitudinal study of lead levels, intelligence, school performance and behavior. Part III. Dentine lead levels and attention/activity. Journal of Child Psychology and Psychiatry. v. 29, p. 811-824, 1988c.

FERGUSSON, J. E.; FORBES, E. A.; SCHROEDER, R. J.; RYAN, D. E. The elemental composition and sources of house dust and street dust. The Science of The Total Environment. v. 50, p. 217-221, 1991.

FERGUSSON, J. E.; FORBES, E. A; SCHROEDER, R. J; RYAN, D. E. The elemental composition and sources of house dust and street dust. Science of the Total Environment. v. 50, p. 217-21, 1986.

FERGUSSON, J. E.; KIM, N. D. Trace elements in street dust and house dusts:sources and speciation. The Science of The Total Environment. v. 100, p. 125-150, 1991.

FERGUSSON, J. R.; FORBES, E. A.; SCHROEDER, R. J. The elemental composition and sources of house dust and street dust. The Science of the Total Environment. v. 50, p. 217-221, 1986.

FERREIRA, MANUEL O. M. Determinação de componentes inorgânicos em plantas medicinais, comercializadas em formas de po(cápsulas) e "in natura", utilizando a técnica de fluorescência de raios $X$ por dispersão de comprimento de onda (WDXRF) e por dispersão de energia (EDXRF) 
definição de perfis inorgânicos quantitativos. 2004. Dissertação (Mestrado) Instituto de Pesquisas Energéticas e Nucleares - IPEN-CNEN/SP, São Paulo.

FIELD EA, PRICE CJ, SLEET RB, GEORGE JD, MARR MC, MYERS CB, SCHWETZ BA, MORRISSEY RE. Developmental toxicity evaluation of diethyl and dimethyl phthalate in rats. Teratology. v. 48, p. 33-44, 1993.

FIGUEIREDO, A. M. G. J.; ENZWEILER, S. P.; CAMARGO, J. B.; SÍGOLO, F. C.; GUMIERO, A. C.; PAVESE, F. M.; MILIAN. Metal contamination in urban park soils of São Paulo. Journal of Radioanalytical and Nuclear Chemistry. v. 280, n. 2, p. 419-425, 2009.

FOSTER, P. M.; THOMAS, L. V.; COOK, M. W.; WALTERS, D. G. Effect of Di-npentyl phthalate treatment on testicular steroidogenic enzymes and cytochrome P450 in the rat. Toxicology Letters. v. 15, p. 265-71, 1983.

FÖSTNER, U., SALOMONS, W. Trace metals analysis on polluted sediments. Part I: Assessments of source and intensities. Environmental Technology Letters. v. 1, p. 495 p-505, 1980.

FREDRICSSON, B.; MOLLER, L.; POUSETTE, A.; WESTERHOLM, R. Human sperm motility is affected by plasticizers and diesel particle extracts. Pharmacology and Toxicology. v. 72, p. 128-133, 1993.

FROMME, H.; LAHRZ, T.; PILOTY, M.; GEBHART, H.;. ODDOY, A.; RUDEN, H. Occurrence of phthalates and musk fragrances in indoor air and dust from apartments and kindergartens in Berlin (Germany). Indoor Air. v. 14, p. 188195, 2004.

GALLEGO, J. L. R.; ORDÓÑEZ, A.; LOREDO, J. Environment International. v. 27, p. 589, 2002. 
GERAB, F. Técnicas analíticas nucleares aplicadas à medida em larga escala de aerossóis atmosféricos na região Amazônica. Dissertação (Doutorado). 1996. Instituto de Física da Universidade de São Paulo (USP), São Paulo.

GIMENO R. A.; MARCÉ R. M.; BORRULL F. Determination of plasticizers by highperformance liquid chromatography and atmospheric pressure chemical ionization mass spectrometry in water and sediment samples. Chromatographia. v. 58, p. 37-41, 2003.

GRAY, L. E. JR; OSTBY, J.; FURR, J.; PRICE, M.; VEERAMACHANENI, D. N.; PARKS, L. Perinatal exposure to the phthalates DEHP, BBP, and DINP, but not DEP, DMP, or DOTP, alters sexual differentiation of the male rat. The Society of Toxicology. v. 58, p. 350-365, 2000.

GREENPEACE. Greenpeace Research Laboratories Technical. David Santillo, Iryna Labunska, Helen Davidson, Paul Johnston, Mark Strutt \& Oliver Knowles. Consuming chemicals: hazardous chemicals in house dust as an indicator of chemical exposure in the home. Note 01/2003 (GRL-TN-01-2003), 2003. Disponível em: http://www.greenpeace.org.uk/MultimediaFiles/Live/FullReport/5679.pdf. Acesso em: 16 maio 2005.

HAMMOND, P. B. e DIETRICH, K. N. Lead exposure in early life: health consequences. Reviews of Environmental Contamination and Toxicology. v. 115, p. 91-124. Springer-Verlag, New York, 1990.

HAN, Y. M.; DU. P .X.; CAO, J. J.; POSMENTIER, E. S. Multivariate analysis of heavy metal contamination in urban dusts of Xi'an, Central China, The Science of The Total Environment. v. 355, p. 176-186, 2006.

HARBOTTLE, G. Activation analysis in archaeology. In NEWTON, G.W.A. (ed). Radiochemistry. London: Chem. Soc. 3, p. 33-72, 1976. 
HAUSER, R.; MEEKER, J. D; DUTY, S.; SILVA, M. J.; CALAFAT, A. M. Altered semen quality in relation to urinary concentrations of phthalate monoester and oxidative metabolites. Epidemiology. v. 17, n. 6, 682- 691, 2006.

HAWLEY, J. K. Assessment of health risk from exposure to contaminated soil. Risk Analysis. v. 5, p. 289-302, 1985.

HEUDORF, U; MERSCH-SUNDERMANN, V.; ANGERER, J. Phthalates: Toxicology and exposure. International Journal of Hygiene and Environmental Health. v. 210, p. 623-634, 2007.

HINWOOD, A.L., SIM, M.R., JOLLEY, D,. DE KLERK, N., BASTONE, E.B., GEROSTAMOULOS, J., AND DRUMMER, O.H. Exposure to inorganic arsenic in soil increases urinary inorganic arsenic concentrations of residents living in old mining areas. Environmental Geochemistry and Health. v. 26, p. 27-36, 2004.

HONG, S.; KIM, Y.; LEM LEY, A. T.; OBENDORF, S. K.; HEDGE, A. Analytical method development for 18 pesticides in house dust and settled residues using SEC, SPE, TMS methylation, and GC-MS. Journal of Chromatographic Science . v. 39, p. 101-112, 2001.

HUD. National survey of lead and allergens in housing, final report. Analysis of lead hazrds. Office of Lead Hazard Control, U. S. Department of Housing and Urban Development. v. 1, 2001.

HYSONG, T.A., BURGESS, J.L., CEBRIAN GARCIA, M.E., AND O'ROURKE, M.K. House dust and inorganic urinary arsenic in two Arizona mining towns. Journal of Exposure Analysis and Environmental Epidemiology. v. 13, p. 211$218,2003$.

IMPERATO, M.; ADAMO, P.; NAIMO, D.;ARIENZO, M.; STANZIONE, D.; VIOLANTE, P. Environmental Pollution. v. 124, p. 247, 2003. 
INMETRO. Guia para a expressão da incerteza de medição. 2ed. Rio de Janeiro: ABNT; INMETRO; SBM, 1998. 121p.

INMETRO. Orientações sobre validação de métodos de ensaios químicos. DOQCGCRE-008, São Paulo, mar. 2003. Disponível em: http://www.inmetro.gov.br/Sidoq/Arquivos/CGCRE/DOQ/DOQ-CGCRE-8 02.pdf. Acesso em: 12 dez. 2007.

INSTITUTO BRASILEIRO DE GEOGRAFIA E ESTATÍSTICA (IBGE). Disponível em: http://www.sidra.ibge.gov.br/bda/tabela/protabl.asp?c=793\&z=cd\&o=17\&i=P e http://www.ibge.gov.br/home/estatistica/populacao/estimativa2009/POP2009 DOU .pdf. Acesso em: 20 out 2009.

JABEEN, N.; AHMED, S.; HASSAN, S. T.; ALAM N. M. Levels and sources of heavy metals in house dust. Journal of Radioanalytical and Nuclear Chemistry. v. 241, n. 1, p. 145-149, 2001.

JACK E. FERGUSSON, ERIC A. FORBES AND ROBYN J. SCHROEDER. The elemental composition and sources of house dust and street dust. The Science of The Total Environment. v. 50, p. 217-221, 1986.

JIRIES, A. Vehicular contamination of dust in Amman, Jordan. The Environmentalist. v. 23, p. 205-210, 2003c.

JIRIES, A.; EL-HASAN, T.; MANASRAH, W. Qualitative evaluation of the mineralogical and chemical composition of dry deposition in the central and southern highlands of Jordan. Chemosphere. v. 48, n. 9, p 933-938, 2002.

JOHN, V. M. Reciclagem de resíduos na construção civil: contribuição à metodologia de pesquisa de desenvolvimento. 2000. Tese de livre docência. Escola Politécnica, Universidade de São Paulo.

JOHNSON, R.; WICHERN, D. Applied Multivariate Statistical Analysis. 1982. v. 3, New Jersey. 
JONES, H. B.; GARSIDE, D. A.; LIU, R.; ROBERTS, J. C. The influence of phthalate esters on Leydig cell structure and function in vitro and in vivo. Experimental and Molecular Pathology. v.58, p. 179-193, 1993.

JONSSON, B. A. G.; RICHTHOFF, J.; RYLANDER, L. Urinary phthalate metabolites and biomarkers of reproductive function in young men. Epidemiology. v. 16, p. $487-493,2005$.

JORGENSEN M., VENDELBO B., NIELS E., SKAKKEBAEK N.E., LEFFERS H. Assaying estrogenicity by quantitating the expression levels of endogenous estrogen-regulated genes. Environmental Health Perspectives. v. 108, n. 5, p. 403-412, 2000.

KABATA-PENDIAS, A.; PENDIAS, $\mathrm{H}$. Trace elements in soils and plants, Boca Raton: CRC Press, 1984.

KERSTEN W.; REICH T. Schwer flüchtige organische Umweltchemikalien in Hamburger Hausstäuben. Gefahrstoffe Reinhalt Luft. v. 63, p. 85-91, 2003.

KIM, N. D.; FERGUSSON, J. Concentrations and zinc in house dust in Christchurch, New Zeland. The Science of The Total Environment. v. 138, p. 121, 1993.

KING, J. C; KEEN, C. L. Zinc. In SHILS, M. et al. Eds. Nutrition in Health and Disease, 9th Edition. Baltimore: Williams \& Wilkins. p. 223-239,1999.

KLERKS, P. L.; LEVINTON, J. S. Rapid evolution of metal resistance in a benthic oligochaete inhabiting a metal-polluted site. Biological Bulletin. v. 176, p. 135$141,1989$.

KOLARIK, B.; NAYDENOV, K.; LARSSON, M.; BORNEHAG, C.; SUNDELL, J. The Association between Phthalates in Dust and Allergic Diseases among Bulgarian Children. Environmental Health Perspectives. v. 116, n. 1, 2008. 
LACHANCE. G. R., CLAISSE, F., Quantitative X-ray fluorescence analysis Theory and Application. Wiley, London, 1995.

LAMB, J. C.; CHAPIN, R. E.; TEAGUE, J.; LAWTON, A. D.; REEL, JR. Reproductive effects of four phthalic acid esters in the mouse. Toxicology and Applied Pharmacology. v. 88, p. 255-269, 1987.

LANDRIGAN, P.; GEHLABACH, S.; ROSENBLUM, B.; SCHOULTS, J.; CANDELARIA, R.; BARTHEL, W.; LIDDLE, J.; SMREK, A.; STAEHLING N, SANDERS J. Epidemic lead absorption near an ore smelter: the role of particulate lead. The New England Journal of Medicine. v. 292, p. 123-129, 1985.

LANPHEAR, B., ROGHMANN, K. Pathways of lead exposure in urban children. Environmental Research. v. 74, p. 67-73, 1997.

LANPHEAR, B.; MATTE, T.; ROGERS, J.; CLICKNER, R.; DIETZ, B.; BORNSCHEIN, R.; SUCCOP, P.; MAHAFFEY, K.; DIXON, S.; GALKEW, RABINOWITZ. M.; FARFEL, M.; ROHDE, C.; SCHWARTZ, J.; ASHLEY, P.; JACOBS, D. The contribution of lead-contaminated house dust and residential soil to children's blood lead levels. A pooled analysis of 12 epidemiologic studies. Environmental Research. v. 79, p. 51-68, 1998.

LASSEN, C., J. MAAG, L.B. HUBSCHMANN, E. HANSEN, A. SEARL, E. DOUST \& C. CORDEN. Data on manufacture, import, export, uses and releases of Dibutyl phthalate (DBP) as well as information on potential alternatives to its use. COWI, IOM \& Entec report to ECHA, 2009.

LEE, C.; FANG, M.; HSIEH, M. Characterization and Distribution of Metals in Surficial Sediments in Southwestern Taiwan. Marine Pollution Bulletht. v. 36, n. 6, p. 464-471, 1998.

LEI FEDERAL 6.938/ 81, ARTIGO 9, INCISOS III E IV. Disponível em: http://www.planalto.gov.br/ccivil 03/Leis/L6938.htm. Acesso em: 11 jun 2009. 
LEWIS, R. G.; FORTMANN, R. C.; CAMANN, D. E. Evaluation of methods for monitoring the potential exposure of small children to pesticides in the residential environment. Archives of Environmental Contamination and Toxicology. v. 26, p. 37-46, 1994.

LI, L. H.; JESTER, W. F. JR; LASLETT, A. L.; ORTH, J. M. A single dose of Di-(2ethylhexyl) phthalate in neonatal rats alters gonocytes, reduces sertoli cell proliferation, and decreases cyclin D2 expression. Toxicology and Applied Pharmacology. v. 166, p. 222-229, 2000.

LI, X.; LEE, S.; WONG, S.; SHI, W.; THORNTON, I. Environmental Pollution. v. 129, p. 113, 2004.

LINDERN, I. H. V.; SPALINGER, S. M.; BERO, B. N.; PETROSYAN, V.; BRAUN, M. C. V. The influence of soil remediation on lead in house dust. The Science of The Total Environment. v. 303, p. 59-78, 2003.

LIOY, P. J.; FREEMAN, N. C.; WAINMAN, T.; STERN, A. H.; BOESCH, R.; HOWELL, T.; SHUPACK, S. I.. Microenvironmental analysis of residential exposure to chromium-laden wastes in and around New Jersey homes. Risk Analysis. v. 2, n. 2, p. 287-99, 1992.

LIOY, P. J.; FREEMAN, N. C. G.; MILLETTE, J. R. Dust: a metric for use in residential and building exposure assessment and source characterization. Environmental Health Perspectives. v. 110, n. 10, p. 969-983, 2002.

LISIEWICZ, A. M.; HEIMBURGERB, R.; GOLIMOWSKIA, H. Granulometry and the content of toxic and potentially toxic elements in vacuum-cleaner collected, indoor dusts of the city of Warsaw. v. 263, p. 69-78, 2000.

LÓPEZ-JIMÉNEZ, F. J.; RUBIO, S.; PÉREZ-BENDITO, D. Determination of phthalate esters in sewage by hemimicelles-based solid-phase extraction and liquid chromatography- mass spectrometry. Analytica Chimica Acta. v. 551, p. 142-9, 2005. 
LOSKA, K.; WIECHUŁA, D. Application of principal component analysis for the estimation of source of heavy metal contamination in surface sediments from the Rybnik Reservoir. Chemosphere. v. 51, p. 723-733, 2003.

LOUREIRO, I. R. A importância e ocorrência de ftalatos em água potável e no ecossistema da Baía de Guanabara. 2002. Tese (Doutoramento) - Pontifícia Universidade Católica do Rio de Janeiro (PUC-Rio), Rio de Janeiro.

LU, Y.; GONG, Z.; ZHANG, G.; BURGHARDT, W. Lu Y, Gong Z, Zhang G, Burghardt W (2003): Concentrations and chemical speciations of $\mathrm{Cu}, \mathrm{Zn}, \mathrm{Pb}$ and Cr of urban soils in Nanjing, China. Geoderma. v. 115, p. 101, 2003.

MAIN, K. M.; MORTENSEN, G. K.; KALEVA, M. M.; BOISEN, K. A.; DAMGAARD, I. N.; CHELLAKOOTY, M. Human breast milk contamination with phthalates and alterations of endogenous reproductive hormones in infants 3 months of age. Environmental Health Perspectives. v. 114, p. 270-6, 2006.

MANTA, D. S.; ANGELONE, M.; BELLANCA, A.; NERI, R.; SPROVIERI, M. The Science of The Total Environment. v. 300, p. 229, 2002.

MARGUÍ, E.; QUERALT, I.; HIDALGO, M. Application of X-ray fluorescence spectrometry to determination and quantitation of metals in vegetal material. TrAC Trends in Analytical Chemistry. v. 28, n. 3, p. 362-372, 2009.

Mason J. Principles of Geochemistry. John Wiley \& Sons: New York, 1966.

MATTULAT, A. SOFIA GmbH Berlin. 2001. Disponível em: http://www.lgl.bayern.de/gesundheit/umweltmedizin/doc/projekt phthalate.pdf.

Acesso em: 11 mar. 2008

MESKAUSKAS, A. Foto de poeira aderida a um dissipador de calor de uma CPU. 30 January 2006 (UTC). Disponível em: http://commons.wikimedia.org/wiki/File:Laptop dust.jpg. Acesso em: 11 jun. 2009. 
MISHRA, V. K.; KIM, K. H.; KANG, C. H.; CHOI, K. C. Wintertime sources and distribution of airborne lead in Korea. Atmospheric Environment. v. 38, n. 17, p. 2653-2664, 2004.

MØLHAVE, L.; SCHNEIDER, T.; KJÆRGAARD, S. K.; LARSEN, L.; NORN, S.; JØRGENSEN, O. House dust in seven danish offices. Atmospheric Environment. v. 34, p. 4767-4779, 2000.

MORAES, A. P.; Qualidade do ar interno com ênfase na concentração de aerodispersóides nos edifícios. 2006. Dissertação (Mestrado) - Escola Politécnica da Universidade de São Paulo, São Paulo.

MORAWSKA L; SALTHAMMER T. Indoor Environment: Airborne Particles and Settled Dust, Wiley-VCH, Weinheim, 2003

MURATURE, D. A.; TANG, S. Y.; STEINHARDT, G.; DOUGHERTY, R. C. Phthalate esters and semen quality parameters. Biomedical and Environmental Mass Spectrometry. v. 14, p.473-477, 1987.

MYLCHREEST, E.; WALLACE, D. G.; CATTLEY, R. C.; FOSTER, P. M. Dosedependent alterations in androgen-regulated male reproductive development in rats exposed to Di(n-butyl) phthalate during late gestation. Society of Toxicology . v. 55, p. $143-511,2000$.

NAGAO, T.; OHTA, R.; MARUMO, H.; SHINDO, T.; YOSHIMURA, S.; ONO, H. Effect of butyl benzyl phthalate in Sprague-Dawley rats after gavage administration: a two-generation reproductive study. Reproductive Toxicology. $v$. 14 , n. 6, 513-32, 2000.

NAGATA, N., BUENO, M. I. M. S. Métodos matemáticos para correção de interferências espectrais e efeitos interelementos na análise quantitativa por fluorescência de raios-X. Química Nova. v. 24, n. 4, p. 531-539, 2001. 
NEEDLEMAN, H. L.; GUNNOE, C.; LEVITON, A.; REED, R.; PERESIE, H.; MAHER, C.; BARRETT, P. Deficits in psychologic and classroom performance of children with elevated dentine lead levels. New England Journal of Medicine. v. 300, p. 689-695, 1979.

NEEDLEMAN, H. L.; SCHELL, A.; BELLINGER, D.; LEVITON, A.; ALLRED, E. N. The long-term effects of exposure to low doses of lead in childhood: an 11-year follow up report. New England Journal of Medicine. v. 322, p. 83-88, 1990.

NRIAGU, J. O. A silent epidemic of environmental metal poisoning? Environmental Pollution. v. 50, p. 139-161, 1988.

O'ROURKE, M. K.; VAN DE WATER, P. K.; JIN, S.; ROGAN, S. P.; WEISS, A. D.; GORDON, S. M.; MOSCHANDREAS, D. M.; LEBOWITZ, M. D. Evaluations of primary metals from NHEXAS Arizona: distributions and preliminary exposures. Journal of Exposure Analysis and Environmental Epidemiology. v. 9, p. 435445, 1999.

ÖZDEMIR, Y.; BÖREKCI, B.; LEVET, A.; KURUDIREK, M. Assessment of trace element concentration distribution in human placenta by wavelength dispersive $X$ ray fluorescence: Effect of neonate weight and maternal age. Applied Radiation and Isotopes. v. 67, n. 10, p. 1790-1795, 2009.

PAOLIELLO, M. M. B; CHASIN, A. A. M. Ecotoxicologia do chumbo e seus compostos. Cadernos de referência ambiental. v. 3, 2001.

PETERS, R. J. B. Substâncias Químicas Perigosas em Produtos ao Consumidor. Relatório TNO. sep. 2003a (R 2003/370).

PETERS, R. J. B. Substâncias Químicas Perigosas na Precipitação. Relatório TNO. maio 2003b (R 2003/198).

PIERSMA, A. H.; VERHOEF, A.; TE BIESEBEEK, J. D.; PIETERS, M. N.; SLOB, W. Developmental toxicity of butyl benzyl phthalate in the rat using a multiple dose study design. Reproductive Toxicology . v. 14, p. 417-425, 2000. 
Pirkle, J. J.; Kaufmann, R. B.; Brody, D. J.; Hickman, T.; Gunter, E. W.; Paschal, D. C. Exposure of the U.S. Population to Lead, 1991-1994. Environmental Health Perspectives v. 106, p.745-750, 1998.

PLATTS-MILLS, T. A.; ERWIN, E.; HEYMANN, P.; WOODFOLK, J. Is the hygiene hypothesis still a viable explanation for the increased prevalence of asthma? Allergy. v. 60 , n. 79 , p. 25-31, 2005.

PREFEITURA DO MUNICÍPIO DE SÃO PAULO (PMSP). Plano Municipal de Habitação. Disponível em: http://ww2.prefeitura.sp.gov.br//arquivos/secretarias/planejamento/plano diretor/PI ano Municipal Habitacao.pdf. Acesso em: 20 maio 2009.

PURI, E. S. S.; HANSSON, H. C., EDNER, H. Urban air pollution source apportment using a combination of aerosol and gas monitoring techniques. Atmospheric Environment . v. 30, n. 15, p. 2795-2809, 1996.

QUE HEE, S.; PEACE, B.; CLARK, C. S.; BOYLE, J. R.; BOULE, J. R.; BORNSCHEIN, R. L.; Hammond, P. B. Evolution of efficient methods to sample lead sources, such as house dust and hand dust, in the homes of children. Environmental Research. v. 38, p. 77-95, 1985.

QUEVAUVILLER, P.; LAVIGNE, R.; CORTEZ, L. Impact of industrial and mine drainage wastes on the heavy metal distribution in the drainage basin and estuary of the Sado River (Portugal). Environmental Pollution. v. 59, p. 267-2 86, 1989.

RASMUSSEN, P. E. Can metal concentrations in indoor dust be predicted from soil geochemistry? Canadian Journal of Applied Spectroscopy. v. 49, p. 166-74, 2004.

RIBEIRO , MARCIA A. Estudos sobre a remoção de metais tóxicos em efluentes industriais apos a irradiação com feixe de elétrons. 2002. Dissertação (Mestrado) - Instituto de Pesquisas Energéticas e Nucleares IPEN/CNEN-SP, São Paulo. 
RIBEIRO, A. P. Procedimento de fracionamento comparado a modelo de atenuação para a avaliação de mobilidade de metais tóxicos em sedimentos da Baía de Sepetiba, Rio de Janeiro. 2006. Tese (Doutoramento) - Instituto de Pesquisas Energéticas e Nucleares - IPEN/CNEN-SP, São Paulo.

RIEDERER, A. M.; SHINE, J. P.; DANAN, L. M.; Ford, T. E. Concentrations of lead and mercury in multimedia samples from homes near the former Clark Air Base, Philippines. The Science of The Total Environment. v. 341, p. 53- 69, 2005.

ROBERTS, J. W.; BUDD, W. T.; RUBY, M. G.; CAMANN, D. E.; FORTMAN, R. C.; LEWIS, R. G., WALLACE, L. A.; SPITTLER, T. M. Human exposure to pollutants in the floor dust of homes and offices. Journal of Exposure Analysis and Environmental Epidemiology. 2 Supplement 1, p. 127-146, 1992.

ROBERTS, J. W.; CAMAAN, D. E.; SPITTLER, T. M. Reducing lead exposure from remodeling and soil track-in in older home. Air and waste management association paper 91-134.2. In: $84^{\text {th }}$ annual meeting and exhibition, Vancouver, British Columbia. p. 16-21, 1991.

ROCHELLE W. TYL, MYERS, C. B.; MARR, M. C.; FAIL, P. A.; SEELY, J. C.; BRINE, D. R.; BARTER, R. A.; BUTALA, J. H. Reproductive toxicity evaluation of dietary butyl benzyl phthalate (BBP) in rats. Reproductive Toxicology. v. 18, n. 2 , p. 241-264, 2004.

RUDEL R. A.; CAMANN, D.E.; SPENGLER, J, D.; KORN, L. R.; BRODY, J. G. Phthalates, alkylphenols, pesticides, polybrominated diphenyl ethers, and other endocrine-disrupting compounds in indoor air and dust. Environmental Science \& Technology. v. 37, n. 20, p. 4543-4553, 2003.

RUDNICK, R. L.; FOUNTAIN, D. M. Reviews of Geophysics. v. 33, p. 267-309, 1995.

SALOMONS, W.; FORSTNER, U. Metals in the Hydrocycle. Springer-Verlag, Berlim, p. 349, 1984. 
SALVADOR, VERA L. R. Separação de efeitos de sobreposição de espectros obtidos por WDXRF usando o método de Rietveld. 2005. Tese (Doutoramento) - Instituto de Pesquisas Energéticas e Nucleares - IPEN-CNEN/SP, São Paulo.

SANTILLO, D., LABUNSKA, I., DAVIDSON, H., JOHNSTON, P., STRUTT, M. \& KNOWLES, O. Consuming chemicals: hazardous chemicals in housedust as an indicator of chemical exposure in the home. Greenpeace Research Laboratories Technical Note 02/2003. p. 71, 2003a.

SANTOS, V. M. Instrumentação e Medida; elementos de análises estatísticas. Universidade de Aveiro, Aveiro, 2001.

SATO, IVONE M. Determinação dos produtos de fissão em rejeito líquido de atividade alta por fluorescência de raio-x .Correção da interferência espectral pela razão das intensidades. 1988. Tese (Doutoramento) - Instituto de Pesquisas Energéticas e Nucleares - IPEN/CNEN-SP, Sao Paulo.

SCAPIN, MARCOS A. Estudo de remoção de constituintes inorgânicos e degradação de compostos orgânicos por radiação gama em óleos lubrificantes usados. 2008. Tese (Doutoramento) - Instituto de Pesquisas Energéticas e Nucleares - IPEN/CNEN-SP, São Paulo.

SCAPIN, VALDIRENE DE O. Aplicação da fluorescência de raios X (WDXRF): determinação da espessura e composição química de filmes finos. 2004. Dissertação (Mestrado) - Instituto de Pesquisas Energéticas e Nucleares IPEN/CNEN-SP, São Paulo.

SCARANO, W. R.; TOLEDO, F. C.; GUERRA, M. T.; CAMPOS, S. G. P.; JUSTULIN JR, L. A.; FELISBINO, S. L.; ANSELMO-FRANCI, J. A.; TABOGA, S. R.; GRAVA KEMPINAS, W. Long-term effects of developmental exposure to di-nbutyl-phthalate (DBP) on rat prostate: Proliferative and inflammatory disorders and a possible role of androgens. Toxicology. v. 262, n. 3, p. 215-223, 2009 
SCHETTLER, T. Human exposure to phthalates via consumer products. International journal of andrology. p. 134-139, 2006.

SCHWARTZ, J. e OTTO, D. Blood lead, hearing thresholds, and neurobehavorial development in children and youth. Archives of Environmental Health. v. 42, p.153-160, 1987.

SCHWARTZ, J. Low-level lead exposure and children's IQ: a meta-analysis and search for a threshold. Environmental Research. v. 65, p. 42-55, 1994.

SEIFER, B.; BECKER, K.; HELM, D.; KRAUSE, C.; SCHUIZ, C.; SEIWERT, M. The German Environmental Survey 1990/1992 (GerES II). Reference concentrations of selected environmental pollutants in blood, urine, hair, house dust, drinking, water and indoor air. Journal Exposure Analysis Environmental Epidomiology. v. 10, p. 552-565, 2000.

SHARPE, R. M.; FISHER, J. S.; MILLAR, M. M.; JOBLING, S.; SUMPTER, J. P. Gestational and lactational exposure of rats to xenoestrogensresults in reduced testicular size and sperm production. Environmental Health Perspectives. v. 103, p.1136-1143, 1995.

SHUQAIR, MAHMUD SAID SHUQAIR. Estudo da contaminação do solo e água subterrânea por elementos tóxicos originados dos rejeitos das minas de carvão de figueira no estado do Paraná. 2002. Tese (Doutoramento) - Instituto de Pesquisas Energéticas e Nucleares - IPEN/CNEN-SP, São Paulo.

SINEX, S. A.; WRIGHT, D. A Distribution of trace metals in the sediments and biota of Chesapeake Bay. Marine Pollution Bulletin. v. 19, p. 425-431, 1988.

SØRENSEN L. K. Determination of phthalates in milk and milk products by liquid chromatography/tandem mass spectrometry. Rapid Communications in Mass Spectrometry. v. 20, p. 1135-43, 2006. 
SPALINGER, S. M.; von BRAUN, M. C.; PETROSYAN, V.; von LINDERN, I. H. Northern Idaho House Dust and Soil Lead Levels Compared to the Bunker Hill Superfund. Environmental Monitoring and Assessment. v. 130, p. 57-72, 2007.

SUTHERLAND, R. A.; TOLOSA, C. A.; TACK F. M. G.; VERLOO, M. G.Characterization of selected element concentrations and enrichment ratios in background and anthropogenically impacted roadside areas. Archives of Environmental Contamination and Toxicology. v. 38, p. 428-438, 2000.

SWAINE, D. J. The trace element content of soils. Techn Comm 48. Harpenden: Commonwealth Bureau of Soil Science. Exp. Stn. Techn. Commun. p. 157, 1955.

SWEET, C. W.; GATZ, D. F. Short Communication Summary and Analysis of available PM2,5 Measurements in Illinois. Atmospheric Environment. v. 32, n. 6, p. $1129-1133$.

TANAKA, T. Reproductive and neurobehavioural effects of bis(2-ethylhexyl) phthalate (DEHP) in a cross-mating toxicity study of mice. Food and Chemical Toxicology. v. 43, n. 4, p. 581-589, 2005.

TAYLOR, S. R.; MCLENNAN, S. M. The continental crust: its composition and evolution. Blackwell scientific Publishers, Oxford, 1985.

THACKER, S. B.; HOFFMAN, A.; STEINBERG, K.; ZACK, M.; SMITH, J. Effect of low-level body burdens of lead on the mental development of children: limitation of meta-analysis in a review of longitudinal data. Archives of Environmental Health. v. 47, p. 336-347, 1992.

THATCHER, T. L.; LAYTON, D. W. Depositation, Resuspension, and Penetration of particles within a residence. Atmospheric Environment. v. 29, p. 1487-1497, 1995.

TODA H.; SAKO K.; YAGOME Y.; NAKAMURA T. Simultaneous determination of phosphate esters and phthalate esters in clean room air and indoor air by gas 
chromatography- mass spectrometry. Analytica Chimica Acta. v. 519, p. 213-8, 2004.

TONG, S. T. Y. Indoor and outdoor household dust contamination in Cincinnati, Ohio, USA. Environmental Geochemistry and Health. v. 20, p. 123-33, 1998.

TONG, S. T. Y.; LAM, K. C. Home sweet home? A case study of household dust contamination in Hong Kong. The Science of The Total Environment. v. 256, p. 115-123, 2000.

TROWBRIDGE, P. R.; BURMASTER, D. E. Parametric distribution for the fraction of outdoor soil in indoor dust. Journal of Soil Contamination. v. 6, n. 2, p. 161168, 1997.

TURNER A.; SIMMONDS L. Elemental concentrations and metal bioaccessibility in UK household dust. The Science of The Total Environment. v. 371, p. 74-81, 2006.

U.S. Environmental Protection Agency (EPA), Office of Air and Radiation. Report to Congress on Indoor Air Quality, Volume II: Assessment and Control of Indoor Air Pollution, p. I, 4-14. EPA-400-I-89-001C, 1989.

U.S. Environmental Protection Agency (EPA). AGÊNCIA DE PROTEÇÃO AMBIENTAL AMERICANA. Disponível em: http://www.epa.gov/iris. Acesso em: 03 dez. 2005.

U.S. Environmental Protection Agency (EPA). Indoor Air Pollution: An Introduction for Health Professionals. Disponível em: http://www.epa.gov/iaq/pubs/hpguide.html Acesso em 26 ago. 2009.

U.S. ENVIRONMENTAL PROTECTION AGENCY (EPA). Indoor quality education and assessment guidance (IBEAM). Acesso em: 11 mai 2009. Disponível em: http://www.epa.gov/iaq/largebldgs/i-beam html/ibeami.htm. Acesso em: 26 ago. 2009. 
U.S. Environmental Protection Agency (EPA). Integrated Risk Information System (IRIS) on Dimethyl Phthalate. National Center for Environmental Assessment, Office of Research and Development, Washington, DC. 1999.

U.S. Environmental Protection Agency (EPA). National Center for Environmental Assessment Office of Research and Development. Exposure Factors Handbook. v. 3 , p. $17,1997$.

UBA (Umweltbundesant). Ergebnisse des Umwelt-Survey 1998. Disponível em: http://www.umweltbundesamt.de/gesundheit/survey/us98/biozide.htm. Acesso em 11 mar. 2008.

VDI 4300-8 Measurement of Indoor air Pollution - Sampling of House Dust. Beuth Verlag. Berlin. 2001.

von LINDERN, I. H.; SPALINGER, S. M.; BER, B. N.; PETROSYANC, V.; von BRAUND, M. C. The influence of soil remediation on lead in house dust. The Science of The Total Environment. v. 303, p. 59-78, 2003.

WebMD. Foto adaptada. Disponível em: http://www.webmd.com/default.htm. Acesso em: 17 out 2009.

WESCHLER, C. J.; SALTHAMMER, T.; FROMME H. Partitioning of phthalates among the gas phase, airborne particles and settled dust in indoor environments. Atmospheric Environment. v. 42, p. 1449-1460, 2008.

WORLD HEALTH ORGANIZATION (WHO). Air quality guidelines. 2nd edition, Regional Office for Europe, 2000.

WORLD HEALTH ORGANIZATION (WHO). Assessment of exposure to indoor air pollutants. Jantunen M, Jaakkola JJK and Krzyzanowski M (editors). WHO Regional Publications, European Series, n. 78, 1997. 
WORLD HEALTH ORGANIZATION (WHO). Indoor air pollutants: exposure and health effects (Euro Reports and Studies, 78). Copenhagen, 1983.

YONGMINGA, H.; PEIXUAN, D.; JUNJI, C.; ERIC, S. Posmentier. Multivariate analysis of heavy metal contamination in urban dusts of Xi'an, Central China The Science of The Total Environment. v. 355, n. 1-3, p. 176-186, 2006.

ZHANG, J.; LIU, C. L. Riverine composition and estuarine geochemistry of particulate metals in China-weathering features, anthropogenic impact and chemical fluxes. Estuarine. Coastal and Shelf Science. v. 54, p. 1051-1070, 2002.

ZHANG, W.; FENG, H; CHANG, J.; QU, J.; XIE, H.; YU, L. Heavy metal contamination in surface sediments of Yangtze River intertidal zone: An assessment from different indexes. Environmental Pollution. v. xxx, p. 1-11, 2009.

ZHIPENG, B.; LIH-MING, Y.; RICH, D. Q.; ADGATE, J. L.; ASHLEYU, P. J.; LIOY, P. J.; RHOADS, G. G.; JUNFENG, Z. Field evaluation and comparison of five methods of sampling lead dust on carpets. American Industrial Hygiene Association Journal. v. 64, p. 528-532, 2003.

ZHU, J.; PHILLIPS, S. P.; FENG, Y. L.; YANG, X. Phthalate esters in human milk: concentration variations over a 6-month postpartum time. Environmental Science \& Technology. v. 40, p. 5276-81, 2006. 